Estruturas de dados topológicas aplicadas em simulações de escoamentos compressíveis utilizando volumes finitos e métodos de alta ordem 


\title{
Estruturas de dados topológicas aplicadas em simulações de escoamentos compressíveis utilizando volumes finitos e métodos de alta ordem
}

\author{
Fernanda Paula Barbosa
}

Orientador: Prof. Dr. Antonio Castelo Filho

Tese apresentada ao Instituto de Ciências Matemáticas e de Computação - ICMC-USP, como parte dos requisitos para obtenção do título de Doutor em Ciências - Ciências de Computação e Matemática Computacional. VERSÃO REVISADA 
Ficha catalográfica elaborada pela Biblioteca Prof. Achille Bassi e Seção Técnica de Informática, ICMC/USP, com os dados fornecidos pelo(a) autor(a)

Barbosa, Fernanda Paula
Es3eruturas de dados topológicas aplicadas em
simulações de escoamentos compressiveis utilizando
volumes finitos e métodos de alta ordem / Fernanda
Paula Barbosa; orientador Antonio Castelo Filho. --
São Carlos, 2013.
212 p.
Tese (Doutorado - Programa de Pós-Graduação em
Ciências de Computação e Matemática Computacional) --
Instituto de Ciências Matemáticas e de Computação,
Universidade de São Paulo, 2013.
lidestrutura de dados. 2. Volumes finitos. 3.
Métodos de alta ordem. I. Filho, Antonio Castelo,
orient. II. Título.


"Agradeço todas as dificuldades que enfrentei; não fosse por elas, eu não teria saído do lugar. As facilidades nos impedem de caminhar. Mesmo as críticas nos auxiliam muito."

(Francisco de Paula Cândido Xavier)

"Que eu jamais me esqueça que Deus me ama infinitamente, que um pequeno grão de alegria e esperança dentro de cada um é capaz de mudar e transformar qualquer coisa, pois a vida é construída nos sonhos e concretizada no amor."

(Francisco de Paula Cândido Xavier)

Aos meus pais e ao querido Ives, com amor. 



\section{Agradecimentos}

Ao professor Antonio Castelo Filho pela oportunidade, orientação e confiança para a realização deste trabalho. Agradeço a paciência e a compreensão nos momentos difíceis. Obrigada pelos ensinamentos, pelas sugestões e pelo apoio no decorrer desses anos.

Aos meus pais Aparecida e João por todo amor, dedicação, apoio e incentivo aos meus estudos, sempre me proporcionando o melhor que podiam. Obrigada pelo exemplo que são para a minha vida e por tudo que conquistei graças ao amor incondicional de vocês. A família é a base de tudo e o amor é capaz de tornar qualquer sonho em realidade. Agradeço também ao meu irmão Júlio César pelo carinho e incentivo ao longo de minha vida.

Ao meu noivo Ives Renê por todos os momentos ao meu lado, pelo amor, carinho, paciência, dedicação. Agradeço por fazer parte da minha vida, por fazer parte desse sonho. É difícil descrever o quanto você é importante para mim, seu amor me fortalece a cada dia, me faz ter um sentido e uma razão a mais para viver. Obrigada por me fazer tão feliz e por tudo que me proporcionaste.

A todos os amigos, professores e funcionários do Instituto de Ciências Matemáticas e de Computação, pelo apoio e convivência. Em especial à minha amiga Gislene Fracolla, pela amizade, pelas palavras de conforto e pelo companheirismo.

À Fundação de Amparo à Pesquisa do Estado de São Paulo (FAPESP), pelo apoio financeiro para a realização desse trabalho. 



\section{Resumo}

A representação de malhas por meio de estrutura de dados e operadores topológicos é um dos focos principais da modelagem geométrica, onde permite uma implementação robusta e eficiente de mecanismos de refinamento adaptativo, alinhamento de células e acesso às relações de incidência e adjacência entre os elementos da malha, o que é de grande importância na maioria das aplicações em mecânica dos fluidos. No caso de malhas não estruturadas, a não uniformidade da decomposição celular é melhor representada por uma estratégia mais sofisticada, que são as estruturas de dados topológicas. As estruturas de dados topológicas indexam elementos de uma malha representando relações de incidência e adjacência entre elementos, garantindo acesso rápido às informações. Um dos aspectos mais comuns aos problemas tratados pela mecânica dos fluidos computacional é a complexidade da geometria do domínio onde ocorre o escoamento. O uso de estruturas de dados para manipular malhas computacionais é de grande importância pois realiza de modo eficiente as consultas às informações da malha e centraliza todas as operações sobre a malha em um único módulo, possibilitando sua extensão e adaptação em diversas situações. Este trabalho visou explorar o acoplamento de uma estrutura de dados topológica, a Mate Face, em um módulo simulador existente, de modo a gerenciar todos os acessos à malha e dispor operações e iteradores para pesquisas complexas nas vizinhanças de cada elemento na malha. $\mathrm{O}$ módulo simulador resolve as equações governantes da mecânica dos fluidos através da técnica de volumes finitos. Foi utilizada uma formulação que atribui os valores das 
propriedades aos centroides dos volumes de controle, utiliza métodos de alta ordem, os esquemas ENO e WENO, que tem a finalidade de capturar com eficiência descontinuidades presentes em problemas governados por equações diferenciais parciais hiperbólicas. As equações de Euler em duas dimensões representam os escoamentos de interesse no presente trabalho. O acoplamento da estrutura de dados Mate Face ao simulador foi realizada através da criação de uma biblioteca desenvolvida que atua como uma interface de comunicação entre os dois módulos, a estrutura de dados e o simulador, que foram implementados em diferentes linguagens de programação. Deste modo, todas as funcionalidades existentes na Mate Face tornaram-se acessíveis ao simulador na forma de procedimentos. Um estudo sobre malhas dinâmicas foi realizado envolvendo o método das molas para movimentação de malhas simulando-se operações de arfagem. A ideia foi verificar a aplicabilidade deste método para auxiliar simulações de escoamentos não estacionários. Uma outra vertente do trabalho foi estender a estrutura Mate Face de forma a representar elementos não suportados a priori, de modo a flexibilizar o seu uso em simulações de escoamentos baseados no método de volumes finitos espectrais. O método dos volumes espectrais é utilizado para se obter alta resolução espacial do domínio computacional, que também atribui valores das propriedades aos centroides dos volumes de controle, porém, os volumes de controle são particionados em volumes menores de variadas topologias. Assim, uma extensão da Mate Face foi desenvolvida para representar a nova malha para a aplicação do método, representando-se cada particionamento localmente em cada volume espectral. Para todas as etapas deste trabalho, realizaram-se experimentos que validaram a utilização da estrutura de dados Mate Face junto a métodos numéricos. Desta forma, a estrutura pode auxiliar as ferramentas de simulações de escoamentos de fluidos no gerenciamento e acesso à malha computacional. 


\section{Abstract}

The storage and access of grid files by data structures and topologic operators is one of the most important goals of geometric modeling research field, which allows an efficient and stable implementation of adaptive refinement mechanisms, cells alignment and access to incidence and adjacency properties from grid elements, representing great concernment in the majority of applications from fluid mechanics. In the case of non-structured grids, the cellular decomposition if non-uniform and is better suited by a more sophisticated strategy - the topologic data structs. The topologic data structs index grid elements representing incidence and adjacency properties from grid elements, ensuring quick access to information. One of most common aspects from problems solved by computational fluid mechanic is the complexity of the domain geometry where the fluid flows. The usage of data structures to manipulate computational grids is of great importance because it performs efficiently queries on grid information and centers all operations to the grid on a unique module, allowing its extension and flexible usage on many problems. This work aims at exploring the coupling of a topologic data structure, the Mate Face, on a solver module, by controlling all grid access providing operators and iterators that perform complex neighbor queries at each grid element. The solver module solves the governing equations from fluid mechanics though the finite volume technique with a formulation that sets the property values to the control volume centroids, using high order methods - the ENO and WENO schemes, which have the purpose of efficiently capture the discontinuities 
appearing in problems governed by hyperbolic conservation laws. The two dimensional Euler equations are considered to represent the flows of interest. The coupling of the Mate Face data structure to the solver module was achieved by a creation of a library that acts as an interface layer between both modules, the Mate Face and the solver, which had been implemented using different programming languages. Therefore, all Mate Face class methods are available to the solver module though the interface library in the form of procedures. A study of dynamic grids was made by using spring methods for the moving grid under pitch movement case. The goal was to analyze the applicability of such method to aid non stationary simulations. Another contribution of this work was to show how the Mate Face can be extended in order to deal with non-supported types of elements, allowing it to aid numeric simulations using the spectral finite volume method. The spectral finite volume method is used to obtain high spatial resolution, also by setting the property values to the control volume centroids, but here the control volumes are partitioned into smaller volumes of different types, from triangles to hexagons. Then, an extension of the Mate Face was developed in order to hold the new generated grid by the partitioning specified by the spectral finite volume method. The extension of Mate Face represents all partitioned elements locally for each original control volume. For all implementations and proposals from this work, experiments were performed to validate the usage of the Mate Face along with numeric methods. Finally, the data structure can aid the fluid flow simulation tools by managing the grid file and providing efficient query operators. 
Lista de Figuras xii

$\begin{array}{ll}\text { Lista de Tabelas } & \text { xvii }\end{array}$

Lista de Abreviaturas xviii

$\begin{array}{lll}\mathbf{1} & \text { Introdução } & \mathbf{1}\end{array}$

1.1 Considerações Iniciais . . . . . . . . . . . . . . . . . . . . . . 1

1.2 A Mecânica dos Fluidos Computacional . . . . . . . . . . . . . . . . . 5

1.3 Métodos de Alta Ordem . . . . . . . . . . . . . . . . . . . . . . . . . . 8

1.4 Modelos Aerodinâmicos . . . . . . . . . . . . . . . . . . . . . . . . 10

1.5 Estruturas de Dados . . . . . . . . . . . . . . . . . . . 15

1.6 Objetivos do Trabalho . . . . . . . . . . . . . . . . . . . 17

1.7 Organização da Tese $\ldots \ldots \ldots$. . . . . . . . . . . . . . . . . 19

2 Conceitos Fundamentais de Modelagem Geométrica 21

2.1 Considerações Iniciais . . . . . . . . . . . . . . . . . . . . . . . . . 21

2.2 Definições básicas . . . . . . . . . . . . . . . . . . . . . . . . . . . . . 22

2.3 Malhas Computacionais . . . . . . . . . . . . . . . . . 27

2.4 Malhas Dinâmicas . . . . . . . . . . . . . . . . . . . . . . . . . . . . . . 29

2.4 .1 Cálculo das Forças Elásticas . . . . . . . . . . . . . . . . . 32

2.5 Considerações Finais $\ldots \ldots \ldots$. . . . . . . . . . . . . . 36

3 Modelo Matemático do Escoamento 39

3.1 Considerações Iniciais . . . . . . . . . . . . . . . . . . . . . . . . . . . . 39

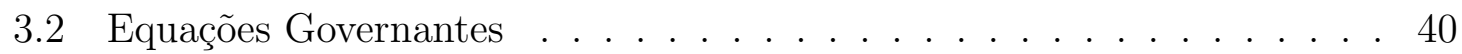

3.3 Adimensionalização das Equações de Navier-Stokes . . . . . . . . . . . 43

3.4 As Equações de Euler . . . . . . . . . . . . . . . . . . . . . . . . . 46 
3.5 O Método dos Volumes Finitos . . . . . . . . . . . . . . . . . . . . . . 47

3.5 .1 Formulação das Equações . . . . . . . . . . . . . . . . . . . 47

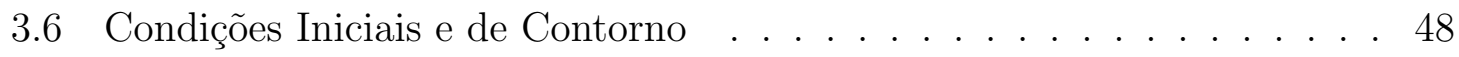

3.6 .1 Condição de Escorregamento . . . . . . . . . . . . . . . . . . . 49

3.6 .2 Condição Não Reflexiva $\ldots . . . .50$

3.6 .3 Condição de Entrada . . . . . . . . . . . . . . . . . . . . . 52

3.6 .4 Condição de Saída . . . . . . . . . . . . . . . . . 53

3.7 Considerações Finais $\ldots \ldots \ldots$. . . . . . . . . . . . . . . . . . 53

4 Estrutura de Dados Topológicas 55

4.1 Considerações Iniciais . . . . . . . . . . . . . . . . . . . . . . . 55

4.2 Estrutura de Dados Topológicas . . . . . . . . . . . . . . . . . 56

$4.3 \quad$ A Estrutura de Dados Opposite Face - OF . . . . . . . . . . . . . . . 60

4.4 A Estrutura de Dados Mate Face - MF . . . . . . . . . . . . . . . . . . 61

4.4 .1 Vetor de Elementos . . . . . . . . . . . . . . . . . . . . . . . . . 62

4.4 .2 Vértices . . . . . . . . . . . . . . . . . . . . . . . 63

$4.4 .3 \quad$ Arestas $\ldots \ldots \ldots \ldots$

4.4 .4 Célula . . . . . . . . . . . . . . . . . . . . . . 64

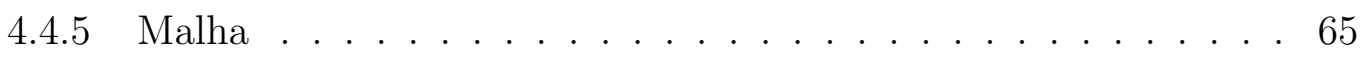

4.5 Considerações Finais . . . . . . . . . . . . . . . . . . . . . . . 71

$\begin{array}{lll}5 & \text { Os Esquemas ENO e WENO } & 73\end{array}$

5.1 Considerações Iniciais . . . . . . . . . . . . . . . . . . . . . 73

5.2 Discretização Espacial . . . . . . . . . . . . . . . . . . 76

5.3 Discretização Temporal . . . . . . . . . . . . . . . . . . . . . . . . . 82

5.4 Reconstrução dos Esquemas ENO e WENO . . . . . . . . . . . . . . 83

5.4 .1 Reconstrução na Segunda Ordem de Precisão . . . . . . . . . . 86

5.4 .2 Reconstrução na Terceira Ordem de Precisão . . . . . . . . . . . 89

5.4 .3 Reconstrução na Quarta Ordem de Precisão . . . . . . . . . . . 92

5.5 Acoplamento da Mate Face ao Simulador . . . . . . . . . . . . . . . . . 95

5.5 .1 Caracterização do Código de Simulação . . . . . . . . . . . . . . 96

5.5 .2 Modificação na Mate Face . . . . . . . . . . . . . . . . . . . . . 100

$5.5 .3 \quad$ Integração dos Códigos . . . . . . . . . . . . . . . . . 102

5.5 .4 A Biblioteca Desenvolvida . . . . . . . . . . . . . . . 107

5.5.5 Exemplos de Utilização da Biblioteca no Simulador . . . . . . . 119

5.6 Utilização da Malha Elástica . . . . . . . . . . . . . . . . . . . . . . . . 122

Os Vértices Ativos . . . . . . . . . . . . . . . . . . . . . . . 123

5.7 Aplicações . . . . . . . . . . . . . . . . . . . . . . . . . 125 
5.7 .1 Análise de Custo Computacional . . . . . . . . . . . . 126

5.7 .2 Escoamento Sobre uma Cunha . . . . . . . . . . . . . . . . . 130

5.7 .3 Escoamento Sobre o Perfil NACA 0012 . . . . . . . . . . . . 133

5.7 .4 Aplicação da Malha Elástica Sobre o Perfil NACA 0012 . . . . . 141

5.8 Considerações Finais $\ldots \ldots \ldots \ldots$. . . . . . . . . . . . 146

6 Método de Volumes Finitos Espectrais $\quad 149$

6.1 Considerações Iniciais $\ldots \ldots \ldots$

6.2 Formulação Geral . . . . . . . . . . . . . . . . . . . . . . . . . . . 152

6.3 Particionamento . . . . . . . . . . . . . . . . . . . . . . 155

6.3 .1 Reconstrução 1D . . . . . . . . . . . . . . . . . . . 157

6.3 .2 Reconstrução 2D . . . . . . . . . . . . . . . . . . . . 158

6.4 Formulação do Limitador de Fluxo … . . . . . . . . . . . . . . 161

6.5 Esquemas de Marcha no Tempo . . . . . . . . . . . . . . . . 166

6.5 .1 Integração Explícita . . . . . . . . . . . . . 166

6.5 .2 Integração Implícita . . . . . . . . . . . . . . . . 167

6.6 Adequação da Mate Face ao Particionamento . . . . . . . . . . . . . . 170

6.7 Aplicações . . . . . . . . . . . . . . . . . . . . . . . . . 183

$6.7 .1 \quad$ Escoamento Sobre o Perfil RAE 2822 . . . . . . . . . . . . . 184

6.7 .2 Escoamento Sobre uma Rampa . . . . . . . . . . . . . . 190

6.8 Considerações Finais $\ldots \ldots \ldots \ldots \ldots$

\begin{tabular}{lll}
\hline 7 & Conclusão & 197
\end{tabular}

\begin{tabular}{ll}
\hline Referências Bibliográficas & 212
\end{tabular} 


\section{Lista de Figuras}

$2.1 \quad$ Exemplos de conjuntos em $\mathbb{R}^{2} . \ldots \ldots \ldots \ldots \ldots \ldots$

2.2 Exemplos de fecho convexo em $\mathbb{R}^{2}$. . . . . . . . . . . . 24

2.3 Exemplos de simplexos. . . . . . . . . . . . . . . . . . . . . . 25

2.4 Exemplos de complexos celulares. . . . . . . . . . . . . . . . 25

2.5 Exemplos de tipos de malha. . . . . . . . . . . . . . . . 28

2.6 Esquema de mola torcional. . . . . . . . . . . . . . . . . . . 34

2.7 Mola semi-torcional proposta por $[$ Blom, 2000]. . . . . . . . . . . . . 35

2.8 As molas torcionais em $v_{k}$ e $v_{l}$ são adicionadas à mola longitudinal na

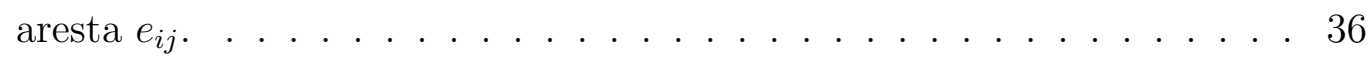

4.1 Representação de vértices na estrutura OF. . . . . . . . . . . . 60

4.2 Células vizinhas nos casos bi e tridimensionais. . . . . . . . . . . . . . . 61

4.3 Esquema de alocação do vetor de elementos. . . . . . . . . . . . . . . . 62

4.4 Exemplo de armazenamento de vértices na MF em uma malha bidimensional. . . . . . . . . . . . . . . . . . . 63

4.5 Exemplo de um vértice singular com células incidentes hachuradas. . . 64

4.6 Representação de células triangulares na MF. . . . . . . . . . . 65

4.7 Representação de células tetraédricas na MF. . . . . . . . . . . . . . 65

4.8 Exemplo de caminhamento em estrela em um dado vértice com célula inicial com identificador zero. . . . . . . . . . . . . . . . 67 67

4.9 Vizinhança de células na MF. . . . . . . . . . . . . . . . . . 68

4.10 Busca na estrela de um vértice em uma malha mista. . . . . . . . . . . 68

4.11 Malha superficial mista na Mate Face representando um modelo de peça de automóvel $[$ Cunha, 2009]. . . . . . . . . . . . . . . . . . . . 69

4.12 Malha representando o Dragão Chinês formada por 1053 mil tetraedros [Cunha, 2009]. . . . . . . . . . . . . . . . . 70 
$5.1 \quad$ Moléculas de cálculos válidas para reconstrução de segunda ordem de precisão. . . . . . . . . . . . . . . . . . . . . . . . 87

5.2 Moléculas de cálculos válidas para reconstrução de terceira ordem de precisão. . . . . . . . . . . . . . . . . . . . 89

5.3 Moléculas de cálculos válidas para reconstrução de quarta ordem de precisão. . . . . . . . . . . . . . . . . . . . . 92

$5.4 \quad$ Exemplo de malha bidimensional. . . . . . . . . . . . . . . . . . . . 97

5.5 Extensão das classes na Mate Face. . . . . . . . . . . . . . . . . . . . 101

5.6 Esquema de integração dos códigos Fortran 77 (Brud2D) e C++ (Mate Face). . . . . . . . . . . . . . . . . 104

5.7 Exemplo de criação da malha na Mate Face via interface. . . . . . . . . 109

5.8 Exemplo do cálculo de área de uma célula triangular. . . . . . . . . . . 111

5.9 Exemplo de cálculo do centroide de uma célula. . . . . . . . . . . . . 111

5.10 Exemplo de cálculo do direction cosine. . . . . . . . . . . . . . . . . 112

5.11 Exemplo de uso do procedimento getedgeids. . . . . . . . . . . . . 113

5.12 Exemplo de uso do procedimento getedgevol. . . . . . . . . . . . . 113

5.13 Exemplo vizinhança em torno de uma célula. . . . . . . . . . . . . . . . 114

5.14 Exemplo de composição das células. . . . . . . . . . . . . . . . . . . . . 114

5.15 Exemplo de uma consulta sobre a localização de um ponto na célula. 115

5.16 Tempo de construção das estruturas variando-se a resolução das malhas. 127

5.17 Consumo de memória comparativo entre as estruturas utilizadas. . . . . 128

5.18 Taxa relativa de crescimento da ocupação de memória variando-se a resolução das malhas. . . . . . . . . . . . . . . . . . . . . . . . . . . . 129

5.19 Representação do domínio computacional, caso escoamento sobre uma cunha. . . . . . . . . . . . . . . . . . . . 131

5.20 Malha computacional utilizada na simulação do escoamento sobre a cunha. . . . . . . . . . . . . . . . . . . . . . 131

5.21 Resultados da densidade. (a) Densidade do domínio pelo simulador Original. (b) Densidade do domínio pelo simulador com a Mate Face. 132

5.22 Distribuição de coeficiente de pressão ao longo da parede da cunha,

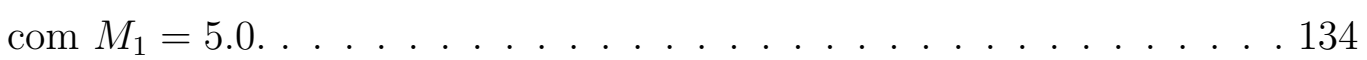

5.23 Histórico do resíduo para a simulação do escoamento sobre a cunha

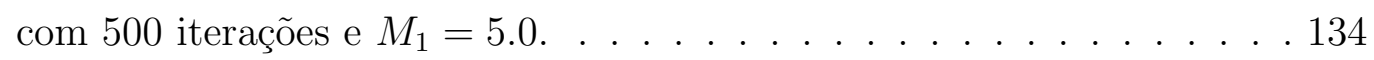

5.24 Representação do esquema do escoamento sobre o aerofólio NACA 0012. 135

5.25 Malha em torno do perfil NACA 0012 com 182 vértices no contorno do aerofólio. . . . . . . . . . . . . . . . . . . . . 135 
5.26 Resultados da densidade. (a) Densidade do domínio pelo simulador

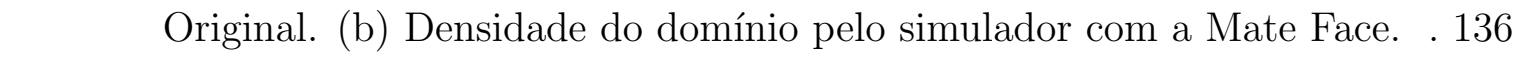

5.27 Distribuição de coeficiente de pressão ao longo do extradorso do aerofólio, com $M_{1}=1.0$ e $\alpha=1.0$. . . . . . . . . . . . . . . 137

5.28 Campo vetorial do escoamento do fluido sobre o perfil NACA 0012, com $M_{1}=1.0$ e $\alpha=1.0$. . . . . . . . . . . . . . . . 137

5.29 Histórico de resíduos nas 2000 primeiras iterações da simulação para uma malha com 5908 vértices. . . . . . . . . . . . . . . . . . . . . . . . 138

5.30 Malha em torno do perfil NACA 0012 com 326 vértices no contorno do aerofólio. . . . . . . . . . . . . . . . . . . . . . 138

5.31 Resultados da densidade. (a) Densidade do domínio pelo simulador

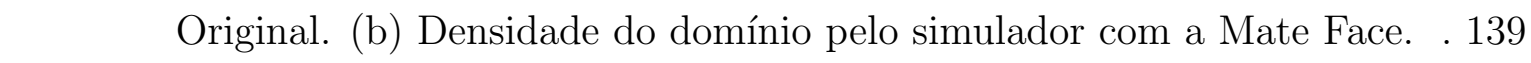

5.32 Distribuição de coeficiente de pressão ao longo do extradorso do aerofólio, com $M_{1}=1.0$, com 7363 vértices. . . . . . . . . . . . . . . . . . 139

5.33 Campo vetorial do escoamento do fluido sobre o perfil NACA 0012, com $M_{1}=1.0$ e $\alpha=1.0$. . . . . . . . . . . . . . . . . . . . . . . . . . . 140

5.34 Histórico de resíduos nas 2000 primeiras iterações da simulação para uma malha com 7363 vértices. . . . . . . . . . . . . . . . . . . . . . . . 140

5.35 Visualização das malhas utilizadas. . . . . . . . . . . . . . . . . . 142

5.36 Movimento em arfagem no aerofólio em três graus. . . . . . . . . . . . 144

5.37 Movimento em arfagem no aerofólio com elementos inválidos. . . . . . . . 145

6.1 Exemplos de particionamento de células de volumes espectrais para o caso unidimensional. . . . . . . . . . . . . . . . . . . . . . . . . . 153

6.2 Exemplos de particionamento de células de volumes espectrais para o caso bidimensional. . . . . . . . . . . . . . . . . . . . . . . . . . . . . . 154

6.3 Classes da estrutura Mate Face estendida para o método SFV. . . . . . . 171

6.4 Exemplo de malha com subdivisões dos volumes espectrais. . . . . . . . . 172

6.5 Associação entre volumes espectrais e volumes de controle para os particionamentos de segunda, terceira e quarta ordem de precisão. . . . . . 175

6.6 Rotulações realizadas nos volumes de controle para identificação interna. 176

6.7 Organização interna dos volumes espectrais. . . . . . . . . . . . . . . 179

6.8 Montagem das arestas espectrais na MF estendida a partir da malha original. . . . . . . . . . . . . . . . . . . . 181

6.9 Esquema de looping em células espectrais. . . . . . . . . . . . . . . . 182

6.10 Representação do esquema do escoamento sobre o aerofólio RAE 2822. 184

6.11 Malha sobre o aerofólio RAE 2822. . . . . . . . . . . . . . . . 185 
6.12 Malha com os volumes espectrais de segunda ordem após o particionamento. Detalhe na região de bordo de ataque (a) e bordo de fuga (b). . . . . . . . . . . . . . . . . . . . . . 185

6.13 Distribuição de coeficiente de pressão ao longo da corda do aerofólio RAE 2822 para SFV de segunda ordem. . . . . . . . . . . . . . . . . 186

6.14 Histórico do resíduo para o aerofólio RAE $2822 \mathrm{com} M_{\infty}=0.729 \mathrm{e}$ $\alpha=2.31^{\circ}$ para SFV de segunda ordem. . . . . . . . . . . . . . . 187

6.15 Malha com os volumes espectrais de terceira ordem após o particionamento. Detalhe na região de bordo de ataque (a) e bordo de fuga (b). . . . . . . . . . . . . . . . . . . . . . . 188

6.16 Distribuição de coeficiente de pressão ao longo da corda do aerofólio RAE 2822 para SFV de terceira ordem. . . . . . . . . . . . . . . . . . 188

6.17 Histórico do resíduo para o aerofólio RAE $2822 \mathrm{com} M_{\infty}=0.729 \mathrm{e}$ $\alpha=2.31^{\circ}$ para SFV de terceira ordem. . . . . . . . . . . . . . . 189

6.18 Malha gerada pelo método de volumes finitos espectral de segunda ordem.190

6.19 Malha gerada pelo método de volumes finitos espectral de terceira ordem.191

6.20 Malha gerada pelo método de volumes finitos espectral de quarta ordem.191

6.21 Histórico dos resíduos para todos os esquemas simulados. . . . . . . . 192

6.22 Gráficos de distribuição de coeficiente de pressão para as ordens de precisão simuladas, (a) segunda ordem de precisão, (b) terceira ordem de precisão e (c) quarta ordem de precisão. . . . . . . . . . . . . . . . 193 


\section{Lista de Tabelas}

5.1 Equivalência de tipos de dados entre Fortran e C++ . . . . . . . . . 105

5.2 Equivalência de blocos de memória entre Fortran e C++ . . . . . . . . 106

5.3 Diferentes resoluções de malhas NACA 0012 utilizadas para os testes. . 126

5.4 Tempo para consulta na vizinhança dos vértices (segundos). . . . . . . 129

5.5 Diferentes resoluções de malhas NACA 0012 utilizadas para os testes. . 141

6.1 Funções polinomiais base para o método espectral. . . . . . . . . . . . . 160

6.2 Relação dos rótulos e suas posições $\ldots$. . . . . . . . . . . . . . 177 


\section{Lista de Abreviaturas}

Aqui seguem abreviações utilizadas ao longo do documento.

$\begin{array}{ll}\text { CFD } & \text { Computational Fluid Dynamics } \\ \text { CHF } & \text { Compact Half-Face } \\ \text { CV } & \text { Control Volume (Volume de Controle) } \\ \text { EDP } & \text { Equação Diferencial Parcial } \\ \text { EDT } & \text { Estrutura de Dados Topológica } \\ \text { ENO } & \text { Essentially Non-Oscillatory } \\ \text { FCT } & \text { Flux-Correted Transport } \\ \text { HRS } & \text { High Resolution Scheme } \\ \text { MDF } & \text { Método de Diferenças Finitas } \\ \text { MEF } & \text { Método de Elementos Finitos } \\ \text { MF } & \text { Mate Face } \\ \text { MVF } & \text { Método de Volumes Finitos } \\ \text { MUSCL } & \text { Monotone Upstream-centered Schemes for Conservation Laws } \\ \text { NACA } & \text { National Adivisory Comittee of Aeronautics } \\ \text { OF } & \text { Opposite Face } \\ \text { PFGM } & \text { Parameter Free Generalized Moment Limiter } \\ \text { SHE } & \text { Singular Handle Edge } \\ \text { SFV } & \text { Spectral Finite Volume } \\ \text { SV } & \text { Spectral Volume (Volume Espectral) } \\ \text { TVD } & \text { Total Variation Diminishing } \\ \text { WENO } & \text { Weighted Essentially Non-Oscillatory } \\ & \end{array}$





\section{Capítulo \\ 1 \\ Introdução}

Neste capítulo são apresentadas as considerações iniciais sobre o trabalho realizado, de modo a contextualizar os assuntos abordados nesta tese. Em seguida, são abordados os tópicos relevantes ao contexto do trabalho, apresentados os objetivos principais que direcionaram as atividades realizadas e por fim a organização dos capítulos deste documento.

\subsection{Considerações Iniciais}

A tarefa de reproduzir ou prever fenômenos da natureza em um ambiente computacional é feita através da simulação numérica. Ela se tornou uma ferramenta importante no desenvolvimento de novas tecnologias, como no monitoramento de sistemas complexos, na previsão de processos evolutivos, e também na reprodução virtual dos fenômenos físicos. Estudos como a previsão do tempo, projeto de pontes, criação de medicamentos e enchimento de reservatórios (represas), fazem uso de simuladores computacionais que são importantes ferramentas para informar o usuário sobre a evolução virtual do fenômeno físico modelado.

A Mecânica dos Fluidos Computacional (Computational Fluid Dynamics) - CFD, 
é o ramo da ciência que tem apresentado cada vez mais importância nos estudos e pesquisas atuais. Estudos nessa área são de grande importância devido ao vasto número de aplicações industriais e de escoamentos encontrados na natureza. Entretanto, obter resultados numéricos cada vez mais confiáveis para um número maior de situações tem sido um dos maiores desafios em vários ramos da ciência. Em particular, a CFD vem sendo utilizada em larga escala para simulações de escoamentos de fluidos.

As equações de Navier-Stokes podem ser utilizadas para solucionar problemas em CFD. Nestas equações, as soluções analíticas são conhecidas apenas para alguns casos Gersten, 2009 Lamb, 1879]. O impedimento para encontrar essas soluções decorre do fato de serem equações diferenciais parciais não lineares e além disso a teoria matemática desta classe de equações não está desenvolvida o suficiente para que seja possível obter soluções para geometrias arbitrárias e condições de contorno gerais.

A CFD busca solucionar as equações que caracterizam o movimento do fluido. Para tal, é necessário aproximar as EDPs, cujas soluções são definidas por infinitos graus de liberdade, obtendo-se sistemas de equações com um número finito de graus de liberdade. Este processo de aproximação é chamado de discretização. A CFD requer o uso de métodos numéricos para calcular as grandezas de interesse nos escoamentos em pontos do domínio físico, denominados de pontos nodais ou nós, que compõem a malha computacional, onde por sua vez modela o domínio físico onde se dá o escoamento. Os principais métodos utilizados em CFD são o método de diferenças finitas, método de volumes finitos e métodos de elementos finitos Fortuna, 2000 Zienkiewicz and Taylor, 2000.

Em conjunto com as simulações desses escoamentos, a modelagem geométrica faz parte de um importante componente utilizado nas simulações computacionais, pois participa do processo de formação da malha computacional. Assim, quanto mais detalhes a modelagem geométrica agrega, melhor será a representação do domínio computacional.

Usualmente, o domínio mapeado é composto de um conjunto de elementos para 
representar objetos ou o meio que o fluido escoa. Esses objetos são representados por conjuntos de pontos no espaço onde a quantidade de pontos define o grau de detalhamento da malha que será gerada. A representação computacional das formas dos objetos podem ser criadas em ferramentas CAD ou mapeadas do próprio objeto.

A partir dos pontos mapeados do objeto, existem diversas técnicas de reconstrução de superfície que constroem a malha computacional criando-se elementos a partir da nuvem de pontos seguindo diversas abordagens Huang and Menq, 2002. Para melhores resultados, em geral é indicado que exista uma maior densidade de pontos nas regiões de interesse ou em curvaturas de objetos Gopi et al., 2000. Os pontos criados definem a geometria da malha e os elementos formados definem sua topologia. Todas essas informações formam um conjunto de dados que define uma malha computacional.

O conjunto de dados é composto por uma estrutura de organização e os dados ligados à estrutura. A estrutura possui uma topologia e uma geometria. A topologia é representada por um conjunto de propriedades que são invariantes se aplicadas algumas transformações geométricas, como a translação ou a rotação, que são transformações afins. A geometria representa a posição espacial dos pontos no espaço. Assim, a definição de um quadrado ou triângulo refere-se à topologia do elemento, enquanto que suas coordenadas referem-se à sua geometria Schroeder et al., 1998.

Uma malha computacional pode conter milhares de pontos e elementos (faces, células ou arestas). Uma busca sequencial para responder algumas pesquisas na malha pode ser ineficiente, pois um método numérico efetua várias delas. Deste modo, uma vez tendo a malha construída, é necessário definir uma estrutura de dados para armazenar os dados da malha e prover um acesso eficiente a eles.

Malhas com um número reduzido de elementos podem ser indexadas por estruturas de dados simples, como por exemplo, matrizes. No caso de malhas não estruturadas, a não uniformidade da decomposição celular é melhor representada por uma estratégia mais sofisticada, que são as estruturas de dados topológicas (EDTs) Shephard, 1997.

Grande parte das EDTs propostas na literatura indexam os dados de modo a 
melhorar o desempenho do acesso às relações de vizinhança e às buscas feitas na construção ou leitura de malhas Kwok et al., 1995, viabilizando o controle de procedimentos adaptativos Bottasso et al., 1998. Além disso, um aspecto importante destas estruturas são os operadores topológicos utilizados na construção e manutenção das mesmas Nielson, 2000.

Métodos que permitam uma manipulação mais eficiente da malha podem levar a uma redução significativa do custo computacional. O tratamento de malhas deformáveis ainda é um grande limitador no desenvolvimento da aeroelasticidade computacional. Diversos métodos, com aplicação em casos com corpos deformáveis, vêm sendo investigados, entre eles o método de molas [Lee-Rausch and Batina, 1996], o método de fronteiras imersas von Terzi et al., 2001, métodos multibloco [Hoffren, 1996] e métodos de cisalhamento simples [Schuster et al., 1990]. Estes métodos podem ser aplicados em EDTs para dar suporte à operação de movimentação de malhas utilizadas em simulações de escoamentos não estacionários.

Assim, este trabalho foca o estudo nas estruturas de dados que representam malhas, e também como provê-las com métodos para a deformação de malhas para investigar movimentações em malhas comumente presentes em problemas não estacionários. Além disso, uma das vertentes deste trabalho possibilitou a extensão de uma EDT para representar malhas adequadas ao método de volumes finitos espectrais, conforme será discutido nos capítulos a seguir.

O estudo realizado nesta tese agrega noções de uma metodologia numérica para resolução de escoamentos bidimensionais baseada no método de volumes finitos em malhas não estruturadas, com aplicação voltada para escoamentos compressíveis. O desenvolvimento de uma biblioteca para gerenciamento de malhas para utilização em uma ferramenta de simulação numérica desenvolvida em Fortran e sua extensão para uso em outros métodos numéricos são objeto de estudo neste trabalho. 


\subsection{A Mecânica dos Fluidos Computacional}

A mecânica dos fluidos computacional é definida como o conjunto de metodologias que permitem simular computacionalmente o escoamento de fluidos [Hirsch, 2007. Pode-se classificar o estudo de CFD de duas formas: os métodos experimentais e os métodos teóricos. Em ambos, busca-se representar, através de um modelo matemático, um fenômeno físico o mais próximo da realidade e assim estudá-lo e conhecer suas características e variáveis que mais o influenciam. Desta forma, a mecânica dos fluidos pode ser utilizada em vários fenômenos da natureza, nos quais pode-se citar o estudo de escoamentos fundamentais como camada limite, escoamentos cisalhantes como jatos, esteiras, ou mesmo escoamentos complexos, que são utilizados na indústria como parte de projetos de aeronaves, veículos, máquinas térmicas, bombas, edificações, dentre outros.

Grande parte da necessidade de simulação numérica em CFD se deve ao fato de que as equações de Navier-Stokes raramente têm uma solução exata conhecida, a menos de casos extremamente simplificados. Em aplicações de mecânica dos fluidos pretende-se, invariavelmente, reproduzir virtualmente o escoamento de um ou mais fluidos em um meio, que pode ser finito ou infinito, conter obstáculos, envolver altas velocidades e portanto grandes gradientes próximos a esses obstáculos, ser confinado ou ainda apresentar superfícies livres, entre uma infinidade de características próprias de cada escoamento.

Uma grande potencialidade da CFD é a possibilidade de simular determinadas operações nas quais seriam necessárias construções de unidades, riscos de acidentes, tempo e recursos financeiros consideráveis. Um exemplo disso é a utilização de túneis de vento no estudo aerodinâmico de automóveis e aviões, onde tal estudo pode ser feito inicialmente em simuladores, como ferramentas complementares, utilizando recursos financeiros bem mais reduzidos de forma segura e intervalos de tempos inferiores. Essa área ganhou muitos adeptos, tanto que atualmente essas simulações são muito utili- 
zadas por engenheiros, pesquisadores e projetistas para a previsão do comportamento de um determinado produto de engenharia, ou uma situação física sendo imposta as devidas condições de contorno. Outros exemplos em que também se utiliza a CFD são: o cálculo de sustentação e arrasto em foguetes; escoamentos em torno de mísseis; escoamento de ar no interior de motores de combustão interna; escoamento de ar de resfriamento dentro de equipamentos eletrônicos e dispersão de poluentes dentro de rios, oceanos e no ar atmosférico.

A mecânica dos fluidos estuda e utiliza métodos numéricos e computacionais para a solução das equações diferenciais parciais (EDPs) associadas aos modelos matemáticos. Sistemas formados por equações diferencias parciais podem ser classificados como: parabólicos, hiperbólicos ou elípticos. Esta classificação revela características específicas do problema que refletem nos métodos numéricos apropriados para sua resolução.

As equações de Navier-Stokes apresentam uma classificação mista, dependendo das condições do problema pode ser hiperbólica, parabólica ou elíptica. As EDPs resolvidas são normalmente as equações de quantidade de movimento, massa, energia. No presente trabalho as equações estudadas são as equações de Euler. Existem várias formas de resolver essas equações, dentre elas pode-se citar os métodos das diferenças finitas, elementos finitos, volumes finitos, entre outros.

O método de diferenças finitas (MDF) consiste em aproximar as derivadas das equações governantes por meio de diferenças finitas, que são obtidas através de expansões em séries de Taylor, truncadas no nível da ordem do erro desejada [Fortuna, 2000], [Ferziger and Peric, 1997]. Esse método pode alcançar uma alta ordem de convergência utilizando fórmulas de alta ordem, sua utilização é mais comum a malhas estruturadas em geometrias simples.

O método de elementos finitos (MEF) surgiu para análise de comportamento estrutural e desde então é usado para resolver equações diferenciais parciais que aparecem nas áreas de mecânica dos sólidos, elasticidade e na dinâmica dos fluidos. Sua 
aplicação tem como base subdividir o domínio do problema em pequenas regiões (elementos) e em cada um destes subintervalos a solução é aproximada através de uma função, normalmente um polinômio Zienkiewicz and Taylor, 2000. Uma importante vantagem apresentada por este método é sua habilidade de lidar com geometrias complexas, uma vez que técnicas para geração de malhas são bem difundidas.

O método de volumes finitos (MVF) consiste em uma integração das equações governantes do escoamento de fluido sobre todos os volumes de controle finitos que compõem o domínio de interesse. A discretização requer a substituição dos termos da equação integrada por uma variedade de aproximações do tipo das diferenças finitas. Isto converte as equações integradas em sistemas de equações algébricas Patankar, 1980, Maliska, 1995. O método de volumes finitos pode ser aplicado a qualquer tipo de malha, por isso adapta-se a geometrias complexas.

Este trabalho utiliza as equações de Euler discretizadas pelo método de volumes finitos. No caso compressível, essas equações são hiperbólicas, apresentando termos convectivos. Estes termos podem ser discretizados por técnicas centradas ou descentradas (upwind). A discretização utilizando técnicas centradas apresentam termos instáveis, sendo necessária a utilização de dissipação artificial para estabilizar o método. Já as técnicas upwind apresentam na própria discretização, termos estabilizantes, não necessitando de dissipação adicional.

Os métodos ou esquemas centrados utilizam uma discretização espacial centrada no ponto ou célula em questão. Desta forma, o estêncil da aproximação utiliza informação de todos os vizinhos à célula em questão de forma similar. Dentre esses esquemas, alguns foram desenvolvidos por Lax e Wendroff [Lax and Wendroff, 1960, porém seus métodos são de primeira ordem de precisão. Mais adiante Briley Briley and McDonald, 1975 aplicou a segunda ordem de precisão para esquemas centrados. Beam e Warming Beam and Warming, 1976 desenvolveram esquemas centrados implícitos no tempo e Jameson et al. Jameson et al., 1981 desenvolveram um esquema centrado explícito no tempo utilizando o método de Runge-Kutta de 
cinco estágios para a integração temporal.

Dentre os métodos upwind, pode-se citar o trabalho de Courant et al. Courant et al., 1952 como um dos pioneiros nesta área. No desenvolvimento de métodos upwind, Godunov Godunov, 1959 propôs a utilização do problema de Riemann exato para modelar o fluxo entrando ou saindo através de uma interface para o caso unidimensional das equações de Euler.

Van Leer van Leer, 1977 desenvolveu um método upwind de primeira ordem de precisão, a partir dos trabalhos de Godunov. Van Leer van Leer, 1979 discute sobre a obtenção de altas ordens de precisão para esses métodos. Seguindo o mesmo assunto, Roe Roe, 1981 desenvolveu o método upwind tipo Godunov, propondo a solução de um problema de Riemman aproximado, sendo um método do tipo separação de diferença de fluxo (Flux-Difference Splitting).

\subsection{Métodos de Alta Ordem}

Esquemas de alta ordem são assim chamados devido ao grau mais elevado de acurácia obtido por sua aplicação, apresentando ordem de aproximação superior a dois. Em alguns casos, apesar da melhora nos resultados, a aplicação destes esquemas apresentam problemas de convergência e estabilidade, ocasionando a formação de falsas oscilações na solução numérica obtida. Estas oscilações podem ser minimizadas e, até mesmo eliminadas, através da aplicação de técnicas específicas ou pelo aumento do refinamento da malha Versteeg and Malalasekera, 2007.

Um dos primeiros a analisar as condições necessárias para que um esquema de alta ordem não apresentasse oscilações numéricas foi Godunov Godunov, 1959, desenvolvendo um conceito de grande importância, a monotonicidade. Segundo ele, as oscilações numéricas são consequências de um comportamento não monotônico apresentado pelos esquemas de aproximação. O teorema de Godunov diz que todos os esquemas monotônicos são necessariamente de primeira ordem. Uma solução 
é monotônica quando a solução numérica não apresenta extremos locais e o valor mínimo local existente é não decrescente e o valor máximo local é não crescente Versteeg and Malalasekera, 2007.

Através desses conceitos, desenvolveram-se esquemas de alta ordem capazes de satisfazer as condições de preservação de monotonicidade da solução, introduzindo componentes não lineares, conhecidos como limitadores, à formulação desses esquemas. O propósito de uma função limitadora é controlar o surgimento das oscilações evitando que os gradientes excedam determinados limites ou mude de sinal entre pontos adjacentes. Estes esquemas são conhecidos como HRS (High Resolution Schemes) e foram inicialmente introduzidos por Van Leer van Leer, 1974, Boris e Book Boris and Book, 1973 e Hirsch Hirsch, 1989.

Boris e Book Boris and Book, 1973 propuseram uma técnica chamada FCT (Flux - Corrected Transport), que possibilitou desenvolver esquemas de alta ordem capazes de satisfazer a condição de monotonicidade. A técnica proposta adiciona ao esquema uma função limitadora que controla o fluxo contra difusivo, garantindo que a solução numérica não produza nenhum máximo ou mínimo.

Harten Harten, 1983 propôs um esquema chamado TVD (Total Variation Diminishing), que tem como objetivo manter a propriedade de monotonicidade da solução fazendo com que a variação total da solução discreta diminua com o tempo, assegurando que nenhuma oscilação incorreta seja gerada. Pode-se encontrar na literatura uma grande quantidade de funções limitadoras de fluxo, que por sua vez dão origem a diferentes métodos de tratamento de oscilações, como é o caso dos métodos de MUSCL desenvolvido por Van Leer van Leer, 1979, MINMOD desenvolvido por Harten Harten, 1983, entre outros.

O esquema ENO (Essentially Non-Oscillatory), introduzido por Harten et al. Harten et al., 1987, representa uma classe distinta de métodos para o tratamento de oscilações. Esta técnica tem como base a utilização de diferentes conjuntos de pontos, denominado estêncil, para aproximação da variável. A utilização do estêncil 
permite selecionar diferentes conjuntos de pontos para a obtenção da solução aproximada de forma a evitar que pontos em lados distintos de uma descontinuidade ou gradiente elevado sejam incluídos na fórmula de interpolação.

Posterior ao desenvolvimento da classe de esquemas ENO, os esquemas WENO (Weighted Essentially Non-Oscillatory) foram introduzidos por Liu et al. Liu et al., 1994 que tem como base os esquemas ENO, em que os esquemas de aproximação são gerados como uma combinação ponderada de diferentes estêncis ao invés de um único estêncil. A seleção do conjunto de pontos que constitui o estêncil e a ponderação atribuída a ele no esquema de interpolação final é realizada também de forma a evitar que pontos de ambos os lados de descontinuidades sejam incluídos na fórmula de interpolação. Mais tarde, Shu et al. Shu and Jiang, 1996, Shu et al., 2002 apresentam critérios para a determinação dos conjuntos de pontos e procedimentos para o obtenção de valores ótimos do peso de cada um dos estêncis no esquema de interpolação final.

Hannappel et al. Hannappel et al., 1995 compararam o esquema ENO com o esquema MUSCL-TVD para a resolução de problemas uni e bidimensionais. Os resultados obtidos pelo esquema ENO apresentaram um alto grau de precisão quando comparados ao esquema MUSCL-TVD. Os resultados obtidos demonstraram a superioridade do esquema ENO frente ao esquema TVD embora a aplicação do esquema seja mais trabalhosa, principalmente nos esquemas bidimensionais.

Existem muitos trabalhos destinados ao tratamento de oscilações em esquemas de alta ordem. Uma revisão detalhada sobre tais esquemas pode ser obtida em Versteeg and Malalasekera, 2007], Hoffman and Chiang, 2000 e Hirsch, 1989.

\subsection{Modelos Aerodinâmicos}

As equações de Navier-Stokes são normalmente consideradas como as equações governantes para a maior parte dos escoamentos em geral, entre eles os aerodinâmicos 
Nixon, 1989, Anderson, 1995. Diante das grandes dificuldades em resolver as equações de Navier-Stokes é recomendável fazer uso de hipóteses simplificadoras. A dificuldade em se encontrar soluções analíticas, mesmo para conjuntos simplificados de equações, decorre do fato que as equações que descrevem o escoamento em regime transônico, por exemplo, são equações diferenciais parciais não lineares.

Um dos maiores interesses por CFD em aeronáutica é a necessidade de se obter soluções confiáveis e práticas de modelos aerodinâmicos. Existem muitos estudos em métodos computacionais em aerodinâmica direcionados no desenvolvimento de ferramentas que utilizam métodos da Dinâmica dos Fluidos Computacional Anderson, 1995, Hirsch, 1989, Fletcher, 1992a Fletcher, 1992b. Grandes avanços estão sendo alcançados e aplicações de CFD na indústria aeronáutica tornaram-se fundamentais.

O desenvolvimento de métodos de modelagem de escoamentos aerodinâmicos em regime transônico é de suma importância para a engenharia aeronáutica. A maior dificuldade no tratamento desses escoamentos está na sua característica não linear devido aos efeitos de compressibilidade e formação de ondas de choque. No trabalho de Osher Osher, 1983 por exemplo, desenvolve-se o método implícito upwind pela eficiência em capturar ondas de choque na solução das equações de Euler em geometrias gerais e multidimensionais e em Pulliam Pulliam, 1988 vários métodos implícitos são utilizados, analisando a convergência da solução.

Os escoamentos aerodinâmicos podem ser classificados através do número de Mach (M), tomando como base os efeitos de compressibilidade. Desta forma, os escoamentos com $M<1$ são chamados de subsônicos, para $M=1$ os escoamentos são chamados de sônicos e para $M>1$ os escoamentos são definidos como supersônicos. Para um valor de $M$ em torno de $0.8<M<1.2$ o escoamento está na transição entre o subsônico e o supersônico. Neste intervalo os escoamentos aerodinâmicos são classificados como transônicos. Mais detalhes podem ser encontradas na literatura aeronáutica, nos trabalhos de Anderson Anderson, 1990, Anderson, 1991, Anderson, 1995. 
O regime de escoamento transônico é caracterizado pela presença de regiões mistas sobre a superfície do corpo aerodinâmico, com possibilidades de ocorrer áreas com $M<1$ e $M>1$. Assim, há o surgimento de ondas de choque, separação de camada limite provocada pelas ondas de choque e a formação de vórtices, trazendo problemas como as não linearidades Anderson, 1991. Então, nos casos específicos de regimes transônicos, as dificuldades para análise aerodinâmica são ainda maiores.

Soluções baseadas na teoria potencial mostraram-se muito eficientes no estudo de escoamentos transônicos com ondas de choque de intensidade fraca. Ashley Ashley, 1980, mostra como o aparecimento de ondas de choque de intensidade moderada na região subsônica do regime transônico possui extrema relevância em análises aeroelásticas do fenômeno de flutter. Flutter é uma oscilação auto-excitada de uma estrutura flexível, pode ser descrito também como um acoplamento instável entre as forças de inércia, elásticas e aerodinâmicas. Ashley Ashley, 1980 prevê a necessidade do emprego de ferramentas avançadas de CFD para a solução de escoamentos tridimensionais não estacionários a fim de estimar a velocidade de flutter no regime transônico, pois neste caso, a teoria potencial e ensaios em túnel de vento podem falhar. No trabalho de Jameson, Schmidt e Turkel JJameson et al., 1981] é apresentado um esquema para solução de escoamentos baseado na formulação de Euler e emprega uma discretização centrada em volumes finitos, combinada com termos dissipativos de terceira ordem e marcha no tempo com esquema do tipo Runge-Kutta.

A partir de 1980 muitos trabalhos utilizaram as formulações dadas pelas equações de Euler e de Navier-Stokes no desenvolvimento de códigos não estacionários, tais como Guruswamy Guruswamy, 1990, Obayashi , Guruswamy e Goorjian Obayashi et al., 1991, Chyu , Davis e Chang Chyu et al., 1981, Dubuc [Dubuc, 1997], Venkatakrishnan e Jameson Venkatakrishnan and Jameson, 1988, Drikakis e Tsangaris Drikakis and Tsangaris, 1992, Hwang e Wu Hwang and Wu, 1993, Batina Batina, 1993, Prananta e Hounjet Prananta and Hounjet, 1996, Neal Neal, 1991, 
Simões e Azevedo Simoes and Azevedo, 1999a, Jameson Jamenson, 1997, Dadone e Moretti [Dadone and Moretti, 1988].

O trabalho de Dowell Dowell, 1996, parte de um equacionamento aerodinâmico no domínio da frequência, utilizando o método de malha de vórtices para o caso não estacionário, e chega a um modelo aerodinâmico de ordem reduzida, obtido a partir da escolha de determinados modos aerodinâmicos. Esta ideia é bem interessante pois diminui bruscamente o tempo de processamento necessário para realizar uma análise de flutter. Outros métodos para resolução de ordem reduzida podem ser encontrados nos trabalhos de Marques Marques, 1997 e Silva et al. Silva, 2004.

O modelo aerodinâmico não estacionário de maior destaque foi o desenvolvido por Theodorsen Theodorsen, 1934 que obteve uma expressão para o carregamento aerodinâmico não estacionário sobre uma placa plana oscilando em um escoamento de ar. A solução proposta por Theodorsen é calculada no domínio da frequência, limitada para movimentos harmônicos simples de pequena amplitude e para escoamentos potenciais e incompressível. Variações na formulação de Theodorsen foram propostas e podem ser encontradas em Bisplinghoff Bisplinghoff et al., 1996. Posteriormente, o carregador aerodinâmico passou a ser representado em asas tridimensionais dividindoas em algumas seções ao longo da envergadura e utilizando uma formulação bidimensional como a de Theodorsen para cada seção. Esta técnica é conhecida como "teoria das faixas" e é clássica em estudos de aeroelasticidade.

Hirsh Hirsch, 1989, Fletcher Fletcher, 1992b, Anderson Anderson, 1991 apresentam modelos para escoamentos compressíveis, não isentrópicos e rotacionais. Essas formulações têm se mostrado satisfatórias na obtenção de resultados aerodinâmicos para escoamentos onde efeitos viscosos não são relevantes. Fletcher [Fletcher, 1984, mostra que as pertubações que ocorrem no interior ou na fronteira do domínio propagam-se sem amortecimento. Isso acontece, pois a formulação não representa a viscosidade natural e as equações de Euler não eliminam erros de alta frequência causados por não linearidades e descontinuidades, como as ondas de choque. Desta 
forma, Pulliam Pulliam, 1986 assume que as equações de Euler são utilizadas apenas em conjuntos com esquemas intrinsecamente dissipativos ou com adição de termos de dissipação artificial. Em Jameson e Mavriplis Jameson and Mavriplis, 1986 é apresentado um método para a solução das equações de Euler num contexto de malhas não estruturadas, mostrando adaptações no modelo de dissipação artificial e aplicações de técnicas de multigrid e suavização implícita de resíduo para o novo formato de células computacionais.

No trabalho de Smith et al. [Smith et al., 2000] são feitas comparações de diversos métodos de interpolação entre malhas estruturais e aerodinâmicas. Sua comparação se baseia na qualidade da interpolação, desvio, erro e suavidade da superfície interpolada. Atualmente existem modelos matemáticos que solucionam simultaneamente a parte estrutural e aerodinâmica [Smith et al., 2000].

Batina Batina, 1990 apresentou a solução de Euler por discretização de volumes finitos aplicadas a malhas triangulares em torno do perfil NACA 0012, onde o mecanismo de malha dinâmica é empregado na movimentação de malha em cálculos não estacionários, e também a lei de conservação geométrica necessária para evitar possíveis erros gerados por tal movimentação.

No trabalho de Oliveira Oliveira, 1993, foi apresentada uma metodologia baseada em método de volumes finitos e malhas não estruturadas para obtenção de respostas aerodinâmicas não estacionárias. Oliveira trata o esquema de geração de malhas não estruturadas e também o algoritmo de malha dinâmica usado na movimentação da malha em simulações não estacionárias. Os termos do operador aerodinâmico são determinados através da análise, no domínio da frequência. Mais adiante, Simões e Azevedo [Simoes and Azevedo, 1999b] mostram a influência do refinamento de malha e do esquema de marcha explícito de Runge-Kutta no tempo e na qualidade dos resultados. Scalabrin Scalabrin, 2002 apresenta um método de volumes finitos tridimensional, e utiliza um esquema de marcha no tempo explícito de segunda ordem de Runge-Kutta para integrar as equações de escoamento, no qual também mostra a 
influência do refinamento de malha.

\subsection{Estruturas de Dados}

Estruturas de dados são usadas para organizar um conjunto de informações e facilitar o acesso a elas de modo estruturado. Elas podem organizar malhas computacionais, que são formadas por coleções de vértices, arestas e faces que definem a forma de um objeto ou um domínio em questão. Alvo de pesquisa nas áreas de modelagem geométrica e também de computação gráfica, essas estruturas de dados facilitam o acesso à malha e oferecem operações necessárias em diversas aplicações.

Deste modo, diferentes representações destas malhas são usadas em diversas aplicações e objetivos. A variedade de operações desempenhadas nelas incluem lógica booleana, suavização, simplificação, refinamento, consultas elaboradas em seus elementos, entre outras. Malhas que representam elementos tridimensionais podem ser construídas a partir de duas abordagens. As malhas volumétricas explicitamente representam a superfície e o volume de uma estrutura, enquanto as malhas poligonais representam apenas a superfície bidimensional, sendo o volume definido de modo implícito. As malhas poligonais são muito utilizadas em computação gráfica, em algoritmos de Ray tracing, detecção de colisão e transformações de corpo rígido de polígonos.

Além destas aplicações, na área de mecânica dos fluidos computacional, um dos problemas enfrentados é representar a complexidade do domínio em que se dá o escoamento, formando diferentes tipos de malhas. Neste caso, as malhas são uma representação geométrica do domínio modelado por um conjunto de elementos.

A maioria dos métodos numéricos nesta área efetuam operações sobre a malha como consultas a elementos vizinhos. Por exemplo, considere uma malha formada por triângulos num espaço bidimensional, consultas típicas envolvem buscar os triângulos vizinhos a um dado triângulo, ou buscar todos os triângulos que compartilhem um 
dado vértice em questão. Essas operações devem ser disponibilizadas pela estrutura de dados que organiza os dados da malha geométrica.

Assim, a modelagem geométrica desempenha um papel importante, uma vez que problemas inerentes dessa área de aplicação, como a representação de domínios complexos, decomposições espaciais, manipulação e movimento de malhas, são naturalmente tratados pelas ferramentas oriundas da modelagem geométrica, disponibilizadas nas estruturas de dados específicas para malhas computacionais.

O desafio em algumas áreas da mecânica dos fluidos computacional é que em algumas simulações numéricas de escoamento de fluidos, algumas superfícies não podem ser consideradas como corpo rígido. Por exemplo, a asa de um avião em voo deformase pela força originária do escoamento de ar sobre a asa. Essa deformação muda as propriedades do escoamento e a configuração das forças sobre ele. Desta maneira, a etapa de simulação do escoamento do fluido em torno de uma estrutura elástica demanda que a deformação da estrutura seja acoplada às simulações deste escoamento. Note que neste caso, a malha em torno da estrutura deformada precisa se ajustar à nova geometria dada.

Ao invés de gerar uma nova malha para cada deformação da geometria, que tornaria o processo de simulação inviável, podemos tratar o problema de duas formas. Uma forma é processar apenas a parte deformada da malha, o que tornaria o processo complexo de ser tratado, e a outra, mais adequada, é movimentar apenas os nós da malha que se deslocaram, evitando alterações nas conectividades de outras células (mantendo a topologia).

Estruturas de dados topológicas aliadas a modelos elásticos possibilitam que inconsistências como sobreposição de células e elementos com razão de aspecto ruim, ou seja, alongados, sejam detectados e tratados dentro de um contexto topológico. Essas estruturas de dados topológicas buscam indexar os elementos da malha de modo a representar as relações de incidência e adjacência entre tais elementos, mantendo sempre a topologia da malha, garantindo ainda um acesso eficiente a suas informações. 
Por fim, deve-se observar que organizar os dados da malha numa estrutura de dados bem elaborada possui a vantagem de reutilizar esta estrutura em diversas aplicações de simulação, onde novas operações ou propriedades podem ser incluídas, estendendo as capacidades de representação e de utilização da estrutura.

\subsection{Objetivos do Trabalho}

Este trabalho teve como objetivo principal o estudo de estruturas de dados para malhas computacionais e a utilização dessas estruturas em simulações de escoamentos de fluidos. A tese é que estruturas de dados podem ser úteis para auxiliar simulações de escoamentos de fluidos de modo a abstrair operações que são usualmente necessárias nos métodos numéricos envolvidos na simulação. Então o foco deste trabalho foi direcionado à utilização destas estruturas de dados para estes fins e como vinculá-las em códigos de simulações existentes ou em novos ambientes de simulação.

A primeira etapa do trabalho constituiu na aplicação de uma estrutura de dados para malhas em um código de simulação já existente, que não usa uma estrutura de dados elaborada. O simulador resolve as equações de Navier-Stokes com média de Reynolds ou as equações de Euler. As simulações de escoamentos utilizam-se de esquemas essencialmente não oscilatórios, do inglês Essentially Non-Oscillatory (ENO), e os esquemas essencialmente não oscilatórios ponderados, do inglês Weighted Essentially Non-Oscillatory (WENO).

A ideia nesta primeira etapa do trabalho foi desvincular toda parte de manipulação, gerenciamento e operações sobre a malha do método numérico e centralizar tudo na estrutura de dados, tornando-a um módulo de gerenciamento de malha. Uma das dificuldades deste primeiro objetivo é que a integração da estrutura de dados no código de simulação envolveu emparelhar implementações realizadas em linguagens de programação diferentes, citando-se Fortran e C++. Uma vez emparelhados, foi realizada uma modificação no código do simulador de modo que todo acesso à malha foi 
feito na estrutura de dados emparelhada, assim como todas as operações de consultas na malha.

A segunda etapa desse trabalho foi investigar ferramentas de modelagem geométrica para movimento dinâmico de malhas discretizadas no contexto da dinâmica dos fluidos computacional. Como parte das operações suportadas por uma estrutura de dados, foi realizado um estudo para a utilização de malhas dinâmicas para o caso de arfagem em aerofólios em simulações numéricas. Deste modo, foi aplicada uma técnica baseada em molas para movimentação de vértices da malha durante uma operação de arfagem de um aerofólio, analisando-se a malha resultante do processo de movimentação para ser utilizada no tratamento de problemas não estacionários.

A última etapa desse trabalho foi a implementação do método de volumes finitos espectrais, que é utilizado para se obter alta precisão espacial do domínio computacional. Para isso, foi realizada uma extensão da estrutura de dados para que ela comportasse a nova geometria necessária para a aplicação do método. As principais características destas simulações incluem uma discretização espacial de segunda, terceira e quarta ordem de resolução.

O cumprimento dos objetivos deste trabalho contribuem para futuros trabalhos na área de mecânica dos fluidos computacional, pois foi desenvolvida uma biblioteca de acesso à estrutura de dados que pode ser facilmente utilizada em simuladores implementados em linguagem Fortran. Além disso, a modularidade da biblioteca permite que a estrutura de dados seja trocada, mantendo-se a correspondência dos operadores modificando apenas sua implementação, permitindo a evolução da estrutura de dados ou a adição de novas funcionalidades. Finalmente, será mostrado que estas estruturas de dados podem ser estendidas para adequarem-se a novos métodos numéricos que surgem na literatura. 


\subsection{Organização da Tese}

Este documento encontra-se dividido em sete capítulos cujo conteúdo é descrito a seguir.

- O capítulo 2 apresenta o embasamento teórico sobre modelagem geométrica, malhas computacionais e malhas dinâmicas;

- O capítulo 3 apresenta as equações governantes para escoamentos de fluidos, o método de discretização de volumes finitos, os parâmetros adimensionais utilizados na resolução das equações, bem como as principais condições de contorno utilizadas no domínio de simulações numéricas;

- O capítulo 4 apresenta as estruturas de dados topológicas existentes na literatura, e detalha a estrutura Mate Face utilizada neste trabalho para auxiliar o armazenamento, acesso e as operações sobre malhas;

- O capítulo 5 apresenta o desenvolvimento de uma biblioteca feita para ser acoplada em um simulador existente que usa esquemas não oscilatórios do tipo Essentially Non - Oscillatory (ENO) e os esquemas Weighted Essentially NonOscillatory (WENO) e suas reconstruções. No capítulo é mostrado como a biblioteca foi construída e acoplada ao simulador, bem como exemplos de utilização;

- O capítulo 6 apresenta a extensão da estrutura de dados Mate Face para adequar-se ao tipo de malha utilizada no método de volumes finitos espectrais. É mostrado como a estrutura foi modificada pois volumes menores são obtidos por particionamento de cada célula;

- Finalmente, o capítulo 7 conclui o trabalho realizado e propõe trabalhos futuros. 


\section{Capítulo \\ 2 \\ Conceitos Fundamentais de Modelagem Geométrica}

Este capítulo apresenta o embasamento teórico definido na modelagem geométrica, apresentando as definições e conceitos utilizados nesta área. Além disso, define os conceitos de malhas computacionais e apresenta métodos propostos na literatura para tratar malhas dinâmicas.

\subsection{Considerações Iniciais}

A construção de uma discretização apropriada do domínio onde se deseja executar a simulação é um passo importante em uma simulação numérica. Assim, este problema é tratado pela geração de malhas. A geração de malhas é uma atividade interdisciplinar, onde seu desenvolvimento se dá mediante avanços em geometria computacional, estrutura de dados, análise numérica e aplicações científicas. Assim sendo, o entendimento de complexos celulares e triangulações são definições importantes desta área, fazendo parte de um conjunto de definições que formalizam a geração de malhas.

Aplicações com domínio variante demandam o tratamento de malhas dinâmicas [Farhat et al., 1998] Burg, 2004]|Helenbrook, 2003] Sudharsan et al., 2004]. Esta 
técnica consiste em manter inalterada a conectividade da malha original e realizar o ajuste à nova configuração do domínio por meio de movimentação de vértices. A malha dinâmica é obtida pela distribuição de molas virtuais sobre a malha a ser movimentada.

Todos esses conceitos são apresentados nas seções subsequentes.

\subsection{Definições básicas}

As definições apresentadas nesta seção são baseadas em Goodman and O'Rourke, 1997, Mantyla, 1988. Um complexo celular é uma estrutura fundamental para formalizar e definir triangulações. Deste modo, a definição desta última necessita de conceitos de complexos celulares e seus elementos básicos. São dados a seguir definições que são importantes para a formalização de complexos celulares.

Definição 2.2.1 (Combinação linear convexa) Uma combinação linear de pontos $P_{1}, P_{2}, \ldots, P_{m} \in \mathbb{R}^{n}$, onde $n$ é a dimensão do espaço euclidiano, é dita convexa se existirem $\lambda_{1}, \lambda_{2}, \ldots, \lambda_{m} \in \mathbb{R}$, tal que

$$
\begin{gathered}
P=\lambda_{1} P_{1}+\lambda_{2} P_{2}+\ldots+\lambda_{n} P_{m}, \\
\lambda_{1}+\lambda_{2}+\ldots+\lambda_{m}=1
\end{gathered}
$$

$e$

$$
\lambda_{1} \geq 0, \lambda_{2} \geq 0, \ldots, \lambda_{m} \geq 0
$$

Uma combinação convexa também é chamada de célula convexa afim. Ela é diferente de uma combinação linear usual pelo fato do acréscimo das restrições 2.2 e 2.3 , que delimitam uma região no espaço. Seguindo esta imposição de limites, definem-se os conjuntos convexos. 
Definição 2.2.2 (Conjunto convexo) Um conjunto $\mathbf{P}, \mathbf{P} \subset \mathbb{R}^{n}$, é denominado convexo se, para quaisquer $P_{i}, P_{j} \in \mathbf{P}, i \neq j$, o segmento de reta

$$
S=\left[P_{i}, P_{j}\right]:=\left\{\lambda P_{i}+(1-\lambda) P_{j} \mid 0 \leq \lambda \leq 1\right\}
$$

está contido em $\mathbf{P}$.

Por exemplo, a Figura 2.1(a) mostra um conjunto convexo e Figura 2.1(b) mostra um conjunto não-convexo em $\mathbb{R}^{2}$. Outros conjuntos convexos são um ponto, um segmento de reta, um quadrado e uma esfera, por exemplo.

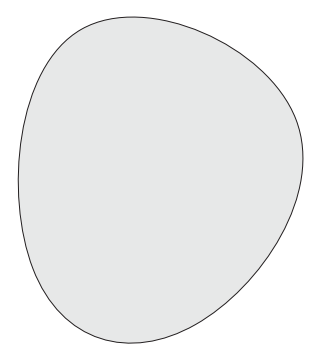

(a) Convexo

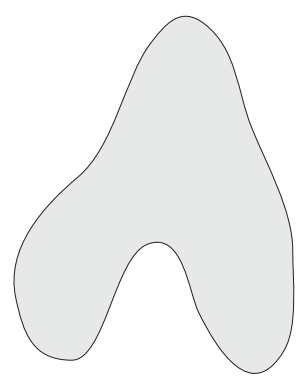

(b) Não-convexo

Figura 2.1: Exemplos de conjuntos em $\mathbb{R}^{2}$.

Para geração de malhas, um tipo de conjunto convexo importante é a definição de fecho convexo, pois ele é usado na definição de simplexos e triangulações.

Definição 2.2.3 (Fecho convexo) Seja um conjunto arbitrário $\mathbf{P}, \mathbf{P} \subset \mathbb{R}^{n}$. O fecho convexo de $\mathbf{P}, \operatorname{conv}(\mathbf{P})$, é o menor conjunto convexo de $\mathbb{R}^{n}$ que contém $\mathbf{P}$.

O fecho convexo de $\mathbf{P}, \operatorname{conv}(\mathbf{P})$, pode ser visto como a intersecção de todos os conjuntos convexos de $\mathbb{R}^{n}$ que contém $\mathbf{P}$. Este é o conjunto de todas as combinações convexas dos elementos de $\mathbf{P}$. Considerando um conjunto finito de pontos $\mathbf{P}=\left\{P_{1}, P_{2}, \ldots, P_{n}\right\}, \mathbf{P} \subset \mathbb{R}^{n}$, isto equivale a:

$$
\operatorname{conv}(\mathbf{P})=\left\{\sum_{i=1}^{n} \lambda_{i} P_{i} \mid P_{i} \in \mathbf{P}, \lambda_{i} \geq 0, \sum_{i=1}^{n} \lambda_{i}=1\right\}
$$


Como pode ser visto na Figura 2.2, o fecho convexo de um conjunto finito de pontos fica inteiramente definido por seus pontos extremos.

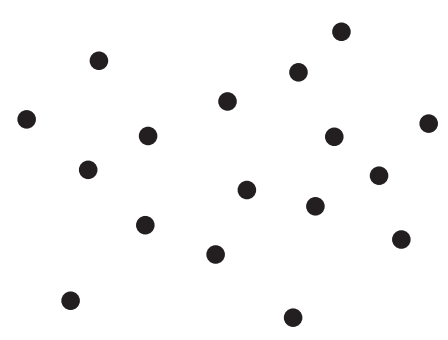

(a) Conjunto de pontos $\mathbf{P}$

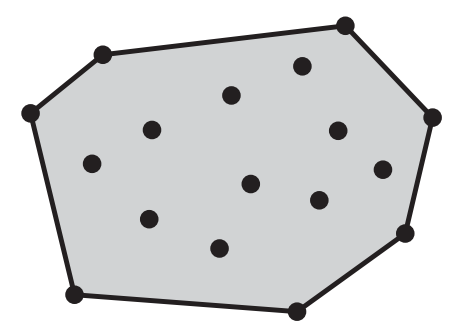

(b) Fecho convexo de $\mathbf{P}$

Figura 2.2: Exemplos de fecho convexo em $\mathbb{R}^{2}$.

A definição de simplexos é uma particularização de fechos convexos, então:

Definição 2.2.4 (Simplexo) Um simplexo de dimensão $n$, ou um n-simplexo, é o fecho convexo de $n+1$ pontos linearmente independentes de $\mathbb{R}^{n}$, os quais são vértices deste simplexo.

Logo, um vértice é um 0-simplexo, uma aresta é um 1-simplexo, um triângulo é um 2-simplexo e um tetraedro é um 3-simplexo, como podem ser vistos na Figura 2.3. Vale lembrar que o conjunto vazio é um $(-1)$-simplexo. Dado um $n$-simplexo $S=$ $P_{1} P_{2} \ldots P_{n+1}$, denominam-se faces de $S$ todos os simplexos gerados por subconjuntos não-vazios de vértices de $S$.

O conjunto de simplexos de interesse é o complexo celular definido como:

Definição 2.2.5 (Complexo celular) Um complexo celular $K$ em $\mathbb{R}^{n}$ é um conjunto finito de simplexos $S_{i}, i=1,2, \ldots, n$, satisfazendo as seguintes condições:

1. Sejam quaisquer dois simplexos $S_{i}$ e $S_{j}, i, j=1,2, \ldots, n, i \neq j$. Se $S_{i} \in K$ e $S_{j} \prec S_{i}$, onde $\prec$ indica que existe uma face em comum, então $S_{j} \in K$;

2. Se $S_{i}, S_{j} \in K, i, j=1,2, \ldots, n, i \neq j$, então $S_{i} \cap S_{j}=\emptyset$, ou $S_{i} \cap S_{j} \prec S_{i}$ e $S_{i} \cap S_{j} \prec S_{j}$ 


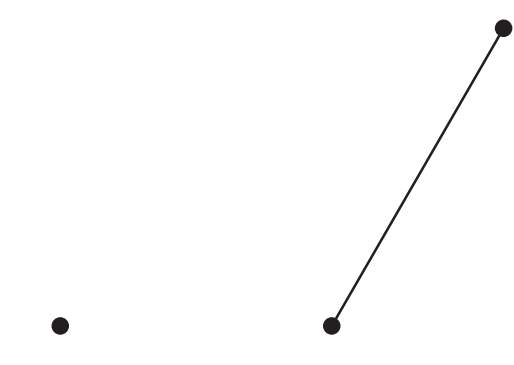

( a ) 0-simplexo
( b ) 1-simplexo

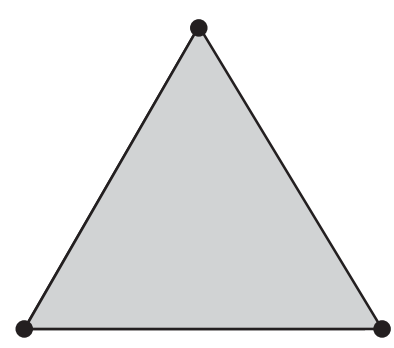

(c ) 2-simplexo

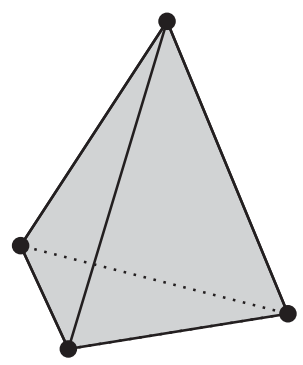

(d) 3-simplexo

Figura 2.3: Exemplos de simplexos.

A condição 1 estabelece que as faces de um simplexo pertencentes a um complexo celular também devem pertencer a este. Já a condição 2 afirma que a interseção entre dois simplexos diferentes pertencentes a um complexo celular pode ser vazia ou deve ser igual a uma face comum entre eles. A Figura 2.4 (a) mostra um exemplo de complexo celular arbitrário e a Figura 2.4 (b) apresenta um conjunto de simplexos os quais não geram um complexo celular.

A dimensão de um complexo celular é a dimensão máxima de seus simplexos. No caso da Figura 2.4 (a), o complexo celular é de dimensão 2. Por fim, um complexo celular é dito puro se qualquer simplexo pertencente a este encontra-se contido em um simplexo com dimensão máxima, como pode ser visto na Figura 2.4 (c).

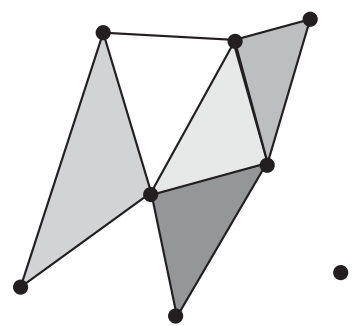

(a) Arbitrário

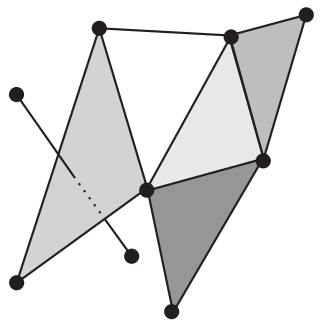

(b) Inválido

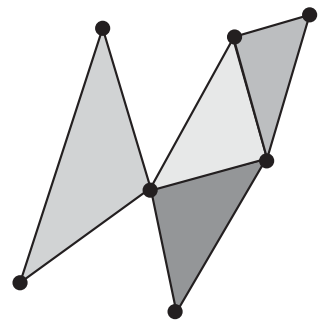

(c) Puro

Figura 2.4: Exemplos de complexos celulares. 
A partir das definições apresentadas até aqui, pode-se definir formalmente triangulações e malhas. À decomposição do espaço em simplexos dá-se o nome de triangulação. Deste modo, esta é definida como um complexo celular puro associado a um fecho convexo, como segue:

Definição 2.2.6 (Triangulação) Seja um domínio $\Omega$ contendo um conjunto finito de pontos $\mathbf{P}=P_{1}, P_{2}, \ldots, P_{m}, \mathbf{P} \subset \mathbb{R}^{n}$, ou seja, $\Omega=\operatorname{conv}(\mathbf{P})$, então uma triangulação $\tau_{\Omega}$ é um complexo celular $n$-dimensional puro, com $n$ simplexos $E_{i}, i=1,2, \ldots, n_{E}$, com as seguintes propriedades:

1. $\Omega=\bigcup_{E_{i} \in \tau_{\Omega}} E_{i}, i=1,2, \ldots, n_{E}$;

2. O conjunto dos vértices de todos os $E_{i}, i=1,2, \ldots, n_{E}$, é igual a $\mathbf{P}$.

Definição 2.2.7 (Triangulação de contorno) Seja $\partial \Omega$ o contorno de $\Omega$ e $Q, Q \subset$ $P$, o conjunto de todos os $m$ pontos percencentes a $\partial \Omega$, então uma triangulação de contorno de $\tau_{\partial \Omega}$ é um complexo celular (n-1)-dimensional puro, com (n-1)-simplexos $F_{i}, i=1,2, \ldots, n_{F}$ possuindo as propriedades:

1. $\partial \boldsymbol{\Omega}=\bigcup_{F_{i} \in \tau_{\partial \Omega}} F_{i}, i=1,2, \ldots, n_{F} e$

2. O conjunto dos vértices de todos os $F_{i}, i=1,2, \ldots, n_{F}$ é igual a $Q$.

Definição 2.2.8 (Malha) Seja um domínio fechado $\Omega$ e limitado em $\mathbb{R}^{n}$ com contorno $\partial \Omega$, então uma triangulação $\tau_{\Omega}$, com $n$-simplexos $E_{i}, i=1,2, \ldots, n_{E}$, é uma malha $\mathbb{M}_{\Omega}$, se esta satisfazer à condição:

1. $\Omega=\bigcup_{E_{i} \in \tau_{\Omega}} E_{i}, i=1,2, \ldots, n_{E}$

Neste trabalho, a malha $\mathbb{M}_{\Omega}$ é composta por triângulos, ou seja, $\mathbb{M}_{\Omega}$ é um complexo celular de dimensão $2, \mathbb{M}_{\Omega} \subset \mathbb{R}^{2}$. 


\subsection{Malhas Computacionais}

Para que o sistema resultante das equações governantes seja resolvido numericamente, é necessário que o domínio do problema seja representado em uma forma discreta, através da subdivisão do domínio do problema em um número finito de sub-regiões. A localização, a forma e o número de células utilizadas definem a posição geométrica e a quantidade de pontos para os quais as variáveis do problema serão calculadas. É extremamente importante que a distribuição e arranjo dos elementos que constroem a malha sejam capazes de representar adequadamente o domínio físico do problema Tannehill et al., 1997.

A etapa de geração de malha é tão importante na aplicação da CFD, que boa parte do tempo gasto na execução de um projeto é dedicado à definição da geometria e a geração da malha do problema. Geralmente qualquer esquema de solução obtém resultados satisfatórios quando aplicado a malhas de boa qualidade. Entretanto, a utilização de malhas de má qualidade, mesmo com esquemas de solução precisos, compromete a validade das soluções Chawner, 2003.

A precisão da solução obtida é influenciada pelo número de células que constroem a malha. Em geral, quanto mais refinada a malha melhor será a precisão dos resultados. No entanto, é necessário ponderar entre precisão e custo computacional referente ao refino da malha Shaw, 1992, assim, o tipo de malha utilizada é um fator essencial sobre o funcionamento da ferramenta de CFD.

Normalmente as malhas podem ser classificadas como estruturadas, não estruturadas e híbridas. Uma maneira comum de diferenciá-las é quanto a topologia da vizinhança dos elementos. Assim, malhas estruturadas são caracterizadas por seus nós internos possuírem número constante de elementos adjacentes (Figura 2.5(a)), malhas não estruturadas possuem nós internos com número de elementos adjacentes variável (Figura 2.5 (b)) e as malhas híbridas, resultado de combinações de malhas estruturadas e não estruturadas e que não possuem características bem definidas (Figura 2.5 
(c)).

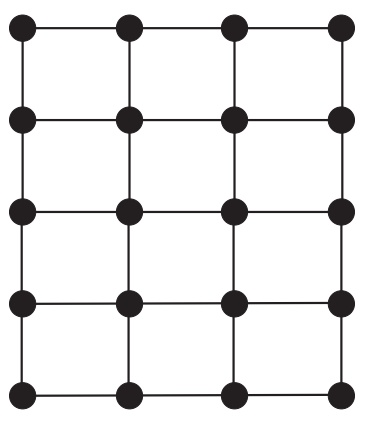

(a) Estruturada

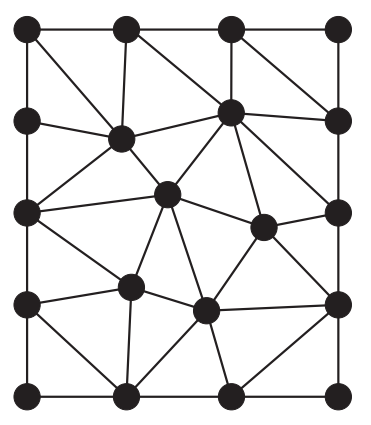

(b) Não estruturada

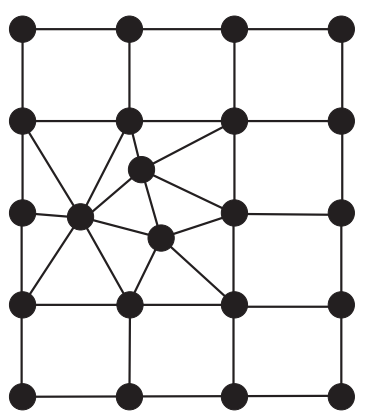

(c) Híbrida

Figura 2.5: Exemplos de tipos de malha.

As malhas estruturadas são bem comportadas, apresentam uma estrutura topológica uniforme, o que não ocorre nas malhas não estruturadas. Os índices dos vizinhos de um nó podem ser obtidos por uma simples função. Essa relação inicial entre os pontos favorece a utilização desse tipo de malha na aplicação de códigos baseados em esquemas de discretização de diferenças finitas, embora não exista restrição quanto ao uso com outros tipos de métodos, como o de volumes finitos. No entanto, as malhas estruturadas não se adaptam facilmente a geometrias complexas, exigindo nesses casos, o uso de técnicas sofisticadas de malhas multibloco, por exemplo, o que é particularmente agravado em casos não estacionários. As malhas estruturadas discretizam o domínio em elementos com conectividade implícita, isto é, apenas com coordenadas dos nós destes obtém-se todas as relações de conectividade existentes, o que acelera o processo de solução.

Por outro lado, para problemas envolvendo domínios complexos, onde as soluções variam rapidamente sobre o domínio, é necessário utilizar uma malha não estruturada. Estas, também permitem a aplicação de refinamento local e adaptativo, o que não é aplicável em malhas estruturadas e de tratamento complexo em malhas híbridas. As malhas não estruturadas possibilitam variar a topologia e o espaçamento em diferentes regiões do domínio, as relações de conectividade são adquiridas explicitamente sob a 
forma de tabelas de conectividade. A obtenção de relações de conectividade em malhas híbridas depende de qual combinação de malhas esta resulta.

Uma vantagem das malhas estruturadas é a enorme facilidade de geração associada e o alto grau intuitivo dos algoritmos numéricos empregados na solução de problemas CFD que usam este tipo de malha. A adaptação das malhas não estruturadas em geometrias mais complexas é melhor devido à variedade de suas células. Vários exemplos de comparação entre estes dois tipos de malha podem ser encontrados em Maliska Maliska, 1995, Ferziger e Peric Ferziger and Peric, 1997] e Lohner Lohner, 2001.

\subsection{Malhas Dinâmicas}

As malhas dinâmicas são normalmente utilizadas em problemas de simulação sobre domínios onde a geometria se altera com o tempo. Para simulações que tratam escoamento de fluidos, existem algumas superfícies que não podem ser tratadas como corpos rígidos. Na asa de um avião, por exemplo, tem-se que a força oriunda do escoamento do ar sobre a asa pode ser grande o bastante para deformar a sua estrutura. Com essa deformação o escoamento de ar é alterado, e consequentemente, a configuração do campo de forças devido ao escoamento do fluido. Assim, a simulação do escoamento de um fluido em torno de uma estrutura elástica, como a asa de um avião, necessita que simulações da deformação da estrutura sejam acopladas às simulações do escoamento do fluido Doi and Alonso, 2002 Kruger et al., 2002. Desta forma, nessa interação fluido-estrutura é necessário ajustar a nova geometria resultante da deformação da estrutura, utilizando o conceito de malhas elásticas para tratar esta questão.

Usualmente, malhas elásticas são desenvolvidas com a distribuição de molas imaginárias sobre os elementos da malha. Deste modo, toda vez que o domínio onde a malha é definida é modificado, as molas atuam movimentando os vértices para que se ajustem com a nova configuração do domínio. A malha computacional é composta 
pelos vértices, nesse caso vistos como partículas, que se deslocam continuamente até que se encontre uma configuração onde haja um equilíbrio das forças. De maneira geral, esses métodos utilizam um sistema de molas, sendo que cada aresta entre dois vértices atua como uma mola que possui um comprimento de equilíbrio. Essas molas contribuem na movimentação dos vértices até que se atinja uma configuração de equilíbrio das forças Batina, 1990, Degand and Farhat, 2002.

Considerando-se que as forças que atuam em um vértice já tenham sido calculadas, seguindo algum esquema de mola, é preciso aplicar alguma equação de movimento para manter o estado dinâmico dos vértices. Pela segunda lei de Newton, tem-se a seguinte equação:

$$
M \ddot{\Delta}=F,
$$

onde $\Delta$ é o vetor deslocamento dos vértices da malha, $\dot{\Delta}$ é o vetor velocidade, $\ddot{\Delta}$ é o vetor aceleração, $M$ é a massa associada aos vértices e $F$ são as forças atuando nos vértices. Pode-se estender este modelo para o caso massa-mola-amortecimento, onde a força $F$ é calculada a partir das forças que agem nos vértices, dadas por:

$F_{K}$ : Representa a força entre vértices, é análoga a uma mola e age apenas entre vértices que são adjacentes.

$F_{D}$ : Representa a força de amortecimento, é contrária ao movimento e contribui para convergência do sistema.

Cada vértice $v_{i}$ tem três variáveis de estado: o vetor deslocamento $\overrightarrow{\delta_{i}}$; o vetor

velocidade $\dot{\vec{\delta}}_{i}$ e o vetor aceleração $\ddot{\overrightarrow{\delta_{i}}}$. Possui também dois atributos, a massa $m_{i}$ e o coeficiente de amortecimento $d_{i}$. Assumindo que todos os vértices possuem a mesma massa e o mesmo coeficiente de amortecimento, o sistema pode ser simplificado.

Para atingir uma configuração estável, a força de amortecimento $F_{D}$ atua na convergência dos vértices, e é proporcional à velocidade do vértice e contrária ao movimento. Ela é definida como $F_{D}=-D \dot{\Delta}$, onde $D$ é uma matriz que contém os coefi- 
cientes de amortecimento. Já a força entre os vértices é contrária ao deslocamento e é proporcional ao coeficiente de resistividade $K$, sendo definida como: $F_{K}=-K \Delta$.

Assim, uma vez definidas as forças de amortecimento e a força entre os vértices, pode-se compor a força total $F$ que atua nos vértices:

$$
\begin{aligned}
F & =F_{K}+F_{D}, \\
& =-K \Delta-D \dot{\Delta} .
\end{aligned}
$$

Portanto, a equação final do sistema pode ser descrita pela equação diferencial ordinária de segunda ordem:

$$
M \ddot{\Delta}+D \dot{\Delta}+K \Delta=0 .
$$

A modelagem desse problema pode ser feita utilizando-se uma equação diferencial de primeira ordem Bossen, 1996]. Essa formulação possui melhor estabilidade numérica, mesmo que tenha chances de estacionar em um mínimo local. Então, o movimento dos vértices fica assim definido por:

$$
K \Delta+D \dot{\Delta}=0
$$

Finalmente, este problema pode ser mais simplificado resultando em um sistema chamado quase-estático Blom, 2000, Farhat et al., 1998, Degand and Farhat, 2002 da seguinte forma:

$$
F_{K}=K \Delta=0
$$

Existem diversas formas para calcular as forças elásticas, pois pode-se utilizar diferentes tipos de molas de modo a criar o sistema de Equações 2.10. Dentre as diversas formas de se calcular essa força em malhas bidimensionais, a analogia com molas são as mais conhecidas e utilizadas em CFD. 
Batina Batina, 1990 propôs as molas chamadas longitudinais, contrárias ao deslocamento, que são atribuídas entre os vértices (na aresta) e sua força determinada pela aplicação da lei de Hook.

As molas longitudinais não levam em consideração a área do triângulo ou o ângulo entre as arestas. Assim, foram propostas as molas torcionais, que realizam um controle sobre os ângulos formados entre as arestas, ao invés de controlar comprimentos como as molas longitudinais [Farhat et al., 1998,

O conceito de mola semi-torcional foi proposto por Blom Blom, 2000 para simplificar a formulação baseada em molas torcionais, de modo a incluir as informações dos ângulos internos dos triângulos em sistemas compostos por molas longitudinais. Isso é feito pelo quociente do coeficiente de rigidez da mola longitudinal pelo valor do ângulo oposto.

A seguir serão apresentados alguns tipos de molas mais relevantes para os cálculos das forças elásticas neste trabalho.

\subsubsection{Cálculo das Forças Elásticas}

A solução do sistema dado necessita da formulação adequada de $F$. Considere $\vec{f}$ uma componente da matriz $F_{K}$. Em se tratando de malhas elásticas, a formulação de $\vec{f}$ é determinante para a solução do sistema.

Dentre as diversas formas de se calcular essa força, a analogia com molas são as mais conhecidas e utilizadas em CFD Batina, 1990]. Ela pode ser descrita da seguinte maneira. Molas chamadas longitudinais, contrárias ao deslocamento, são atribuídas entre os vértices e assim é determinada a força pela aplicação da lei de Hook:

$$
\vec{f}=-k \vec{\delta}
$$

onde $k$ é o coeficiente de resistividade da mola e $\vec{\delta}$ é a deformação na mola.

Assim, cada aresta da malha é tratada como sendo uma mola longitudinal que 
possui associado um coeficiente de rigidez. A força resultante em um vértice é então calculada para todas as molas que o incidem, de modo que a conectividade da malha determina quais vértices influenciarão neste cálculo de forças atuantes. Então, todas forças atuantes no vértice $i$ a partir de seus vértices vizinhos $j$ são consideradas. Além disso, é interessante que se preserve a proporção entre os comprimentos das arestas.

A equação da força pode então ser escrita como:

$$
\vec{f}_{i}=\sum_{v_{j} \in S\left(v_{i}\right)} k_{i j}\left(\vec{\delta}_{j}-\vec{\delta}_{i}\right)
$$

onde $\overrightarrow{\delta_{i}}$ é o deslocamento do vértice $i$ e $S\left(v_{i}\right)$ representa o conjunto de vértices adjacentes ao vértice $i$.

Batina Batina, 1990] define que os coeficientes de rigidez das molas longitudinais sejam inversamente proporcionais ao comprimento de suas arestas. Portanto, o coeficiente de rigidez da mola pode ser calculado como:

$$
k_{i j}=\frac{a}{\left(l_{i j}\right)^{b}}
$$

onde $l_{i j}^{b}$ é o comprimento da aresta entre os vértices $i$ e $j$ na malha inicial, ou seja, antes da deformação, e $a$ e $b$ são constantes (usualmente iguais a 1).

Além de serem indicadas para resolver problemas com pequenas deformações, uma deficiência deste método é que não se pode garantir que algum vértice não ultrapasse uma aresta, criando elementos inválidos com área de valor negativo, pois as molas previnem que dois vértices adjacentes colidam, mas não impede que um vértice cruze sua aresta oposta.

A causa desta deficiência nessas molas é que elas não levam em consideração a área do triângulo ou o ângulo entre as arestas. Uma solução para este problema consiste em agregar molas torcionais ao sistema Farhat et al., 1998.

As molas torcionais realizam um controle sobre os ângulos formados entre as ares- 
tas, ao invés de controlar comprimentos como as molas longitudinais. Para compor o sistema desta abordagem, as molas torcionais são usadas em conjunto com as longitudinais. Seja o triângulo $t_{i j k}$ composto pelos vértices $v_{i}, v_{j}$ e $v_{k}$, como mostrado na Figura 2.6. Define-se $\theta_{i}^{i j k}$ o ângulo entre arestas $e_{i}$ e $e_{i k}$, e $A\left(t_{i j k}\right)$ a área do triângulo $t_{i j k}$. Então, o coeficiente da mola torcional no vértice $v_{i}$ do triângulo $t_{i j k}$ é definido como:

$$
C_{i}^{i j k}=\frac{1}{1+\cos \left(\theta_{i}^{i j k}\right)} \frac{1}{1-\cos \left(\theta_{i}^{i j k}\right)}=\frac{1}{\operatorname{sen}\left(\theta_{i}^{i j k}\right)^{2}}=\frac{\left(e_{i j}\right)^{2}\left(e_{i k}\right)^{2}}{4 A\left(t_{i j k}\right)^{2}},
$$

É importante notar que o coeficiente $C_{i}^{i j k}$ da mola torcional tende ao infinito se o ângulo entre as arestas for próximo de 0 ou de $180^{\circ}$.

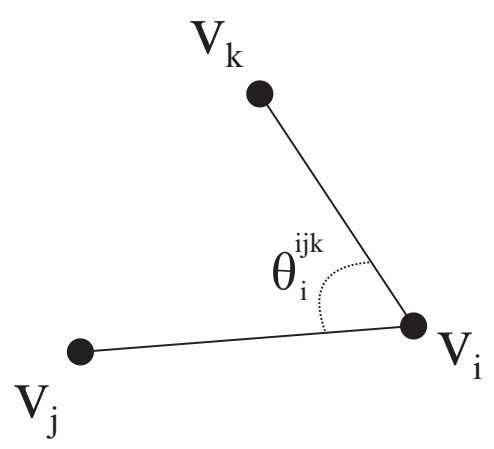

Figura 2.6: Esquema de mola torcional.

A montagem do sistema de molas é feita associando-se uma mola torcional para cada ângulo interno de cada célula da malha. Além disso, uma mola torcional é associada para cada vértice da malha a cada triângulo incidente. A formulação baseada em molas torcionais é eficaz na melhoria da razão de aspecto dos elementos. Mas, após a movimentação da malha, essa formulação também é restrita para pequenos deslocamentos e possui uma implementação não trivial, além de ser computacionalmente custosa.

O conceito de mola semi-torcional foi proposto por Blom Blom, 2000 para simplificar a formulação baseada em molas torcionais, de modo a incluir as informações 
dos ângulos internos dos triângulos em sistemas compostos por molas longitudinais. A ideia é promover a influência dos ângulos internos nos coeficientes de rigidez das molas longitudinais, forçando a utilização também das molas longitudinais no sistema de molas. Isso é feito pelo quociente do coeficiente de rigidez da mola longitudinal pelo valor do ângulo oposto. Considerando-se a Figura 2.7 a título de exemplo, o coeficiente da mola longitudinal na aresta $e_{i j}$ é dividido pelo valor do ângulo interno do triângulo $t_{i j k}$ em $v_{k}\left(\theta_{k}^{i j k}\right)$. Então, o coeficiente de resistividade da mola semi-torcional é definido como:

$$
k_{i j}^{B l o m}=\frac{k_{i j}}{\theta_{k}^{i j k}}
$$

Observe que $k^{\text {Blom }}$ praticamente não se modifica quando o triângulo é equilátero, uma vez que $\theta_{i}^{i j k}=\theta_{j}^{i j k}=\theta_{k}^{i j k}$. Note que quanto mais agudo for o ângulo, mais firme será a mola. Por outro lado, quanto mais obtuso, mais flexível será a mola, o que deve-se evitar.

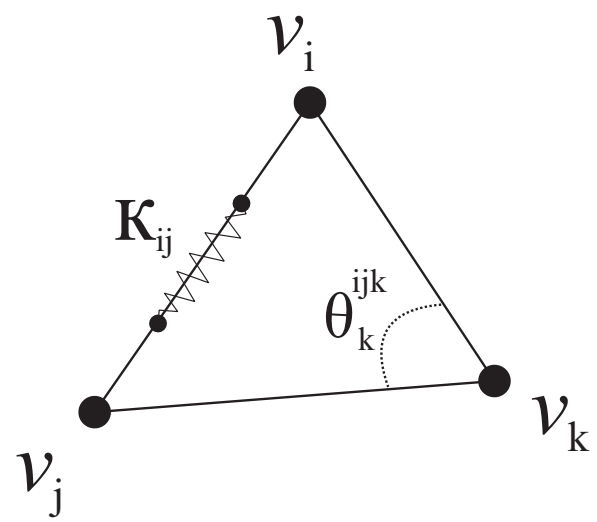

Figura 2.7: Mola semi-torcional proposta por [Blom, 2000].

No trabalho de Zeng et al. Zeng and Ethier, 2001 foi proposta uma melhoria nas molas semi-torcionais, de modo a adicionar o coeficiente de uma mola torcional ao coeficiente da mola longitudinal oposta. Assim, tomando base na Figura 2.8, o coeficiente de rigidez total $k_{i j}^{t}$ da mola ligando os vértices $v_{i}$ e $v_{j}$ é dado por : 


$$
k_{i j}^{\text {total }}=k_{i j}+C_{k}^{i j k}+C_{l}^{i j l}
$$

onde $C$ é o coeficiente de rigidez da mola torcional dado pela Equação 2.14 .

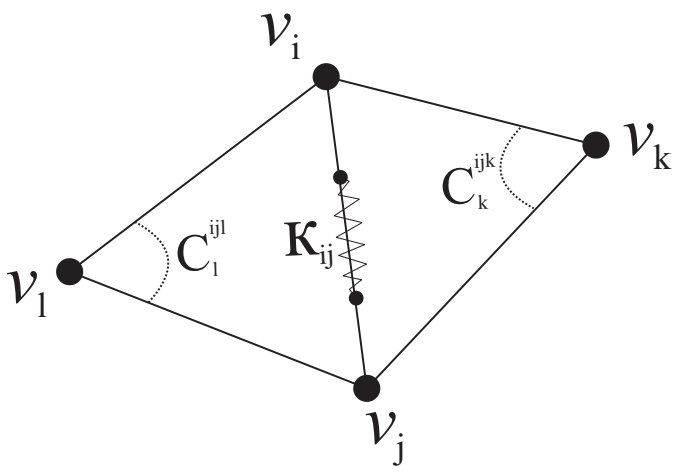

Figura 2.8: As molas torcionais em $v_{k}$ e $v_{l}$ são adicionadas à mola longitudinal na aresta $e_{i j}$.

Uma vez conhecido o coeficiente de rigidez das molas semi-torcionais, pode-se escrever a equação geral das forças nos vértices $v_{i}$ para este tipo de mola:

$$
\vec{f}_{i}=\sum_{j \in S\left(v_{i}\right)} k_{i j}^{\text {total }} \cdot\left[\vec{\delta}_{j}-\vec{\delta}_{i}\right]
$$

onde $S\left(v_{i}\right)$ representa o conjunto de vértices adjacentes ao vértice $i$.

Além do fato de que a formulação de molas semi-torcionais ser aplicável quando há grandes deformações, uma outra vantagem deste tipo de mola em relação as molas torcionais é a exigência de um menor número de operações computacionais durante sua execução. Por outro lado, o enrijecimento de molas torcionais pelo uso de molas semi-torcionais não evita o surgimento de elementos inválidos para todos os casos.

\subsection{Considerações Finais}

Este capítulo mostrou que a geração de malhas é uma atividade interdisciplinar, onde seu desenvolvimento se dá mediante avanços em geometria computacional. Foram 
apresentados conceitos fundamentais referentes à geometria computacional, além de definições que formalizam a geração de malhas, como complexos celulares e triangulações. Um gerador de malhas pode gerar diferentes tipos de malhas, e foram explicadas as características de cada malha e como pode-se classificá-la de acordo com a formação de seus elementos ou a sua vizinhança.

Foi mostrado que as malhas dinâmicas, normalmente utilizadas em problemas de simulação sobre domínios cuja geometria varia com o tempo, mantêm inalterada a conectividade da malha original quando realiza o ajuste à nova configuração do domínio por meio de movimentação de vértices. Foi mostrado que uma malha dinâmica é obtida pela distribuição de molas virtuais sobre a malha a ser movimentada. 


\section{Capítulo \\ 3 \\ Modelo Matemático do Escoamento}

Este capítulo apresenta as equações básicas que modelam escoamentos de fluidos dadas pelas leis de conservação de massa, quantidade de movimento e energia, apresenta o desenvolvimento das equações de Navier-Stokes com média de Reynolds, os parâmetros adimensionais usados na resolução das equações e a apresentação das equações de Euler. Também apresenta o método dos volumes finitos utilizado na discretização das equações e as condições de contorno mais utilizadas no domínio das simulações numéricas.

\subsection{Considerações Iniciais}

Para que a CFD seja aplicada de forma segura e também confiável, deve-se atender um conjunto de pré-requisitos, dentre estes, a obtenção de um modelo matemático que seja capaz de descrever adequadamente o processo ou fenômeno a ser simulado e a aplicação de ferramentas numéricas adequadas para a resolução do modelo proposto. O processo de modelagem matemática envolve as equações de conservação de massa (continuidade), quantidade de movimento, energia, equações de estado e equações constitutivas. O resultado obtido deve ser capaz de reproduzir satisfato- 
riamente os fenômenos de interesse, desta forma, a potencialidade da mecânica dos fluidos é enorme, uma vez que é possível através das simulações computacionais projetar, otimizar e avaliar um grande número de fenômenos, operações ou processos.

\subsection{Equações Governantes}

Um fluido é uma substância que se deforma continuamente sob a ação de uma tensão de cisalhamento, não importa quão pequena ela seja [Fox et al., 2004]. O movimento de um fluido é causado pela ação de forças externas. As forças de movimento mais comuns são: pressão, ação da gravidade e tensões superficiais. O conceito de contínuo é a base da fluidodinâmica clássica. Quando a hipótese do contínuo é válida é possível abstrair-se da composição molecular e sua consequente descontinuidade, assim, qualquer pequena parte considerada do fluido (normalmente chamada de partícula ou ponto material), por menor que seja, é capaz de representar o comportamento do fluido como um todo.

Considerando-se a hipótese de meio contínuo, as equações que modelam escoamentos de fluidos são conhecidas como equações de Navier-Stokes. Estas equações, considerando um escoamento sem a geração de calor e desprezando as forças de campo, podem ser escritas como:

$$
\left\{\begin{array}{c}
\frac{D \rho}{D t}+\rho \nabla \cdot \mathbf{u}=0 \\
\rho \frac{D \mathbf{u}}{D t}=-\nabla p+\nabla \cdot \tilde{\tau} \\
\rho \frac{D H}{D t}=\frac{\partial p}{\partial t}+\nabla \cdot(\tilde{\tau} \cdot \mathbf{u}-\mathbf{q})
\end{array}\right.
$$

onde $\rho$ é a densidade do fluido, $p$ é a pressão, $H$ é a entalpia total. Os vetores $\mathbf{u}$ e q representam o vetor de velocidades e o vetor de fluxos de calor do fluido em um sistema cartesiano de coordenadas, respectivamente. O termo $\tilde{\tau}$ representa o tensor 
de tensões viscosas e $t$ é o tempo. A derivada total $D / D t$ é dada por:

$$
\frac{D}{D t}=\frac{\partial}{\partial t}+\mathbf{u} \cdot \nabla
$$

Este sistema de equações não é fechado e necessita de mais equações no sentido de prover igual número de variáveis e equações. De acordo com o tipo de escoamento e fluido que se deseja estudar, algumas hipóteses podem ser aplicadas às Equações 3.1. No caso de estudo de escoamentos de fluidos newtonianos, as componentes do tensor de tensões viscosas são dadas por

$$
\tau_{i j}=\mu\left(\frac{\partial u_{i}}{\partial x_{j}}+\frac{\partial u_{j}}{\partial x_{i}}\right)+\lambda(\nabla \cdot \mathbf{u}) \delta_{i j}
$$

onde $\mu$ é o coeficiente de viscosidade, $\delta_{i j}$ é o delta de Kronecker e $\lambda$ é o segundo coeficiente de viscosidade, definido pela hipótese de Stokes como

$$
\lambda=-\frac{2}{3} \mu
$$

Além disto, o fluido pode ser tratado como um gás perfeito, desta forma, a equação de estado para um gás perfeito pode ser adicionada ao sistema:

$$
p=\rho R T=(\gamma-1) \rho e_{i},
$$

onde a energia interna específica, $e_{i}$, é dada por

$$
e_{i}=C_{v} T
$$

Nesta equação, $C_{v}$ é o calor específico a volume constante do fluido, $T$ é a temperatura do fluido, $R$ é a constante do gás e $\gamma=C_{p} / C_{v}$ é a razão de calores específicos. O fluxo de calor é calculado de acordo com a lei de condução de calor de Fourier como 


$$
\mathbf{q}=-\kappa \nabla T
$$

onde $\kappa$ é o coeficiente de condutividade térmica do fluido. A entalpia total do fluido é definida como

$$
H=e_{i}+\frac{p}{\rho}+\frac{1}{2}|\mathbf{u}|^{2}
$$

Em escoamentos onde os termos viscosos não são importantes, as equações de Euler são usadas como modelo matemático. Para este tipo de escoamento, o número de Reynolds, Re, é assumido como extremamente elevado, fazendo com que a contribuição dos termos viscosos, no balanço completo de fluxos, tenda a zero. Desta maneira, uma forma de se obter as equações de Euler é tomar o limite das equações de Navier-Stokes com $R e$ tendendo ao infinito.

As equações de Navier-Stokes na forma conservativa podem ser escritas como

$$
\begin{gathered}
\frac{\partial \rho}{\partial t}+\frac{\partial}{\partial x_{j}}\left(\rho u_{j}\right)=0 \\
\frac{\partial}{\partial t}\left(\rho u_{i}\right)+\frac{\partial}{\partial x_{j}}\left(\rho u_{i} u_{j}\right)+\frac{\partial p}{\partial x_{i}}-\frac{\partial \tau_{i j}}{\partial x_{j}}=0 \\
\frac{\partial e}{\partial t}+\frac{\partial}{\partial x_{j}}\left[(e+p) u_{j}-\tau_{i j} u_{i}+q_{j}\right]=0
\end{gathered}
$$

onde $e$ é a energia total por unidade de volume de fluido e é dada por

$$
e=\rho\left[e_{i}+\frac{1}{2}|\mathbf{u}|^{2}\right]
$$




\subsection{Adimensionalização das Equações de Navier- Stokes}

As equações da dinâmica dos fluidos são frequentemente colocadas na forma adimensional, pois alguns erros numéricos podem surgir em operações numéricas que envolvem números de magnitude muito diferentes. Portanto, é muito importante quando resolve-se numericamente um sistema de equações, que os termos envolvidos nos cálculos sejam de mesma ordem de magnitude, evitando assim problemas oriundos de erros de trucamento computacionais. As variáveis são adimensionalizadas da seguinte forma:

- Tempo

$$
\bar{t}=t \frac{c_{\infty}}{l_{0}}
$$

onde $c_{\infty}$ é a velocidade do som do escoamento livre e $l_{0}$ é o comprimento característico do problema;

- Coordenadas

$$
\overline{x_{i}}=\frac{x_{i}}{l_{0}}, \quad x_{i}=x, y, z
$$

- Densidade

$$
\bar{\rho}=\frac{\rho}{\rho_{\infty}}
$$

onde $\rho_{\infty}$ é a densidade do escoamento livre.

- Componentes de velocidade

$$
u_{i}=\frac{u_{i}}{c_{\infty}}
$$

- Pressão

$$
\bar{p}=\frac{p}{\rho_{\infty} c_{\infty}^{2}}
$$


- Energia total

$$
\bar{e}=\frac{e}{\rho_{\infty} c_{\infty}^{2}}
$$

- Coeficiente de viscosidade

$$
\bar{\mu}=\frac{\mu}{\mu_{\infty}}
$$

onde $\mu_{\infty}$ é a viscosidade do escoamento livre.

Substituindo as variáveis adimensionais, obtém-se as equações de Navier-Stokes adimensionais sob a forma de vetor, dadas por

$$
\frac{\partial \mathbf{Q}}{\partial t}+\frac{\partial \mathbf{E}}{\partial x}+\frac{\partial \mathbf{F}}{\partial y}+\frac{\partial \mathbf{G}}{\partial z}=\frac{M_{\infty}}{R e}\left(\frac{\partial \mathbf{E}_{\mathbf{v}}}{\partial x}+\frac{\partial \mathbf{F}_{\mathbf{v}}}{\partial y}+\frac{\partial \mathbf{G}_{\mathbf{v}}}{\partial z}\right)
$$

onde $\mathbf{Q}$ é o vetor das variáveis conservadas, E, F, G são os vetores de fluxo convectivos nas direções $x, y$ e $z$, respectivamente, $\mathbf{E}_{\mathbf{v}}, \mathbf{F}_{\mathbf{v}}, \mathbf{G}_{\mathbf{v}}$ são os vetores de fluxos viscosos nas direções $x, y$ e $z$ e Re é o número de Reynolds definido por

$$
R e=\frac{\rho_{\infty} c_{\infty} l_{0}}{\mu_{\infty}}
$$

e $M_{\infty}$ é o número de Mach no escoamento não perturbado dado por

$$
M=\frac{\left|\mathbf{u}_{\infty}\right|}{c_{\infty}}
$$

A definição do vetor de variáveis conservadas $\mathbf{Q}$, considerando as variáveis adimensionais sem as barras superiores, para simplificar a notação, é dada por

$$
\mathbf{Q}=\left\{\begin{array}{c}
\rho \\
\rho u \\
\rho v \\
\rho w \\
e
\end{array}\right\}
$$


Os vetores de fluxo convectivos são dados por

$$
\mathbf{E}=\left\{\begin{array}{c}
\rho u \\
\rho u^{2}+p \\
\rho v u \\
\rho w u \\
(e+p) u
\end{array}\right\}, \quad \mathbf{F}\left\{\begin{array}{c}
\rho v \\
\rho u v \\
\rho v^{2}+p \\
\rho w v \\
(e+p) v
\end{array}\right\}, \quad \mathbf{G}=\left\{\begin{array}{c}
\rho w \\
\rho u w \\
\rho v w \\
\rho w^{2}+p \\
(e+p) w
\end{array}\right\} \text {. }
$$

Os vetores de fluxos viscosos são dados por
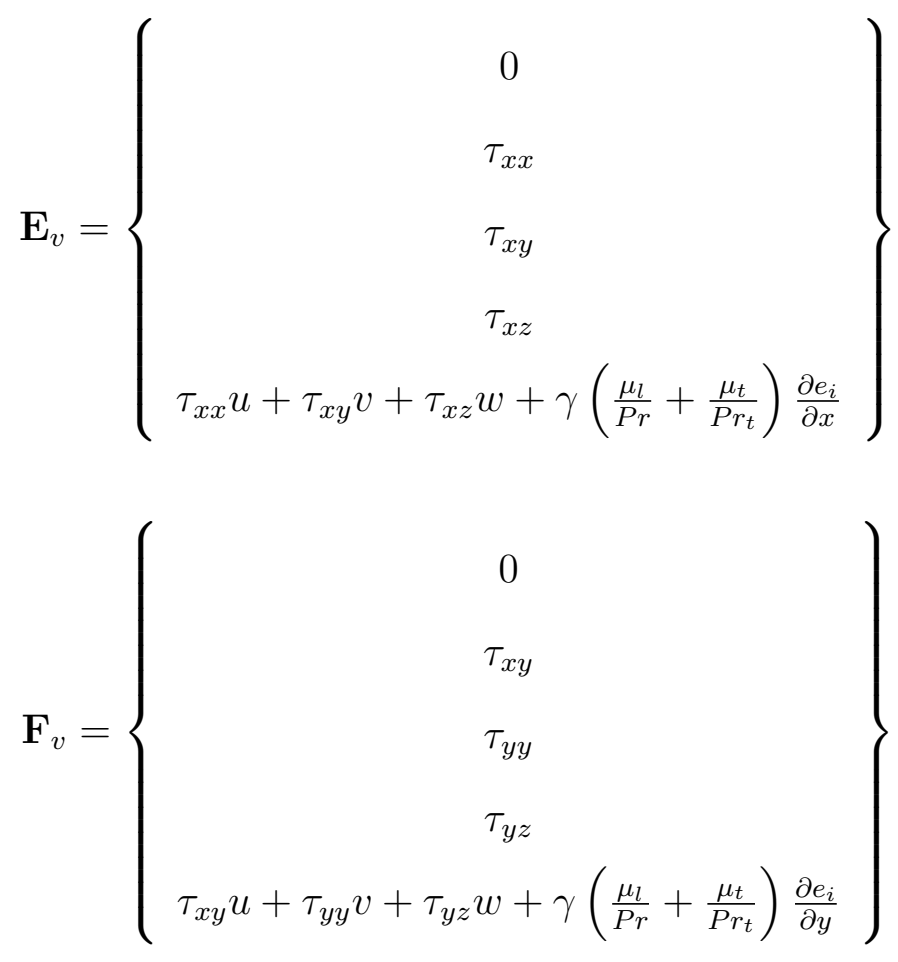

$$
\mathbf{G}_{v}=\left\{\begin{array}{c}
0 \\
\tau_{x z} \\
\tau_{y z} \\
\tau_{z z} \\
\tau_{x z} u+\tau_{y z} v+\tau_{z z} w+\gamma\left(\frac{\mu_{l}}{P r}+\frac{\mu_{t}}{P r_{t}}\right) \frac{\partial e_{i}}{\partial z}
\end{array}\right\}
$$


A equação de estado adimensional é dada por

$$
p=(\gamma-1)\left[e-\frac{1}{2} \rho|\mathbf{u}|^{2}\right]
$$

\subsection{As Equações de Euler}

No presente trabalho considera-se simulações de escoamentos com número de Reynolds elevados, isto é, onde os efeitos de transporte molecular são desprezíveis. Sendo assim, as equações de Euler representam os escoamentos em questão, e os termos viscosos e de condução de calor podem ser descartados. São estudados problemas em duas dimensões, e portanto, as variáveis na direção cartesiana z são desprezadas.

As equações de Euler em duas dimensões, são dadas em sua forma conservativa vetorial por

$$
\frac{\partial \mathbf{Q}}{\partial t}+\frac{\partial \mathbf{E}}{\partial x}+\frac{\partial \mathbf{F}}{\partial y}=0
$$

onde

$$
\mathbf{Q}=\left\{\begin{array}{c}
\rho \\
\rho u \\
\rho v \\
e
\end{array}\right\}
$$

$\mathrm{e}$

$$
\mathbf{E}=\left\{\begin{array}{c}
\rho u \\
\rho u^{2}+p \\
\rho v u \\
(e+p) u
\end{array}\right\}, \quad \mathbf{F}\left\{\begin{array}{c}
\rho v \\
\rho u v \\
\rho v^{2}+p \\
(e+p) v
\end{array}\right\}
$$

O sistema de equações fica completo com a expressão para o cálculo da pressão $p$ para um gás perfeito 


$$
p=(\gamma-1)\left[e-\frac{1}{2} \rho|\mathbf{u}|^{2}\right]
$$

\subsection{O Método dos Volumes Finitos}

A aplicação do método de volumes finitos é iniciada com a geração da malha do problema, nesta fase o domínio é transformado de um domínio contínuo para um domínio discreto, definido pelos volumes de controle adotados. As equações governantes são integradas em cada um destes volumes, resultando em um sistema de equações pelas variáveis localizadas nas interfaces dos volumes de controle. Como os valores das variáveis localizadas nas faces dos volumes de controle não são conhecidos é necessária a utilização de funções de interpolação que tem por finalidade obter valores aproximados para estas variáveis através dos valores das variáveis localizadas nos centros dos volumes de controle vizinhos. Por fim, o sistema algébrico ou diferencial resultante é resolvido através de uma rotina numérica apropriada.

\subsubsection{Formulação das Equações}

A formulação de volumes finitos é obtida pela integração das equações governantes em um volume de controle finito. Desta forma, as equações de Euler escritas em sua formulação integral resulta em

$$
\frac{\partial}{\partial t} \int_{V} \mathbf{Q} d V+\int_{V}(\nabla \cdot \mathbf{P}) d V=0
$$

onde $\mathbf{P}=\mathbf{E}_{\hat{i}}+\mathbf{F}_{\hat{j}}$. Aplicando o teorema de Gauss na Equação 3.33, resulta em

$$
\frac{\partial}{\partial t} \int_{V} \mathbf{Q} d V+\int_{S}(\mathbf{P} \cdot \mathbf{n}) d S=0
$$

onde $V$ representa o volume da célula, $S$ representa a superfície da célula e $\mathbf{n}$ é o vetor unitário normal à superfície $S$, positivo na direção para fora da mesma. 
Neste trabalho, o método de volumes finitos é utilizado na discretização numérica das equações, portanto a Equação 3.34, discretizada em um contexto de volumes finitos centrados nas faces, pode ser reescrita para um volume de controle $i$ como

$$
\frac{\partial \mathbf{Q}_{i}}{\partial t}=-\frac{1}{V_{i}} \int_{S_{i}}(\mathbf{P} \cdot \mathbf{n}) d S
$$

sendo $\mathbf{Q}_{\mathbf{i}}$ o valor médio de $\mathbf{Q}$ no instante de tempo $t$, no volume de controle $V_{i}$, dado por

$$
\mathbf{Q}_{\mathbf{i}}=\frac{1}{V_{i}} \int_{V_{i}} \mathbf{Q} d V
$$

A formulação final para uma discretização das equações de Euler em duas dimensões em um contexto de volumes finitos pode ser escrita como

$$
\frac{\partial \mathbf{Q}_{\mathbf{i}}}{\partial t}=-\frac{1}{V_{i}} \sum_{k=1}^{n f}\left(\mathbf{E}_{\mathbf{k}} \hat{i}+\mathbf{F}_{\mathbf{k}} \hat{j}\right) \cdot \mathbf{S}_{\mathbf{k}}, \quad \frac{\partial \mathbf{Q}_{\mathbf{i}}}{\partial t}=\mathbf{R}_{i}
$$

onde $n f$ é o número de faces que formam o volume de controle $i, s_{k}$ é o comprimento da aresta vizinha da célula e $\mathbf{R}_{i}$ é o vetor residual correspondente, que tem relação com a evolução das variáveis da solução no tempo.

\subsection{Condições Iniciais e de Contorno}

Um método de integração numérica deve partir de condições iniciais usadas na primeira iteração. No caso de problemas estacionários, quanto mais próximas da solução forem tais condições, mais rapidamente convergirá o código. No caso de escoamentos não estacionários, pode-se tomar como condição inicial uma resposta de estado estacionário convergido, ou seja, antes de realizar qualquer experimento numérico de casos não estacionários, é necessário aplicar a ferramenta de CFD na obtenção de um estado estacionário de interesse.

No código de simulação desenvolvido, as condições de contorno são impostas 
utilizando-se os chamados volumes fictícios (do inglês ghost volumes), os quais consistem em volumes de controle definidos fora do domínio de cálculo e dividem arestas com os volumes de fronteira. Atribui-se valores das variáveis que se pretende calcular a estes volumes de acordo com a condição de contorno aplicada.

\subsubsection{Condição de Escorregamento}

Esta condição de contorno é utilizada para representar fronteiras sólidas não viscosas em contato com o fluido, ou seja, deve-se utilizar uma formulação do tipo Euler como a utilizada neste trabalho para representar os escoamentos de interesse. A condição de contorno para paredes não viscosas requer que a componente de velocidade normal à superfície seja nula. Um sistema de coordenadas auxiliar é usado de forma a garantir essa condição. Neste sistema, um dos eixos, denominado n, é paralelo ao vetor normal à face e o eixo $\mathbf{t}$ é tangente à mesma. A velocidade no volume interno à fronteira, em coordenadas cartesianas, é dada por

$$
\mathbf{u}=u \hat{i}+v \hat{j}
$$

Neste caso, no sistema auxiliar, as projeções desse vetor velocidade são

$$
\begin{gathered}
u_{n}=\mathbf{u} \cdot \mathbf{n}=u n_{x}+v n_{y} \\
u_{t}=\mathbf{u} \cdot \mathbf{t}=u t_{x}+v t_{y}
\end{gathered}
$$

Ao somar a velocidade no volume fantasma ao volume interno, a resultante normal à face deve ser nula. A partir dessa imposição, as componentes de velocidade no volume fantasma, no sistema de coordenadas auxiliar são

$$
u_{g_{n}}=-u_{n}, u_{g_{t}}=u_{t},
$$


onde o subscrito $g$ indicam as componentes de velocidade no volume fantasma.

O vetor velocidade neste volume fantasma, no sistema auxiliar é

$$
\mathbf{u}_{g}=u_{g_{n}} \mathbf{n}+u_{g_{t}} \mathbf{t}
$$

Escrevendo os vetores $\mathbf{n}$ e $\mathbf{t}$ em termos das componentes cartesianas $\hat{i}$ e $\hat{j}$, a velocidade no volume fantasma, que satisfaz a condição de contorno, pode ser escrita em coordenadas cartesianas como

$$
\mathbf{u}_{g}=\left(u_{g_{n}} n_{x}+u_{g_{t}} t_{x}\right) \hat{i}+\left(u_{g_{n}} n_{y}+u_{g_{t}} t_{y}\right) \hat{j}
$$

Os valores das propriedades de densidade $\rho$ e energia $e$ no volume fantasma são

$$
\rho_{g}=\rho_{n_{g}}, \quad e_{g}=e_{n_{g}}
$$

\subsubsection{Condição Não Reflexiva}

Esta condição de contorno é implementada utilizando-se invariantes de Riemann Hirsch, 1989. Os invariantes de Riemann derivam das condições características obtidas para as equações de Euler e, portanto, verificam localmente se a condição do escoamento é de entrada ou saída na face. O cálculo é feito através da componente de velocidade normal à face e também da velocidade do som local. As expressões relacionadas nesses cálculos são

$$
R^{-}=R_{\infty}^{-}=u_{\infty_{n}}-\frac{2}{\gamma-1} c_{\infty}
$$

e

$$
R^{+}=R_{n g}^{+}=u_{n}+\frac{2}{\gamma-1} c_{n g},
$$


onde $u_{\infty_{n}}=\mathbf{u}_{\infty} \cdot \mathbf{n}, u_{n}=\mathbf{u} \cdot \mathbf{n}$, onde $\mathbf{n}$ é o vetor normal unitário, $u_{n}$ é a componente de velocidade normal do volume interno adjacente à fronteira e $u_{\infty_{n}}$ é a componente de velocidade normal à superfície exterior do escoamento não perturbado. Calculando para $u_{n}$ e $c$, tem-se

$$
u_{n_{f}}=\frac{R^{+}+R^{-}}{2}
$$

$\mathrm{e}$

$$
c_{f}=\frac{\gamma-1}{4}\left(R^{+}+R^{-}\right)
$$

onde o índice $f$ representa a propriedade calculada na superfície da fronteira. Para uma condição de saída do escoamento, $u_{n_{f}}>0$, os componentes de velocidade são obtidos através da extrapolação do componente tangencial de velocidade do volume interno. Uma maneira de se fazer isto, sem ter que efetivamente calcular esta componente, é escrever

$$
\begin{aligned}
& u_{f}=u+\left(u_{n_{f}}-u_{n}\right) \hat{i}, \\
& v_{f}=v+\left(u_{n_{f}}-u_{n}\right) \hat{j} .
\end{aligned}
$$

As propriedades densidade e pressão são obtidas por meio da extrapolação da entropia do volume interno para a fronteira. Logo, pode-se escrever

$$
\rho_{f}=\left(\frac{\rho^{\gamma} c_{f}^{2}}{\gamma p}\right)^{\frac{1}{\gamma-1}}
$$

e

$$
p_{f}=\left(\frac{\rho_{f} c_{f}^{2}}{\gamma}\right)
$$

Para uma condição de entrada do escoamento, $u_{n_{f}}<0$, os componentes de velocidade são obtidos, de forma análoga, por meio da extrapolação do componente tangencial da velocidade no escoamento não perturbado, portanto, pode-se escrever 


$$
\begin{aligned}
& u_{f}=u_{\infty}+\left(u_{n_{f}}-u_{n_{\infty}}\right) \hat{i} . \\
& v_{f}=v_{\infty}+\left(u_{n_{f}}-u_{n_{\infty}}\right) \hat{j} .
\end{aligned}
$$

As propriedades de densidade e pressão são obtidas por meio de se atribuir à interface o valor da entropia do escoamento não perturbado, o que fornece

$$
\rho_{f}=\left(\frac{\rho_{\infty}^{\gamma} c_{f}^{2}}{\gamma p_{\infty}}\right)^{\frac{1}{\gamma-1}}
$$

$\mathrm{e}$

$$
p_{f}=\left(\frac{\rho_{f} c_{f}^{2}}{\gamma}\right)
$$

A expressão para o vetor de variáveis conservadas no volume fantasma é dada por

$$
\mathrm{Q}_{\mathrm{g}}=2 \mathrm{Q}_{\mathrm{f}}-\mathrm{Q}
$$

Caso o escoamento seja supersônico, ou seja, $u_{n_{f}} / c_{f}>1$, considera-se para a região de entrada do escoamento $\mathbf{Q}_{\mathrm{g}}=\mathrm{Q}_{\infty}$, e para a região de saída do escoamento, considera-se $\mathrm{Q}_{\mathrm{g}}=\mathrm{Q}$.

\subsubsection{Condição de Entrada}

Para a condição de contorno de entrada deve-se verificar se o escoamento é subsônico ou supersônico. Caso seja subsônico, extrapola-se a componente principal de velocidade do escoamento do volume interior

$$
u_{g}=u
$$

As outras propriedades devem ser fornecidas. Estas propriedades são a direção da velocidade obtida com o ângulo $\alpha(x, y)$, a temperatura total $T_{t}$ e a pressão total $P_{t}$. Utilizando as relações para escoamento isentrópico e a velocidade extrapolada do 
interior do escoamento, tem-se

$$
\begin{gathered}
v_{g}=u \tan (\alpha), \\
T=T_{0}\left[1-\frac{\gamma-1}{\gamma+1}\left(\frac{u_{g}^{2}+v_{g}^{2}}{c_{*}^{2}}\right)\right],
\end{gathered}
$$

e

$$
P=P_{0}\left[1-\frac{\gamma-1}{\gamma+1}\left(\frac{u_{g}^{2}+v_{g}^{2}}{c_{*}^{2}}\right)\right]^{\frac{\gamma}{\gamma-1}},
$$

onde $c_{*}$ é a velocidade do som crítica calculada por

$$
c_{*}^{2}=2 \gamma \frac{\gamma-1}{\gamma+1} c_{v} T_{0}
$$

Se o escoamento for supersônico, deve-se fornecer todas as propriedades para a condição de entrada.

\subsubsection{Condição de Saída}

Para esta condição, verifica-se se o escoamento é subsônico ou supersônico. Caso este seja subsônico deve-se fornecer a pressão estática de saída e extrapola-se as outras propriedades do escoamento. Se o escoamento for supersônico, todas as propriedades são extrapoladas do escoamento.

\subsection{Considerações Finais}

Este capítulo apresentou as equações básicas dadas pelas leis de conservação de massa, quantidade de movimento e energia que modelam escoamentos de fluidos. Foi apresentado o que é um fluido e a hipótese de meio contínuo. O desenvolvimento das equações de Navier-Stokes bem como os parâmetros adimensionais mais usados na resolução das equações foram mostrados. Um modelo de turbulência foi apresentado baseado no processo de média de Reynolds e também apresentada as equações de 
Euler.

O método de volumes finitos utilizado para a discretização das equações foi apresentado. Por fim, as condições de contorno utilizadas no domínio das simulações numéricas foram apresentadas. 


\section{Capítulo \\ 4 \\ Estrutura de Dados Topológicas}

Neste capítulo são apresentados alguns trabalhos sobre estruturas de dados topológicas, mostrando a estrutura de cada uma para organizar as informações de malhas. Dentre elas, será dada ênfase à estrutura de dados Mate Face, pois ela foi escolhida como base para o desenvolvimento do trabalho.

\subsection{Considerações Iniciais}

A representação de malhas por meio de estrutura de dados e operadores topológicos é um dos focos principais da modelagem geométrica, onde permite uma implementação robusta e eficiente de mecanismos de refinamento adaptativo, alinhamento de células e acesso às relações de incidência e adjacência entre os elementos da malha, o que é de grande importância na maioria das aplicações em mecânica dos fluidos.

Os problemas enfrentados na área de mecânica dos fluidos, como por exemplo a representação de domínios complexos, decomposições espaciais, manipulação e movimento de malhas, podem ser tratados pelas ferramentas da modelagem geométrica.

Além das questões relacionadas com a representação de malhas e domínios, problemas envolvendo movimentação de malhas, típicos de problemas em aeroelasticidade, 
podem ser tratados mais facilmente com o uso de modelagem geométrica. Deste modo, a malha em torno da estrutura onde será efetuada a simulação precisa se ajustar à novas descrições geométricas provindas de deformações estruturais. Essas operações podem ser implementadas nessas estruturas de dados, de modo a manter a sua topologia.

Muitas estruturas de dados topológicas foram propostas na literatura, mas elas diferem entre si em sua abordagem de armazenamento das informações da malha e principalmente como representar a vizinhança entre os elementos armazenados. Na seção a seguir será feito um levantamento dos vários trabalhos existentes na literatura sobre as estruturas de dados topológicas, e nas seções subsequentes serão detalhadas duas estruturas de maior interesse a este trabalho.

\subsection{Estrutura de Dados Topológicas}

Malhas simples são caracterizadas por uma indexação dos elementos por meio de estruturas de dados simples, como por exemplo, matrizes. No caso de malhas não estruturadas, a não uniformidade da decomposição celular é melhor representada por uma estratégia mais sofisticada, que são as estruturas de dados topológicas [Shephard, 1997]. As estruturas de dados topológicas indexam elementos de uma malha representando relações de incidência e adjacência entre elementos, garantindo acesso rápido às informações.

Estruturas de dados topológicas (EDT) também são muito úteis em aplicações onde existem deformações constantes na malha. Elas permitem a movimentação dinâmica dos nós da malha sem modificar sua topologia (conectividade). Neste contexto, tais estruturas podem representar malhas elásticas, que podem ser do tipo superficial ou volumétrica, simples ou mista.

As malhas manipuladas numa simulação podem representar diferentes tipos de elementos, como triângulos e quadriláteros (no caso bidimensional) e tetraedros, 
pirâmides e hexaedros (no caso tridimensional). Existe ainda a possibilidade da composição da malha por diferentes elementos, neste caso a malha denomina-se mista.

Embora existam muitas estruturas de dados topológicas dedicadas à representação de malhas volumétricas, poucas fazem uso formal de operadores topológicos no controle dos elementos armazenados, sendo este um ponto de grande interesse na atualidade [Nielson, 2000].

As estruturas de dados tridimensionais representam decomposições celulares volumétricas. As malhas destas decomposições são do tipo poliedral, sendo os tetraedros os mais comuns entre os poliedros utilizados na literatura.

Grande parte das EDTs propostas na literatura indexa os dados de modo a facilitar o acesso às relações de vizinhança e às buscas feitas na construção ou leitura de malhas Kwok et al., 1995, viabilizando o controle de procedimentos adaptativos Bottasso et al., 1998. Além disso, um aspecto importante destas estruturas são os operadores topológicos utilizados na construção e manutenção das mesmas Nielson, 2000.

Deste modo, são vários os trabalhos que desenvolveram estruturas de dados para a representação dos diversos tipos de malhas, de modo que eles são diferentes entre si na maneira que eles armazenam os vértices, arestas e as faces. Mais especificamente, elas diferem na representação explícita ou implícita das informações, ou seja, a informação está diretamente disponível (explícita), armazenadas em vetores ou listas ligadas, ou indiretamente disponível (implícita), sendo necessárias algumas operações algébricas para buscar a informação.

A vantagem em se utilizar representações implícitas é o menor consumo de memória e a maior simplicidade de implementação dos operadores topológicos, além de reduzir a redundância de informações distribuídas na estrutura de dados. Isso melhora a robustez das estruturas, mas a desvantagem é a dificuldade de aplicá-la em decomposições celulares que envolvem diferentes tipos de células. Deste modo, na literatura encontramos representações implícitas com eficientes técnicas de recuperação das relações 
de adjacência usando apenas para malhas triangulares ou tetraedrais Kettner, 1999. Boissonnat et al., 2000.

Muitas estruturas de dados topológicas descritas na literatura têm operadores específicos dedicados à manutenção da consistência topológica dos objetos representados. Como exemplo, podemos citar a estrutura Winged-Edge de Baumgart Baumgart, 1975 e a Half-Edge de Mäntylä Mantyla, 1989, que utilizam os chamados operadores de Euler para garantir a integridade de malhas bidimensionais.

A Winged-Edge representa explicitamente os vértices, arestas e as faces de uma malha. Cada vértice tem armazenadas as arestas em que ele participa, cada aresta tem armazenados os nós das extremidades, junto com as faces de que participa e as suas arestas antecessoras e sucessoras em relação às faces de que participa. Por fim, a lista das faces tem armazenadas as arestas que a formam. Esta representação facilita as aplicações que necessitam realizar operações de divisão/mesclagem de células, pois as modificações são realizadas diretamente na estrutura.

Na estrutura Half-Edge, as arestas mantém informações de incidência de vértices, arestas e faces. Cada aresta é decomposta em duas Half-Edges com orientação induzida por sua célula incidente. Uma face incidente e um vértice incidente são armazenados em cada Half-Edge, e, para cada face e vértice, uma Half-Edge é armazenada.

Uma estrutura de dados específica para malhas triangulares é a Corner-Table Rossignac et al., 2001. Nesta estrutura, é utilizado o conceito de corners para representar a associação de um triângulo a um de seus vértices ou, isto é, associar um corner ao bordo oposto de um corner, onde cada triângulo é definido por três corners consecutivos que definem sua orientação.

Outro exemplo é a estrutura Quad-Edge de Guibas e Stolfi Guibas and Stolfi, 1985, que emprega um operador denominado splice para o controle topológico de malhas 2-D. Uma extensão da Quad-Edge chamada FacetEdge foi proposta por Dobkin e Laslo Dobkin and Laszlo, 1989, de modo a representar complexos celulares que são subdivisões de uma esfera tridimensional. 
Contudo, a Facet-Edge trata somente complexos celulares orientáveis.

Ainda no contexto bidimensional, Nonato et. al. Nonato et al., 2008 desenvolveram uma estrutura chamada Singular Handle-Edge (SHE), que emprega operadores de Morse no controle topológico dos elementos armazenados.

Uma versão estendida da Handle-Edge, a Handle-Face, foi proposta por Lopes e Tavares Lopes and Tavares, 1997] para representação de malhas volumétricas formadas por tetraedros. Esta utiliza o conceito de Half-Face representada por um triângulo, cuja orientação é induzida pelo tetraedro a que ela pertence. Bem como a Handle-Edge, esta estrutura utiliza ponteiros para representar os tipos de nós de cada elemento da malha.

Proposta por De Floriani e Hui Floriani and Hui, 2003, a estrutura de dados "Non-Manifold Indexed Data Structure with Adjacencies" mostra uma abordagem para tratar operações de busca na vizinhança de seus componentes. Porém, esta estrutura não permite representar não-variedades.

Apresentando características similares às estrutura Handle-Face, a estrutura Compact Half-Face (CHF), proposta por Lage [Lage et al., 2005], foi desenvolvida para representar malhas tetraédricas usando a característica de escalabilidade de estruturas. Ela é composta por quatro níveis de escalabilidade, sendo o nível zero com menor uso de memória e o nível três com maior uso de memória, porém com melhor desempenho de processamento para dados topológicos.

Como visto, são inúmeras as contribuições de estruturas de dados para representar malhas e cada uma delas possui suas vantagens e desvantagens, seguindo diferentes abordagens. A seguir será brevemente explicada uma estrutura de dados que é interessante a este trabalho, a Opposite Face [Lizier, 2006], e será mostrada com mais detalhes a Mate Face Cunha, 2009, a estrutura de dados escolhida e utilizada em todo o desenvolvimento deste trabalho. 


\subsection{A Estrutura de Dados Opposite Face - OF}

A Opposite Face (OF) proposta por Lizier Lizier, 2006], foi baseada nos trabalhos realizados na estrutura Corner-Table. Uma das preocupações para a definição da estrutura foi a minimização do consumo de memória necessário para a representação da malha. Outro ponto observado foi prover facilidade de utilização e flexibilidade.

A estrutura faz uso dos dois modelos de representação, ou seja, os vértices, triângulos e tetraedros são representados explicitamente; as arestas e faces são representadas implicitamente. A estrutura foi projetada para representar malhas simpliciais, bidimensionais e tridimensionais. Além disso, podem ser acrescentados mais dados que caracterizam a malha de modo dinâmico. Uma das suas principais características é fornecer o acesso rápido a dados topológicos e disponibilizar funções para execução de cálculos para malha.

Os vértices e células são armazenados em vetores separados e identificados por um número inteiro, positivo e único para cada elemento presente em seu respectivo vetor. Esse identificador único permite acesso direto a qualquer um desses elementos, pois há uma associação entre a posição da memória deste elemento e seu identificador. Os vértices são formados pelas suas coordenadas geométricas e pelo identificador de uma de suas células incidentes, como pode ser visto na Figura 4.1, um exemplo para o caso bidimensional.
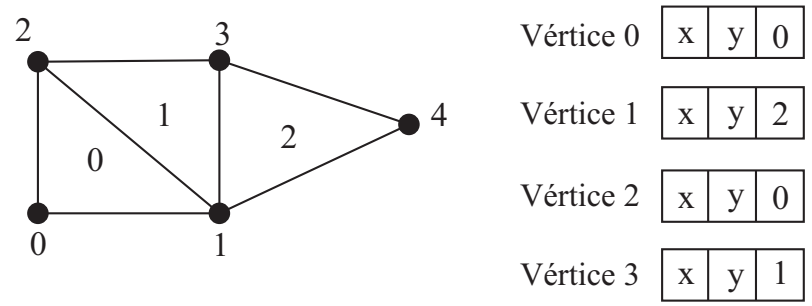

Figura 4.1: Representação de vértices na estrutura OF.

Dependendo da dimensão atribuída, as células podem representar triângulos, tetraedros ou simplexos de dimensões superiores da malha. Em cada célula são ar- 
mazenadas referências para todos os vértices que a formam (três, quatro ou mais) e também para todas as células vizinhas por arestas ou faces.

Assim como ocorre na Corner-Table, a relação de vizinhança é obtida a partir da relação entre um vértice de uma célula e uma outra célula oposta a esse vértice. No caso de malhas tridimensionais formadas por tetraedros, esta ideia pode ser estendida facilmente, já que células vizinhas compartilham uma face entre si e os vértices opostos a essas faces são únicos para cada célula. Por exemplo, as Figuras 4.2(a) e 4.2 (b) mostram células vizinhas por aresta (no caso bidimensional) e dois tetraedros vizinhos por face (no caso tridimensional), respectivamente.

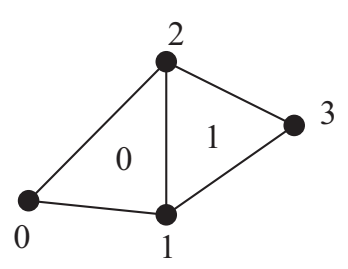

Célula 0

$$
\begin{array}{l|l|l|l|}
\cline { 2 - 3 } \text { Vértices } & 0 & 1 & 2 \\
\cline { 2 - 4 } \text { Opostas } & 1 & - & - \\
\cline { 2 - 4 } & &
\end{array}
$$

Célula 1

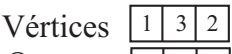

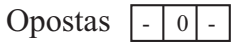

(a) Bidimensional

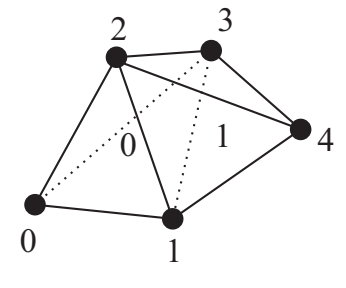

Célula 0

Vértices \begin{tabular}{l|l|l|l|l|}
\cline { 2 - 4 } & 0 & 1 & 2 & 3 \\
\cline { 2 - 4 } & & &
\end{tabular}

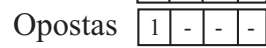

Célula 1

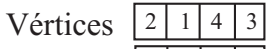

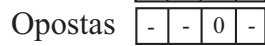

Figura 4.2: Células vizinhas nos casos bi e tridimensionais.

\subsection{A Estrutura de Dados Mate Face - MF}

Esta seção foi baseada no trabalho de Cunha Cunha, 2009, relacionando as principais características da estrutura de dados Mate Face.

Assim como a Opposite Face (OF), a estrutura Mate Face (MF) também possibilita a representação de malhas bidimensionais (superficiais) e tridimensionais (volumétricas), sendo elas simples ou mistas para malhas superficiais, e apenas simples para malhas volumétricas.

Uma das principais diferenças entre a OF e a MF é que a MF representa as arestas e faces explicitamente. Outra diferença está no fato que a MF representa malhas mistas, adaptando a operação de determinação de vizinhança de uma célula, onde na OF é 
feita usando o conceito de corners opostos.

Todas as classes da MF dependem de parâmetros templates que precisam ser definidos no momento de sua declaração. Com isso, ela torna-se flexível podendo representar tipos de malhas diferentes, com dados associados em elementos distintos.

\subsubsection{Vetor de Elementos}

A MF utiliza um vetor alocado em partes com gerenciamento de posições vazias para a representação do vetor de elementos. Assim, blocos de memória são alocados dinamicamente, na medida em que novos elementos são inseridos em seus respectivos vetores. Esta estratégia contorna o problema do limite imposto pelo tamanho de espaço de memória alocado a um vetor. Tal esquema de alocação pode ser visualizada na Figura 4.3 .

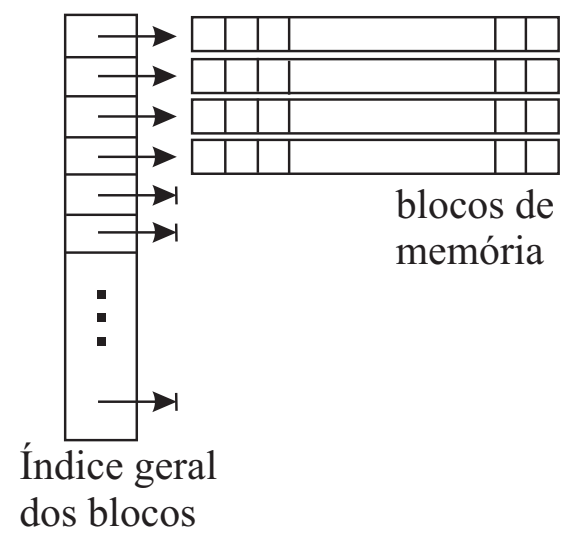

Figura 4.3: Esquema de alocação do vetor de elementos.

Assim, os blocos são indexados em um vetor de ponteiros, sendo que a posição de um bloco no vetor pode ser determinada pela divisão inteira do identificador do elemento pelo tamanho do bloco. A posição do elemento no bloco é então determinada pelo resto desta divisão. Mesmo que o limite ainda seja estabelecido no momento em que o vetor de ponteiros é alocado, pode-se definir uma ordem de grandeza maior do número de elementos de uma malha, minimizando a limitação imposta pela linguagem 
de programação, ou seja, o tamanho máximo alocado para um vetor em memória.

\subsubsection{Vértices}

Os vértices armazenam as informações geométricas da malha, onde cada um está associado a uma posição no espaço, base para a maioria das operações geométricas. Cada vértice na MF também armazena uma referência para uma célula incidente a ele, através de um identificador. Um exemplo de armazenamento de vértices de uma malha bidimensional é mostrado na Figura 4.4 .

Vértices
\begin{tabular}{|l|l|}
\hline 0 & $x, y, 1$ \\
\hline \hline 1 & $x, y, 0$ \\
\hline \hline 2 & $x, y, 0$ \\
\hline \hline 3 & $x, y, 2$ \\
\hline \hline 4 & $x, y, 2$ \\
\hline
\end{tabular}

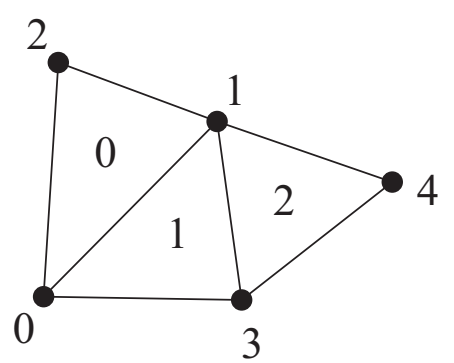

Figura 4.4: Exemplo de armazenamento de vértices na MF em uma malha bidimensional.

Um vértice é singular quando não possui uma vizinhança homeomórfica do plano. Assim, a estrutura MF também suporta a representação de vértices singulares, uma vez que este tratamento é bastante útil em aplicações de geração de malhas. Deste modo, na representação do vértice, se este for singular, é armazenado o identificador de uma célula de cada componente da singularidade.

Assim, uma lista de singularidade é associada ao vértice, sendo possível percorrer diretamente todas células incidentes ao vértice. Um exemplo pode ser visto na Figura 4.5. no qual um vértice singular é pertencente a dois componentes diferentes.

\subsubsection{Arestas}

Conforme já mencionado, na MF as arestas são representadas de maneira explícita. Tal representação tem a vantagem de permitir que informações sejam associadas dire- 


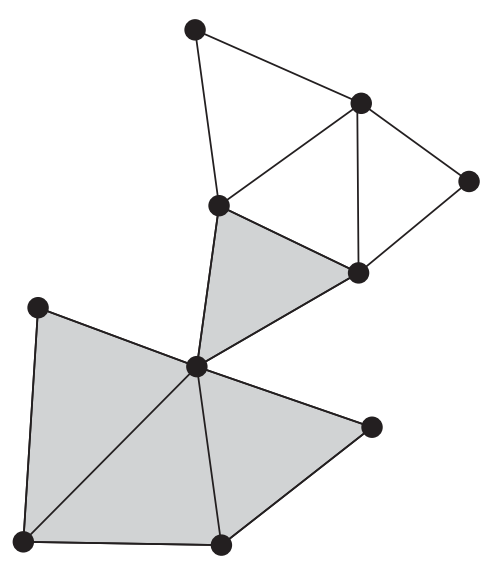

Figura 4.5: Exemplo de um vértice singular com células incidentes hachuradas.

tamente à aresta. Na MF também é possível configurar uma representação implícita, caso não se deseje lhe atribuir informações, consumindo assim menos memória. Embora o tratamento de singularidade nos vértices é realizado, nas arestas não há este suporte.

\subsubsection{Célula}

Na representação de cada célula da malha, a estrutura MF armazena referências aos vértices, arestas e faces. Além disso, as referências às células vizinhas também são armazenadas, através de arestas ou faces incidentes. Note que a utilização da componente face só é considerada no caso tridimensional, podendo ser representada por um triângulo ou um quadrilátero, assim como uma célula no caso bidimensional. As Figuras 4.6 e 4.7 mostram exemplos de representação de células bidimensionais e tridimensionais, respectivamente.

A indexação de células bidimensionais é simples, uma vez que não há necessidade da representação da face (pois a célula já é uma face), então o número de vértices é o número de arestas e vizinhos. A orientação segue o sentido anti-horário na célula, e no caso da aresta a indexação é igual ao índice do primeiro vértice. As células tridimensionais são mais complexas pela presença da face, pois o número de vértices 


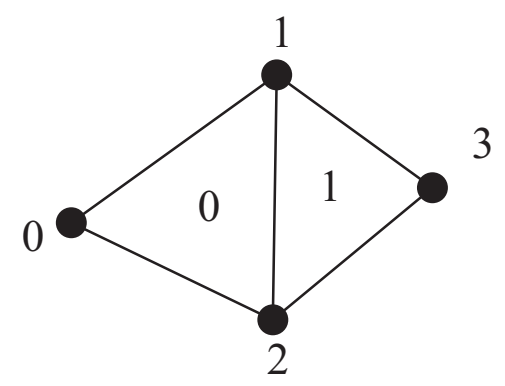

Célula 0:

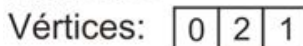

Arestas: 02 21 10

Vizinhos: $1-1$ -

Célula 1:

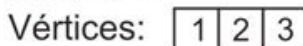

Arestas: 122331

Vizinhos: \begin{tabular}{llll} 
& 0 & - & - \\
\cline { 3 - 3 } & &
\end{tabular}

Figura 4.6: Representação de células triangulares na MF.

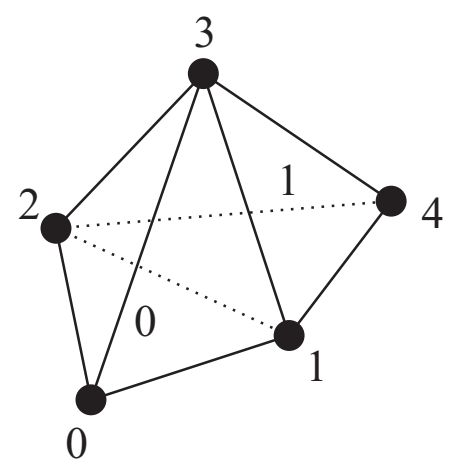

Célula 0:

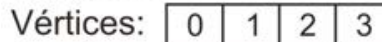

Arestas: \begin{tabular}{lllll|l|l|l|} 
& 01 & 02 & 03 & 12 & 13 & 23 \\
\hline
\end{tabular}

Faces: 132023031012

Vizinhos: 11 - 1 - 1 -

Célula 1:

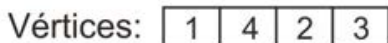

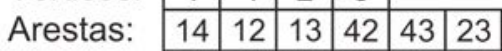

Faces: 432123134142

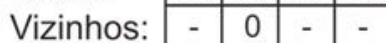

Figura 4.7: Representação de células tetraédricas na MF.

não é igual ao número de faces, tornando inviável a operação de vizinhança por vértice oposto (isso só seria possível no tetraedro), e o número de arestas é diferente do número de vértices, impossibilitando a representação de arestas por um único vértice.

\subsubsection{Malha}

A malha é definida pelo tipo de vértice, aresta, face e células, alocados em seus respectivos vetores da malha. A MF dispõe de operadores de manipulação da malha, como a adição ou remoção de algum componente.

Atualmente, a MF suporta o carregamento de malhas provindos de diferentes formatos de arquivos: VTK ${ }^{1}, \mathrm{OFF}^{2}$, VRML Ames et al., 1996, PLY ${ }^{3}$ e HEX ${ }^{4}$.

Além de operadores de manipulação da malha, a estrutura também dispõe de

\footnotetext{
${ }^{1}$ VTK - Site: http://www.vtk.org

${ }^{2}$ Geomview - Site : http://www.geom.uiuc.edu/software/geomview

${ }^{3} \mathrm{PLY}$ - Polygon File Format - Site: http://local.wasp.uwa.edu.au/ pbourke/dataformats/ply

${ }^{4}$ Unstructured Hexahedral Meshes - Site: http://www.cc.gatech.edu/ lindstro/data/hexzip
} 
operadores de consulta e caminhamento na malha, onde caminhamento são operações em que uma ordem específica de consulta é determinada a priori. Estes operadores são implementados na forma de iteradores, facilitando a utilização da estrutura. Os iteradores suportados pela MF são:

- mfVerticesIterator, mfCellsIterator, mfEdgesIterator e mfFacesIterator: percorrem respectivamente todos os vértices, células, arestas e faces da malha;

- mfVertexStarIterator: percorre todas as células que contém um determinado vértice (estrela do vértice). Os nomes das classes deste tipo de iterador terminam com o sufixo relacionado ao tipo de célula da malha;

- mfEdgeStarIterator: percorre todas as células que contém uma determinada aresta (estrela da aresta). Os nomes das classes deste tipo de iterador terminam com o sufixo relacionado ao tipo de célula da malha 3D;

- mfMateCelliteratorTri, mfMateCelliteratorQuad, mfMateCelliteratorHybrid2D: percorre todas as células vizinhas de uma determinada célula (vizinhas por vértice(s) comuns e não apenas por aresta ou face comuns);

- mfBoundaryCelliterator: percorre todas as células que possuem ao menos um vértice na fronteira. Os nomes das classes deste iterador terminam com o sufixo relacionado ao tipo de célula da malha 2D.

A operação de caminhamento de estrela de um vértice na MF têm diferentes comportamentos dependendo do tipo de vértice centrado. Os diferentes caminhamentos podem ser vistos na Figura 4.8, que consideram vértice interno ou de fronteira. Pelos exemplos vemos que a busca segue o sentido anti-horário a partir da célula inicial, até não haver mais células a percorrer ou quando for feita a volta completa. Caso seja atingida uma célula de fronteira, a busca toma o caminho inverso a partir da célula inicial. 

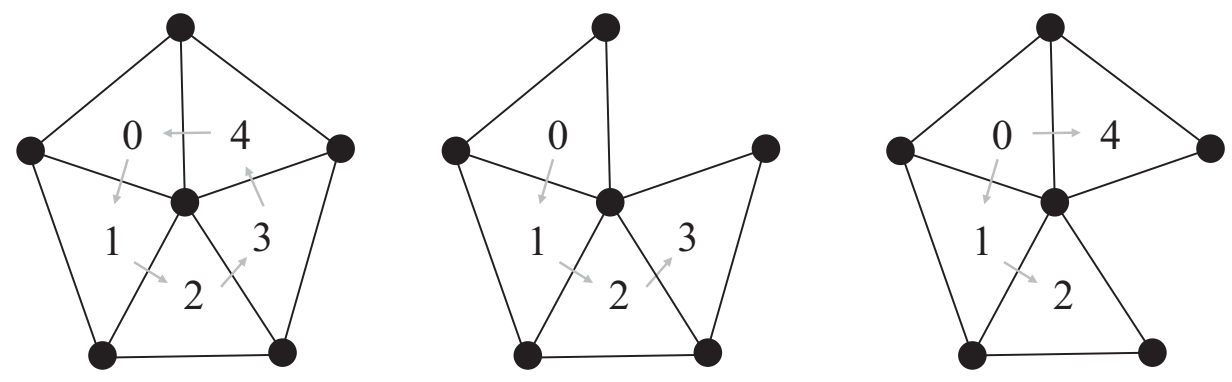

Figura 4.8: Exemplo de caminhamento em estrela em um dado vértice com célula inicial com identificador zero.

Além das operações de caminhamento na malha, a estrutura MF também dispõe de operadores geométricos, dispondo operações geométricas simples como:

- dist: Calcula a distância entre dois pontos (no espaço 2D ou 3D);

- orientation2D: Orienta três pontos no espaço bidimensional (para triângulos ou quadriláteros);

- orientation3D: Orienta os quatro pontos de um tetraedro;

- inCircle: Verifica se um ponto está dentro ou fora de um círculo definido por um triângulo;

- getCircuncircle: Retorna as coordenadas do centro do circuncirculo de um triângulo;

- inDiametralCircle: Verifica se um ponto está dentro ou fora do círculo diametral de uma aresta;

- inTetrahedron: Verifica se um ponto está dentro ou fora de um tetraedro;

A representação da vizinhança das células utilizado na estrutura MF é diferente da utilizada na estrutura OF (método de uso de corners opostos), pelo fato de que os tipos de elementos suportados, quadriláteros e hexaedros, não condizem com o método anteriormente utilizado. A MF utiliza Half-Edges em malhas superficiais e 
Half-Faces em malhas volumétricas. A Figura 4.9 mostra a abordagem de vizinhança usando Half-Edge em células quadriláteras (a) e usando Half-Face para o caso de células tetraédricas (b).

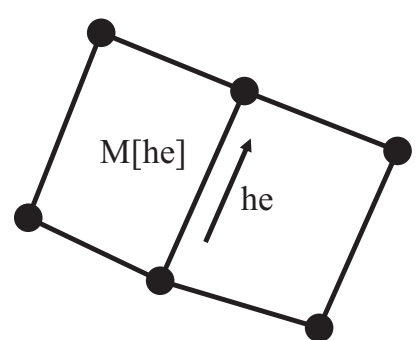

(a) half-edge

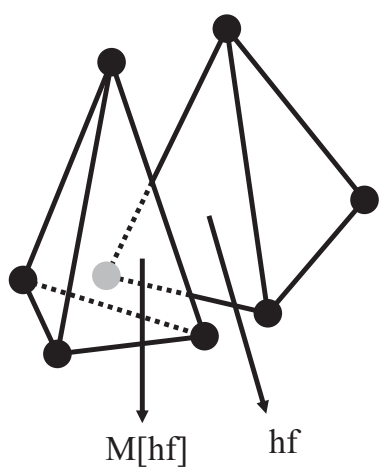

(b) half-face

Figura 4.9: Vizinhança de células na MF.

A representação de vizinhança de células na Mate Face permite executar consultas na estrutura com um custo proporcional ao número de vizinhos procurado. Por exemplo, em uma busca pelas células que compartilham um vértice, chamada de busca na estrela de um vértice, basta acessar o método relacionado à informação de vizinhos (Mate) de cada célula visitada. No caso de malhas mistas, a operação é realizada de forma similar, atentando apenas à escolha correta da célula vizinha, como pode ser vista na Figura 4.10, onde $i$ é a posição do vértice na célula em questão.

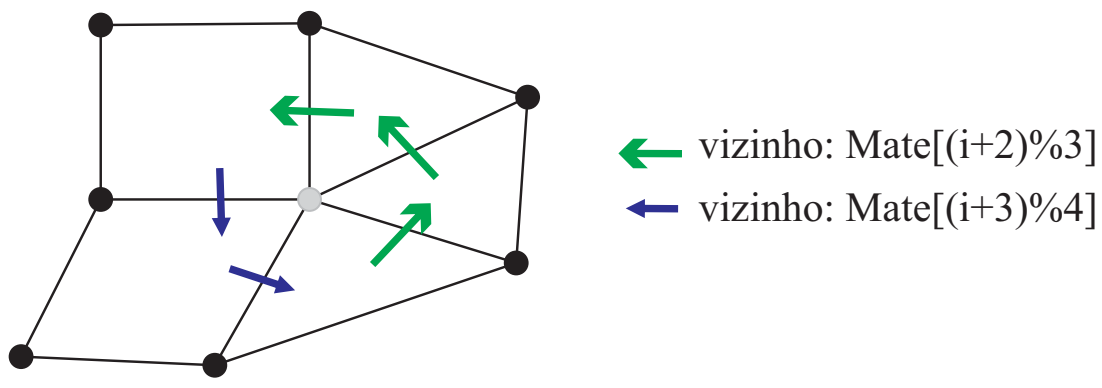

Figura 4.10: Busca na estrela de um vértice em uma malha mista. 
Para exemplificar uma malha mista representada pela Mate Face, uma malha superficial pode ser visualizada na Figura 4.11, que mostra o modelo CAD de uma peça de automóvel, formada por 5215 vértices e 8432 células. Dentre as células representadas, 6418 delas são triângulos e 2014 são quadriláteros. A região destacada no centro da peça ilustra um exemplo de consulta na estrela de um determinado vértice.

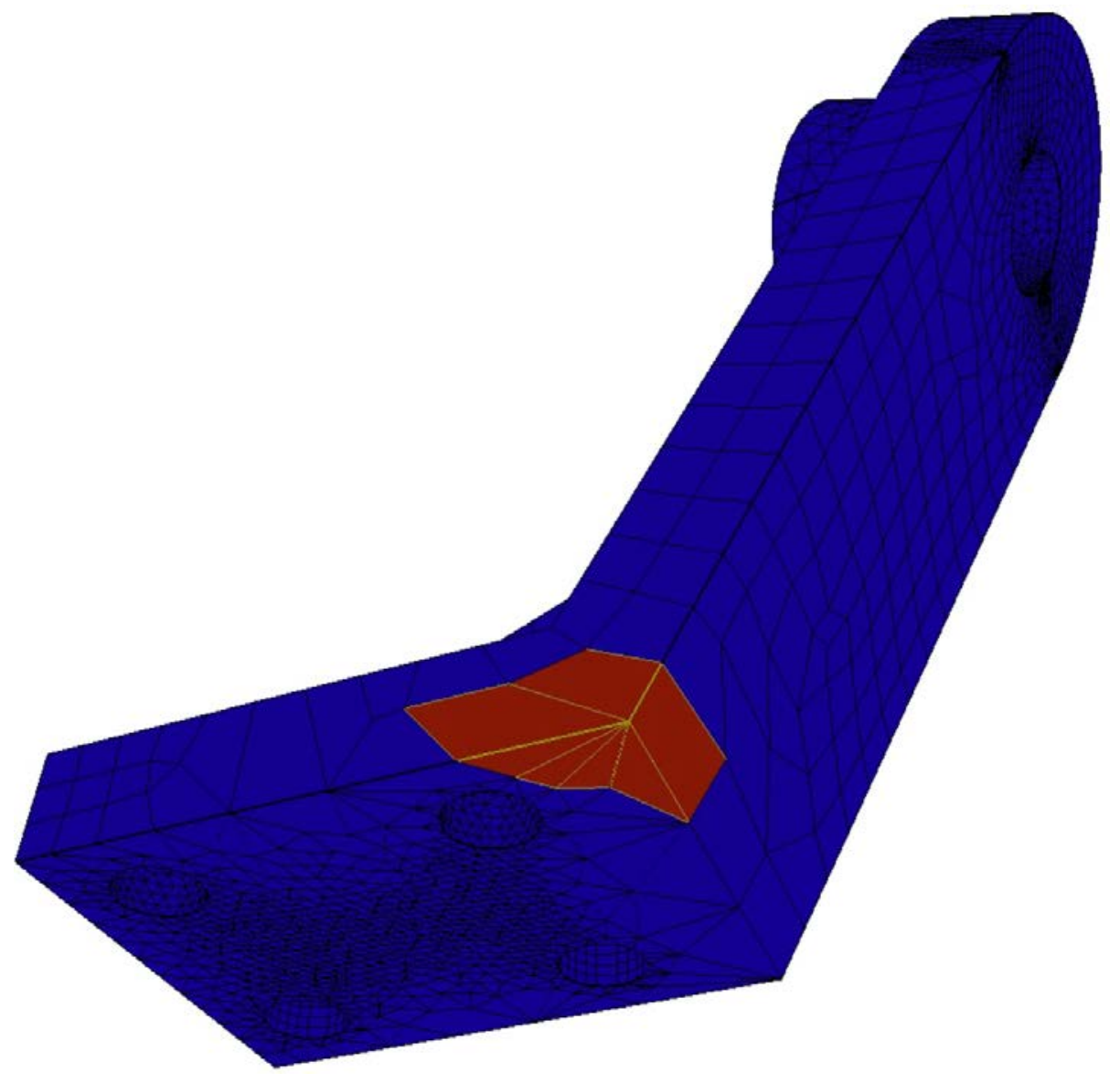

Figura 4.11: Malha superficial mista na Mate Face representando um modelo de peça de automóvel Cunha, 2009.

A Figura 4.12 mostra a representação de uma malha para o modelo do Dragão Chinês com três diferentes visualizações, sendo que a Figura 4.12(d) mostra a malha completa, enquanto as Figuras 4.12 (a) 4.12 (b) e 4.12 (c) representam as malhas seccionadas de modo a ilustrar a adaptatividade interna. 


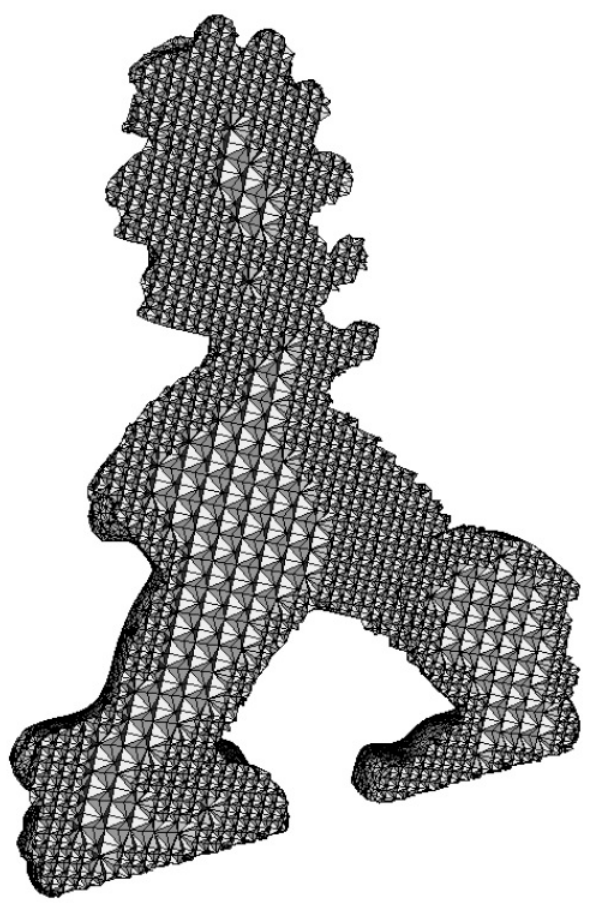

(a)

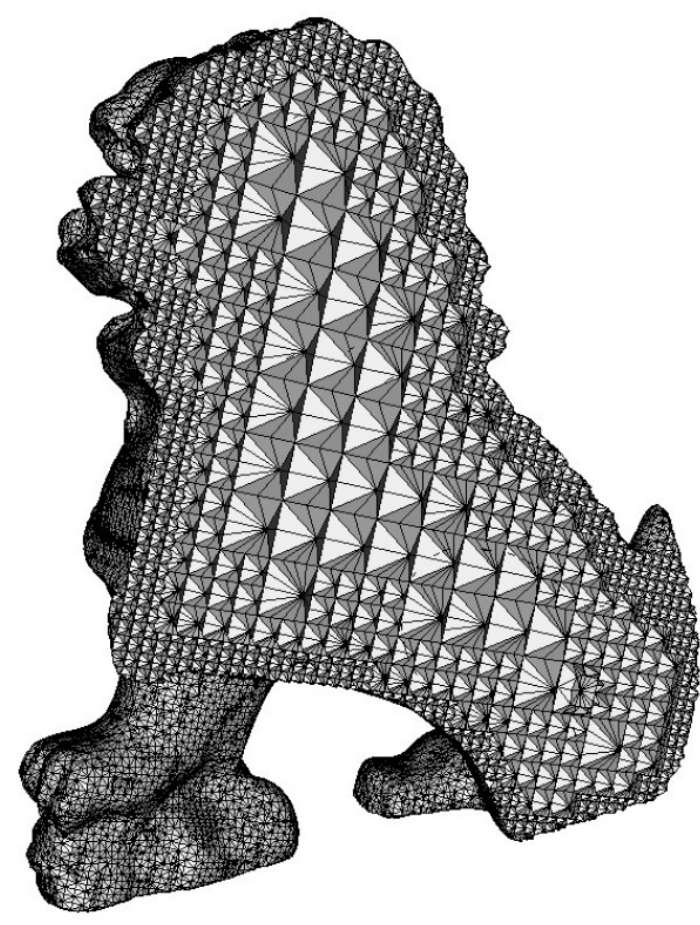

(c)

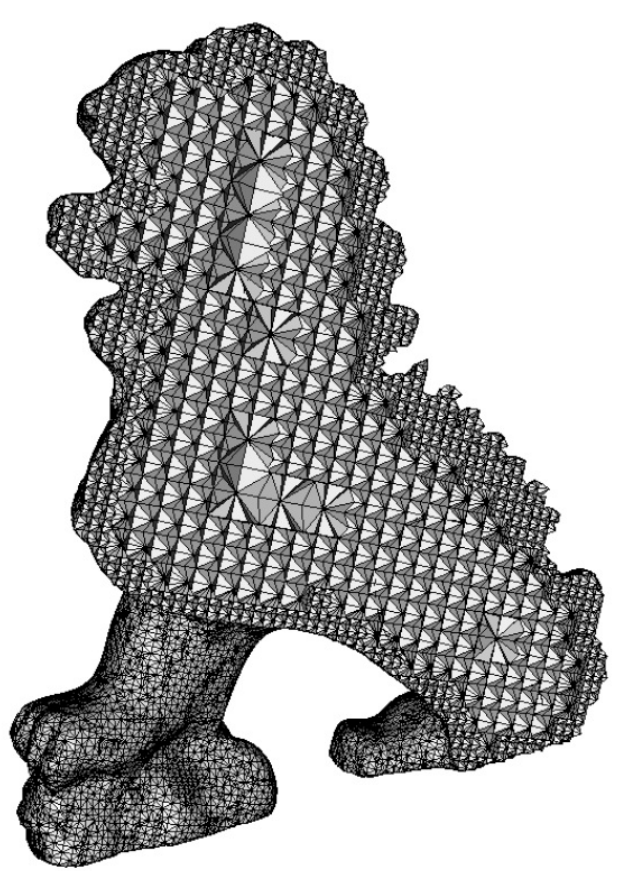

(b)

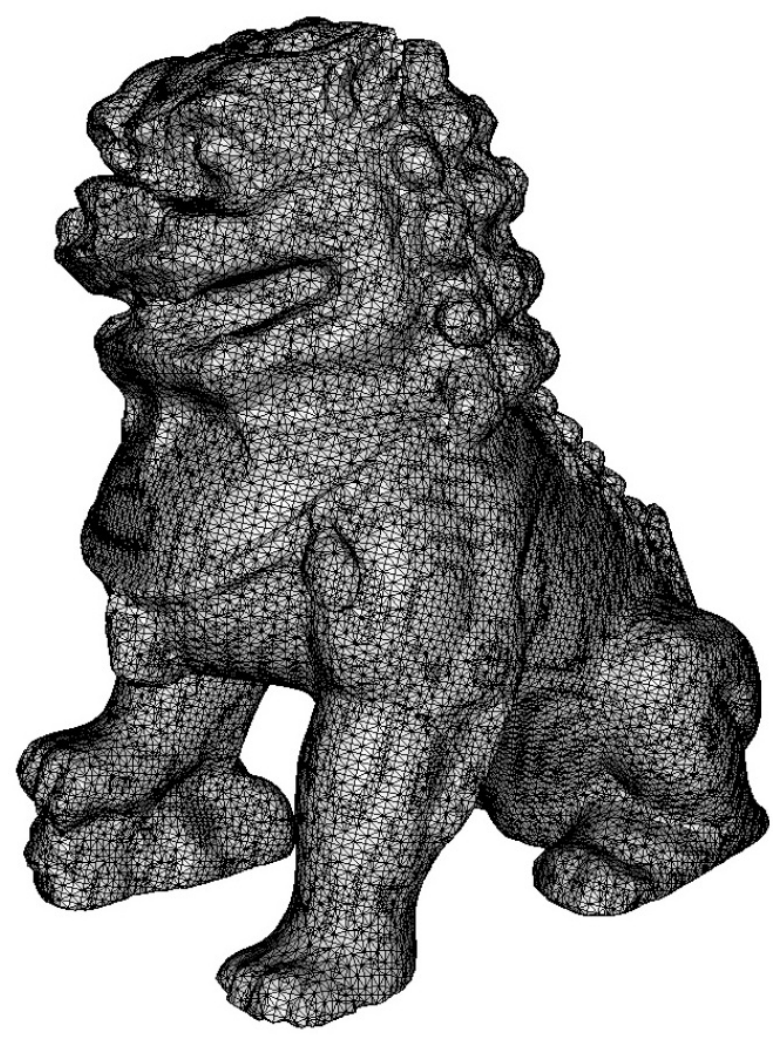

(d)

Figura 4.12: Malha representando o Dragão Chinês formada por 1053 mil tetraedros Cunha, 2009. 


\subsection{Considerações Finais}

Neste capítulo foram apresentadas as estruturas de dados topológicas propostas na literatura para representação de malhas computacionais. Elas diferem quanto a representação implícita ou explícita dos elementos da malha e também diferem quanto à representação da vizinhança destes elementos.

Dentre elas, foi detalhada a estrutura Mate Face na qual possui suporte para manipulação de malhas bidimensionais e tridimensionais, além de ser bastante eficiente no acesso às informações da malha bem como operações geométricas e de consulta. A Mate Face é a estrutura de dados escolhida para ser utilizada neste trabalho, pois comporta as funcionalidades necessárias para dar apoio a métodos numéricos para simulações de escoamentos de fluidos em CFD. 


\section{Capítulo \\ 5 \\ Os Esquemas ENO e WENO}

Este capítulo apresenta os esquemas não oscilatórios do tipo Essentially NonOscillatory (ENO), os esquemas Weighted Essentially Non-Oscillatory (WENO) e suas reconstruções para esquemas de segunda, terceira e quarta ordem de precisão. A discretização espacial, baseada no contexto do método de volumes finitos e a discretização temporal utilizadas na ferramenta de simulação em questão são apresentadas. É feita uma discussão sobre o acoplamento da estrutura de dados Mate Face ao código de simulação, mostrando exemplos de utilização da estrutura e consultas utilizadas no simulador. Simulações numéricas são realizadas para o caso de escoamentos estacionários afim de validar a integração Mate Face e simulador e por fim, uma análise da malha dinâmica é apresentada utilizando como teste o perfil NACA 0012.

\subsection{Considerações Iniciais}

Simulações numéricas que utilizam valores altos para o Mach possuem fortes descontinuidades, isto é, ondas de choque presentes nos escoamentos aerodinâmicos estudados. Alguns esquemas abordados na literatura, os esquemas upwind, como os métodos de separação de vetores de fluxo Van Leer, 1982 Liou, 1996, foram propostos e testa- 
dos utilizando-se o esquema de reconstrução MUSCL Anderson, 1963 linear, gerando discretizações com segunda ordem de precisão espacial. Porém, existe uma redução na ordem de precisão efetiva destes esquemas de segunda ordem de precisão nominal quando têm-se malhas não estruturadas Azevedo et al., 2010. Além disso, reconstruções do tipo MUSCL levam a esquemas de redução de variação total TVD, onde esquemas com essa propriedade mostram uma redução da ordem de precisão na presença de descontinuidades causadas pela utilização dos limitadores de fluxo Boris and Book, 1973 van Leer, 1974.

Deste modo, tanto os métodos numéricos de volumes finitos ou diferenças finitas quanto a interpolação polinomial consistem na interpolação das variáveis que se deseja obter através da utilização de polinômios. Tais métodos funcionam bem para problemas cujas funções são suaves, porém para funções descontínuas esses métodos não conseguem boas aproximações nas regiões de descontinuidades, apenas uma suavização nessa região. O método numérico Essencialmente Não-Oscilatório - ENO, proposto por Harten et. al. Harten et al., 1987 apresenta resultados significativamente melhores com respeito a diminuição da dissipação numérica além de produzirem soluções essencialmente não-oscilatórias nas regiões de descontinuidades (choques) na solução.

Os esquemas ENO não possuem as limitações dos esquemas TVD, pois pode-se construir esquemas de qualquer ordem de precisão sem existir redução de ordem na região das descontinuidades. O esquema ENO nada mais é do que uma interpolação polinomial, que pode ser baseado no método tanto de volumes finitos como o de diferenças finitas. Quanto maior a ordem do polinômio utilizado para a aproximação dos valores das variáveis, maior a ordem de precisão obtida pelos esquemas. Ele é baseado na utilização de molécula de cálculo adaptável, que se ajusta a suavização da solução, onde são usados polinômios de alta ordem para a reconstrução das variáveis de estado nas células destes. Posteriormente, foram propostos os esquemas WENO (Weighted Essentially Non-Oscilattory) por Liu et. al. Liu et al., 1994 e Jiang e Shu 
Jiang and Shu, 1996 para melhorar a razão de convergência, maior suavização para os vetores de fluxo e maior acurácia usando as mesmas moléculas de cálculo que os esquemas ENO utilizam.

A principal diferença entre os esquemas ENO e WENO é que os esquemas WENO utilizam todos os polinômios interpoladores calculados nos esquemas ENO, ao invés do polinômio que representa as variáveis de estado de forma mais suave. Assim, uma combinação dos polinômios nos esquemas ENO nas possíveis moléculas de cálculo é construída e pesos são atribuídos para fornecer as contribuições desses polinômios para um polinômio aproximador. A vantagem de se utilizar o esquema WENO é a maior suavização dos vetores de fluxo, a melhor convergência e maior precisão.

$\mathrm{Na}$ literatura são encontrados muitos esquemas ENO e WENO. Diferentes aplicações são alvo de pesquisa, incluindo simulações com interações entre ondas de choque e turbulência $\mathrm{Hu}$ and Shu, 1999 Adams and Shariff, 1996, simulações de equações hidrodinâmicas Dolezal and Wong, 1995, simulações com interações entre ondas de choque e vórtices Casper and Atkins, 1993 [ERLEBACHER et al., 1997, simulações de escoamentos incompressíveis Harten and Chakravarthy, 1991, simulações de escoamentos viscoelásticos Shu and Zeng, 1997 e até em processamento de imagens Osher and Sethian, 1988. O uso de esquemas ENO e WENO em malhas não estruturadas também se enquadra em uma área de pesquisa Käser and Iske, 2005. Wolf Wolf, 2006 aplicou os esquemas ENO e WENO em malhas não-estruturadas através da técnica de volumes finitos em uma ferramenta já existente, que resolve as equações de Euler em duas dimensões. A reconstrução dos esquemas ENO e WENO foi feita para polinômios de diferentes graus de acurácia, que interpolam variáveis primitivas em pontos de quadratura de Gauss utilizando moléculas de cálculo determinadas por vizinhanças compostas por volumes de controle adjacentes a um volume principal.

Este trabalho foca este conceito, onde uma estrutura de dados foi utilizada para controlar os acessos feitos às malhas não estruturadas neste contexto. A seguir é 
mostrada como é feita a discretização espacial para este domínio de aplicação, assim como a discretização temporal para o avanço no tempo da solução. Maiores detalhes podem ser encontrados no trabalho de Wolf Wolf, 2006.

\subsection{Discretização Espacial}

A discretização espacial das equações governantes do escoamento define a menor escala de comprimento a ser representada na simulação, enquanto que a precisão com a qual as escalas são representadas é determinada pelo método numérico. O método de volumes finitos é uma metodologia utilizada em simulações numéricas para este fim.

A Equação 3.35 foi obtida no contexto de volumes finitos centrados nas células para um volume de controle $i$. A discretização para a integral no termo direito da equação define a discretização espacial. Assim, todos os volumes de controle em malhas não estruturadas são formados por um número finito de faces (arestas) $\Gamma$. Deste modo, decompondo-se a integral da Equação 3.35 obtêm-se

$$
\int_{S_{i}}(\mathbf{P} \cdot \mathbf{n}) d S=\sum_{j} \int_{\Gamma_{j}}(\mathbf{P} \cdot \mathbf{n}) d S
$$

sendo $\vec{n}$ constante para cada face $\Gamma_{j}$.

O lado direito da Equação 5.1 é discretizado usando uma fórmula de integração gaussiana de $N$ pontos com grau $2 N-1$ e ordem de precisão $2 N$. Desta forma, obtém-se a seguinte aproximação

$$
\int_{S_{i}}(\mathbf{P} \cdot \mathbf{n}) d S \approx \sum_{j}\left|\Gamma_{j}\right| \sum_{l=1}^{N} w_{l} \mathbf{P}\left(\mathbf{Q}_{\mathbf{j}}\left(\mathbf{G}_{\mathbf{l}}\right), t\right) \cdot \mathbf{n},
$$

onde $\mathbf{G}_{\mathbf{l}}$ e $w_{l}$ são os pontos de Gauss e os pesos na face $\Gamma_{j}$, respectivamente.

Somente um ponto de Gauss é necessário para a integração em esquemas de segunda ordem de precisão. Assim, obtém-se o ponto de Gauss como o ponto médio da face. Uma vez conhecidas as coordenadas dos pontos nas extremidades da face em 
questão, definidas como $\mathbf{z}_{1}$ e $\mathbf{z}_{2}$, o ponto médio da face pode ser calculado como

$$
\mathbf{G}_{1}=\frac{\mathbf{z}_{1}+\mathbf{z}_{2}}{2}
$$

O peso $w_{1}$ é definido por $w_{1}=1$ neste caso. Já nos esquemas de terceira e quarta ordem de precisão, são necessários dois pontos de Gauss na integração, onde os valores desses pontos são definidos por

$$
\mathbf{G}_{\mathbf{1}}=\frac{\sqrt{3}+1}{2 \sqrt{3}} \mathbf{z}_{\mathbf{1}}+\left(1-\frac{\sqrt{3}+1}{2 \sqrt{3}}\right) \mathbf{z}_{\mathbf{2}} \quad e \quad \mathbf{G}_{\mathbf{2}}=\frac{\sqrt{3}+1}{2 \sqrt{3}} \mathbf{z}_{\mathbf{2}}+\left(1-\frac{\sqrt{3}+1}{2 \sqrt{3}}\right) \mathbf{z}_{\mathbf{1}},
$$

onde os pesos $w_{1}$ e $w_{2}$ são definidos por $w_{1}=w_{2}=\frac{1}{2}$.

Assim, a discretização espacial se resume em calcular os valores de $Q_{i}$ para um instante de tempo $t$, e a partir destes valores médios, reconstruir polinômios que representam as variáveis primitivas, $\rho, u, v$ e $p$. Então, pode-se calcular os valores das variáveis conservadas nos pontos de Gauss. Uma vez que os valores reconstruídos das variáveis conservadas nas faces dos volumes de controle apresentam descontinuidades, utiliza-se uma função de fluxo numérico de modo a aproximar os valores dos fluxos nas faces das células. Nesta etapa pode-se utilizar o método de separação de diferenças de fluxo de Roe Roe, 1981] e o método de separação de vetores de fluxo de Liou, o AUSM+ Liou, 1996], para tais aproximações. Maiores detalhes podem ser encontrados em Wolf [Wolf, 2006].

Utilizando-se o esquema de Roe, o cálculo do fluxo na Equação 5.2 é definido por

$$
\begin{aligned}
\mathbf{P}\left(\mathbf{Q}_{j}\left(\mathbf{G}_{l}\right), t\right) \cdot \mathbf{n} & \approx \mathbf{P}\left(\mathbf{Q}_{i}\left(\mathbf{G}_{l}\right), \mathbf{Q}_{n g}\left(\mathbf{G}_{l}\right), t ; \mathbf{n}\right)=\frac{1}{2}\left[\mathbf{P}\left(\mathbf{Q}_{i}\left(\mathbf{G}_{l}\right)\right)+\mathbf{P}\left(\mathbf{Q}_{n g}\right)\left(\mathbf{G}_{l}\right)\right] \cdot \mathbf{n} \\
& -\frac{1}{2}\left|A\left(\mathbf{Q}_{i}\left(\mathbf{G}_{l}\right), \mathbf{Q}_{n g}\left(\mathbf{G}_{l}\right), t ; \mathbf{n}\right)\right|\left[\mathbf{Q}_{n g}\left(\mathbf{G}_{l}\right)-\mathbf{Q}_{i}\left(\mathbf{G}_{l}\right)\right]
\end{aligned}
$$

Pela Equação 5.5, onde $|A|$ é dada como a matriz semidefinida positiva que é 
formada através da matriz jacobiana de fluxos de forma, como definido por Roe Roe, 1981, $Q_{i}\left(G_{l}\right)$ é o vetor de variáveis conservadas que é calculado nos pontos de quadratura, $G_{l}$, usando a reconstrução polinomial no volume de controle $i$. Da mesma forma, ainda na equação, o vetor de variáveis conservadas $Q_{n g}\left(G_{l}\right)$ calculado no mesmo ponto de quadratura $G_{l}$, mas agora usando a reconstrução polinomial no volume de controle $n g$. Assume-se que a célula $n g$ é vizinha da célula $i$, pela face $\Gamma_{j}$.

Avaliando-se o último termo do lado direito da Equação 5.5, pode-se calcular o fluxo numérico como

$$
\left|A\left(\mathbf{Q}_{i}\left(\mathbf{G}_{l}\right), \mathbf{Q}_{n g}\left(\mathbf{G}_{l}\right), t ; \mathbf{n}\right)\right|\left[\mathbf{Q}_{n g}\left(\mathbf{G}_{l}, t\right)-\mathbf{Q}_{i}\left(\mathbf{G}_{l}, t\right)\right]=\sum_{m}|\lambda| \partial \omega_{m} r^{(m)}
$$

onde $r^{(m)}$ são os autovetores pela direita da matriz jacobiana de fluxos, $\lambda_{m}$ são os autovalores da mesma matriz e $\partial \omega_{m}$ representam as variáveis características. Para se obter o fluxo numérico de Roe Roe, 1981, deve-se primeiramente realizar a avaliação da propriedades médias como

$$
\begin{gathered}
\tilde{\rho}=\sqrt{\rho_{i} \rho_{n g}}, \\
\tilde{u}=\frac{u_{i} \sqrt{\rho_{i}}+u_{n g} \sqrt{\rho_{n g}}}{\sqrt{\rho_{i}}+\sqrt{\rho_{n g}}}, \\
\tilde{v}=\frac{v_{i} \sqrt{\rho_{i}}+v_{n g} \sqrt{\rho_{n g}}}{\sqrt{\rho_{i}}+\sqrt{\rho_{n g}}}, \\
\tilde{H}=\frac{H_{i} \sqrt{\rho_{i}}+H_{n g} \sqrt{\rho_{n g}}}{\sqrt{\rho_{i}}+\sqrt{\rho_{n g}}} .
\end{gathered}
$$

O termo da densidade média considerado nesta formulação é a definido por Hirsch Hirsch, 1990. Assim, para se obter a componente da velocidade normal à face, utiliza-se os valores médios das componentes de velocidade cartesianas como $\tilde{V}_{n}=\tilde{u} n_{x}+\tilde{v} n_{y}$, onde $n_{x}$ e $n_{y}$ são as componentes do vetor unitário normal à face $j$, positivo para fora do volume $i$, nas direções $x$ e $y$ cartesianas, respectivamente. Após estes cálculos, deve-se calcular a velocidade média do som definida por $\tilde{c}$ da seguinte 
forma

$$
\tilde{c}^{2}=(\gamma-1)\left(\tilde{H}-\frac{\tilde{u}^{2}+\tilde{v}^{2}}{2}\right)
$$

Os autovalores da matriz $A$ e os autovetores pela direita associados a ela são obtidos pelas seguintes relações:

$$
\begin{gathered}
\lambda_{1}=\tilde{V}_{n}, \\
\lambda_{2}=\tilde{V}_{n}, \\
\lambda_{3}=\tilde{V}_{n}+\tilde{c}_{n}, \\
\lambda_{4}=\tilde{V}_{n}-\tilde{c}_{n} \\
r^{(1)}=\left\{\begin{array}{c}
{ }^{2} \\
\tilde{u} \\
\frac{1}{2}\left(\tilde{u}^{2}+\tilde{v}^{2}\right)
\end{array}\right\}, r^{(2)}=\tilde{\rho}\left\{\begin{array}{c}
n_{y} \\
-n_{x} \\
\tilde{u} n_{y}-\tilde{v} n_{x}
\end{array}\right\}, r^{(3)}=\frac{\tilde{\rho}}{2 \tilde{c}}\left\{\begin{array}{c}
\tilde{u}+\tilde{c} n_{x} \\
\tilde{v}+\tilde{c} n_{y} \\
\tilde{H}+\tilde{c} \tilde{V}_{n}
\end{array}\right\}, r^{(4)}=\frac{\tilde{\rho}}{2 \tilde{c}}\left\{\begin{array}{c}
1 \\
\tilde{u}-\tilde{c} n_{x} \\
\tilde{v}-\tilde{c} n_{y} \\
\tilde{H}-\tilde{c} \tilde{V}_{n}
\end{array}\right\} .
\end{gathered}
$$

As variáveis características são definidas como

$$
\begin{gathered}
\partial w_{1}=\partial \rho-\frac{\partial p}{\tilde{c}^{2}}, \\
\partial w_{2}=n_{x} \partial u-n_{x} \partial v \\
\partial w_{3}=n_{x} \partial u+n_{y} \partial v+\frac{\partial p}{\tilde{c} \tilde{\rho}}, \\
\partial w_{4}=-n_{x} \partial u-n_{y} \partial v+\frac{\partial p}{\tilde{c} \tilde{\rho}},
\end{gathered}
$$

onde $\partial()=()_{n g}-()_{i}$.

Esta formulação utiliza o esquema de Liou [Liou, 1996], onde o operador convectivo 
é expresso como uma soma dos termos convectivos e de pressão. Os vetores de fluxo são descritos por

$$
\begin{aligned}
& \mathbf{E}=u \boldsymbol{\Phi}+\mathbf{p}_{\mathbf{x}}=M_{x} c \boldsymbol{\Phi}+\mathbf{p}_{\mathbf{x}}, \\
& \mathbf{F}=v \boldsymbol{\Phi}+\mathbf{p}_{\mathbf{y}}=M_{y} c \boldsymbol{\Phi}+\mathbf{p}_{\mathbf{y}},
\end{aligned}
$$

onde os vetores $\boldsymbol{\Phi}, \mathbf{p}_{\mathbf{x}}$ e $\mathbf{p}_{\mathbf{y}}$ são definidos como

$$
\boldsymbol{\Phi}=\left\{\begin{array}{c}
\rho \\
\rho u \\
\rho v \\
\rho H
\end{array}\right\}, \mathbf{p}_{\mathbf{x}}=\left\{\begin{array}{c}
0 \\
p \\
0 \\
0
\end{array}\right\}, \mathbf{p}_{\mathbf{y}}=\left\{\begin{array}{c}
0 \\
0 \\
p \\
0
\end{array}\right\} .
$$

onde $p$ representa a pressão, $H$ é a entalpia específica total e $M_{x}=u / c$ e $M_{y}=v / c$ são os números de Mach locais nas direções cartesianas. Assim, o fluxo pode ser calculado como

$$
\begin{gathered}
\mathbf{P}\left(\mathbf{Q}_{\mathbf{j}}\left(\mathbf{G}_{l}, t\right)\right) \cdot \mathbf{n} \approx \mathbf{P}\left(\mathbf{Q}_{\mathbf{i}}\left(\mathbf{G}_{l}\right)\right), \mathbf{Q}_{\mathbf{n g}}\left(\mathbf{G}_{l}, t ; \mathbf{n}\right)=\frac{1}{2} M_{i, n g} c_{i, n g}\left(\boldsymbol{\Phi}_{\mathbf{i}}+\boldsymbol{\Phi}_{\mathbf{n g}}\right) \\
-\frac{1}{2}\left|M_{i, n g}\right| c_{i, n g}\left(\mathbf{\Phi}_{\mathbf{n g}}-\boldsymbol{\Phi}_{\mathbf{i}}\right)+\left\{\begin{array}{llll}
0 & p_{i, n g} n_{x} & p_{i, n g} n_{y} & 0
\end{array}\right\}^{T},
\end{gathered}
$$

onde $M_{i, n g}$ é o número de Mach na interface definido de acordo com Liou como $M_{i, n g}=M_{i}^{+}+M_{n g}^{-} \operatorname{com} M_{i}^{+}=M^{+}\left(M_{i}\right)$ e $M_{n g}^{-}=M^{-}\left(M_{n g}\right)$. As separações dos números de Mach são dadas por

$$
M_{i}^{+}=\left\{\begin{array}{l}
\frac{1}{2}\left(M_{i}+\left|M_{i}\right|\right), \text { se }\left|M_{i}\right| \geq 1 \\
M_{\beta}^{+}\left(M_{i}\right), \text { caso contrário }
\end{array}\right.
$$

e

$$
M_{n g}^{-}=\left\{\begin{array}{l}
\frac{1}{2}\left(M_{n g}-\left|M_{n g}\right|\right), \text { se }\left|M_{n g}\right| \geq 1 \\
M_{\beta}^{-}\left(M_{n g}\right), \text { caso contrário. }
\end{array}\right.
$$


Podem-se definir os termos $M_{\beta}^{ \pm}$como

$$
M_{\beta}^{ \pm}(M)= \pm \frac{1}{4}(M \pm 1)^{2} \pm \beta\left(M^{2}-1\right)^{2} .
$$

Conforme sugerido por Liou Liou, 1995, utilizou-se $\beta=\frac{1}{8}$. Os números de Mach normais à face para os volumes $i$ e $n g$ são dados por

$$
M_{i}=\frac{\tilde{V}_{i}}{c_{i, n g}} \quad \text { e } \quad M_{n g}=\frac{\tilde{V}_{n g}}{c_{i, n g}},
$$

onde $\tilde{V}_{i}=u_{i} n_{x}+v_{i} n_{y}$ e $\tilde{V}_{n g}=u_{n g} n_{x}+v_{n g} n_{y}$. A velocidade do som correspondente na interface, $c_{i, n g}$, é dada por $c_{i, n g}=\min \left(c_{i}, c_{n g}\right)$, onde

$$
\begin{gathered}
c_{i}=c_{i}^{*} \min \left(1, \frac{c_{i}^{*}}{\left|\tilde{V}_{i}\right|}\right), \\
c_{i}^{*}=\sqrt{\frac{2(\gamma-1)}{\gamma+1} H_{i}},
\end{gathered}
$$

e considera-se definir $c_{n g}$ de forma análoga.

A pressão, $p_{i, n g}$, na interface entre as células $i$ e $n g$ é dada por $p_{i, n g}=p_{i}^{+} p_{i}+$ $p_{n g}^{-} p_{n g}$. As separações de pressões, também seguindo as expressões propostas por Liou Liou, 1995, podem ser escritas como

$$
p_{i}^{+}=\left\{\begin{array}{l}
\frac{1}{2}\left(1+\operatorname{sign}\left(M_{i}\right)\right), \text { se }\left|M_{i}\right| \geq 1 \\
p_{\alpha}^{+}\left(M_{i}\right), \text { caso contrário. }
\end{array}\right.
$$

e de forma análoga,

$$
p_{n g}^{-}=\left\{\begin{array}{l}
\frac{1}{2}\left(1-\operatorname{sign}\left(M_{n g}\right)\right), \text { se }\left|M_{n g}\right| \geq 1 \\
p_{\alpha}^{-}\left(M_{n g}\right), \text { caso contrário. }
\end{array}\right.
$$

Por fim, os termos $p_{\alpha}^{ \pm}$podem ser definidos por 


$$
p_{\alpha}^{ \pm}(M)=\frac{1}{4}(M \pm 1)^{2}(2 \mp M) \pm \alpha M\left(M^{2}-1\right)^{2},
$$

onde $\alpha=\frac{3}{16}$, de acordo com Liou Liou, 1995.

\subsection{Discretização Temporal}

Os métodos de Runge-Kutta são bastante utilizados para a discretização temporal. Eles procuram a precisão da aproximação da série de Taylor sem a necessidade de calcular as derivadas de alta ordem.

A discretização temporal está relacionada com a solução de um sistema de equações diferenciais ordinárias, que pode ser escrito como

$$
\frac{d Q_{i}}{d t}=-\frac{1}{V_{i}} C\left(Q_{i}\right)
$$

onde $C\left(Q_{i}\right)$ representa o termo convectivo e é dado por

$$
C\left(Q_{i}\right)=\sum_{k=1}^{n f}\left(E_{k} \hat{i}+F_{k} \hat{j}\right) .
$$

Na ferramenta de CFD utilizada, um esquema de Runge-Kutta é utilizado para avançar a solução das equações no tempo. Especificamente, é utilizado o esquema de Runge-Kutta TVD de três estágios e terceira ordem de precisão proposto por Shu e Osher Shu and Osher, 1988.

Para o esquema de Runge-Kutta TVD explícito de terceira ordem de precisão tem-se

$$
\begin{gathered}
Q_{i}^{(0)}=Q_{i}^{n}, \\
Q_{i}^{(1)}=Q_{i}^{0}-\alpha_{1} \frac{\Delta t_{i}}{V_{i}} C\left(Q_{i}^{(0)}\right), \\
Q_{i}^{(2)}=Q_{i}^{(0)}-\alpha_{2} \frac{\Delta t_{i}}{V_{i}} C\left(Q_{i}^{(0)}\right)-\alpha_{3} \frac{\Delta t_{i}}{V_{i}} C\left(Q_{i}^{(1)}\right),
\end{gathered}
$$




$$
\begin{gathered}
Q_{i}^{(3)}=Q_{i}^{(0)}-\alpha_{4} \frac{\Delta t_{i}}{V_{i}} C\left(Q_{i}^{(0)}\right)-\alpha_{5} \frac{\Delta t_{i}}{V_{i}} C\left(Q_{i}^{(1)}\right)-\alpha_{6} \frac{\Delta t_{i}}{V_{i}} C\left(Q_{i}^{(2)}\right), \\
Q_{i}^{(n+1)}=Q_{i}^{(3)}
\end{gathered}
$$

onde os coeficientes $\alpha$ conforme sugerido por Shu e Osher Shu and Osher, 1988] são dados por: $\alpha_{1}=1, \alpha_{2}=\frac{1}{2}, \alpha_{3}=\frac{1}{4}, \alpha_{4}=\frac{1}{6}, \alpha_{5}=\frac{1}{6}$ e $\alpha_{6}=\frac{2}{3}$.

\subsection{Reconstrução dos Esquemas ENO e WENO}

Os esquemas ENO e WENO foram desenvolvidos com a finalidade de capturar com eficiência descontinuidades presentes em problemas governados por equações diferenciais parciais hiperbólicas.

O processo de reconstrução dos esquemas ENO tem base na aproximação dos valores médios das variáveis primitivas para cada volume de controle da malha por polinômios de uma ordem inferior à ordem de precisão espacial desejada Wolf, 2006. Para a construção de polinômios de ordem $\eta$ deve-se utilizar $N(\eta)$ células, onde $N(\eta)=$ $(\eta+1)(\eta+2) / 2$. Para a reconstrução polinomial para cada volume de controle, é necessário definir um possível conjunto de células que formarão as moléculas de cálculo a serem utilizadas. Pela discretização de volumes finitos do tipo centrada nas células, as moléculas de cálculo podem ser escolhidas através de uma relação de vizinhança entre as células. Para uma reconstrução linear que fornecerá um esquema de segunda ordem de precisão, escolhe-se os volumes que são vizinhos primários da célula onde se pretende efetuar a reconstrução. Os vizinhos primários são células que compartilham pelo menos uma aresta com o volume de controle central para o qual a reconstrução está sendo realizada. Este procedimento é estendido para o caso de uma reconstrução de ordem mais elevada, utilizando vizinhos secundários da célula principal e assim por diante. A estrutura de dados Mate Face possui operadores que facilitam esta operação, mais detalhes são discutidos na Seção 5.5 .

$\mathrm{Na}$ ferramenta de simulação, os volumes de controle podem ter a forma de 
triângulos ou quadriláteros e por isso pode-se calcular os polinômios aproximadores para estes volumes de controle como

$$
p(x, y)=\sum_{|\beta| \leq \eta} r_{\beta_{1} \beta_{2}}\left(x-x_{c}\right)^{\beta_{1}}\left(y-y_{c}\right)^{\beta_{2}}
$$

onde $|\beta|=\beta_{1}+\beta_{2}$, com $\beta_{i} \in\{0,1,2, \ldots\}, x_{c}$ e $y_{c}$ são as coordenadas cartesianas dos baricentros dos volumes de controle e $r_{\beta_{1} \beta_{2}}$ são os coeficientes do polinômio que representam aproximações para as derivadas das variáveis primitivas reconstruídas. Considerando-se que a integração de $p(x, y)$ em cada célula da molécula de cálculo retorna o valor médio da variável primitiva na célula, é possível escrever um sistema linear, $[R]=r=\bar{u}$, de $N(\eta)$ equações com $N(\eta)$ incógnitas que são os coeficientes do polinômio, $r_{\beta_{1} \beta_{2}}$. Tem-se que $[R]$ é a matriz dos momentos de área dos volumes de controle, que são calculados de acordo com Gooch [Gooch, 1997], usando a técnica de escalonamento proposta por Friedrich Friedrich, 1998, para evitar matrizes mal condicionadas. Assim, $r$ é o vetor de coeficientes que deve ser calculado e $\bar{u}$ é o vetor composto pelos valores médios nas células para cada variável primitiva.

Os momentos de área dos volumes de controle que compõe a matriz $[R]$, que deve ser inversível, são definidos como

$$
{\overline{x^{n} y^{m}}}_{i} \equiv \frac{1}{V_{i}} \int_{S_{i}}\left(x-x_{c}\right)^{n}\left(y-y_{c}\right)^{m} d S
$$

e são calculados utilizando-se uma integração por quadratura de Gauss partindo do mesmo procedimento utilizado no cálculo dos fluxos numéricos. Com o intuito de evitar o cálculo dos momentos de área para cada célula em relação à célula principal onde se efetua a reconstrução, pode-se substituir os termos $\left(x-x_{c}\right)$ e $\left(y-y_{c}\right)$, que são as distâncias entre os pontos de quadratura de Gauss do volume de controle vizinho $V_{j}$ até o centroide do volume de controle principal $V_{i}$, por $\left[\left(x-x_{c j}\right)+\left(x_{c j}-x_{c}\right)\right] \mathrm{e}$ $\left[\left(y-y_{c j}\right)+\left(y_{c j}-y_{c}\right)\right]$, respectivamente. Os novos termos que surgem nas equações representam a separação das distâncias dos pontos de quadratura de Gauss em $V_{j}$ e as 
coordenadas do centroide do volume $V_{j}$ e do volume principal $V_{i}$. Então, os momentos de área dos volumes de controle são obtidos pela expressão final geral

$$
\begin{aligned}
\overline{x^{n} y_{i j}^{m}} & \equiv \frac{1}{V_{i}} \int_{S_{i}}\left[\left(x-x_{c j}\right)+\left(x_{c j}-x_{c}\right)\right]^{n}\left[\left(y-y_{c j}\right)+\left(y_{c j}-y_{c}\right)\right]^{m} d S \\
& =\sum_{l=0}^{m} \sum_{k=0}^{n}\left(\begin{array}{c}
m \\
l
\end{array}\right)\left(\begin{array}{c}
n \\
k
\end{array}\right)\left(x-x_{c j}\right)^{k}\left(y-y_{c j}\right)^{l} \overline{x^{n-k} y^{m-l}}
\end{aligned}
$$

Os valores são calculados na primeira iteração para então serem armazenados. Após obter-se a reconstrução polinomial para cada célula e para cada variável primitiva, deve-se verificar qual polinômio é o menos oscilatório, onde a oscilação é obtida utilizando-se um indicador que provê uma medida de suavidade de $p(x, y)$. Abgrall Abgrall, 1994 propôs o indicador de oscilação, que é definido como

$$
O I_{A b}[p(x, y)]=\sum_{|\beta|=\eta}\left|r_{\beta_{1} \beta_{2}}\right|
$$

que é basicamente composto pela somatória dos valores absolutos dos coeficientes de maior grau do polinômio reconstruído. Harten e Chakravarthy Harten and Chakravarthy, 1991 propuseram o indicador definido por

$$
O I_{H C}[p(x, y)]=\sqrt{\sum_{n=1}^{n} \sum_{|\beta|=n} r_{\beta_{1} \beta_{2}}^{2}}
$$

Jiang e Shu Jiang and Shu, 1996 propuseram um indicador adequado para um contexto de malhas não-estruturadas, que pode ser definido por

$$
O I_{J S}[p(x, y)]=\left\{\sum_{1 \leq|\beta| \leq \eta} \int_{V_{i}} h^{|\beta|-1}\left[\frac{\partial^{|\beta|} p(x, y)}{\partial x^{\beta 1 \partial y^{\beta 2}}}\right]^{2} d x d y\right\}^{\frac{1}{2}}
$$

onde $h$ é uma medida do comprimento característico da malha Abgrall, 1994.

Os esquemas WENO usam todos os polinômios reconstruídos em sua formulação, diferente dos esquemas ENO. Estes polinômios são adicionados, multiplicados seus 
respectivos pesos, para a construção de um único polinômio aproximado $p(x, y)=$ $\sum_{k=1}^{m} \omega_{k} p_{k}(x, y)$. Os pesos $\omega_{k}$ são obtidos pelos indicadores de oscilação das moléculas de cálculo. Eles são de ordem um nas regiões suaves do escoamento e da ordem de precisão desejada na solução nas regiões descontínuas, sendo obtidos por

$$
\omega_{k}=\frac{\epsilon+O I\left[p_{k}(x, y)\right]^{-\theta}}{\sum_{k^{\prime}=1}^{m}\left\{\epsilon+O I\left[p_{k^{\prime}}(x, y)\right]\right\}^{-\theta}}
$$

onde $\epsilon$ possui magnitude muito pequena e é usado para evitar divisões por zero e $\theta$ é um número inteiro positivo. Como já mencionado, os esquemas WENO são mais suaves e estáveis nas regiões suaves do escoamento, mas esta propriedade não é garantida caso se escolha para $\theta$ um número com valor absoluto grande. Para estes casos em especial, esses esquemas tendem a se comportar assim como os esquemas ENO.

A implementação da reconstrução para as diferentes ordens de precisão envolvem escolher as células na vizinhança da célula principal para compor a molécula de cálculo e a construção dos polinômios. A premissa básica é escolher todos os vizinhos para compor a molécula de cálculo, mas nem sempre este é o melhor caso. Um estudo detalhado sobre a construção das moléculas de cálculo foi realizado por Wolf Wolf, 2006. Então, as próximas subseções mostram os melhores resultados da escolha das células para a composição da molécula de cálculo de forma a reduzir as oscilações no método.

\subsubsection{Reconstrução na Segunda Ordem de Precisão}

Neste caso linear, os polinômios são construídos a partir de três células. O termo constante do polinômio é dado pelo valor médio das propriedades primitivas do volume principal em questão. Assim, é necessário calcular dois coeficientes dos termos lineares no polinômio interpolador. Isto é feito resolvendo um sistema linear de duas equações.

A melhor configuração para este tipo de reconstrução envolve selecionar uma combinação de células vizinhas primárias e secundárias, de modo a obter estabilidade no método e correção das oscilações presentes próximas às ondas de choque. Um exemplo 
de uma configuração válida nesta configuração é mostrada na Figura 5.1. Na figura, são mostradas duas configurações de moléculas, uma para malhas triangulares e outra para malhas quadriláteras, onde $V_{1}$ e $V_{2}$ representam as células escolhidas para compor a molécula de cálculo.
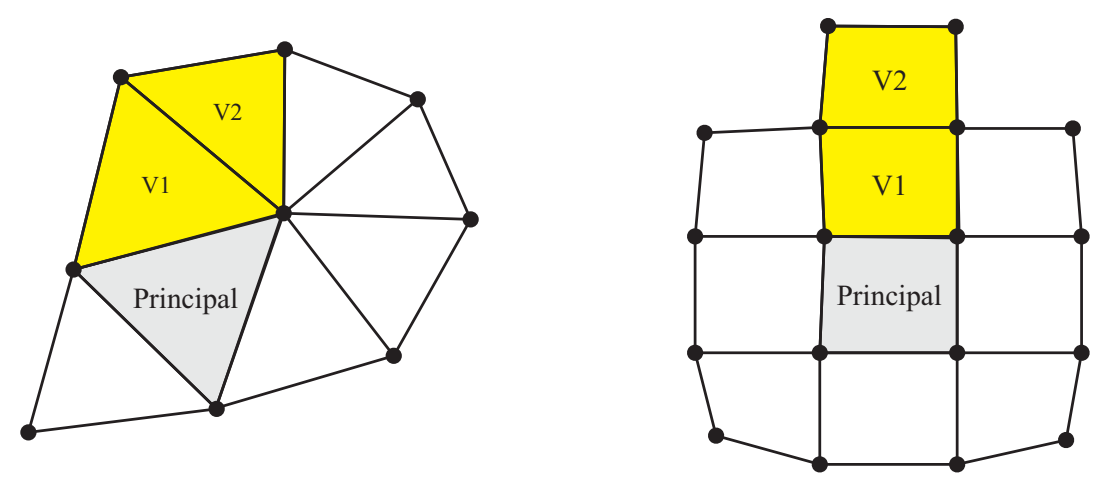

Figura 5.1: Moléculas de cálculos válidas para reconstrução de segunda ordem de precisão.

Os polinômios lineares para esta reconstrução, são representados por

$$
p(x, y)=r_{00}+r_{10}\left(x-x_{c}\right)+r_{01}\left(y-y_{c}\right),
$$

onde $r_{00}$ é o coeficiente constante com valor igual ao valor médio da propriedade do volume de controle principal e $r_{10}$ e $r_{01}$ correspondem aos coeficientes dos termos lineares do polinômio obtidos através do sistema linear:

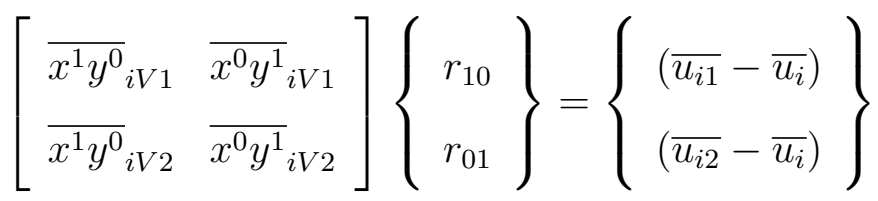

Os termos da matriz são os momentos de área dos volumes de controle utilizados na reconstrução e os termos $\overline{u_{i}}, \overline{u_{i 1}}$ e $\overline{u_{i 2}}$ são os valores das variáveis primitivas nas células principal e vizinhas utilizadas na reconstrução. Os momentos de área dos volumes de controle para uma célula arbitrária em uma reconstrução linear são obtidos de acordo com a Equação 5.29 como 


$$
{\overline{x^{1} y^{0}}}_{i j}=\frac{1}{V_{i}} \int_{S_{i}}\left(x-x_{c}\right)_{V j} d S=\sum_{l=0}^{0} \sum_{k=0}^{1}\left(\begin{array}{l}
0 \\
l
\end{array}\right)\left(\begin{array}{c}
1 \\
k
\end{array}\right)\left(x-x_{c j}\right)^{k}\left(y-y_{c j}\right)^{l} \overline{x^{1-k} y^{0-l}}
$$

e

$$
{\overline{x^{0} y^{1}}}_{i j}=\frac{1}{V_{i}} \int_{S_{i}}\left(y-y_{c}\right)_{V j} d S=\sum_{l=0}^{1} \sum_{k=0}^{0}\left(\begin{array}{l}
1 \\
l
\end{array}\right)\left(\begin{array}{l}
0 \\
k
\end{array}\right)\left(x-x_{c j}\right)^{k}\left(y-y_{c j}\right)^{l} \overline{x^{0-k} y^{1-l}}
$$

Os indicadores de oscilação para uma reconstrução linear podem ser escritos de diferentes maneiras. O indicador proposto por Abgrall Abgrall, 1994 é definido como

$$
O I[p(x, y)]_{A b}=\sum_{|\beta|=1}\left|r \beta_{1} \beta_{2}\right|=\left|r_{10}\right|+\left|r_{01}\right|
$$

e o indicador proposto por Harten e Chakravarthy Harten and Chakravarthy, 1991 é definido como

$$
O I[p(x, y)]_{H C}=\sqrt{\sum_{n=1}^{1} \sum_{|\beta|=n} r_{\beta_{1} \beta_{2}}^{2}}=\sqrt{r_{10}^{2}+r_{01}^{2}},
$$

e, finalmente, o indicador proposto por Jiang e Shu Jiang and Shu, 1996 é definido como

$$
\begin{gathered}
O I[p(x, y)]_{J S}=\left\{\sum_{1 \leq|\beta| \leq 1} \int_{V_{i}} h^{|\beta|-1}\left[\frac{\partial^{|\beta|} p(x, y)}{\partial x^{\beta 1} \partial y^{\beta 2}}\right]^{2} d x d y\right\}^{\frac{1}{2}} \\
\sqrt{\int_{V_{i}} h^{0}\left[\frac{\partial p(x, y)}{\partial x}\right]^{2} d x d y+\int_{V_{i}} h^{0}\left[\frac{\partial p(x, y)}{\partial y}\right]^{2} d x d y}
\end{gathered}
$$




\subsubsection{Reconstrução na Terceira Ordem de Precisão}

Para os esquemas da terceira ordem de precisão, a molécula de cálculo é formada por seis células para a reconstrução polinomial. Novamente, o coeficiente constante do polinômio é o valor médio das propriedades primitivas do volume principal. Assim, é necessário obter-se dois coeficientes dos termos lineares e três coeficientes dos termos quadráticos para o polinômio interpolador, que são obtidos resolvendo-se um sistema linear de cinco equações.

A configuração da molécula de cálculo que apresentou melhores resultados consiste em considerar todas moléculas de cálculo possíveis para uma reconstrução de terceira ordem de precisão, e selecionar aquela que é a mais suave. Um exemplo desse tipo de configuração pode ser vista na Figura 5.2 , onde $V_{1}, V_{2}, \ldots, V_{5}$ representam as células escolhidas para a molécula de cálculo. Embora custosa computacionalmente, apresentou os melhores resultados. Uma possível relaxação nessa abordagem envolve primeiramente selecionar a molécula mais suave dentre as vizinhanças primárias em uma reconstrução linear, e combinar com as vizinhanças secundárias. Isso gera menos moléculas de cálculo e também tem bons resultados.
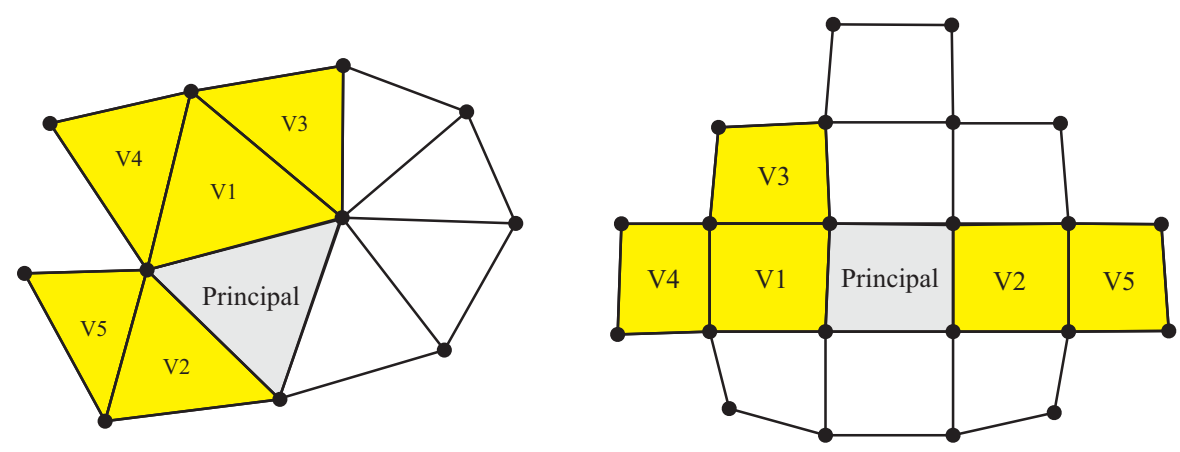

Figura 5.2: Moléculas de cálculos válidas para reconstrução de terceira ordem de precisão.

Referente ao caso quadrático (reconstrução de terceira ordem de precisão), os polinômios são representados por 
$p(x, y)=r_{00}+r_{10}\left(x-x_{c}\right)+r_{01}\left(y-y_{c}\right)+r_{20}\left(x-x_{c}\right)^{2}+r_{11}\left(x-x_{c}\right)\left(y-y_{c}\right)+r_{02}\left(y-y_{c}\right)^{2}$,

onde $r_{00}$ é o termo constante do polinômio, considerado como o valor médio da propriedade primitiva do volume de controle principal, e os termos $r_{10}, r_{01}, r_{20}, r_{11}, r_{02}$ são os coeficientes do polinômio obtidos através do sistema linear dado por

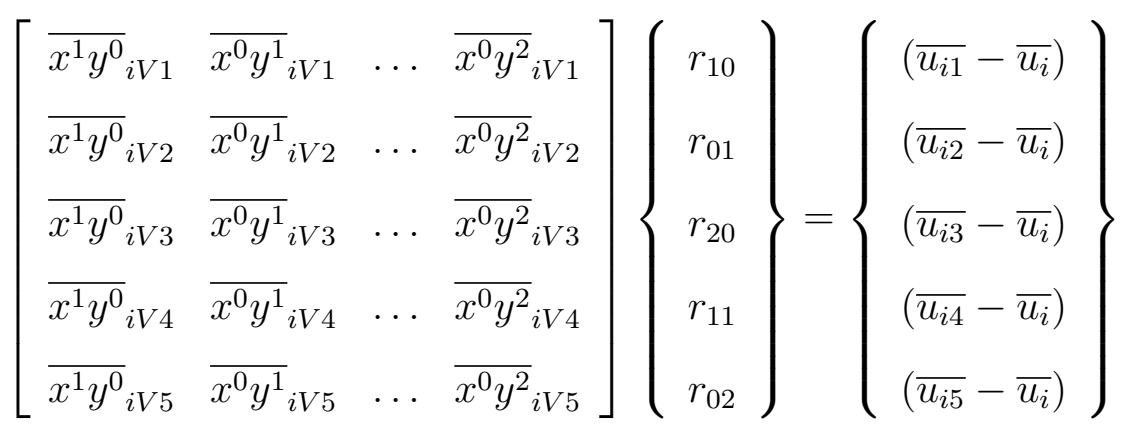

Os termos da matriz são os momentos de área dos volumes de controle utilizados na reconstrução e os termos $\overline{u_{i}}, \overline{u_{i 1}}, \overline{u_{i 2}}, \overline{u_{i 3}}, \overline{u_{i 4}}$ e $\overline{u_{i 5}}$ são os valores das variáveis primitivas nas células principal e vizinhas utilizadas na reconstrução. Os termos de ordem mais alta dos momentos de área dos volumes de controle para uma célula arbitrária em uma reconstrução quadrática são dados por

$$
\begin{gathered}
{\overline{x^{2} y^{0}}}_{i j}=\frac{1}{V_{i}} \int_{S_{i}}\left(x-x_{c}\right)_{V j}^{2} d S=\sum_{l=0}^{0} \sum_{k=0}^{2}\left(\begin{array}{c}
0 \\
l
\end{array}\right)\left(\begin{array}{l}
2 \\
k
\end{array}\right)\left(x-x_{c j}\right)^{k}\left(y-y_{c j}\right)^{l} x^{2-k} y^{0-l} \\
{\overline{x^{1} y^{1}}}_{i j}=\frac{1}{V_{i}} \int_{S_{i}}\left(x-x_{c}\right)\left(y-y_{c}\right)_{V j} d S=\sum_{l=0}^{1} \sum_{k=0}^{1}\left(\begin{array}{l}
1 \\
l
\end{array}\right)\left(\begin{array}{l}
1 \\
k
\end{array}\right)\left(x-x_{c j}\right)^{k}\left(y-y_{c j}\right)^{l} \overline{x^{1-k} y^{1-l}}
\end{gathered}
$$


e

$$
{\overline{x^{0} y^{2}}}_{i j}=\frac{1}{V_{i}} \int_{S_{i}}\left(y-y_{c}\right)_{V j}^{2} d S=\sum_{l=0}^{2} \sum_{k=0}^{0}\left(\begin{array}{c}
2 \\
l
\end{array}\right)\left(\begin{array}{l}
0 \\
k
\end{array}\right)\left(x-x_{c j}\right)^{k}\left(y-y_{c j}\right)^{l} \overline{x^{0-k} y^{2-l}}
$$

Os outros momentos de área são os definidos pelas Equações 5.36 e 5.37 .

Os indicadores de oscilação para uma reconstrução quadrática também podem ser escritos de diferentes maneiras. O indicador proposto por Abgrall Abgrall, 1994 é definido como

$$
O I[p(x, y)]_{A b}=\sum_{|\beta|=2}\left|r \beta_{1} \beta_{2}\right|=\left|r_{20}\right|+\left|r_{11}\right|+\left|r_{02}\right|
$$

e o indicador proposto por Harten e Chakravarthy Harten and Chakravarthy, 1991 definido como

$$
O I[p(x, y)]_{H C}=\sqrt{\sum_{n=1}^{2} \sum_{|\beta|=n} r_{\beta_{1} \beta_{2}}^{2}}=\sqrt{r_{10}^{2}+r_{01}^{2}+r_{20}^{2}+r_{11}^{2}+r_{02}^{2}},
$$

e, finalmente, o indicador proposto por Jiang e Shu Jiang and Shu, 1996 definido como

$$
\begin{gathered}
O I[p(x, y)]_{J S}=\left\{\sum_{1 \leq|\beta| \leq 2} \int_{V_{i}} h^{|\beta|-1}\left[\frac{\partial^{|\beta|} p(x, y)}{\partial x^{\beta 1} \partial y^{\beta 2}}\right]^{2} d x d y\right\}^{\frac{1}{2}}= \\
\left\{\int_{V_{i}} h^{0}\left[\frac{\partial p(x, y)}{\partial x}\right]^{2} d x d y+\int_{V_{i}} h^{0}\left[\frac{\partial p(x, y)}{\partial y}\right]^{2} d x d y+\int_{V_{i}} h^{1}\left[\frac{\partial^{2} p(x, y)}{\partial x^{2}}\right]^{2} d x d y\right. \\
\left.\int_{V_{i}} h^{1}\left[\frac{\partial^{2} p(x, y)}{\partial x \partial y}\right]^{2} d x d y+\int_{V_{i}} h^{1}\left[\frac{\partial^{2} p(x, y)}{\partial y^{2}}\right]^{2} d x d y\right\}^{\frac{1}{2}}
\end{gathered}
$$




\subsubsection{Reconstrução na Quarta Ordem de Precisão}

Para a reconstrução na quarta ordem de precisão, é necessário selecionar dez células para a reconstrução polinomial. Aqui o coeficiente constante do polinômio também é dado pelo valor médio das propriedades primitivas do volume principal. É necessário, então, obter-se dois termos dos coeficientes lineares, três coeficientes dos termos quadráticos e quatro coeficientes dos termos cúbicos para o polinômio interpolador, calculados a partir de um sistema linear de nove equações.

O procedimento para a seleção da molécula de cálculo segue a mesma abordagem apresentada para a terceira ordem de precisão, em particular a abordagem relaxada, pois neste caso, teríamos muitas moléculas de cálculo possíveis para análise e isso se tornaria demasiadamente custoso computacionalmente, uma vez que ao considerar vizinhos terciários, muitas possibilidades surgem.
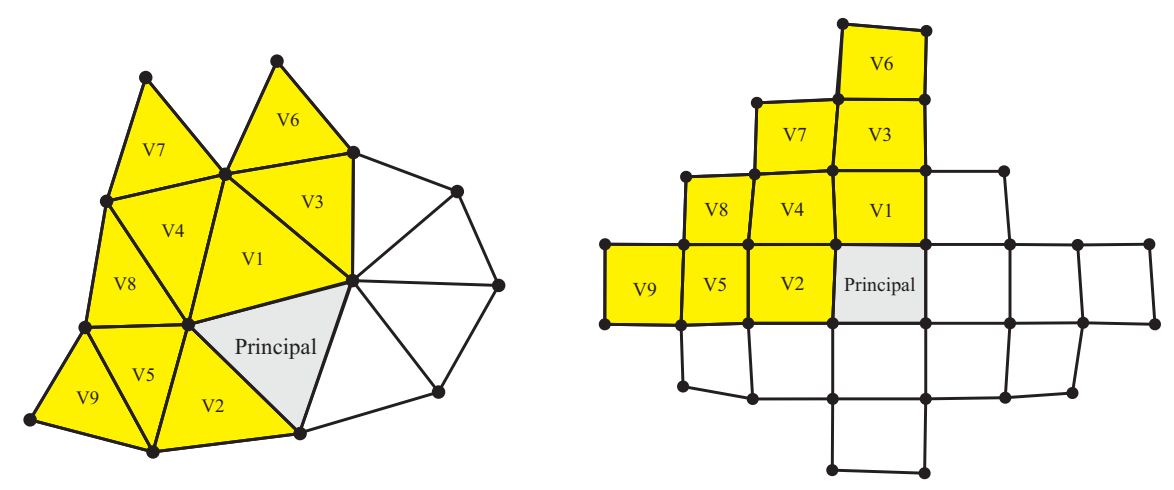

Figura 5.3: Moléculas de cálculos válidas para reconstrução de quarta ordem de precisão.

A Figura 5.3 mostra uma possível configuração de uma molécula de cálculo para esta ordem de precisão, segundo esta abordagem, onde onde $V_{1}, V_{2}, \ldots, V_{9}$ representam as células escolhidas para a molécula de cálculo. Note que são muitas combinações para a formação da molécula. Para elementos triangulares, o número máximo de vizinhos terciários são 6 , gerando 15 possibilidades de moléculas de cálculo para a seleção da mais suave. No caso de elementos quadriláteros, existem no máximo 8 
vizinhos terciários, gerando 70 possibilidades de moléculas de cálculo para a seleção da mais suave. No caso mais comum, o número de volumes de controle para elementos triangulares é de 5 vizinhos terciários, e portanto, 5 possibilidades de formação de moléculas de cálculo para a seleção da mais suave. Considerando-se quadriláteros, um caso típico envolve 6 vizinhos terciários e, assim, 15 possibilidades de moléculas de cálculo para a seleção.

Para o caso cúbico (reconstrução de quarta ordem), os polinômios são representados por

$$
\begin{aligned}
& p(x, y)=r_{00}+r_{10}\left(x-x_{c}\right)+r_{01}\left(y-y_{c}\right)+r_{20}\left(x-x_{c}\right)^{2}+r_{11}\left(x-x_{c}\right)\left(y-y_{c}\right)+r_{02}\left(y-y_{c}\right)^{2} \\
& \quad+r_{30}\left(x-x_{c}\right)^{3}+r_{21}\left(x-x_{c}\right)^{2}\left(y-y_{c}\right)+r_{12}\left(x-x_{c}\right)\left(y-y_{c}\right)^{2}+r_{03}\left(y-y_{c}\right)^{3}, \quad(5.50)
\end{aligned}
$$

onde $r_{00}$ é o termo constante do polinômio, considerado como o valor médio da propriedade primitiva do volume de controle principal, e os termos $r_{10}, r_{01}, r_{20}, r_{11}, r_{02}$, $r_{30}, r_{21}, r_{12}$ e $r_{03}$ são os coeficientes do polinômio obtidos através do sistema linear dado por

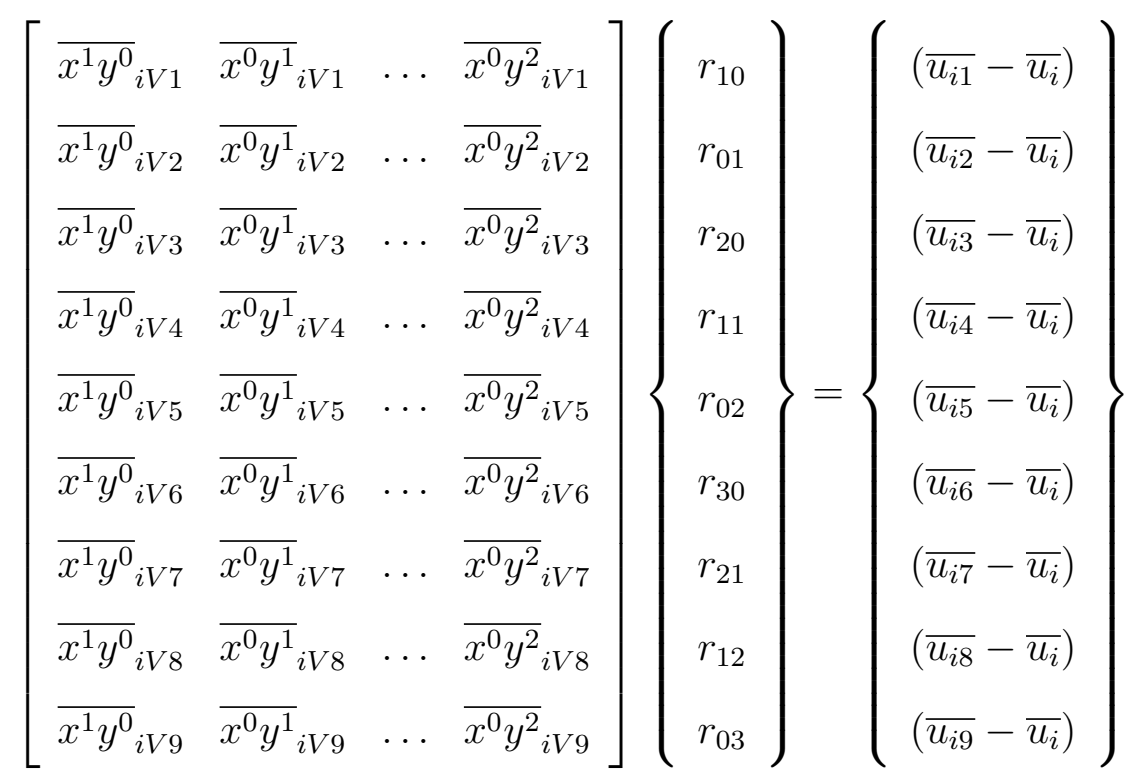

Os termos da matriz são os momentos de área dos volumes de controle utilizados na 
reconstrução e os termos $\overline{u_{i}}, \overline{u_{i 1}}, \overline{u_{i 2}}, \overline{u_{i 3}}, \overline{u_{i 4}}, \overline{u_{i 5}}, \overline{u_{i 6}}, \overline{u_{i 7}}, \overline{u_{i 8}}$ e $\overline{u_{i 9}}$ são os valores médios das variáveis primitivas nas células principal e vizinhas utilizadas na reconstrução. Os termos de ordem mais alta dos momentos de área dos volumes de controle para uma célula arbitrária em uma reconstrução cúbica são dados por

$$
\begin{aligned}
& {\overline{x^{3} y^{0}}}_{i j}=\frac{1}{V_{i}} \int_{S_{i}}\left(x-x_{c}\right)_{V j}^{3} d S=\sum_{l=0}^{0} \sum_{k=0}^{3}\left(\begin{array}{l}
0 \\
l
\end{array}\right)\left(\begin{array}{l}
3 \\
k
\end{array}\right)\left(x-x_{c j}\right)^{k}\left(y-y_{c j}\right)^{l} x^{3-k} y^{0-l} \\
& {\overline{x^{2} y^{1}}}_{i j}=\frac{1}{V_{i}} \int_{S_{i}}\left(x-x_{c}\right)^{2}\left(y-y_{c}\right)_{V j} d S=\sum_{l=0}^{1} \sum_{k=0}^{2}\left(\begin{array}{l}
1 \\
l
\end{array}\right)\left(\begin{array}{l}
2 \\
k
\end{array}\right)\left(x-x_{c j}\right)^{k}\left(y-y_{c j}\right)^{l} \overline{x^{2-k} y^{1-l}} \\
& {\overline{x^{1} y^{2}}}_{i j}=\frac{1}{V_{i}} \int_{S_{i}}\left(x-x_{c}\right)\left(y-y_{c}\right)_{V j}^{2} d S=\sum_{l=0}^{2} \sum_{k=0}^{1}\left(\begin{array}{l}
2 \\
l
\end{array}\right)\left(\begin{array}{l}
1 \\
k
\end{array}\right)\left(x-x_{c j}\right)^{k}\left(y-y_{c j}\right)^{l} \overline{x^{1-k} y^{2-l}}
\end{aligned}
$$

$\mathrm{e}$

$$
{\overline{x^{0} y^{2}}}_{i j}=\frac{1}{V_{i}} \int_{S_{i}}\left(y-y_{c}\right)_{V j}^{3} d S=\sum_{l=0}^{3} \sum_{k=0}^{0}\left(\begin{array}{l}
3 \\
l
\end{array}\right)\left(\begin{array}{l}
0 \\
k
\end{array}\right)\left(x-x_{c j}\right)^{k}\left(y-y_{c j}\right)^{l} x^{0-k} y^{3-l}
$$

Os outros momentos de área são os definidos pelas Equações 5.36, 5.37, 5.43, 5.44 e 5.45 .

Os indicadores de oscilação para a reconstrução cúbica são dados a seguir. O indicador proposto por Abgrall Abgrall, 1994 é definido como

$$
O I[p(x, y)]_{A b}=\sum_{|\beta|=2}\left|r \beta_{1} \beta_{2}\right|=\left|r_{30}\right|+\left|r_{21}\right|+\left|r_{12}\right|+\left|r_{03}\right|,
$$

e o indicador proposto por Harten e Chakravarthy Harten and Chakravarthy, 1991 definido como 
$O I[p(x, y)]_{H C}=\sqrt{\sum_{n=1}^{2} \sum_{|\beta|=n} r_{\beta_{1} \beta_{2}}^{2}}=\sqrt{r_{10}^{2}+r_{01}^{2}+r_{20}^{2}+r_{11}^{2}+r_{02}^{2}+r_{30}^{2}+r_{21}^{2}+r_{12}^{2}+r_{03}^{2}}$,

e, finalmente, o indicador proposto por Jiang e Shu [Jiang and Shu, 1996 definido como

$$
\begin{gathered}
O I[p(x, y)]_{J S}=\left\{\sum_{1 \leq|\beta| \leq 3} \int_{V_{i}} h^{|\beta|-1}\left[\frac{\partial^{|\beta|} p(x, y)}{\partial x^{\beta 1} \partial y^{\beta 2}}\right]^{2} d x d y\right\}^{\frac{1}{2}}= \\
\left\{\int_{V_{i}} h^{0}\left[\frac{\partial p(x, y)}{\partial x}\right]^{2} d x d y+\int_{V_{i}} h^{0}\left[\frac{\partial p(x, y)}{\partial y}\right]^{2} d x d y+\int_{V_{i}} h^{1}\left[\frac{\partial^{2} p(x, y)}{\partial x^{2}}\right]^{2} d x d y\right. \\
+\int_{V_{i}} h^{1}\left[\frac{\partial^{2} p(x, y)}{\partial x \partial y}\right]^{2} d x d y+\int_{V_{i}} h^{1}\left[\frac{\partial^{2} p(x, y)}{\partial y^{2}}\right]^{2} d x d y+\int_{V_{i}} h^{2}\left[\frac{\partial^{3} p(x, y)}{\partial x^{3}}\right]^{2} d x d y \\
\left.+\int_{V_{i}} h^{2}\left[\frac{\partial^{3} p(x, y)}{\partial x^{2} \partial y}\right]^{2} d x d y+\int_{V_{i}} h^{2}\left[\frac{\partial^{3} p(x, y)}{\partial x \partial y^{2}}\right]^{2} d x d y+\int_{V_{i}} h^{2}\left[\frac{\partial^{3} p(x, y)}{\partial y^{3}}\right]^{2} d x d y\right\}^{\frac{1}{2}}
\end{gathered}
$$

\subsection{Acoplamento da Mate Face ao Simulador}

A tarefa de acoplamento da Mate Face ao Simulador é composta pelas seguintes etapas. Primeiro, analisou-se o código do simulador existente, verificando como que a malha computacional é organizada e armazenada internamente. Assim, foi feito um mapeamento de todas matrizes, vetores e variáveis que dizem respeito à malha interna. Além disso, foi analisado todo o código buscando chamadas à malha para identificar quais operações são necessárias para ser disponibilizadas usando-se a Mate Face. A subseção seguinte mostra o resultado desta análise, mostrando quais matrizes serão substituídas pelo acesso à estrutura Mate Face. 


\subsubsection{Caracterização do Código de Simulação}

O código de simulação, aqui chamado de Brud2D, objeto de estudo de tese de Wolf Wolf, 2006, é desenvolvido em grande parte usando a linguagem Fortran 77, e sua estrutura fundamental baseia-se em uma série de arquivos contendo sub-rotinas, atreladas a um arquivo principal, a saber brud2d.f. Este arquivo age como o maestro de todas as subpartes do código, coordenando a execução das diversas rotinas envolvidas, bem como coordenando a entrada/saída de dados do código. A estes arquivos de extensão ".f" adiciona-se um arquivo de declaração de variáveis, comm.h (definições do tipo common block). Neste arquivo encontram-se todas as variáveis empregadas no código declaradas de acordo com seu tipo.

O simulador tem capacidade de tratar escoamentos em números de Mach elevados utilizando métodos numéricos de alta ordem de precisão, com ênfase em particular em esquemas das classes ENO e WENO, com o propósito de capturar descontinuidades presentes em problemas governados por equações diferenciais parciais hiperbólicas.

A implementação usa uma série de matrizes e vetores para alocar vértices, arestas e células. Para representar as consultas usuais, elas são também armazenadas em matrizes com seus valores pré-calculados após o carregamento da malha.

O funcionamento básico do programa consiste em ler os arquivos com as condições iniciais, os dados da malha e a tabela de conectividade, armazenar os nós, volumes da malha e volumes de contorno em matrizes, calcular o resíduo baseado no método de Runge-Kutta de 5 estágios, verificar se convergiu ou não. Se ainda não atingiu os níveis pré-estabelecidos avança um passo na simulação e atualiza a solução aplicando as condições de contorno. Ao atingir o número de iterações previsto ou calcular um resíduo menor que o resíduo mínimo especificado, grava a solução e também um arquivo contendo os valores de $\rho$ (densidade em cada volume de controle da malha), $\rho * u, \rho * v$ e $\rho * w$ (vetores de quantidade de movimento) e o valor da energia em cada volume de controle da malha. 
Assim, os dados da malha ficam armazenados em matrizes e vetores para acesso posterior pelo método numérico. Para exemplificar como o simulador na fase inicial guarda essas informações, será dado como exemplo uma malha simples mostrada na Figura 5.4. Na Figura tem-se cinco vértices, sete arestas e três células triangulares.

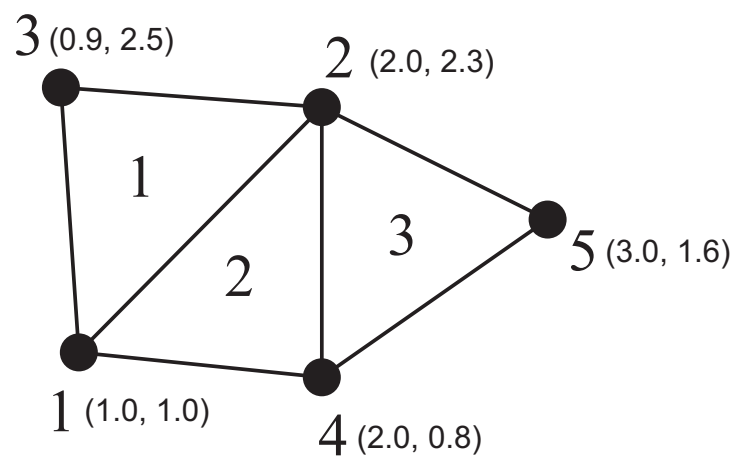

Figura 5.4: Exemplo de malha bidimensional.

Deste modo, o simulador reúne muitas variáveis que armazenam a malha. Como se trata de um código feito em Fortran, temos a convenção dos índices começarem na posição um, diferente de $\mathrm{C}++$, que considera a posição zero inicial de vetores de qualquer dimensão. Esta característica é importante para o acoplamento da Mate Face ao simulador, pois qualquer passagem de parâmetros entre o simulador e a Mate Face deve seguir uma regra de equivalência de memória. Todos estes aspectos serão cobertos em seções futuras.

A seguir serão listadas todas variáveis no código do simulador, referente ao armazenamento dos dados da malha. Serão mostradas suas dimensões e qual informação é alocada. Será utilizada a malha ilustrada na Figura 5.4 como exemplo de caso.

- xynodes(vérticeID, coordenada): Armazena as coordenadas bidimensionais $x_{i}$ e $y_{i}$ cada vértice $i$ da malha. O número de linhas depende do número de vértices na malha, e o número de colunas é fixo em duas dimensões. O identificador do vértice (dimensão vérticeID) é a posição na tabela de coordenadas, a posição um na dimensão Coordenada é associada à coordenada $x$ e a posição 
dois à coordenada $y$ do vértice. No exemplo da Figura 5.4, a matriz xynode é configurada da seguinte maneira:

$$
\begin{aligned}
& \operatorname{xynode}(1,1)=1.0 \\
& \operatorname{xynode}(1,2)=1.0 \\
& \operatorname{xynode}(2,1)=2.0 \\
& \operatorname{xynode}(2,2)=2.3 \\
& \operatorname{xynode}(3,1)=0.9 \\
& \operatorname{xynode}(3,2)=2.5 \\
& \operatorname{xynode}(4,1)=2.0 \\
& \operatorname{xynode}(4,2)=0.8 \\
& \operatorname{xynode}(5,1)=3.0 \\
& \operatorname{xynode}(5,2)=1.6
\end{aligned}
$$

- itable(célulaID, número_vértice): Armazena a tabela de conectividade de cada célula. No caso de malhas triangulares, cada célula (linha na matriz) terá três vértices associados (colunas). O identificador de uma célula é a posição da linha nesta matriz, na dimensão célulaID, e a dimensão número_vértice representa os vértices associados à célula, variando de um a três, no sentido anti-horário na célula. No exemplo mostrado na Figura 5.4, a matriz itable é configurada da seguinte maneira:

$$
\begin{aligned}
& \text { itable }(1,1)=1 \\
& \text { itable }(1,2)=2 \\
& \text { itable }(1,3)=3 \\
& \text { itable }(2,1)=1 \\
& \text { itable }(2,2)=4 \\
& \text { itable }(2,3)=2 \\
& \text { itable }(3,1)=4 \\
& \text { itable }(3,2)=5 \\
& \text { itable }(3,3)=2
\end{aligned}
$$

- iedges(ArestaID, número_info): Armazena as informações sobre as arestas da malha. No caso de malhas triangulares, cada aresta (linha na matriz) terá quatro informações associadas (colunas). O identificador de uma aresta é a posição dela na dimensão ArestaID, e na dimensão número_info serão armazenadas na sequência, os dois vértices da extremidade da aresta, e as duas células 
que compartilham esta aresta, esquerda e direita. Esta tabela é montada após registrar-se todos vértices e células da malha. No caso de arestas da fronteira, registra-se apenas a célula interior, e a oposta registra-se um número negativo. No exemplo mostrado na Figura 5.4, a matriz iedges é configurada da seguinte maneira:

iedges $(1,1)=1 \quad$ iedges $(1,2)=2$ iedges $(1,3)=1$ iedges $(1,4)=2$
iedges $(2,1)=2$ iedges $(2,2)=3$ iedges $(2,3)=1$ iedges $(2,4)=-$
iedges $(3,1)=3$ iedges $(3,2)=1$ iedges $(3,3)=1$ iedges $(3,4)=-$
iedges $(4,1)=1$ iedges $(4,2)=4$ iedges $(4,3)=2$ iedges $(4,4)=-$
iedges $(5,1)=4$ iedges $(5,2)=2$ iedges $(5,3)=2$ iedges $(5,4)=3$
iedges $(6,1)=4$ iedges $(6,2)=5$ iedges $(6,3)=3$ iedges $(6,4)=-$
iedges $(7,1)=5$ iedges $(7,2)=2$ iedges $(7,3)=3$ iedges $(7,4)=-$

- neighbor(célulaID, número_vizinho): Armazena as informações de vizinhança de cada célula. No caso de malhas triangulares, cada célula (linha na matriz) terá três células vizinhas (colunas). O identificador de uma célula é a posição da linha nesta matriz, na dimensão célulaID, e a dimensão número_vizinho representa os identificadores das células vizinhas à célula em questão. Note que esta tabela é montada apenas quando todos vértices, arestas e células tiverem sido registrados nas variáveis apropriadas, e abstrai uma operação de busca a células vizinhas a outra célula. Note que células no bordo da malha não possui três células vizinhas, e no código é atribuído um número negativo para representar isso. No exemplo mostrado na Figura 5.4, a matriz neighbor é configurada da seguinte maneira:

$$
\begin{aligned}
& \text { neighbor }(1,1)=2 \\
& \text { neighbor }(1,2)=- \\
& \text { neighbor }(1,3)=- \\
& \text { neighbor }(2,1)=- \\
& \text { neighbor }(2,2)=3 \\
& \text { neighbor }(2,3)=1 \\
& \text { neighbor }(3,1)=2 \\
& \text { neighbor }(3,2)=- \\
& \text { neighbor }(3,3)=-
\end{aligned}
$$


- ivolnei(VérticeID, célula_vizinha): Armazena as informações de vizinhança de células em torno de um vértice. No caso de malhas triangulares, cada vértice (linha da matriz) terá um número variável de células que compartilham este vértice (colunas). Neste caso, é mantido um vetor chamado itotnei que informa em quantas células um determinado vértice participa. Esta tabela é montada apenas quando todos vértices, arestas e células tiverem sido registrados nas variáveis apropriadas, e abstrai uma operação de busca a células vizinhas a um vértice. Assim, no exemplo mostrado na Figura 5.4, a matriz ivolnei é configurada da seguinte maneira:

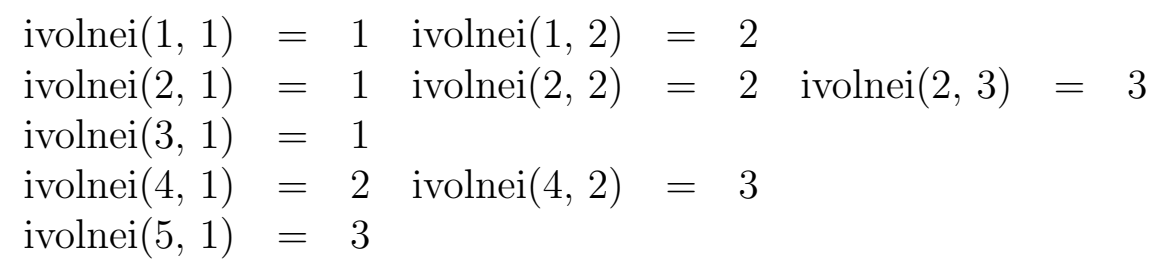

Note que as duas últimas matrizes são consultas aos vizinhos de cada elemento, células e vértices. Então, para completar essas matrizes, são percorridas várias vezes as células e vértices completando as consultas de cada uma na matriz geral. Isso acarreta em um consumo adicional de memória e um pré-processamento maior durante o carregamento da malha.

Uma vez mapeadas todas as matrizes e vetores que armazenam as informações da malha, verificou-se em todo o código do simulador ocorrências de acesso a essas variáveis. Além disso, baseado nessas variáveis, diversas informações são calculadas, como centroides, áreas, raios internos e características das células da malha, para uso nos métodos numéricos.

\subsubsection{Modificação na Mate Face}

Durante a verificação da utilização das variáveis, notou-se que o código do simulador frequentemente utiliza consultas às células vizinhas de cada célula. Mas, a Mate 
Face não possui referência entre aresta e célula de modo explícito, então foi feita uma modificação na estrutura de modo a incluir esta referência. Para cada aresta armazenada, foram incluídas as referências às células vizinhas de cada aresta, esquerda e direita, de modo que as arestas de bordo possuam apenas a referência da célula interna, ou seja, a da direita, conforme o padrão da regra da mão direita adotada na estrutura. Assim, a Figura 5.5 mostra o novo esquema de classes da Mate Face, com a modificação em suas arestas.

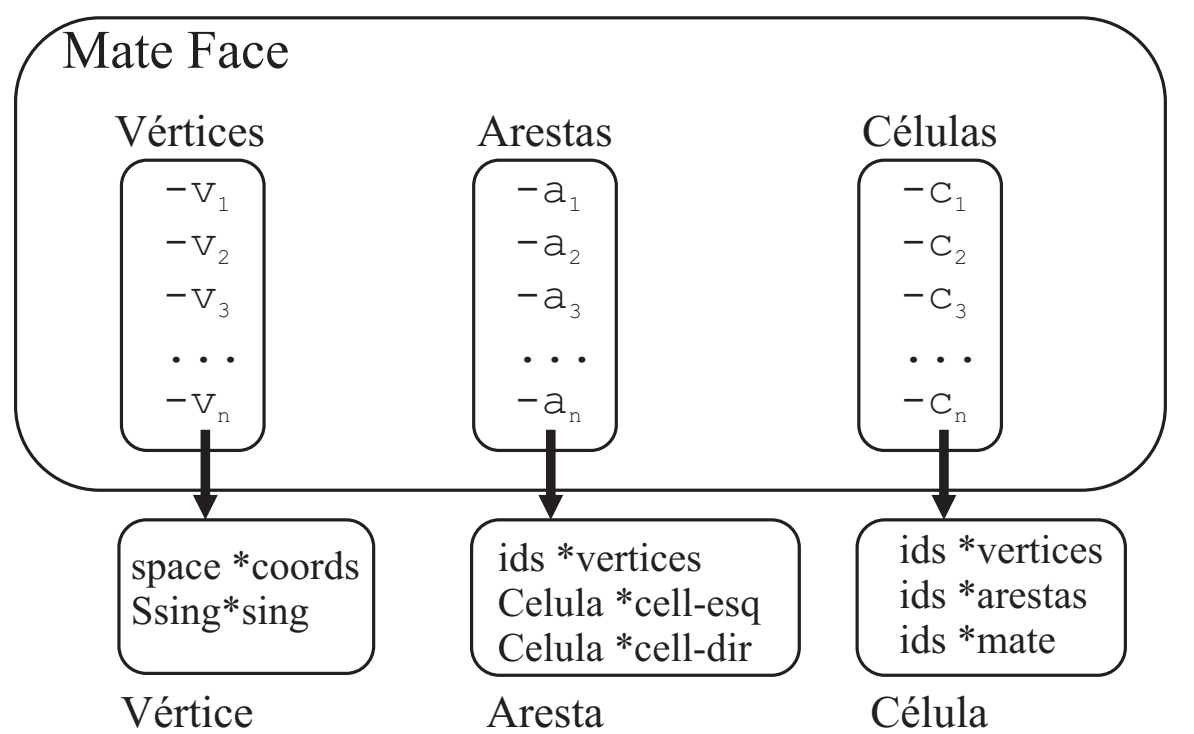

Figura 5.5: Extensão das classes na Mate Face.

De acordo com a Figura 5.5, a Mate Face armazena explicitamente todos os vértices, arestas e células da malha. Para cada vértice, tem-se suas coordenadas e as informações sobre singularidade explicadas na Seção 4.4 ao longo do Capítulo 4. Cada célula possui a lista dos vértices que a compõem, além das arestas que a forma. A relação de vizinhança da célula está armazenada no vetor Mate, que conforme explicado na Seção 4.4 do Capítulo 4 , informa quais células são vizinhas à célula atual de acordo com os vértices da célula em questão. Com esse mesmo vetor Mate, podese explicitamente realizar consultas do tipo estrela de um vértice e células vizinhas de uma célula. Mas, por facilidade de uso, é possível utilizar os iteradores definidos 
especificamente para estes casos, não precisando analisar o vetor Mate, uma vez que o iterador abstrai a consulta e informa o resultado mais facilmente. Por fim, a modificação realizada foi na estrutura das arestas na Mate Face, cada aresta armazena os vértices da extremidade dela, mas foi incluído também a informação de vizinhança das células da aresta. Isto não trouxe nenhum custo adicional, uma vez que a informação estava disponível durante a construção das arestas.

O próximo passo foi a integração da Mate Face no simulador. Para isso, foi necessário estabelecer regras de conversão entre programas Fortran e C++, uma vez que manipulam a memória de maneira diferente.

\subsubsection{Integração dos Códigos}

Utilizar um código feito em $\mathrm{C}++$ em Fortran não é uma tarefa simples. Em primeiro lugar, $\mathrm{C}++$ é uma linguagem orientada a objetos enquanto Fortran é estruturada. Além disso, vetores de qualquer dimensão em Fortran podem ter índices negativos, mas não possuem a posição zero, já em $\mathrm{C}++$ só pode haver posições positivas começando em zero. Isso causou uma adaptação no acoplamento da Mate Face ao simulador. Qualquer referência das variáveis internas no simulador que se associe a alguma célula da malha necessitou de uma transformação das posições.

O desafio de dispor um código com classes em $\mathrm{C}++$ para o Fortran utilizar foi solucionado criando-se uma camada intermediária entre o código simulador e a estrutura Mate Face. Esta camada intermediária possui funções que acessam os métodos da Mate Face.

Um outro problema enfrentado é que toda passagem de parâmetro em Fortran é por default por referência, podendo ser controlada internamente na rotina. Quando acoplamos um código em $\mathrm{C}++$ com o Fortran, todas chamadas de funções são por referência, forçando uma implementação inteiramente usando ponteiros em $\mathrm{C}++$. Além disso, as duas linguagens organizam matrizes de modo diferente, uma sequenciando em memória linhas seguidas de linhas, e a outra sequenciando as colunas, ou seja, 
uma matriz em Fortran é a transposta em $\mathrm{C}++$ quando for feito um alinhamento em memória ou cópia bit a bit.

A camada intermediária que foi construída para dispor funções que acessam os métodos da Mate Face foi chamada de Interface. Ela realmente funciona como uma interface entre os dois códigos e foi construída em $\mathrm{C}++$ como um conjunto de funções em um bloco de exportação (export). Todas essas funções da interface possuem seus parâmetros como ponteiros, para serem compatíveis para serem chamados pelo código em Fortran.

Para integrar estes dois códigos, utilizou-se os compiladores da GNU, tanto para Fortran (f77) quanto para $\mathrm{C}++(\mathrm{g}++)$, pois são compatíveis entre si. Mas para a compilação ser realizada com sucesso, todas versões de codificação devem ser a mesma em cada linguagem. Isso não ocorria com o código do simulador. Uma porção do código estava feita em Fortran 90 enquanto que sua grande maioria estava codificada em Fortran 77. Então, foi feita uma reescrita do código que estava em Fortran 90 para a versão 77 de modo a compatibilizar os compiladores. Como o código do simulador e a estrutura de dados foram desenvolvidos utilizando diferentes linguagens de programação, uma etapa de integração do simulador (Fortran) e a Mate Face $(\mathrm{C}++)$ foi realizada em tempo de compilação. Primeiro compila-se a interface junto com a Mate Face gerando uma biblioteca (arquivo objeto de extensão .o), que possui todos os procedimentos dentro do bloco de exportação com suas assinaturas convertidas. Em seguida, compilou-se o código do simulador acrescentando-se a biblioteca gerada no passo anterior na sua lista de lincagem do programa principal.

Portanto, a troca de informações entre o simulador e a Mate Face é realizada por uma interface. A maneira como esta interface atua pode ser vista na Figura 5.6. codificada em $\mathrm{C}++$, composta por um conjunto de procedimentos devidamente configurados para serem acessados por um programa Fortran. A interface traduz e controla todas as chamadas aos métodos implementados na estrutura de dados feitas pelo simulador. Toda troca de informação entre os módulos é feita em memória 
principal e em tempo de execução de forma automática pela interface.

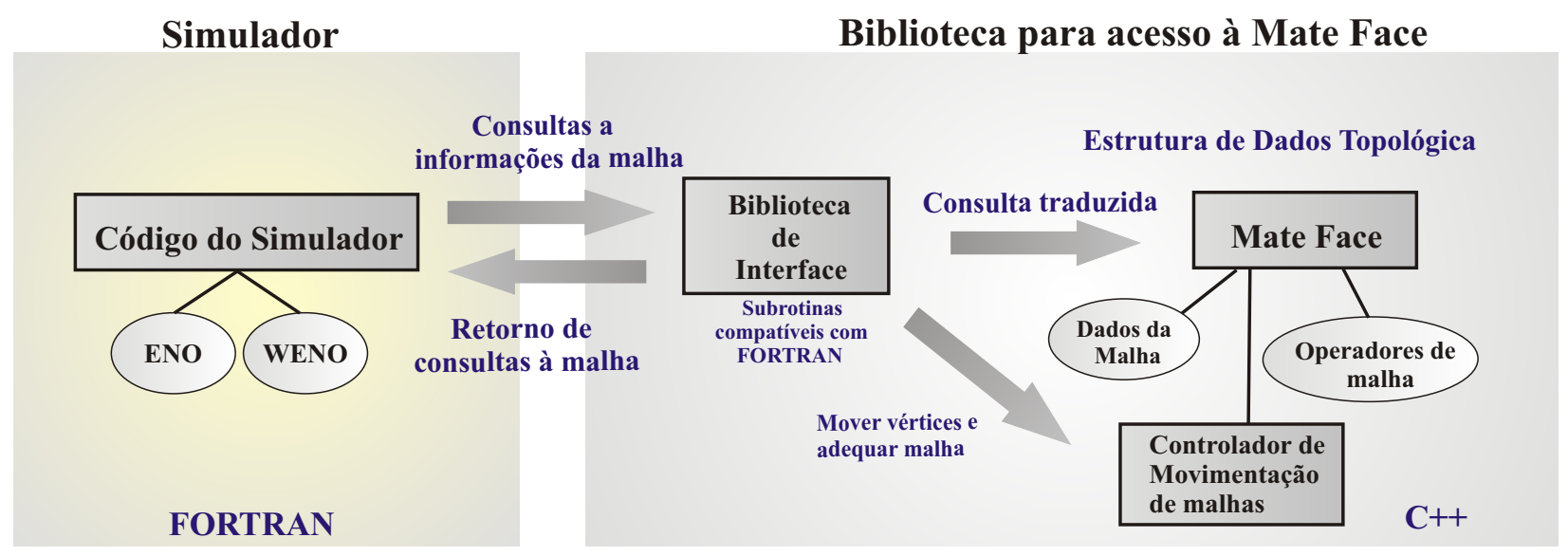

Figura 5.6: Esquema de integração dos códigos Fortran 77 (Brud2D) e C++ (Mate Face).

A interface é definida por um conjunto de procedimentos que são acessados diretamente do simulador. Todas as chamadas de procedimentos na interface é feita diretamente em memória principal, onde uma lista de parâmetros de cada procedimento compartilha uma região da memória (ponteiro em $\mathrm{C}++$ ). É dessa maneira que o simulador desenvolvido em Fortran tem acesso às informações acessadas na interface. Esta, por sua vez, transforma toda funcionalidade da estrutura de dados Mate Face em procedimentos. E por compatibilidade, todos procedimentos possuem suas listas de parâmetros definidas como ponteiros aos tipos de dados transmitidos.

Um aspecto computacional muito importante foi a definição da equivalência dos tipos de dados entre o código do simulador e a interface que acessa a Mate Face. Além do alinhamento de memória ser diferente, como já explicado o caso das matrizes serem transpostas, o tipo de dado precisa ser compatível caso contrário a informação passada será incorreta. Além disso, vários cuidados devem ser tomados para que o acoplamento seja compatível.

A primeira regra é a equivalência dos tipos de dados. Em Fortran e em $\mathrm{C}++$, os tipos definidos de dados utilizam diferentes bytes na alocação em memória principal. Então, quando um procedimento escrito e compilado em $\mathrm{C}++$ é exportado para ser 


\begin{tabular}{|l|l|}
\hline C++ & Fortran $\mathbf{7 7}$ \\
\hline unsigned char & byte \\
short int & integer*2 \\
long int e int & integer \\
int matriz[3][2] & integer matriz $(2,3)$ \\
long int ou int & logical \\
bool & logical*1 \\
float & real \\
double & real*8 \\
long double & real*16 \\
\#define & parameter \\
\hline
\end{tabular}

Tabela 5.1: Equivalência de tipos de dados entre Fortran e $\mathrm{C}++$

utilizado em Fortran, deve haver uma equivalência dos tipos de dados em todos os seus parâmetros. Essa equivalência pode ser visualizada na Tabela 5.1 .

Deste modo, foi utilizada a Tabela 5.1 para definir os tipos de dados que a interface e o simulador manipulam em memória, para não haver perda de informação.

Os procedimentos criados na interface seguem um padrão para uma compilação específica para lincagem posterior. Para serem utilizados no Fortran, os procedimentos na interface em $\mathrm{C}++$ devem estar dentro de um escopo de extern "C". Um requerimento adicional é que todos os procedimentos na interface retornem void.

$\mathrm{Na}$ interface, os nomes dos procedimentos devem finalizar com um caractere adicional "_" ao final do nome do procedimento na interface. Ao ser chamado no código Fortran, este procedimento é chamado sem este caracter adicional. Por exemplo, considere um procedimento chamado initialize, que inicializa a Mate Face alocando memória para a estrutura. $\mathrm{Na}$ interface, o método estaria declarado como "void initialize_(void);", já no programa do simulador em Fortran a chamada seria "call initialize()", ou seja, sem o caractere final.

Além de incluir o caractere extra no final de cada nome de procedimento, todos os parâmetros nos procedimentos na interface devem ser passados como ponteiros, pois todos parâmetros em Fortran são passados por referência. Por exemplo, para recuperar o centroide de uma célula, em Fortran chamaríamos o método por "call getcen- 


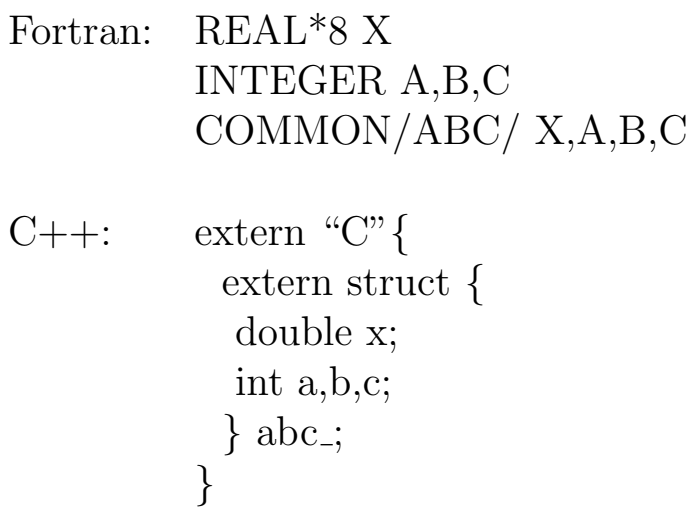

Tabela 5.2: Equivalência de blocos de memória entre Fortran e $\mathrm{C}++$

troid(cellid, centx, centy)", onde cellid é o identificador da célula e centx, centy, são as variáveis onde estarão armazenadas os valores das coordenadas do centroide daquela célula (parâmetro de saída). A implementação dessa chamada na interface é "void getcentroid(int *cellid, double *centx, double *centy);", ou seja todos os parâmetros são ponteiros para as áreas de memória compartilhada ao programa Fortran. Deste modo, os procedimentos na interface vão decidir quais parâmetros são de entrada, e quais são os de saída.

A passagem de strings (coleção de caracteres) são diferentes entre os dois compiladores. Uma chamada do tipo "call setfile(string_a, string_b)" em Fortran deve ser tratada em $\mathrm{C}++$ por "setfile(char *string_a, leng_a, char *string_b, leng_b);", ou seja, o tamanho das strings deve ser passado após cada string no parâmetro do procedimento.

Apesar de não ser possível referenciar objetos instanciados de classes em $\mathrm{C}++\mathrm{em}$ Fortran, é possível compartilhar blocos de dados em memória, quando necessário. As structs em $\mathrm{C}++$ são equivalentes aos common blocks em Fortran. Mas para isso devese definir o bloco em $\mathrm{C}++$ com o mesmo nome do definido em Fortran, adicionar o caractere ao final dele e externalizá-lo. Por exemplo, a Tabela 5.2 mostra um exemplo de common block em Fortran, e sua equivalência em $\mathrm{C}++$. 


\subsubsection{A Biblioteca Desenvolvida}

A biblioteca de interface para a Mate Face foi construída a partir das funcionalidades exigidas pelo código do simulador e também as funcionalidades que são comuns a aplicações que manipulam malhas computacionais.

Além de procedimentos que recuperam as propriedades básicas da malha, foram criados iteradores na interface, organizados em conjuntos de procedimentos para cada tipo de consulta.

Um iterador é uma maneira de acessar de maneira sequencial um conjunto de elementos sem saber a sua estrutura de representação interna. Em outras linguagens também é conhecido como cursor. A intenção é isolar a estrutura interna de representação da coleção dos elementos e poder mudá-la sem afetar quem a utilize. Assim, a ideia é retirar do usuário a responsabilidade de percorrer a coleção na ordem correta em que se deve e atribuir esta responsabilidade em um objeto chamado iterador. Por exemplo, para navegar em uma estrutura de dados do tipo árvore, na forma pré-ordem (ou seja seguir a sequência: nó da subárvore esquerda, central e nó da subárvore direita), o usuário que utiliza o iterador não precisa saber a ordem para percorrer os nós, ele apenas acessa o iterador e parte para o próximo item da coleção. Por exem-

plo, para um iterador de nome cursor, usualmente o trecho ${ }^{*}$ cursor ou cursor.get() retorna o elemento atual da coleção e o trecho cursor ++ ou cursor.next() avança para o próximo.

Assim, os iteradores na interface variam desde o acesso sequencial de vértices, arestas ou células para iteradores mais sofisticados como navegação da estrela de vértices ou arestas. A interface também provê operações como cálculo de área de células, generalizando tal operação no simulador quando no uso de malhas híbridas, uma vez que a interface trata de forma automática a forma do elemento. Futuras funcionalidades para esta interface envolvem um conjunto de procedimentos que definem a movimentação da malha a partir de dados do simulador. 
Para definir a interface, um conjunto de procedimentos foi elaborado para suprir a necessidade dos métodos numéricos no código do simulador. Aqui serão mostrados todos os procedimentos criados e qual sua funcionalidade. Após a definição destes procedimentos criados na interface, serão mostrados alguns exemplos de utilização feita no código do simulador, de modo a compararmos como os dados eram lidos antes, e como são lidos após a reescrita acoplada com a interface construída.

- void initialize_(void): Este procedimento inicializa a estrutura Mate Face, alocando-se memória e inicializando-se as suas variáveis internas. Ele deve ser chamado antes do carregamento da malha. Além disso, todos os iteradores utilizados são criados e suas variáveis de controle internas são zeradas.

- void destroy_(void): Este procedimento desaloca todos os iteradores, e destrói a malha indexada na Mate Face, ou seja, toda a estrutura interna da Mate Face é desalocada da memória.

- void readmesh_(char $*_{\text {filename, int }}^{*}$ strlen $)$ : Este procedimento lê a malha do arquivo de entrada filename e cria todos os elementos necessários na estrutura para representar os vértices, arestas e as células. Foi implementado um leitor de malhas que lê diferentes tipos formatos de malhas (ex: vtk, ply, wrl) para uma melhor abrangência de aplicações, como parte da biblioteca.

- void readforts_(void): Foi necessário implementar outro procedimento para leitura de malhas, pois o código do simulador existente utiliza um formato próprio de estruturação das informações da malha em arquivos. Isso foi realizado para manter a compatibilidade no programa simulador. O formato próprio do simulador para entrada de dados de malhas é dividido em três arquivos. Os arquivos tem o nome de "fort" e tem extensão 1, 2 e 3, cada arquivo contendo diferentes informações, ou seja, um para os vértices, outro para as células, e o terceiro para as arestas. Apesar das informações das arestas serem encontradas 
nas células, o simulador conta com uma numeração negativa para os elementos no bordo da malha, para representar os "volumes fantasmas", os quais são utilizados pelos métodos numéricos. A numeração dos volumes fantasmas é contida no terceiro arquivo de dados. Um exemplo de criação da malha na Mate Face é mostrada na Figura 5.7. Na figura temos um pseudo-código mostrando alguns métodos necessários para criar os vértices e as células da estrutura. Além disso, pode-se notar que as arestas são construídas mediante um método próprio contido na interface. Isso se deve ao fato de que além da ordem das arestas ser importante, a numeração negativa dos volumes fantasmas neste contexto específico é importante para a simulação numérica. Além disso, como foi estendida a estrutura para incluir as referências das células vizinhas de cada aresta, esquerda e direita, isso também é realizado neste método específico CreateEdges da biblioteca criada.

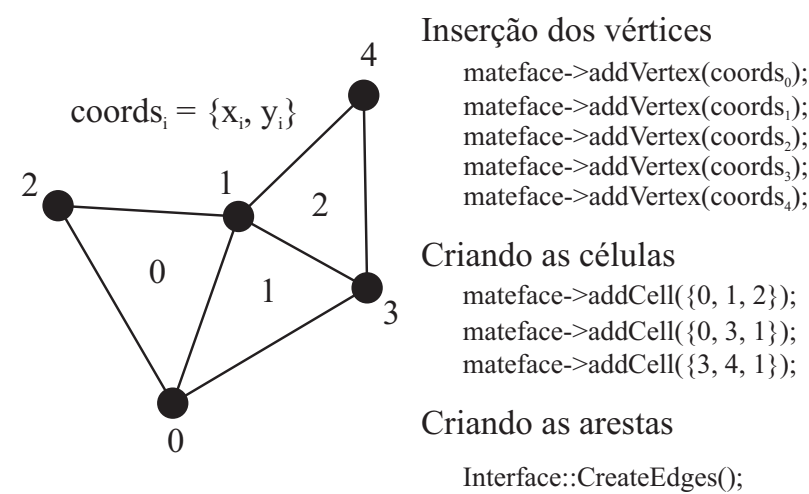

Figura 5.7: Exemplo de criação da malha na Mate Face via interface.

- void getnumberofvertices_(int $*^{*}$ nvertex): Este procedimento retorna o número de vértices indexados na estrutura. Embora existam iteradores para percorrer todos os vértices sequencialmente, também é possível usar um contador e percorrer manualmente, uma vez sabido o número total de vértices. O resultado desta consulta é armazenado no parâmetro nedges, por referência. 
- void getnumberofedges_(int *nedges): Este procedimento retorna o número de arestas indexadas na estrutura. Novamente, existem iteradores para estas consultas, mas também é possível uma consulta manual ou específica a uma determinada aresta. O resultado desta consulta é armazenado no parâmetro nedges, por referência.

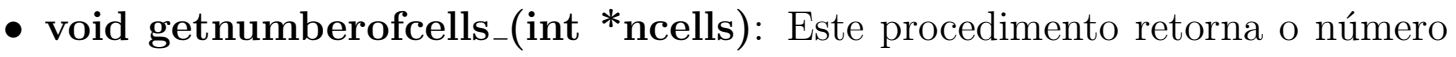
de células indexadas na estrutura. Também existem iteradores para este tipo de consulta, porém um percurso manual é permitido, uma vez que existem outros métodos na interface para acessar propriedades específicas de células. O resultado desta consulta é armazenado no parâmetro ncells, por referência.

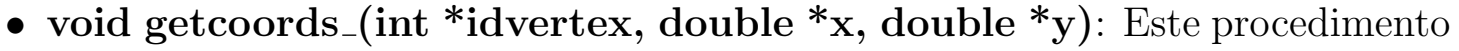
retorna as coordenadas de um dado vértice na estrutura. O parâmetro de entrada idvertex é o identificador do vértice que deve ser menor que o número total de vértices indexados. O resultado é armazenado nos dois parâmetros de saída $x$ e $y$, por referência.

- void getnvolnd_(int $*_{\text {idcell, int }}^{*}$ nvolnd): Este procedimento retorna o número de vértices que compõem uma célula. O parâmetro de entrada idcell identifica qual a célula de consulta, e o resultado é armazenado no parâmetro de saída nvolnd. Como a Mate Face pode indexar malhas mistas, note que esse número pode mudar dependendo do tipo de elemento indexado, por exemplo triângulos ou quadriláteros.

- void getarea_(int * cellid, double *areacell): Um procedimento muito utilizado métodos baseados em volumes finitos, ele retorna a área de uma célula cellid, armazenando o resultado no parâmetro de saída areacell. Como este procedimento pode ser chamado frequentemente, ele é calculado apenas uma vez por célula e armazenado internamente associado à sua célula. O cálculo só é 
forçado quando houver a indicação de movimentação na malha. No caso de malhas triangulares, o cálculo usado é o definido pelo teorema de Herons, como mostrado no exemplo na Figura 5.8 .
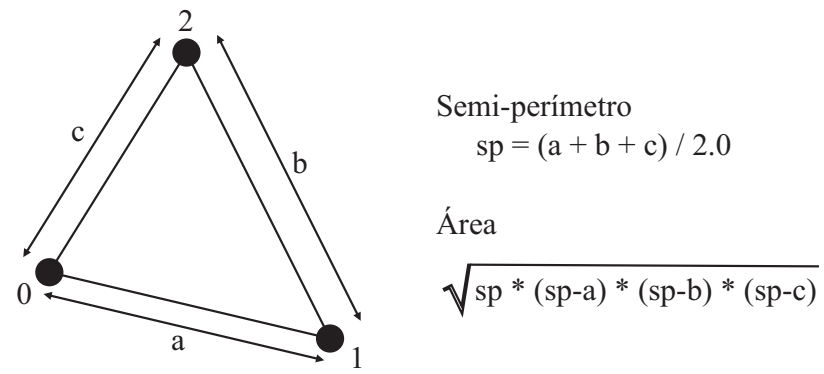

Figura 5.8: Exemplo do cálculo de área de uma célula triangular.

- void getcentroid_(int $*$ cellid, double ${ }^{*} \operatorname{centx}$, double ${ }^{*}$ centy): Um procedimento também muito utilizado nos métodos numéricos estudados neste trabalho, ele recupera as coordenadas do centroide de uma célula de consulta identificada por cellid, armazenando o resultado nos parâmetros de saída centx e centy, por referência. O centroide é calculado pela média das coordenadas da célula de busca, como pode ser visto no exemplo mostrado na Figura 5.9. Também é calculado uma vez por célula para evitar cálculos desnecessários.

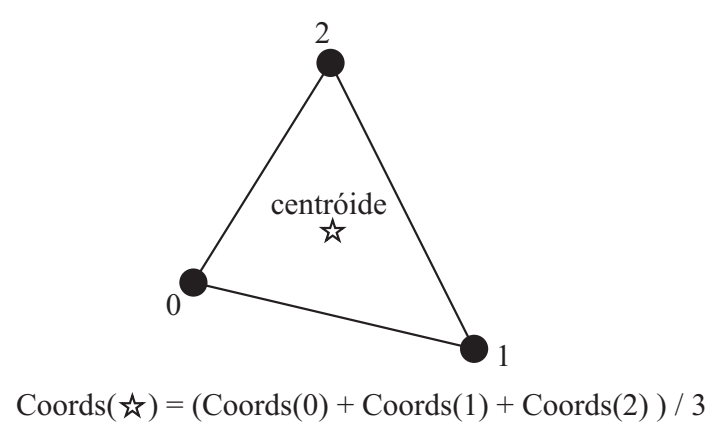

Figura 5.9: Exemplo de cálculo do centroide de uma célula.

- getcharacteristiclength_(int $*^{*}$ cellid, double ${ }^{*}$ clenght): Este procedimento calcula o comprimento da característica de uma célula identificada pelo parâmetro de entrada cellid, ele é baseado no raio do círculo inscrito na célula, e 
seu cálculo usa dados como a área da célula e o seu semi-perímetro. O resultado é armazenado no parâmetro de saída clenght. Ele é calculado uma vez por célula para evitar cálculos desnecessários.

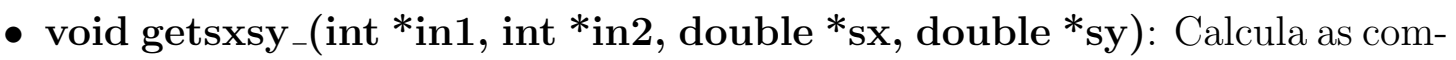
ponentes do cosseno do ângulo da aresta especificada, para formar o chamado direction cosine, termo presente na geometria analítica. Este cálculo é útil para calcular o vetor base ortonormal da aresta, utilizado nos métodos numéricos. Os parâmetros de entrada in1 e in2 são os identificadores dos vértices na extremidade da aresta que se quer o cálculo, e o resultado é armazenado nos dois parâmetros de saída $s x$ e $s y$.

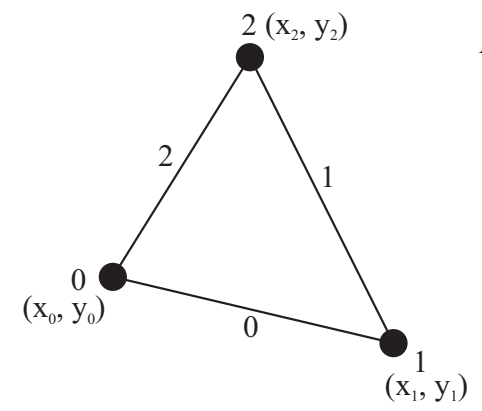

Aresta 0:

Comprimento:

$$
C=\sqrt{\left(y_{1}-y_{0}\right)^{2}+\left(x_{1}-x_{0}\right)^{2}}
$$

Direction Cosine:

$\mathrm{Sx}=\left(\mathrm{x}_{1}-\mathrm{x}_{0}\right) / \mathrm{C}$

$\mathrm{Sy}=\left(\mathrm{y}_{1}-\mathrm{y}_{0}\right) / \mathrm{C}$

Figura 5.10: Exemplo de cálculo do direction cosine.

- void getedgeids_(int $*_{\text {ide, int }} *_{\text {ida, }}$ int $*$ idb): Este procedimento recupera os identificadores dos vértices na extremidade da aresta indicada pelo parâmetro de entrada ide, como mostrado no exemplo na Figura 5.11. O resultado é armazenado nos parâmetros de saída $i d a$ e $i d b$. O código do simulador faz uso deste método para recuperar os vértices associados à aresta de cálculo atual e algumas vezes para calcular as propriedades na vizinhança destes vértices.

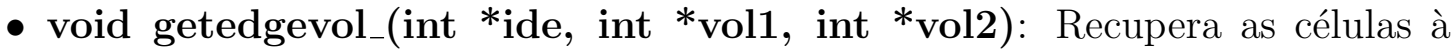
esquerda e à direta da aresta de busca identificada pelo parâmetro de entrada $i d e$, de acordo com o exemplo mostrado na Figura 5.12, O resultado é armazenado nos parâmetros de saída vol1 (célula à esquerda) e vol2 (célula à direita). 


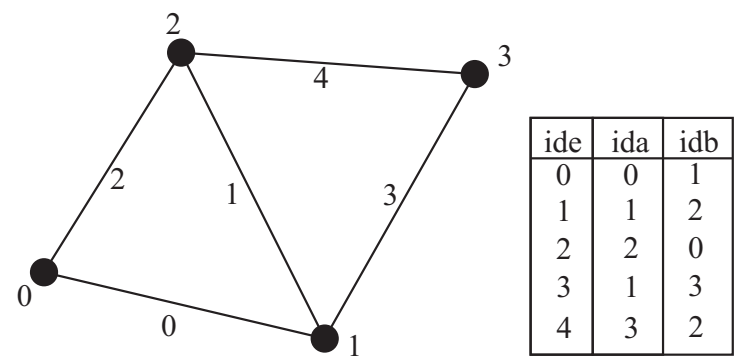

Figura 5.11: Exemplo de uso do procedimento getedgeids.

Essas informações estão diretamente armazenadas em cada objeto aresta na Mate Face, conforme foi citado anteriormente, mediante uma alteração feita na estrutura de dados.

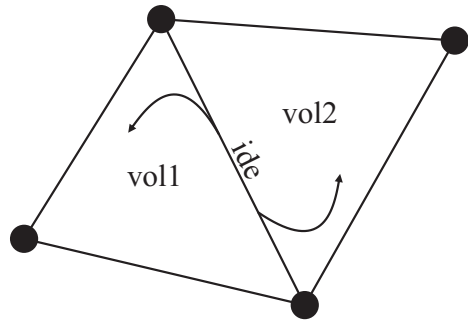

Figura 5.12: Exemplo de uso do procedimento getedgevol.

- void neighbour_(int $*_{\text {idc, }}$ int $*^{*}$ neigidx, int $*^{*}$ neig): Este procedimento recupera os vizinhos de uma célula. Esta consulta percorre a vizinhança de uma célula retornando as células ao redor da célula de busca identificada pelo parâmetro de entrada $i d c$. No caso de malhas triangulares, cada célula terá três vizinhos, e no caso de malhas quadrangulares, quatro. Tanto o vetor de vizinhança Mate quanto a informação armazenada nas arestas podem ser usados para compor a resposta desta consulta. O parâmetro de entrada neigidx informa qual vizinho quer-se consultar, assumindo os valores zero, um e dois, no caso de triângulos. O resultado da consulta é armazenado no parâmetro de saída neig. Um exemplo de vizinhança que é recuperada neste procedimento é mostrado na Figura 5.13, quando se pede um vizinho que não existe, é retornado um número negativo. Note que essa consulta é uma maneira manual de consultar os vizinhos 
de uma dada célula, sem utilizar um iterador.

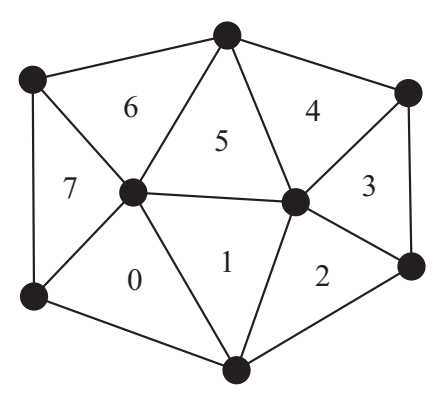

Célula: vizinhos

Célula 0: 17

Célula 1: 00225

Célula 2: 3 1

Célula 3: 442

Célula 4: 5 | 3

Célula 5: 6 6 114

Célula 6: 75

Célula 7: 60

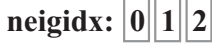

Figura 5.13: Exemplo vizinhança em torno de uma célula.

- void getcellvertid_(int $*_{\text {idcel, int }}^{*}$ vertidx, int $*^{*}$ vertid): Este procedimento retorna a informação similar à tabela itable existente no código do simulador, ou seja, a informação dos vértices que compõem uma célula de busca identificada pelo parâmetro de entrada idcel. Um exemplo desta informação é mostrada na Figura 5.14. O parâmetro vertidx é qual célula vizinha se quer recuperar, por exemplo, um triângulo tem três vizinhos. Caso não haja vizinho naquele índice, é retornado um número negativo, normalmente evidenciando que a célula de busca está no bordo da malha.

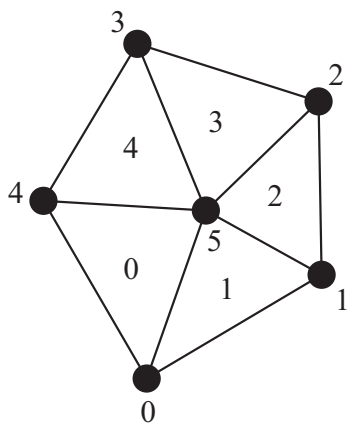

Célula: Vértices

Célula 0: $\quad 0 \quad 5 \quad 4$

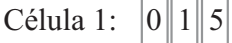

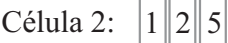

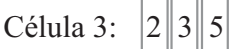

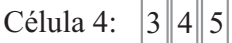

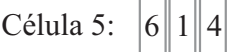

vertidx: \begin{tabular}{l|l|l|l} 
& $\mathbf{1}$ & $\mathbf{2}$ \\
\hline
\end{tabular}

Figura 5.14: Exemplo de composição das células.

- void testdido_(int $*_{\text {idcel, double }}^{*} \mathrm{x}$, double* ${ }^{*}$, int $*_{\text {where, int }}^{*}$ edge

): Este procedimento realiza uma pesquisa sobre a localização de um ponto 
com coordenadas $x$ e $y$ sobre uma célula identificada por $i d c e l$. Um exemplo de comportamento desta consulta pode ser visualizada na Figura 5.15. O resultado da pesquisa é armazenada nos parâmetros de saída where e edge, onde o valor do parâmetro where indica onde o ponto está localizado: 0 (dentro da célula); 1 (fora da célula); 2 (sobre uma aresta da célula, neste caso o parâmetro edge indicará qual aresta); 3 (sobre um dos vértices da célula, nesse caso o parâmetro edge indicará qual vértice).

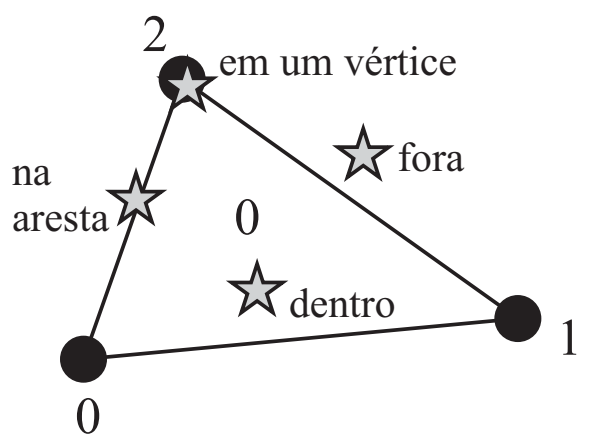

Figura 5.15: Exemplo de uma consulta sobre a localização de um ponto na célula.

Foram construídos procedimentos que controlam os iteradores mais comuns para serem utilizados no código do simulador. Os iteradores podem ser divididos entre consultas básicas e elaboradas. As consultas básicas são iteradores que percorrem os vértices, arestas ou células sequencialmente, dando acesso às informações de cada um deles. Os iteradores que abstraem consultas elaboradas percorrem sequencialmente os elementos vizinhos a outros elementos, por exemplo as células vizinhas a uma célula ou a células na estrela de um vértice.

A seguir serão listados os procedimentos que controlam essas consultas.

- Iterador de Vértices: O iterador de vértices acessa sequencialmente e sem repetição todos os vértices da malha. Durante a consulta, pode-se acessar as coordenadas do vértice ou seu número identificador. A seguir os procedimentos que controlam o acesso à sequência. 
- void initializevertexiterator_(int *init): Este procedimento inicializa o iterador informando qual o vértice que deseja-se iniciar a varredura.

- void currentvertex_(double ${ }^{*} x$, double $\left.{ }^{*} y\right)$ : Este procedimento recupera as coordenadas do vértice atual da pesquisa armazenando-as nos parâmetros de saída $x$ e $y$.

- void currentvertexid_(int ${ }^{*}$ idvert): Este procedimento recupera o número identificador do vértice atual da pesquisa armazenando-o no parâmetro de saída idvert.

- void itsvertexnext_(void): Este procedimento avança para o próximo vértice da lista.

- void itsvertexfinish_(int *finish): Este procedimento consulta se o iterador chegou ao fim da lista de vértices, onde o resultado é armazenado no parâmetro finish.

- Iterador de Células: O iterador de células acessa sequencialmente e sem repetição todas as células da malha. Durante a consulta, pode-se acessar os identificadores dos vértices que compõe a célula assim como o identificador da célula atual na sequência. A seguir os procedimentos que controlam o acesso à sequência.

- void initializecelliterator_(int *init): Este procedimento inicializa o iterador informando qual a célula que deseja-se iniciar a varredura.

- void currentcellidvertex_(int *vertnum, int *idvert): Este procedimento recupera os identificadores dos vértices que compõem a célula atual na busca. O parâmetro de entrada vertnum indica qual vértice quer-se recuperar, e no parâmetro de saída idvert será armazenado o resultado da consulta.

- void currentcellid_(int ${ }^{*}$ idcell): Este procedimento recupera o número identificador da célula atual da pesquisa armazenando-o no parâmetro de saída 
idcell.

- void itscellnext_(void): Este procedimento avança para a próxima célula da lista.

- void itscellfinish_(int ${ }^{*}$ finish): Este procedimento consulta se o iterador chegou ao fim da lista de células, onde o resultado é armazenado no parâmetro finish.

- Iterador de Arestas: O iterador de arestas acessa sequencialmente e sem repetição todas as arestas da malha. Durante a consulta, pode-se acessar as células vizinhas na aresta atual como o identificador da aresta atual na sequência. A seguir os procedimentos que controlam o acesso à sequência.

- void initializeedgeiterator_(int *init): Este procedimento inicializa o iterador informando qual a aresta que deseja-se iniciar a varredura.

- void currentedgeids_(int ${ }^{*} i d a$, int $\left.{ }^{*} i d b\right)$ : Este procedimento recupera os identificadores dos vértices que compõem a aresta atual na busca. Nos parâmetros de saída $i d a$ e $i d b$ serão armazenados o resultado da consulta.

- void currentedgeid_(int *idedge): Este procedimento recupera o número identificador da aresta atual da pesquisa armazenando-o no parâmetro de saída idedge.

- void itsedgenext_(void): Este procedimento avança para a próxima aresta da lista.

- void itsedgefinish_(int ${ }^{*}$ finish): Este procedimento consulta se o iterador chegou ao fim da lista de arestas, onde o resultado é armazenado no parâmetro finish.

- Iterador na Estrela de um Vértice: O iterador na estrela de um vértice acessa sequencialmente e sem repetição todas células na estrela de um vértice. Durante a consulta, pode-se acessar informações de cada célula ao redor do 
vértice. A seguir são listados os procedimentos que controlam o acesso à essa sequência de células.

- void initializevertexstariterator_(int *init): Este procedimento inicializa o iterador para percorrer na estrela do vértice indicado pelo parâmetro de entrada init.

- void currentvertexstarcell_(int *idcel): Este procedimento recupera o identificador da célula atual na sequência de pesquisa, onde o resultado é armazenado no parâmetro de saída idcel.

- void currentvertexstar- $\left(\right.$ int ${ }^{*} a$, int ${ }^{*} b$, int $\left.{ }^{*} c\right)$ : Este procedimento recupera os identificadores dos vértices que compõem a célula atual de busca na sequência de visita, armazenados nos parâmetros de saída $a, b$ e $c$.

- void itsvertexstarnext_(void): Este procedimento avança para a próxima célula na estrela do vértice.

- void itsvertexstarfinish_(int ${ }^{*}$ finish): Este procedimento consulta se o iterador chegou ao fim da lista de células na estrela do vértice pesquisado, armazenando no parâmetro de saída finish esta condição.

- Iterador Vizinhos de uma Célula: O iterador vizinhos de uma célula acessa sequencialmente e sem repetição as células que estão ao redor de uma célula de busca. Novamente, pode-se acessar as células em cada passo que se percorre a lista sequencial. A seguir são listados os procedimentos que controlam o acesso à esta sequência.

- void initializecellneighiterator_(int *init): Este procedimento inicializa o iterador para percorrer as células ao redor da célula de busca indicada pelo parâmetro de entrada init.

- void currentcellneigh_(int *idcel): Este procedimento recupera o identificador da célula atual na sequência de pesquisa, onde o resultado é armazenado 
no parâmetro de saída idcel.

- void currentcellvertneigh_(int ${ }^{*} a$, int ${ }^{*} b$, int $\left.{ }^{*} c\right)$ : Este procedimento recupera os identificadores dos vértices que compõem a célula atual de busca na sequência de visita, armazenados nos parâmetros de saída $a, b$ e $c$.

- void itscellneighnext_(void): Este procedimento avança para a próxima célula na vizinhança da célula de busca.

- void itscellneighfinish_(int *finish): Este procedimento consulta se o iterador chegou ao fim da lista de células vizinhas, armazenando no parâmetro de saída finish esta condição.

\subsubsection{Exemplos de Utilização da Biblioteca no Simulador}

Nesta subseção são apresentados alguns exemplos da utilização desta biblioteca desenvolvida dentro do código existente do simulador como caso de teste. Pretende-se exemplificar desde as funcionalidades básicas como recuperação de dados simples da malha e alguns exemplos de iteradores.

Como os índices de todos elementos diferem entre Fortran e $\mathrm{C}++$, uma vez que a posição inicial dos vetores em Fortran começa em 1 e em $\mathrm{C}++$ em 0 , o mapeamento destes foi realizado internamente em cada procedimento desenvolvido na interface.

O acesso às informações básicas da malha, feitas acessando variáveis globais, conforme definidas na Seção 5.5.1, foram substituídas por chamadas aos procedimentos da nova biblioteca, definidos na Seção 5.5.4. Os exemplos são mostrados na lista a seguir, de acordo com a informação recuperada.

- Número de vértices de uma célula. Esta informação era acessada num vetor global chamado nvolnd:

$$
n v n d=\operatorname{nvolnd}(i)
$$


e foi substituído pelo procedimento getnvolnd

$$
\text { call getnvolnd }(i, \text { nvnd })
$$

- Vizinhança de uma célula. Esta informação era acessada numa matriz global chamada neighbor

$$
n b=\text { neighbor }(i, k)
$$

e foi substituída pelo procedimento neighbour da interface

$$
\text { call neighbour }(i, k, n b)
$$

- Arestas. A recuperação das informações de uma dada aresta era acessada numa matriz global chamada iedges

$$
\begin{aligned}
& \operatorname{vol} 1=\operatorname{iedges}(j, 1) \\
& \operatorname{vol} 2=\operatorname{iedges}(j, 2) \\
& i=i \operatorname{edges}(j, 3) \\
& n b=i \operatorname{edges}(j, 4)
\end{aligned}
$$

e foi substituída por dois procedimentos, getedgeids e getedgevol

$$
\begin{aligned}
& \text { call getedgeids }(j, \text { vol } 1, \text { vol2 }) \\
& \text { call getedgevol }(j, i, n b)
\end{aligned}
$$

- Vértices. A recuperação das coordenadas dos vértices era acessada numa ma- 
triz global chamada xynode

$$
\begin{aligned}
& x 1=x y n o d e(n o(1), 1) \\
& y 1=x y n o d e(n o(1), 2) \\
& x 2=x y n o d e(n o(2), 1) \\
& y 2=x y n o d e(n o(2), 2) \\
& x 3=x y n o d e(n o(3), 1) \\
& y 3=x y n o d e(n o(3), 2)
\end{aligned}
$$

e foi substituída pelo procedimentos da interface getcoords

$$
\begin{aligned}
& \text { call getcoords }(n o(1), x 1, y 1) \\
& \text { call getcoords }(n o(2), x 2, y 2) \\
& \text { call getcoords(no }(3), x 3, y 3)
\end{aligned}
$$

de uma forma mais simples de acessar.

- Células. A recuperação dos vértices de uma célula era acessada numa matriz global chamada itable

$$
\begin{aligned}
& i d a 1=\text { itable }(\text { cell }, 1) \\
& i d a 2=i t a b l e(\text { cell }, 2) \\
& i d a 3=\text { itable }(\text { cell }, 3)
\end{aligned}
$$

e foi substituída pelo procedimento getcellvertid na interface

$$
\begin{aligned}
& \text { call getcellvertid(cell, } 0, i d a 1) \\
& \text { call getcellvertid(cell, } 1, i d a 2) \\
& \text { call getcellvertid(cell, } 2, \text { ida3) }
\end{aligned}
$$

- Consulta na estrela do vértice. A consulta deste tipo utilizava uma matriz pré-calculada com as informações sobre os vizinhos chamada ivolnei, onde as informações da quantidade total de células vizinhas aos vértices era armazenada 
num vetor chamado itotnei. Por exemplo, uma consulta na estrela de um vértice $i$ era realizada desta maneira:

$$
\begin{aligned}
& \text { do } j=1, \text { itotnei }(i) \\
& i v o l=i v o l n e i(i, j) \\
& r h o=q(\text { ivol }, 1) \\
& \ldots \\
& \text { enddo }
\end{aligned}
$$

o que foi substituída pelo uso do iterador adequado a esta consulta na seguinte forma

$$
\begin{aligned}
& \text { call initializevertexstariterator }(i) \\
& \text { itfinish }=0 \\
& \text { do while }(\text { itfinish }<>1) \\
& \quad \text { call currentvertexstarcell }(\text { ivol }) \\
& \text { rho }=q(\text { ivol }, 1) \\
& \ldots \\
& \text { callitsvertexstarfinish }(\text { itfinish }) \\
& \text { enddo }
\end{aligned}
$$

\subsection{Utilização da Malha Elástica}

A solução do sistema de equações governantes da malha elástica conduz aos deslocamentos associados aos vértices presentes no interior da malha movimentada, de modo a buscar o equilíbrio estático das forças entre os vértices. Este sistema é linear e pode ser resolvido iterativamente pelo método de Gauss-Seidel, em que o novo deslocamento referente ao vértice iterativo $v_{i}, \vec{\delta}_{i}^{\text {new }}$, é dependente dos deslocamentos previamente calculados, $\vec{\delta}^{\text {old }}$. Para o caso de molas semi-torcionais, o valor de $\vec{\delta}_{i}^{n e w}$ é dado por 


$$
\vec{\delta}_{i}^{\text {new }}=\frac{\sum_{v_{w} \in S\left(v_{i}\right)} k_{i w}^{\text {total }} \vec{\delta}_{w}^{\text {old }}}{\sum_{v_{w} \in S\left(v_{i}\right)} k_{i w}^{\text {total }}}
$$

onde $w$ são valores advindos da conectividade da malha, $S\left(v_{i}\right)$ é o conjunto de vértices adjacentes ao vértice $v_{i}$ e $k_{i w}^{\text {total }}$ é o coeficiente de rigidez da mola semi-torcional, dado pela Equação 2.16 apresentada na Seção 2.4 . Pela Equação 5.59 percebe-se $\vec{\delta}_{i}^{\text {new }}$ equivale à média dos deslocamentos vizinhos ponderada pelos coeficientes de rigidez das molas adjacentes: o membro da esquerda da Equação 5.59 é, logo, dependente da configuração de molas que constituem a malha dinâmica.

O Algoritmo 1 mostra os passos realizados para a movimentação da malha. Assim, tendo por entrada a malha a ser movimentada, o conjunto de vértices das fronteiras desta malha e os coeficientes de rigidez torcionais que compõem o coeficiente da mola semi-torcional $k^{\text {total }}$, é possível implementar o processo iterativo pelo método de Gauss-Seidel modificado em que, partindo da Equação 5.59, os valores dos deslocamentos dos vértices da malha são atualizados a cada iteração. O critério utilizado para a conclusão do processo iterativo é o máximo valor absoluto dentre os valores de deslocamento obtidos entre uma iteração e outra para todos os vértices da malha. Desta forma, nota-se que o algoritmo de fato não desloca os vértices da malha, mas apenas atualiza os valores de deslocamento associados aos mesmos. Ao final de todo o processo iterativo, o deslocamento calculado conduz à nova posição assumida pelos vértices da malha.

\section{Os Vértices Ativos}

Pelo algoritmo mostrado na seção anterior, vemos que os vértices internos são processados a cada iteração, até que seja atingida uma situação de convergência, controlado pela variável $\epsilon$. Desta maneira o valor de $\epsilon$ torna-se fisicamente mais intuitivo; isto é, para $\epsilon=0,01$ a parada ocorrerá somente se para cada vértice $v_{w} \in T$ o deslocamento relativo for inferior a $0.01 e_{m i n}^{w}$. Entende-se $\epsilon$ como o grau de refinamento da malha. 


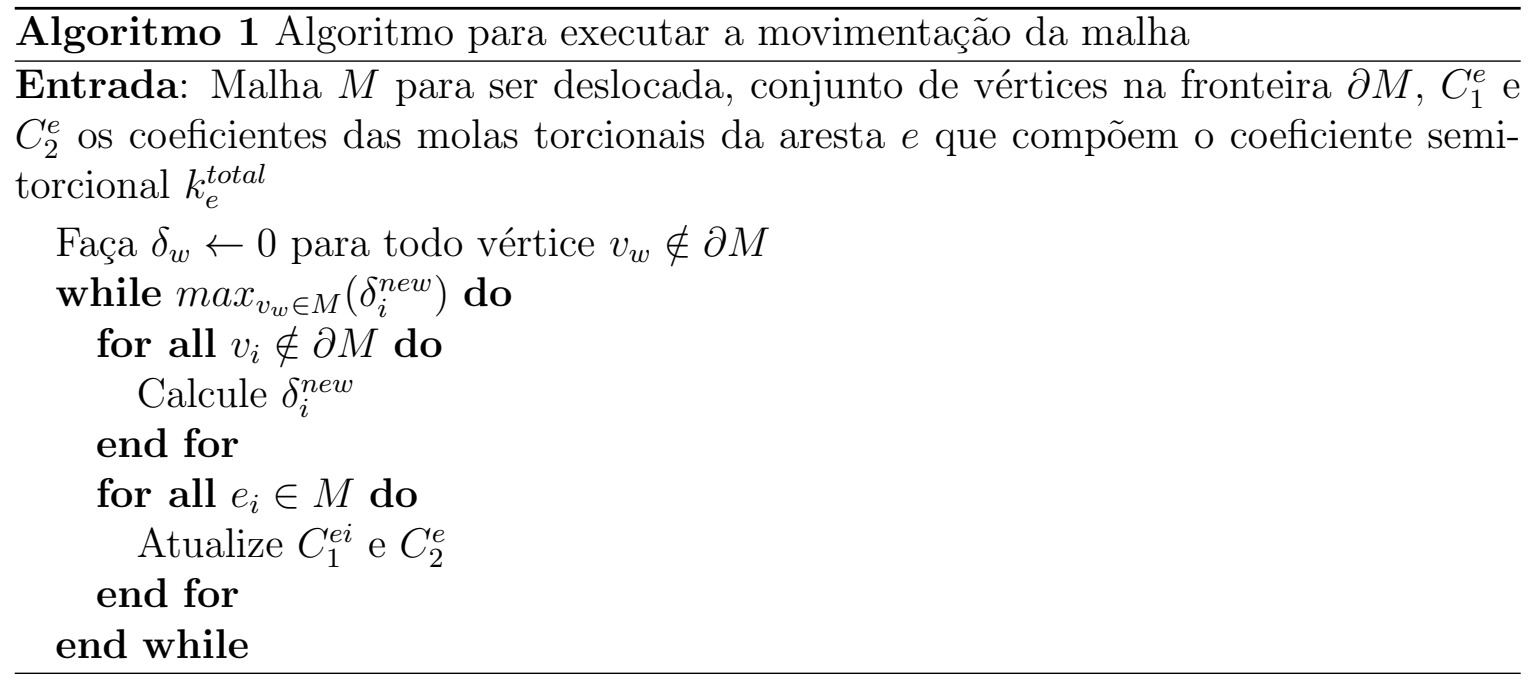

Para melhorar o desempenho computacional, utiliza-se o esquema de vértices ativos, proposto por Soares [Soares, 2007]. Além de controlar o número de vezes em que os vértices são visitados, monitora também a sequência em que isto ocorre, o que influencia diretamente no tempo de processamento e na convergência do método numérico empregado. A sequência de processamento consiste em iterar os vértices em camadas, iniciando da fronteira para o interior da malha. Deste modo, os vértices devem ser rotulados da seguinte maneira:

Vértice Ativo: Indica que o vértice está disponível para ser processado;

Vértice Inativo : Indica que o vértice não será processado;

Vértice Fixo: Indica que o vértice é fixo, ou seja, imóvel.

Uma vez que cada vértice deve ter apenas um rótulo, pode-se separar todos os vértices da malha em três conjuntos disjuntos: $\mathcal{A}, \mathcal{I}$ e $\mathcal{F}$ representando, respectivamente, os conjuntos dos vértices ativos, dos inativos e dos fixos. É feito um pré-processamento antes de aplicar as movimentações, e os vértices da malha são inicialmente rotulados de diferentes formas. Primeiramente, todos os vértices que pertencem à fronteira móvel da malha são rotulados como fixos. Então, os vértices que estão diretamente conectados aos vértices fixos são rotulados como ativos, e eles 
possuem deslocamento inicial zero. Por fim, todos os vértices não rotulados no passo anterior são rotulados como inativos.

Desta forma, são iterados apenas os vértices ativos: $\mathcal{A}$ é inicialmente composto dos vértices do interior, adjacentes à fronteira móvel da malha, propiciando assim que os primeiros vértices iterados sejam aqueles que potencialmente sofrerão o maior deslocamento. Nesta nova metodologia, existe a alternância entre os rótulos ativo e inativo para um mesmo vértice ao longo do processo iterativo: quando seu deslocamento relativo torna-se insignificante, um vértice ativo torna-se inativo; porém, se sua movimentação for significativa, seu status permanecerá como ativo, bem como o de todos os vértices inativos a ele adjacentes.

\subsection{Aplicações}

Esta seção apresenta as aplicações e os resultados obtidos utilizando as técnicas e métodos expostos até o momento. São utilizadas as equações de Euler para representar o movimento do fluido compressível não viscoso. Os resultados obtidos nesta etapa do trabalho estão organizados em três frentes.

Primeiramente, são realizados experimentos que medem o custo computacional associado à utilização da estrutura de dados Mate Face no simulador. São medidos o tempo de construção e espaço em memória ocupados para a organização da malha, bem como tempo para efetuar-se consultas.

Posteriormente, são realizadas simulações para a validação do acoplamento da estrutura de dados Mate Face com o código de simulação. A validação consiste em comparar os resultados gerados na ferramenta de simulação sem o acoplamento da estrutura Mate Face com os resultados gerados na simulação com o acoplamento da Mate Face. Assim, o foco é mostrar que a estrutura Mate Face pode ser utilizada e acoplada ao simulador, produzindo resultados compatíveis com os produzidos pelo simulador original. Foram efetuados experimentos usando dois domínios diferentes, 
um caso de escoamento sobre uma cunha e um caso de escoamento sobre o perfil NACA 0012.

Finalmente, é feita uma análise sobre malhas dinâmicas investigando a possibilidade de uso nas simulações numéricas. Para isso, uma investigação sobre a metodologia de molas semi-torcionais é realizada no intuito de verificar a qualidade da malha após a movimentação e surgimento de células inválidas. Isso é um fato importante para casos de escoamentos não estacionários, onde os movimentos do aerofólio em arfagem necessitam de uma angulação considerável durante as simulações. Para realizar esta análise, foi implementado um ambiente de simulação dessas movimentações de arfagem de modo a utilizar o método de molas semi-torcionais.

\subsubsection{Análise de Custo Computacional}

Esta seção apresenta uma análise sobre o custo computacional do uso da estrutura de dados Mate Face comparada com a utilização de tabelas internas pré-calculadas no momento de carregamento da malha. Foram analisadas a construção das estruturas, efetuadas no momento de leitura dos dados da malha, e também consultas mais complexas como busca na estrela de um vértice da malha.

Para os experimentos, foram utilizadas quatro malhas NACA 0012 com diferentes resoluções, conforme indicado na Tabela 5.3 . Observe que o número de vértices e de células aumenta para cada malha listada.

\begin{tabular}{|c|c|c|}
\hline Malha & No. de vértices & No. de Células \\
\hline 1 & 5908 & 11634 \\
\hline 2 & 6995 & 13744 \\
\hline 3 & 7363 & 14400 \\
\hline 4 & 9100 & 17844 \\
\hline
\end{tabular}

Tabela 5.3: Diferentes resoluções de malhas NACA 0012 utilizadas para os testes.

A análise de custo é feita mensurando o tempo gasto para a construção das es- 
truturas e também o tamanho ocupado em memória principal para ambas abordagens. Para realizar tal comparação e obter-se uma análise sobre diferentes malhas, foi realizado um teste de escalabilidade sobre as medidas coletadas nos experimentos. Assim, efetuaram-se os mesmos testes para malhas de diferentes resoluções, ou seja, aumentando-se o número de elementos para uma análise de escalabilidade.

A Figura 5.16 mostra o tempo de construção necessário para a leitura da malha e construção das estruturas utilizadas, variando-se a resolução da malha para a construção. Pela figura, nota-se que o tempo de construção da Mate Face é linear e baixo, enquanto a abordagem de tabelas internas torna-se custosa e cresce rapidamente conforme aumenta-se o número de elementos na malha.

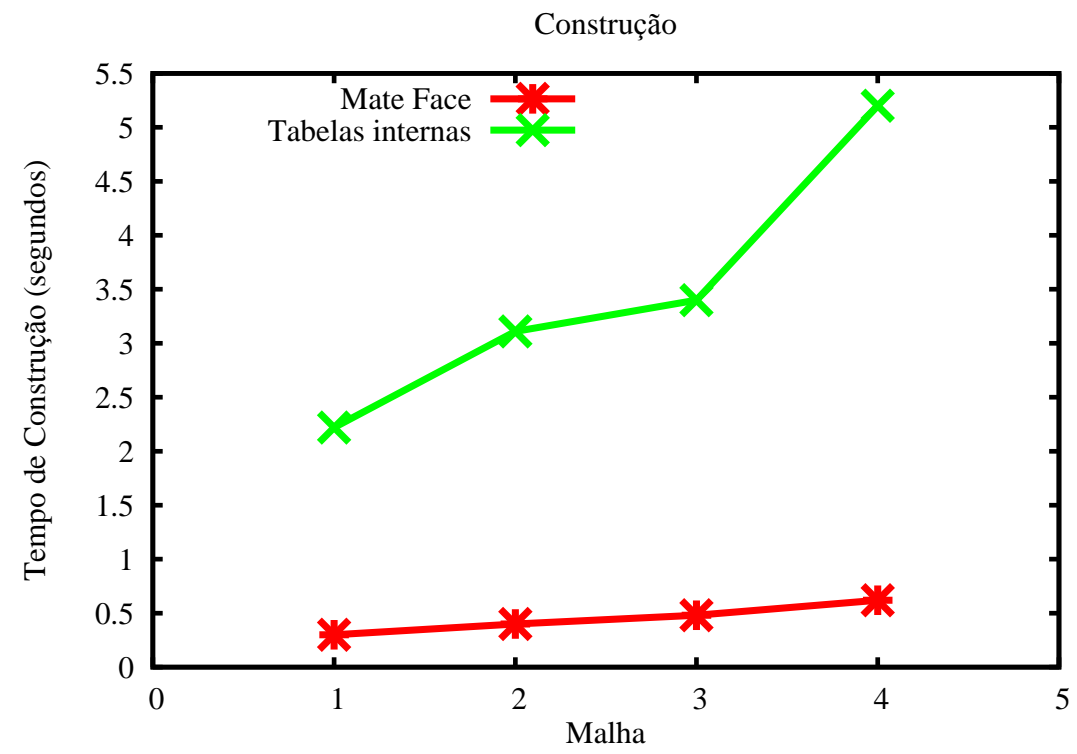

Figura 5.16: Tempo de construção das estruturas variando-se a resolução das malhas.

Outra medida realizada referente à construção para comparação entre as abordagens de armazenamento é o espaço em memória utilizado tanto pela Mate Face quanto pelas tabelas internas. Embora a Mate Face seja uma estrutura implícita onde todas as relações de incidência e adjacência são obtidas em tempo constante, ela representa células, arestas e faces de modo explícito, ocupando uma taxa de memória adicional. Porém, uma construção rápida é mais importante para a utilização das estruturas de 
dados em diversas aplicações.

A Figura 5.17 mostra comparativamente o custo de memória associado à construção das estruturas utilizadas, variando-se a resolução das malhas para leitura. Pela figura, nota-se que embora a estrutura Mate Face utilize mais espaço em memória quando comparada à técnica de tabelas internas, essa diferença diminui conforme aumenta-se a resolução das malhas indexadas.

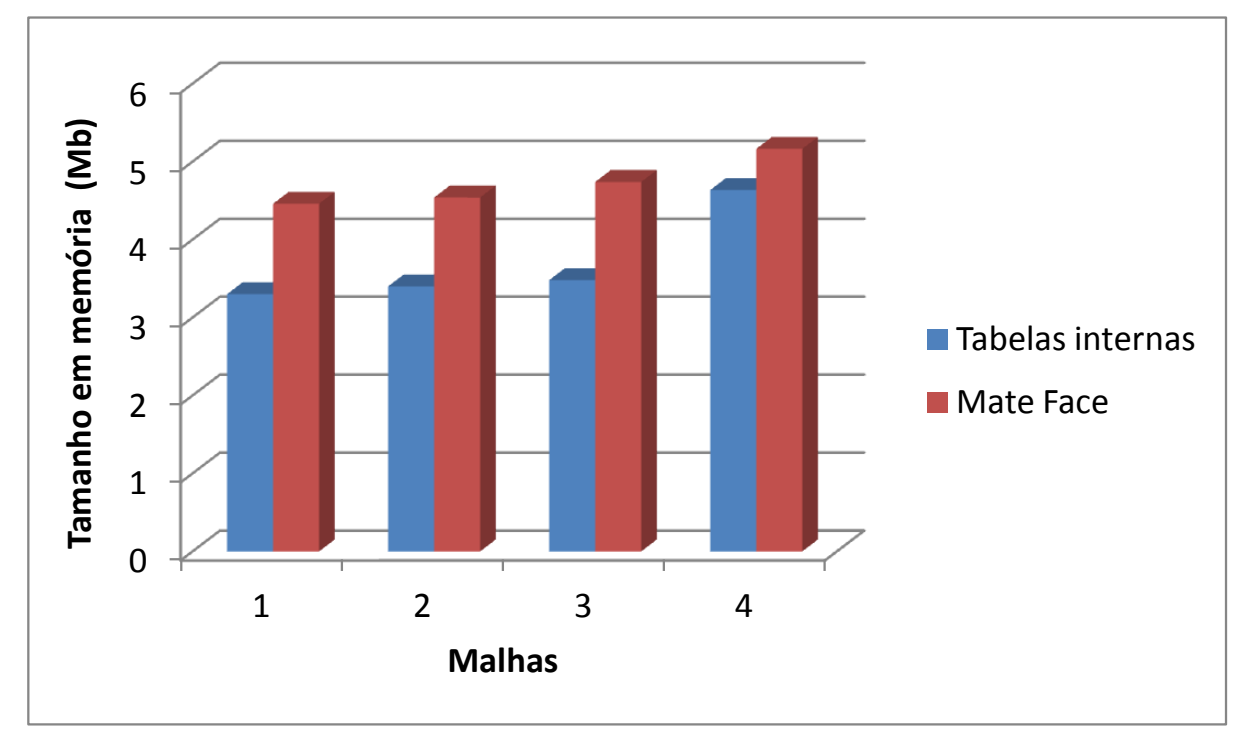

Figura 5.17: Consumo de memória comparativo entre as estruturas utilizadas.

A Figura 5.18 mostra a taxa relativa de crescimento na ocupação de memória principal referente à leitura das malhas. A indicação $(1,2)$ refere-se à taxa relativa de crescimento entre as malhas 1 e 2 utilizadas, e os resultados são apresentados na escala logarítmica na forma de porcentagem de crescimento. Pela análise do gráfico, nota-se que o crescimento do consumo de memória da Mate Face é menor do que a técnica de tabelas internas, sendo escalável em memória.

Após construídas as estruturas, a maioria das consultas realizadas na Mate Face são realizadas em tempo constante devido a seu modo explícito de representação de vértices, células e arestas. Porém, consultas complexas como a busca na vizinhança de um vértice é a consulta mais custosa a ser executada na estrutura.

Foi realizado um experimento que mede o tempo total gasto para executar 50 vezes 


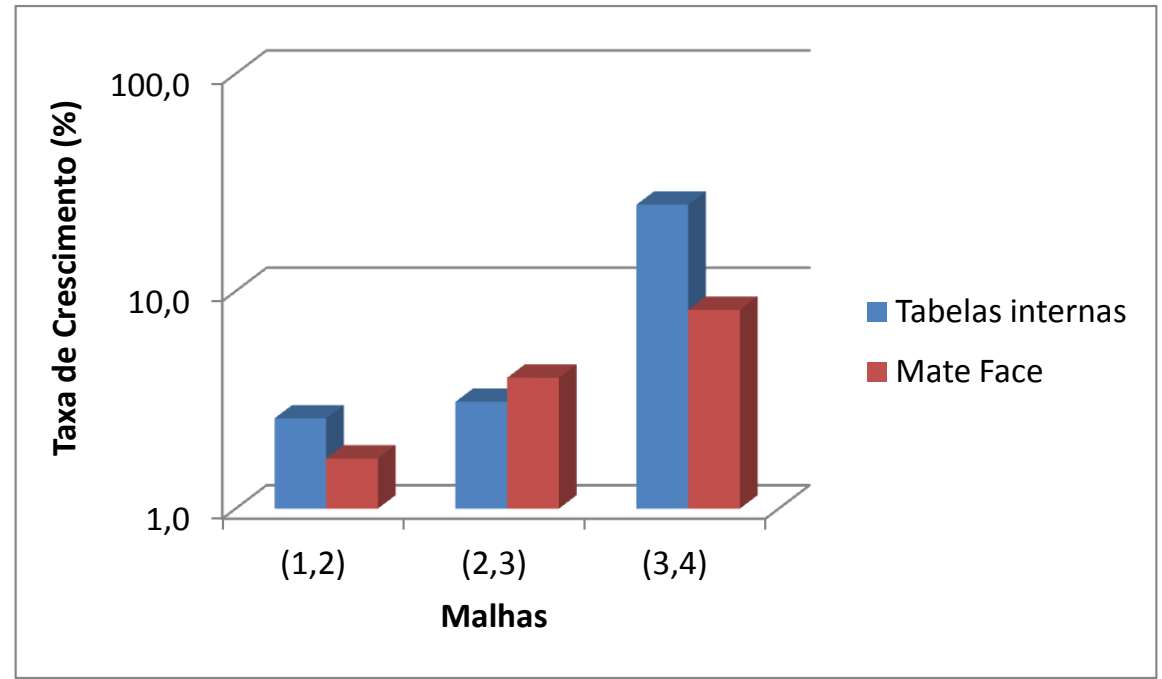

Figura 5.18: Taxa relativa de crescimento da ocupação de memória variando-se a resolução das malhas.

a consulta na vizinhança de um vértice (busca na estrela do vértice) para todos os vértices existentes nas malhas. Sabe-se que o tempo de consulta utilizando as tabelas internas é sempre o mesmo, uma vez que todas consultas são pré-calculadas durante a construção, o que a torna custosa. Porém, analisando-se a Tabela 5.4, vê-se que embora a Mate Face apresente um tempo maior para realizar todas as consultas, esse tempo é pequeno e menor que um segundo.

\begin{tabular}{|c|c|c|}
\hline Malha & Tabelas internas & Mate Face \\
\hline 1 & 0.01 & 0.54 \\
\hline 2 & 0.01 & 0.64 \\
\hline 3 & 0.01 & 0.67 \\
\hline 4 & 0.01 & 0.85 \\
\hline
\end{tabular}

Tabela 5.4: Tempo para consulta na vizinhança dos vértices (segundos).

Deste modo, foi realizada uma análise sobre o custo computacional da utilização da estrutura de dados Mate face. Pelos resultados, notou-se que o tempo para a construção da estrutura MF tem comportamento linear comparado à utilização de tabelas internas, o que viabiliza a utilização em grandes malhas com muitos vértices e muitos elementos. Além disso, foi visto que o consumo de memória da MF também é escalável conforme utiliza-se diferentes malhas. A realização de consultas na vizinhança 
dos vértices mostrou que a estrutura MF proporciona um bom desempenho, após feita uma medida sob uma bateria de consultas sobre todos os vértices das malhas utilizadas nos testes.

\subsubsection{Escoamento Sobre uma Cunha}

Neste experimento são validados os resultados gerados pela adaptação da estrutura Mate Face ao simulador existente, de forma a substituir a malha interna. O objetivo é comparar os resultados gerados por ambas implementações. Neste experimento, foi considerado o escoamento supersônico sobre uma cunha. O mesmo experimento foi realizado nas duas implementações utilizando-se os mesmos parâmetros de simulação e a mesma malha computacional. Assim, os resultados devem ser compatíveis, salvo exceções como arrendondamento de ponto flutuante que diferem entre Fortran e $\mathrm{C}++$.

O semi-ângulo da cunha é de $\theta=10^{\circ}$. A Figura 5.19 representa o domínio que define a cunha. O domínio é delimitado pela superfície da cunha e por uma seção de saída do escoamento ao longo de seu limite inferior, conforme mostra a figura. À esquerda e acima do domínio computacional tem-se a condição de contorno de entrada do escoamento e à direita tem-se a condição de contorno de saída do escoamento.

No presente experimento, utilizou-se o método de discretização WENO de quarta ordem, método de Roe para cálculo do fluxo numérico, e marcha no tempo RungeKutta TVD de 3 estágios para a discretização temporal. A malha utilizada possui 816 nós e 1504 volumes triangulares, e pode ser observada na Figura 5.20. Para este caso, o bordo de ataque da cunha está localizado pelas coordenadas cartesianas $x=0.25 \mathrm{e}$ $y=0.0$.

Para esta simulação em específico, existe uma solução analítica Anderson, 1982. A solução fornece as mudanças das propriedades do escoamento através da onda de choque oblíqua como função do ângulo do choque e do número de Mach do escoamento não perturbado. O ângulo de choque é obtido como função implícita do número de Mach do escoamento não perturbado e do semi ângulo da cunha (relação $\theta-\beta-$ 


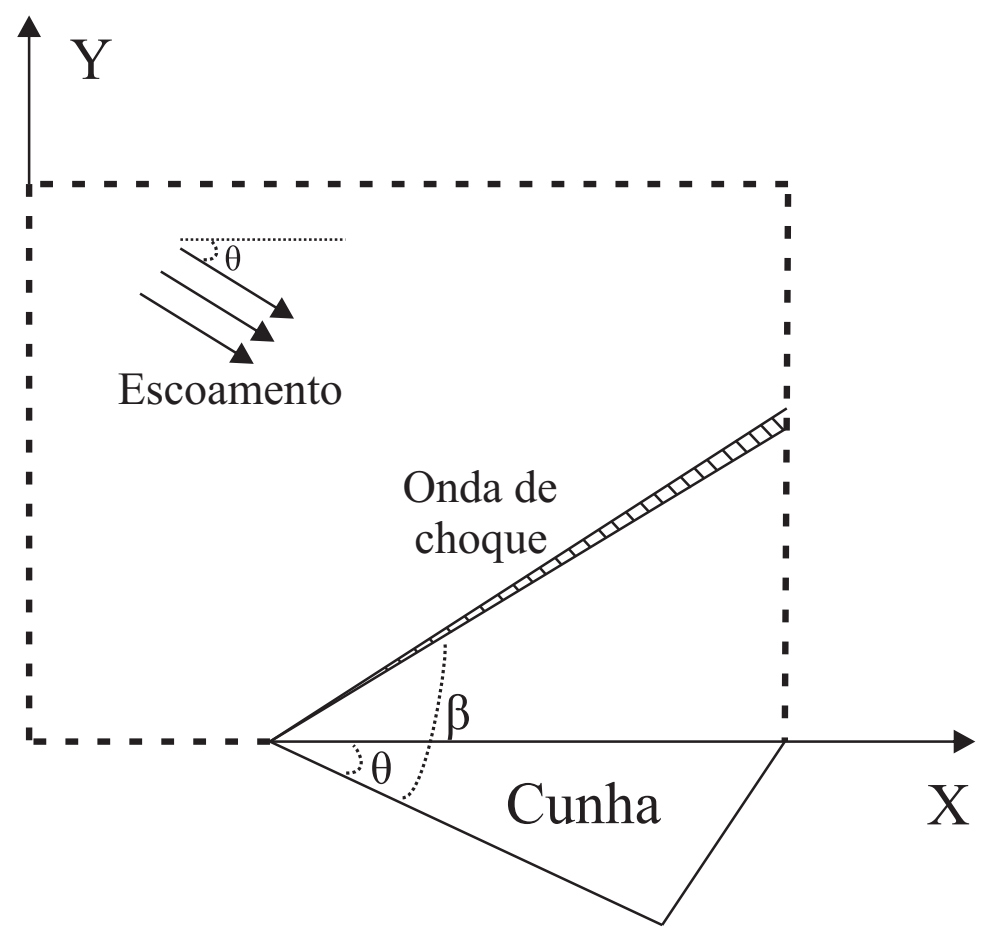

Figura 5.19: Representação do domínio computacional, caso escoamento sobre uma cunha.

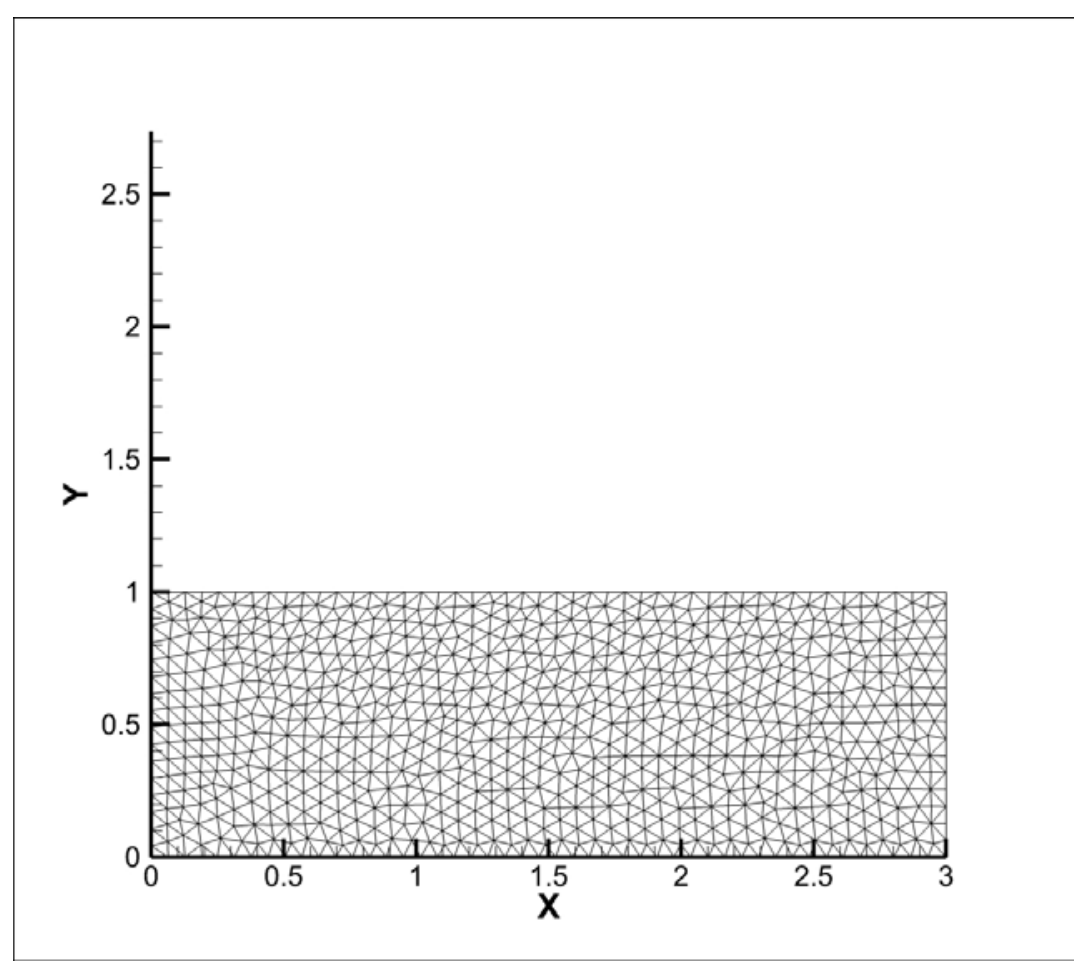

Figura 5.20: Malha computacional utilizada na simulação do escoamento sobre a cunha. 
Mach) Anderson, 1982.

Para o caso aqui testado, utilizou-se $M_{1}=5.0$ e, de acordo com as relações analíticas dadas por Anderson Anderson, 1982, é possível determinar o ângulo da onda de choque oblíqua $\beta=19.5^{\circ}$.

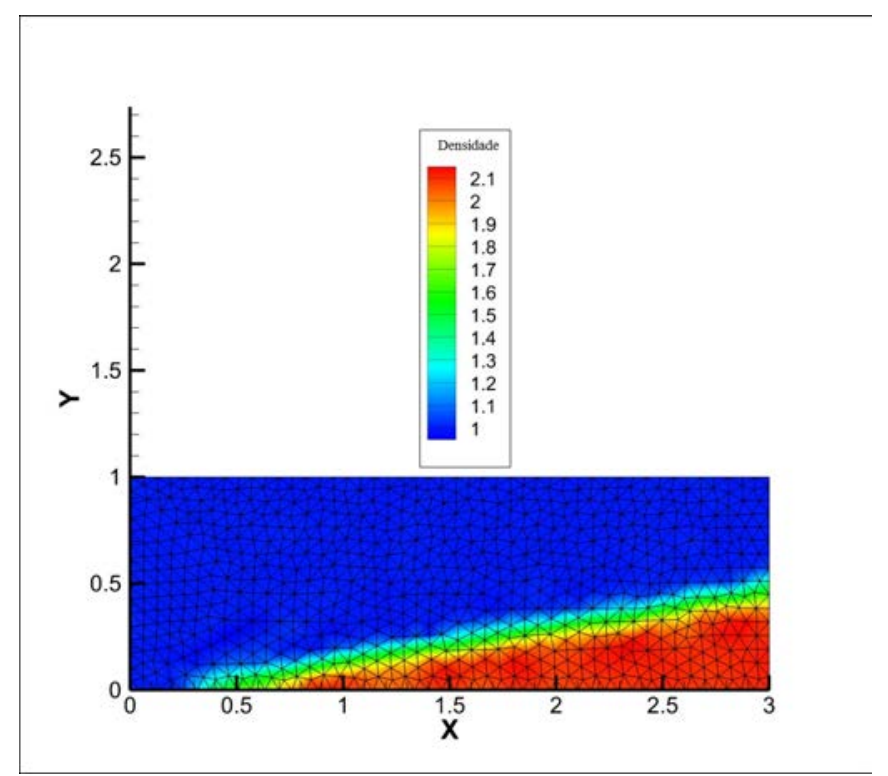

(a)

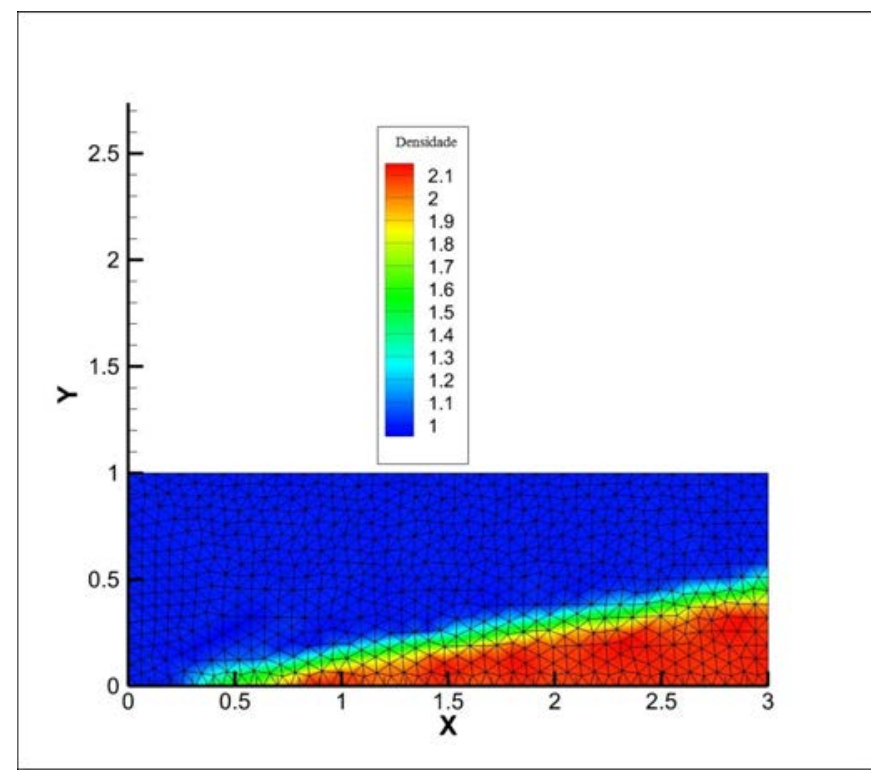

(b)

Figura 5.21: Resultados da densidade. (a) Densidade do domínio pelo simulador Original. (b) Densidade do domínio pelo simulador com a Mate Face.

A primeira verificação dos resultados foi comparar os resultados da densidade 
calculada pelas duas implementações. A Figura 5.21 mostra os resultados dos cálculos das densidades para as simulações realizadas em ambas implementações: sem a MF e com a MF. Pelos resultados, observa-se que são compatíveis e similares. As figuras mostradas foram geradas utilizando-se a ferramenta de visualização Tecplot 3601 .

A segunda verificação consistiu em analisar a distribuição de coeficiente de pressão (Cp) ao longo da parede da cunha, onde foram apresentadas os resultados para ambas implementações, comparando-se com a solução analítica para o caso, como mostrado na Figura 5.22. Nota-se uma ótima concordância entre a ferramenta de simulação com a utilização da Mate Face (MF) com a ferramenta original.

O indicador de oscilação utilizado é o proposto por Jiang e Shu [Jiang and Shu, 1996]. O eixo horizontal na figura, começa no bordo de ataque da cunha.

A Figura 5.23 mostra o histórico do resíduo gerado para este caso, nas primeiras 500 iterações efetuadas. De acordo com Wolf [Wolf, 2006], o patamar dos resíduos para este caso varia bastante dependendo do indicador de oscilação utilizado.

\subsubsection{Escoamento Sobre o Perfil NACA 0012}

Este caso de teste considera o escoamento transônico sobre um aerofólio NACA 0012 com incidência de um grau. Foram realizados dois casos de teste, utilizando duas malhas com números de vértices e volumes diferentes. O número de Mach do escoamento livre foi considerado como $M_{\infty}=1.0$. A Figura 5.24 mostra a representação esquemática do escoamento considerado nesse teste. O primeiro caso utiliza uma malha com 5908 nós e 11634 volumes de controle triangulares. A Figura 5.25 mostra a malha utilizada neste caso, sendo que na Figura 5.25(a) é mostrada a malha total sem aproximação do perfil, e a Figura 5.25(b) mostra a malha em torno do perfil NACA que possui 182 vértices presentes no contorno do aerofólio.

Foi utilizado o esquema WENO com reconstrução de ordem 4 de precisão, indica-

\footnotetext{
${ }^{1}$ http://www.tecplot.com
} 


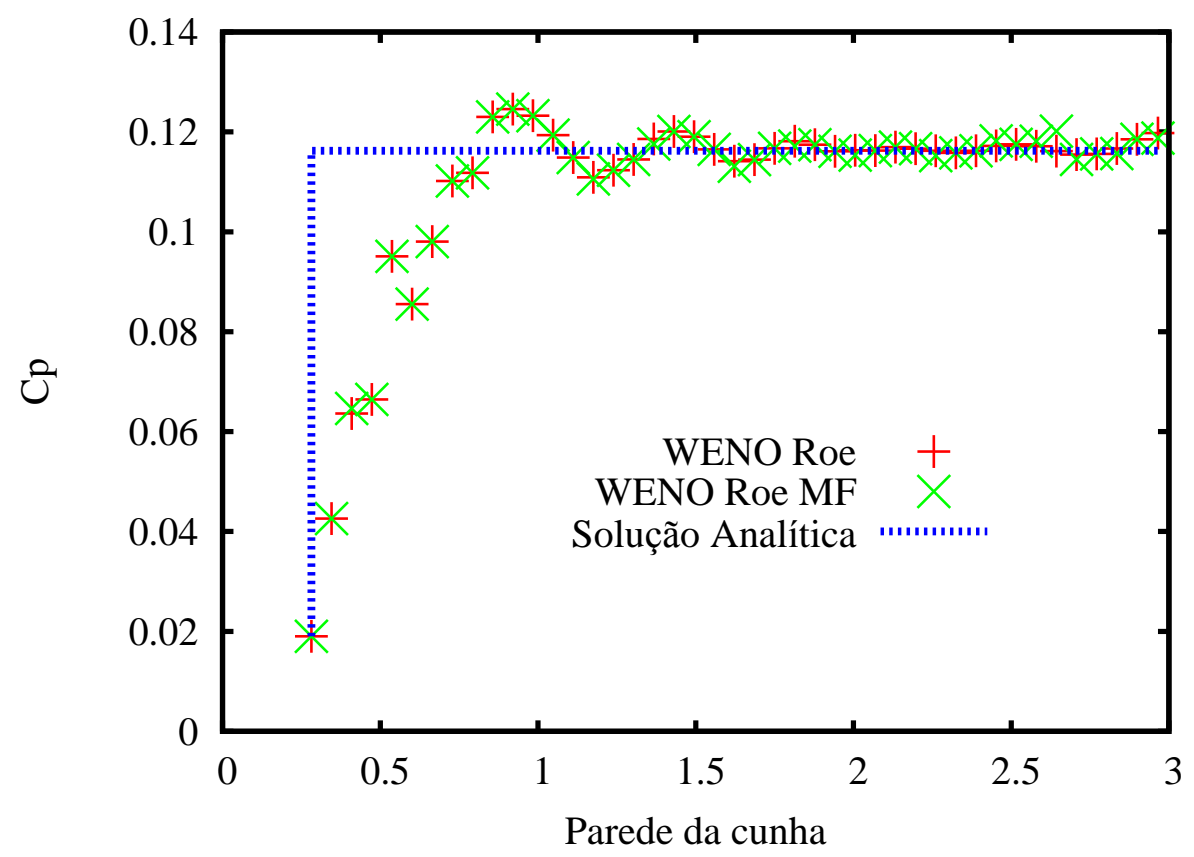

Figura 5.22: Distribuição de coeficiente de pressão ao longo da parede da cunha, com $M_{1}=5.0$.

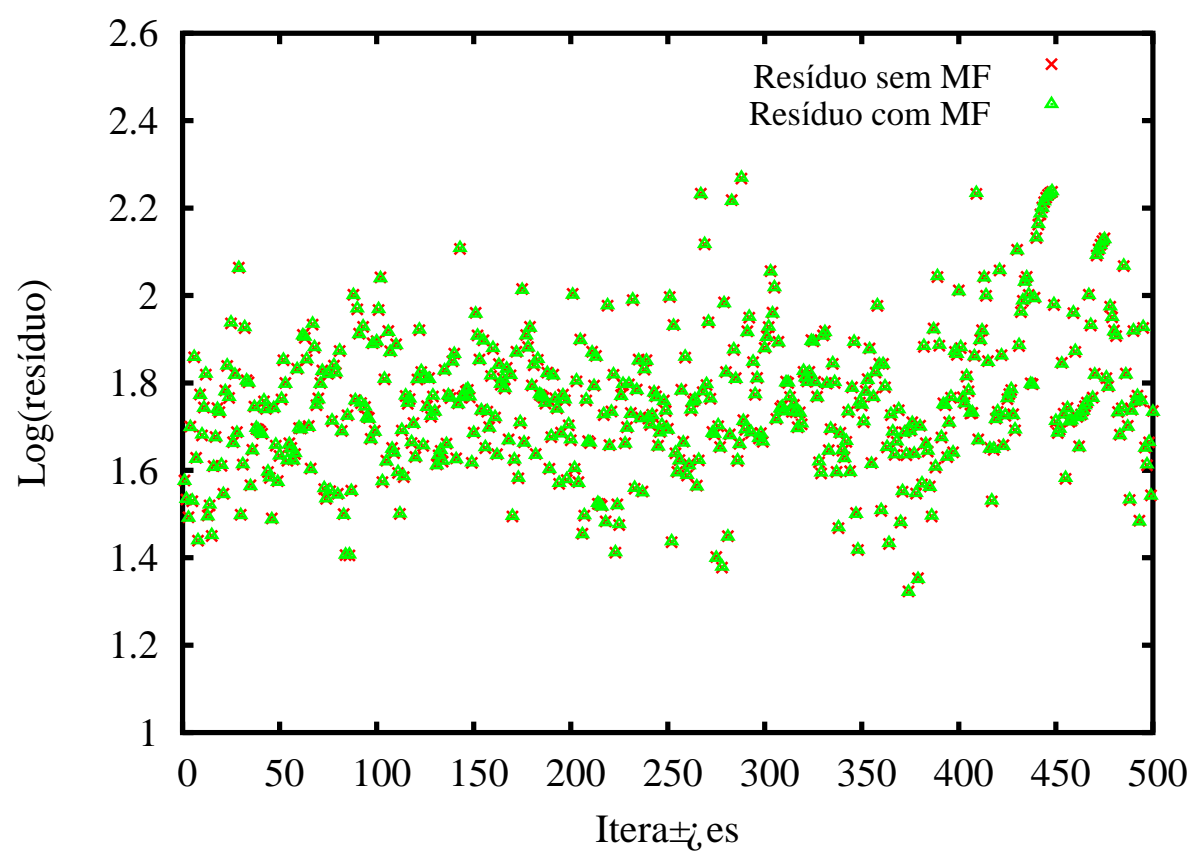

Figura 5.23: Histórico do resíduo para a simulação do escoamento sobre a cunha com 500 iterações e $M_{1}=5.0$.

dor de oscilação de Jiang e Shu, método de Roe para avaliação do fluxo numérico nas arestas, e para a marcha no tempo foi utilizado o método TVD Runge-Kutta de três 


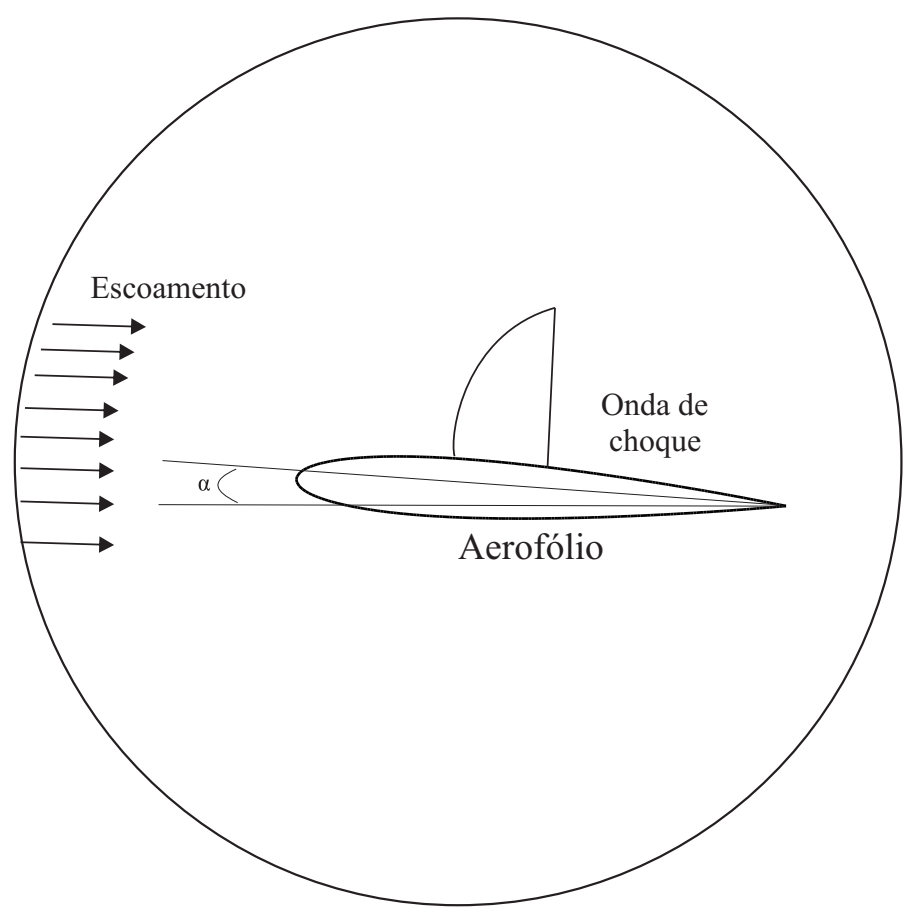

Figura 5.24: Representação do esquema do escoamento sobre o aerofólio NACA 0012.

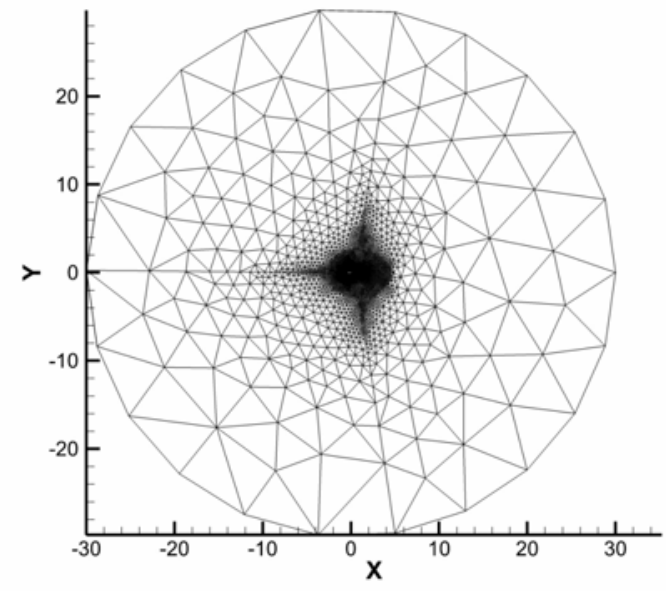

(a) Malha original

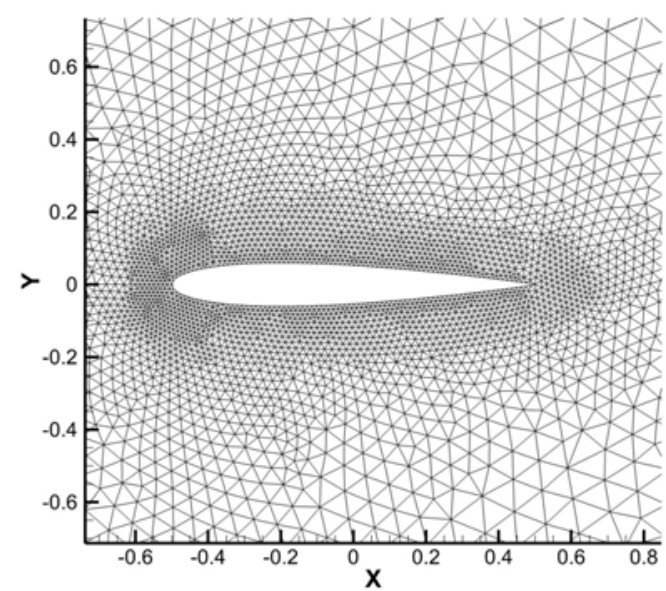

(b) Malha ao redor do aerofólio

Figura 5.25: Malha em torno do perfil NACA 0012 com 182 vértices no contorno do aerofólio.

estágios. A densidade foi adimensionalizada com respeito à densidade do escoamento livre e a pressão foi adimensionalizada com respeito à densidade multiplicada pela velocidade do som ao quadrado.

A Figura 5.26 mostra os resultados alcançados pela simulação em relação à densidade no domínio computacional, em ambas implementações. Pelas figuras, vemos que 
os resultados são compatíveis e similares, pois a malha utilizada é a mesma para o simulador original e para o simulador acoplado com a Mate Face. As figuras mostradas foram geradas utilizando-se a ferramenta de visualização Tecplot 3602 .

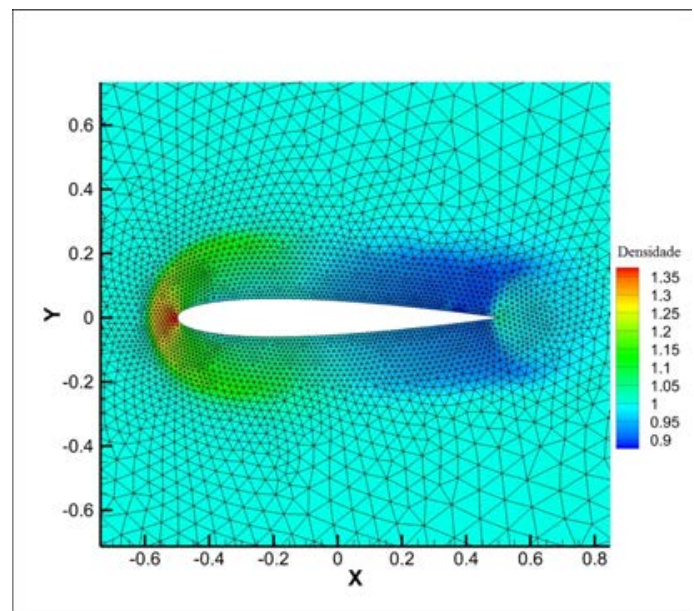

(a)

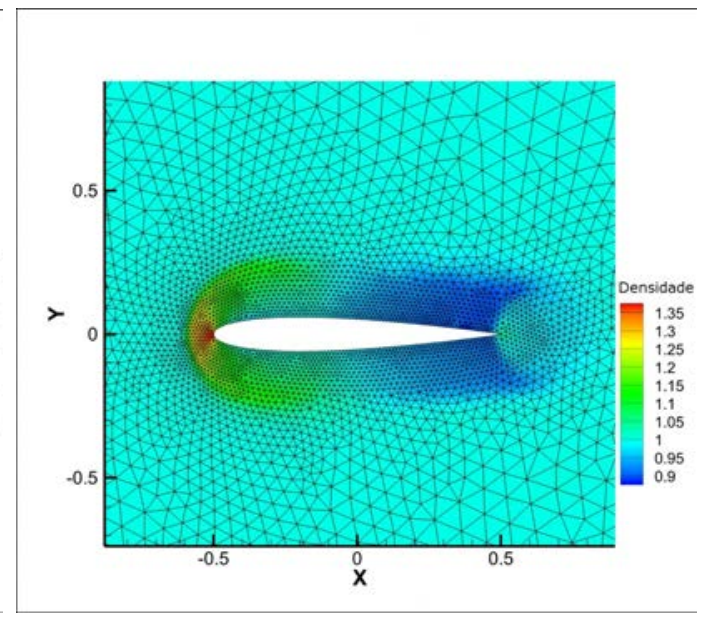

(b)

Figura 5.26: Resultados da densidade. (a) Densidade do domínio pelo simulador Original. (b) Densidade do domínio pelo simulador com a Mate Face.

Outro resultado mostrado na Figura 5.27 refere-se à distribuição de coeficiente de pressão (Cp) ao longo do extradorso do aerofólio, onde foram apresentadas os resultados para ambas implementações. O indicador de oscilação utilizado é o proposto por Jiang e Shu Jiang and Shu, 1996.

Uma outra análise é a visualização do campo vetorial do escoamento. Com as componentes de velocidades $u$ e $v$ calculadas nos experimentos, é possível visualizar o campo vetorial do escoamento próximo ao perfil do aerofólio. Na Figura 5.28(a) é mostrado o campo vetorial na região do bordo de ataque no perfil, onde pode-se notar a direção dada pelos vetores calculados a partir das componentes de velocidades calculadas. A Figura 5.28(b) mostra o campo vetorial próximo ao bordo de fuga do aerofólio.

O histórico do resíduo nas primeiras 2000 iterações é mostrado na Figura 5.29. De acordo com os critérios definidos por Wolf [Wolf, 2006], ficou claro que a queda dos

\footnotetext{
${ }^{2}$ http://www.tecplot.com
} 


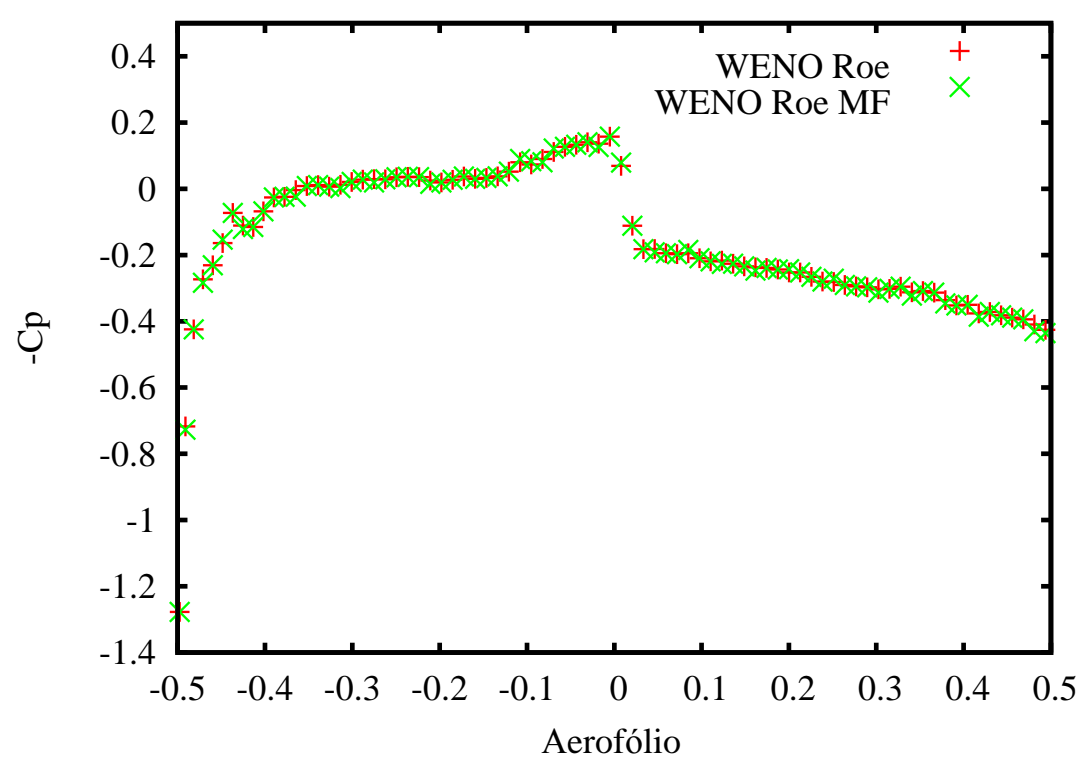

Figura 5.27: Distribuição de coeficiente de pressão ao longo do extradorso do aerofólio, com $M_{1}=1.0$ e $\alpha=1.0$.

resíduos também se mostrou pequena, e o acompanhamento da solução indica que este para de variar, indicando convergência dos resultados.

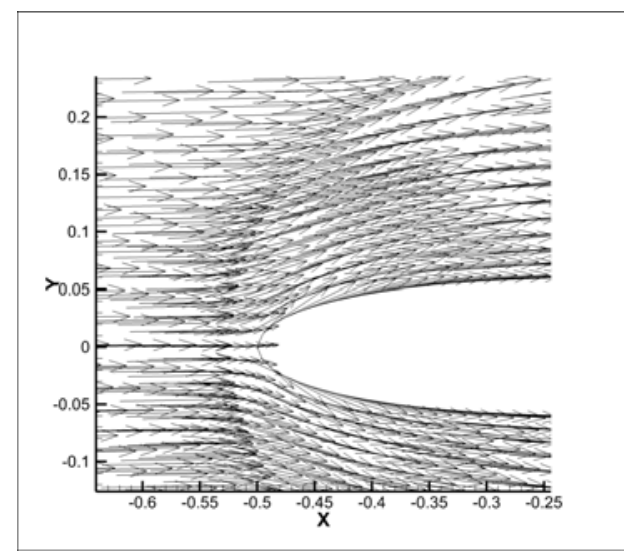

(a) Campo vetorial no bordo de ataque

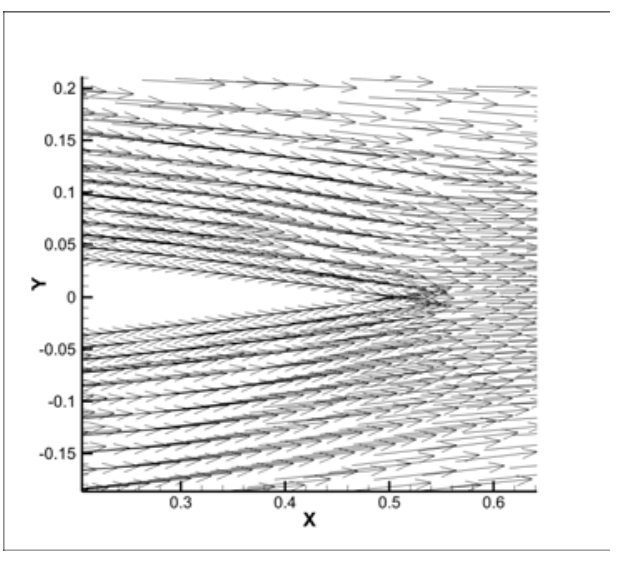

(b) Campo vetorial no bordo de fuga

Figura 5.28: Campo vetorial do escoamento do fluido sobre o perfil NACA 0012, com $M_{1}=1.0$ e $\alpha=1.0$.

Uma segunda malha com mais vértices e mais volumes foi utilizada para este mesmo esquema de escoamento. A malha possui 7363 vértices e 14400 volumes, e pode ser visualizada na Figura 5.30, onde em (a) é mostrada a malha sem aproximação do perfil, e em (b) é mostrada a malha com aproximação no perfil. 


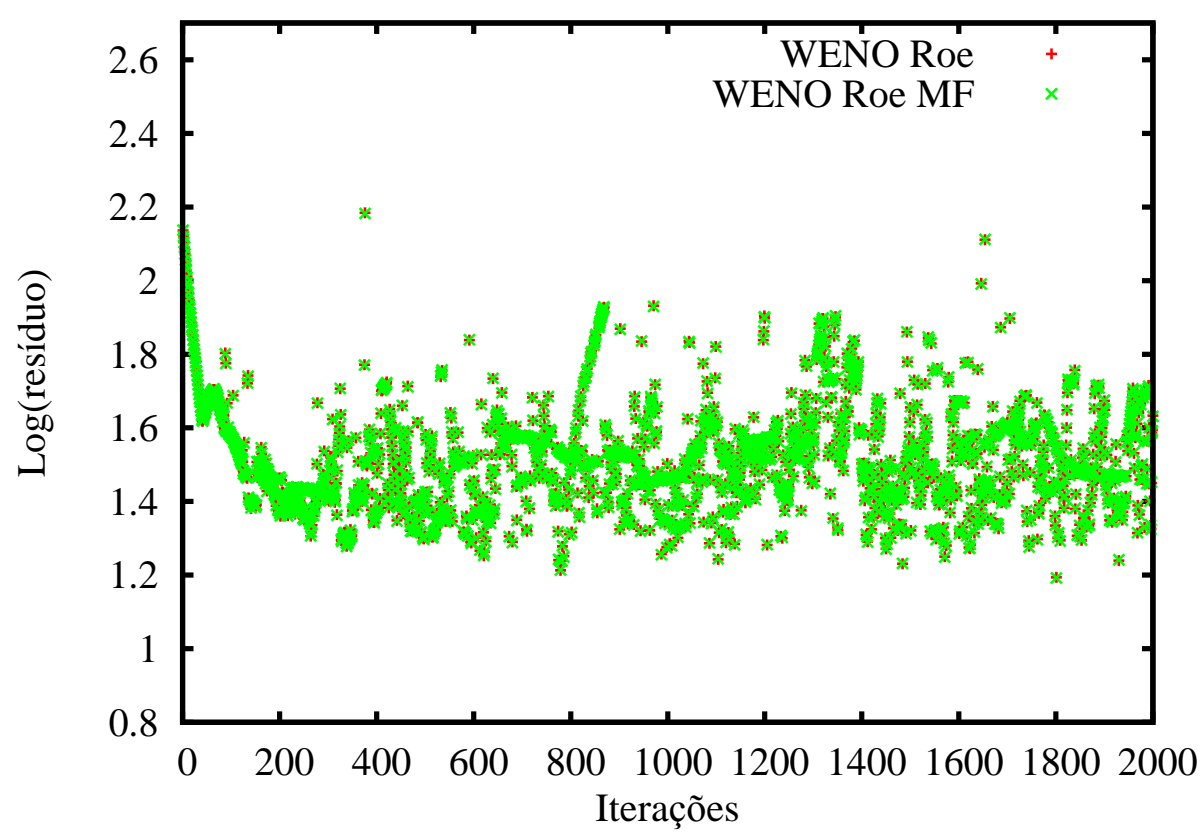

Figura 5.29: Histórico de resíduos nas 2000 primeiras iterações da simulação para uma malha com 5908 vértices.

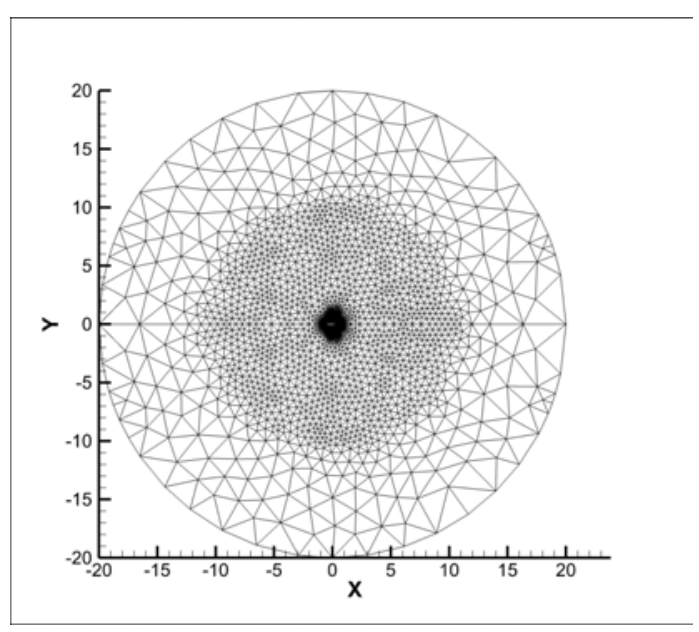

(a) Malha original

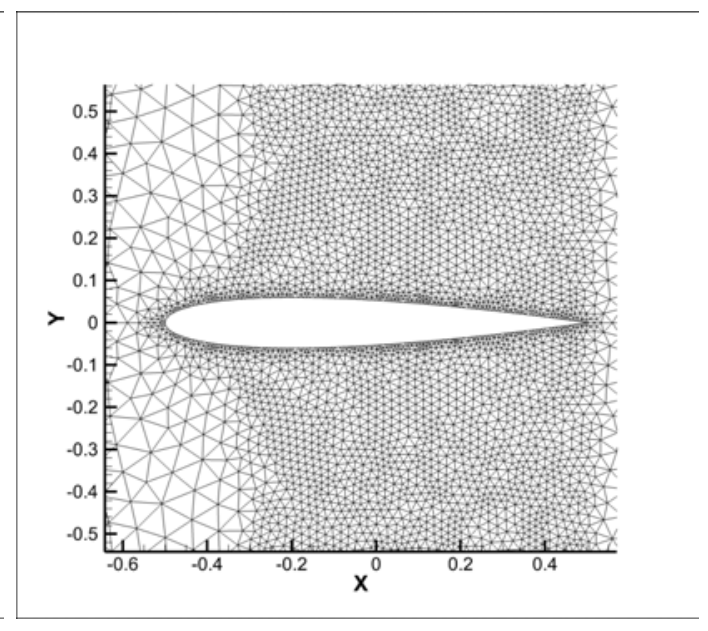

(b) Malha ao redor do aerofólio

Figura 5.30: Malha em torno do perfil NACA 0012 com 326 vértices no contorno do aerofólio.

A Figura 5.31 mostra os resultados alcançados pela simulação em relação à densidade no domínio computacional, em ambas implementações, só que agora nesta malha mais refinada. Nota-se uma pequena alteração nos valores das densidades uma vez que a malha possui maior refinamento na região do perfil.

Outro resultado mostrado na Figura 5.32 refere-se à distribuição de coeficiente de 


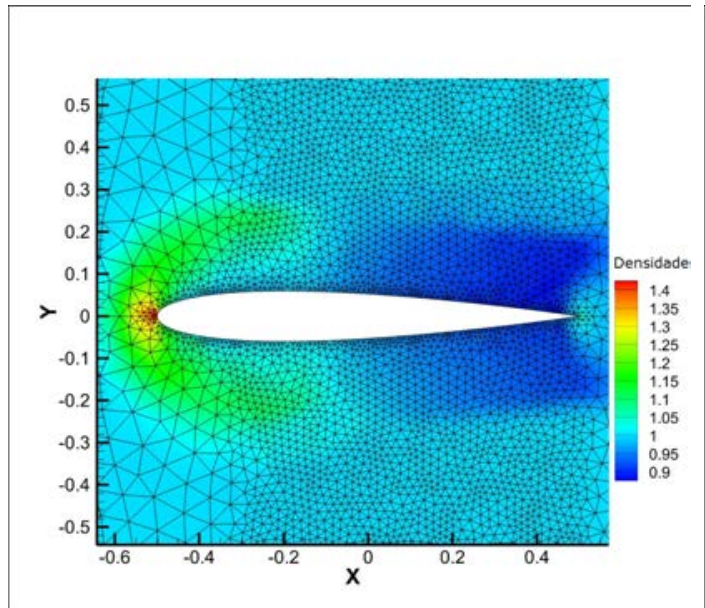

(a)

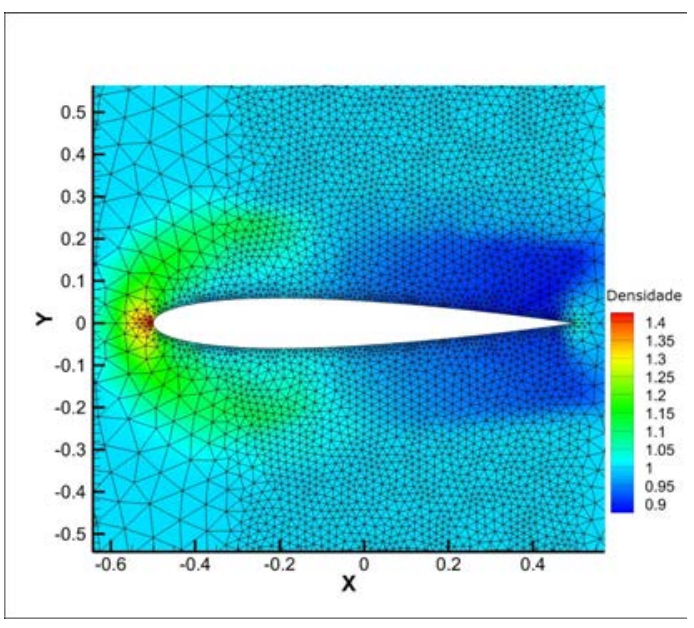

(b)

Figura 5.31: Resultados da densidade. (a) Densidade do domínio pelo simulador Original. (b) Densidade do domínio pelo simulador com a Mate Face.

pressão (Cp) ao longo do extradorso do aerofólio, onde foram apresentados os resultados para ambas implementações. O indicador de oscilação utilizado é o proposto por Jiang e Shu Jiang and Shu, 1996. O esquema WENO capturou a onda de choque com dois pontos em seu interior.

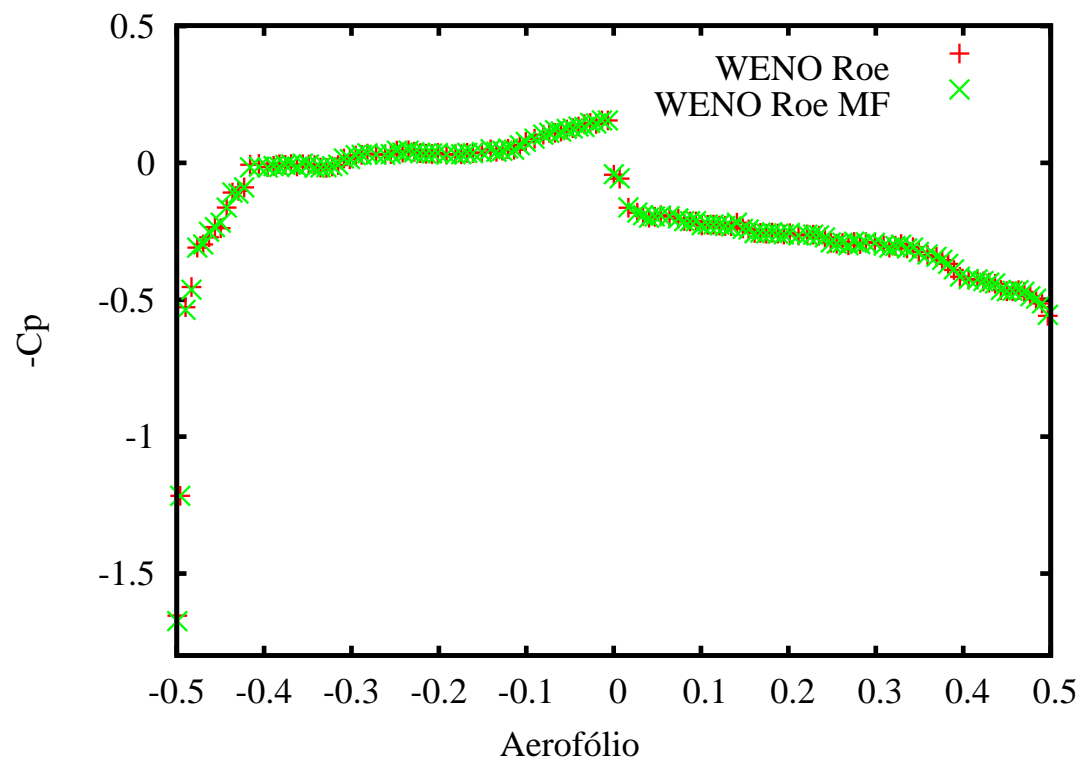

Figura 5.32: Distribuição de coeficiente de pressão ao longo do extradorso do aerofólio, com $M_{1}=1.0$, com 7363 vértices.

Na Figura 5.33(a) é mostrado o campo vetorial na região do bordo de ataque 
no perfil, onde pode-se notar a direção dada pelos vetores calculados a partir das componentes de velocidades calculadas. A Figura 5.33(b) mostra o campo vetorial próximo ao bordo de fuga do aerofólio.

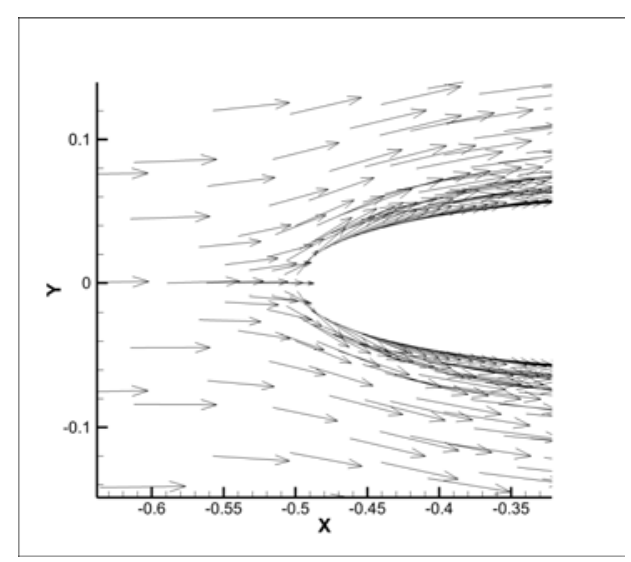

(a) Campo vetorial no bordo de ataque

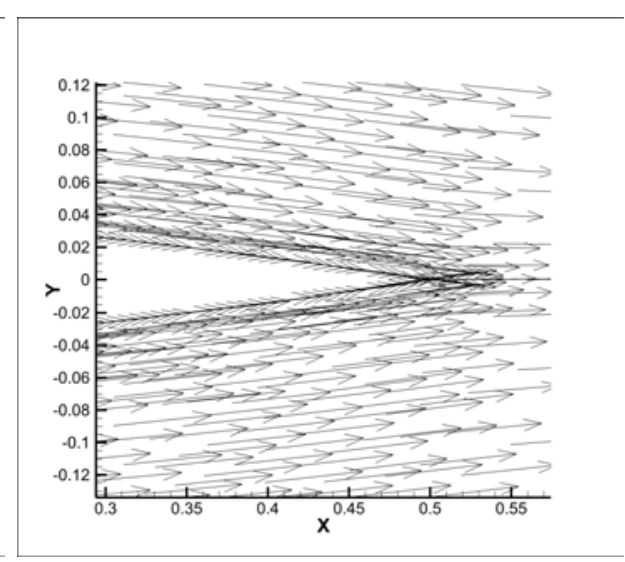

(b) Campo vetorial no bordo de fuga

Figura 5.33: Campo vetorial do escoamento do fluido sobre o perfil NACA 0012, com $M_{1}=1.0$ e $\alpha=1.0$.

O histórico do resíduo nas primeiras 2000 iterações é mostrado na Figura 5.34. Pode-se notar que a variação do resíduo na malha mais refinada é menor que a simulação na malha anterior, indicando melhor convergência na simulação.

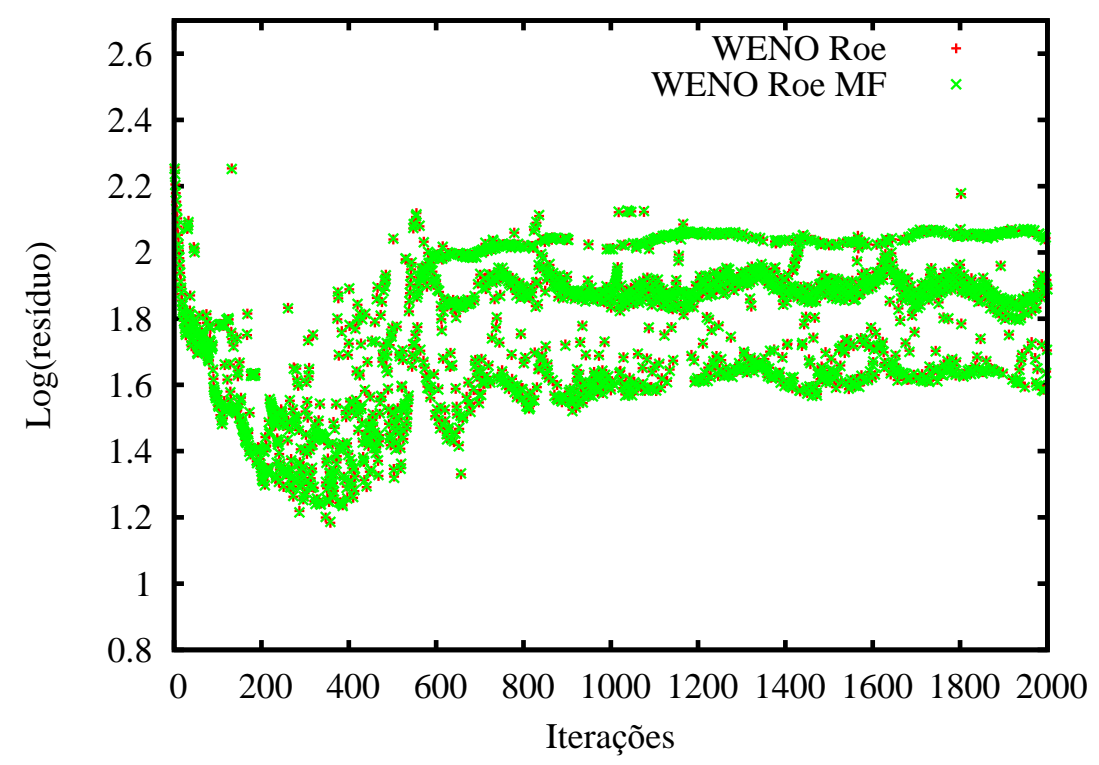

Figura 5.34: Histórico de resíduos nas 2000 primeiras iterações da simulação para uma malha com 7363 vértices. 


\subsubsection{Aplicação da Malha Elástica Sobre o Perfil NACA 0012}

Nesta seção é apresentada a verificação do algoritmo de malha dinâmica. A investigação aqui é verificar o comportamento das molas elásticas em movimentações de malha típicas em simulações de escoamentos não estacionários. Em especial, verificouse como as molas semi-torcionais se comportam mediante este tipo de movimentação, e se elas podem ser utilizadas de forma segura nessas simulações.

Para os testes, foram utilizadas três malhas que representam um aerofólio NACA 0012 em diferentes resoluções de malhas. A Tabela 5.5 mostra as características dessas malhas, referente ao número de vértices, de células e de vértices presentes no contorno do aerofólio.

\begin{tabular}{|c|c|c|c|}
\hline Malha & No. de vértices & No. de Células & No. de vértices no contorno do aerofólio \\
\hline 1 & 5908 & 11634 & 182 \\
\hline 2 & 7363 & 14400 & 326 \\
\hline 3 & 9100 & 17844 & 356 \\
\hline
\end{tabular}

Tabela 5.5: Diferentes resoluções de malhas NACA 0012 utilizadas para os testes.

São apresentadas nas Figuras 5.35(a), 5.35(b) e 5.35(c) as vistas parciais das malhas computacionais para um deslocamento do perfil com ângulo de arfagem. Observe que existem diferentes níveis de resolução perto do contorno do aerofólio, que será movimentado segundo um movimento de arfagem.

Dentre os movimentos possíveis em um aerofólio, a arfagem constitui a movimentação dos pontos no contorno do aerofólio segundo uma rotação em torno de um eixo elástico. Cada grau de arfagem movimenta os pontos do contorno e o restante da malha deve se adequar a estas mudanças. Nesta seção considera-se a arfagem definida nos pontos mediante as expressões

$$
\begin{gathered}
x_{i}^{n+1}=\left(x_{i}^{0}-x_{e a}\right) \cos (\alpha(t)) . \\
y_{i}^{n+1}=y_{i}^{0}-\left(x_{i}^{0}-x_{e a}\right) \sin (\alpha(t)) .
\end{gathered}
$$




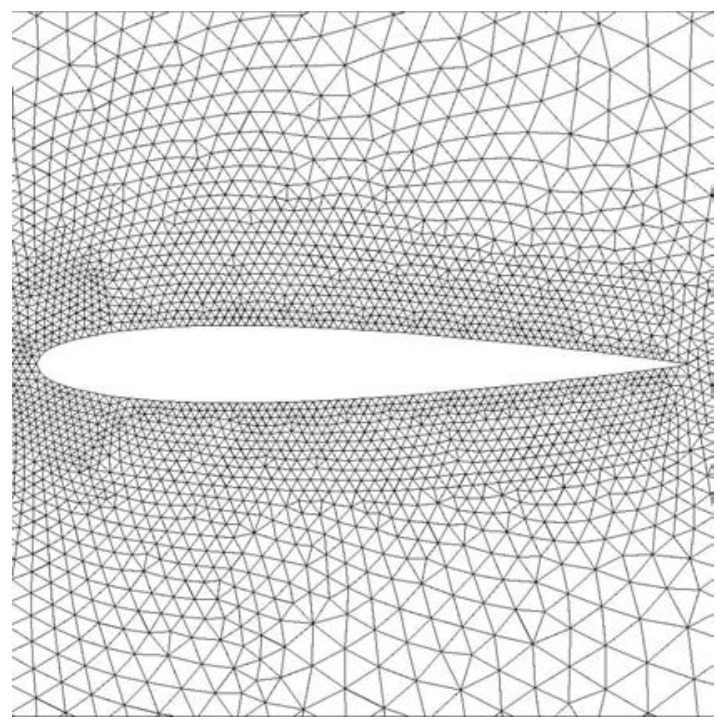

(a) Malha 1

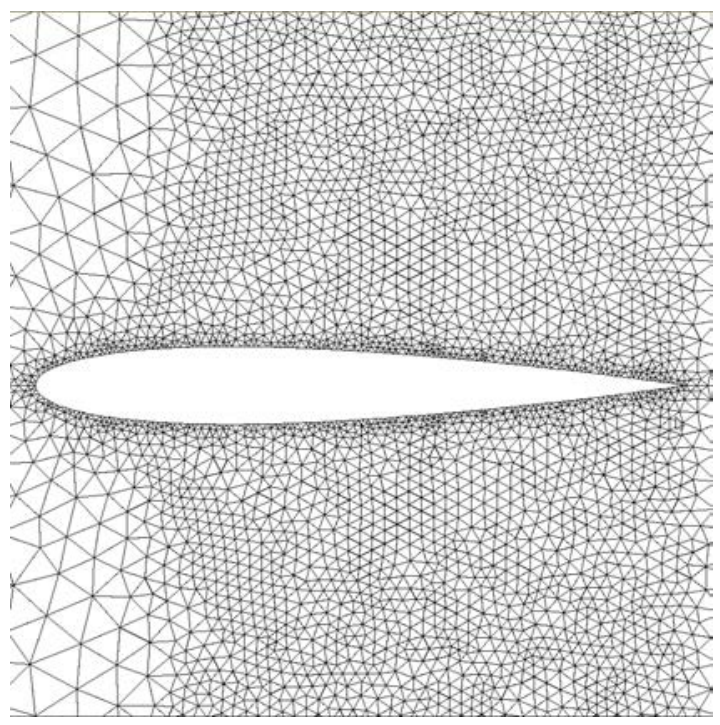

(b) Malha 2

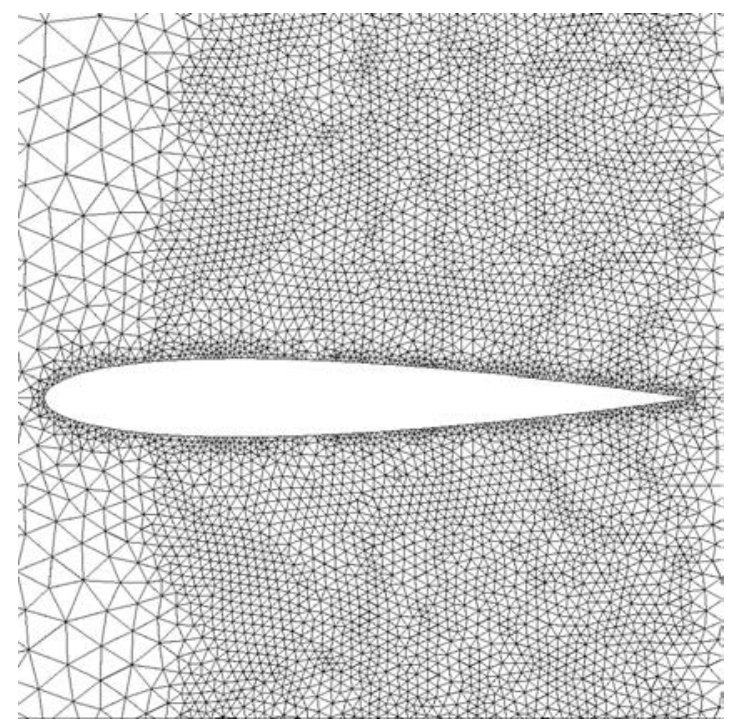

(c) Malha 3

Figura 5.35: Visualização das malhas utilizadas.

onde o subscrito ea refere-se à coordenadas do eixo elástico.

Os testes realizados utilizaram molas semi-torcionais incorporadas à Mate Face, seguindo-se a metodologia exposta na seção anterior. Embora os testes aqui sejam realizados em um ambiente controlado, pode-se assim testar diferentes angulações e analisar o comportamento do algoritmo. Em uma simulação de escoamentos não estacionários, o primeiro passo da simulação usualmente estima o primeiro valor da angulação de arfagem através de uma função senoidal, e as angulações subsequentes 
são determinadas pelo movimento do fluido e as propriedades aerodinâmicas. Usualmente, devido às oscilações na solução do escoamento, os incrementos e decrementos do ângulo de arfagem podem assumir valores grandes, e além disso, as simulações exploram grandes variações angulares.

Assim, o método de adaptação da malha dinâmica provido pela estrutura de dados deve gerar malhas consistentes, de modo que não existam elementos inválidos formados pela movimentação dos vértices no contorno do aerofólio. Os elementos que são considerados inválidos são aqueles onde um ou mais de seus vértices cruzam arestas de elementos vizinhos, causando o efeito de "área negativa". A área negativa se explica no fato de que a área de um polígono pode ser calculada pela soma das áreas de partições deste polígono. Por exemplo, um quadrado pode ser dividido em dois triângulos traçando uma linha imaginária em sua diagonal. Caso exista um cruzamento de vértices sobre arestas, a soma das áreas do polígono final (considerando uma vizinhança completa) será maior do que deveria, causando inconsistência nos métodos numéricos utilizados, como por exemplo volumes finitos. Então, a região sobreposta causada pelo cruzamento na aresta provoca inconsistência nos volumes da malha completa.

As simulações aqui realizadas são feitas de modo controlado, onde a angulação máxima é atingida incrementalmente por valores muito pequenos, pois grandes oscilações em pequenas etapas prejudicam o método baseado em molas. Testou-se variações de angulações para averiguar o comportamento da malha dinâmica. Durante os experimentos, foram encontradas algumas angulações em que produziram triangulações inválidas, em diferentes angulações para cada malha testada. As diferentes resoluções de malhas foram utilizadas para averiguar a influência que ela exerce sobre o método, testando se o refinamento da malha pode influenciar.

As malhas apresentadas na Figura 5.36 produziram malhas válidas, sem a existência de células inválidas, utilizando-se um ângulo de arfagem de 3graus. Nesse caso, este ângulo é considerado pequeno e o movimentador produziu bons resultados 
para as malhas testadas.

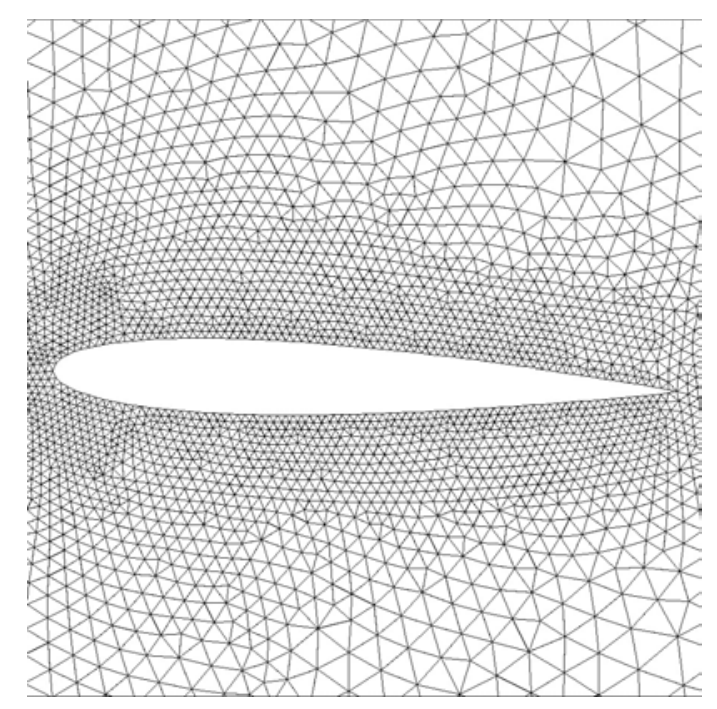

(a) Malha 1

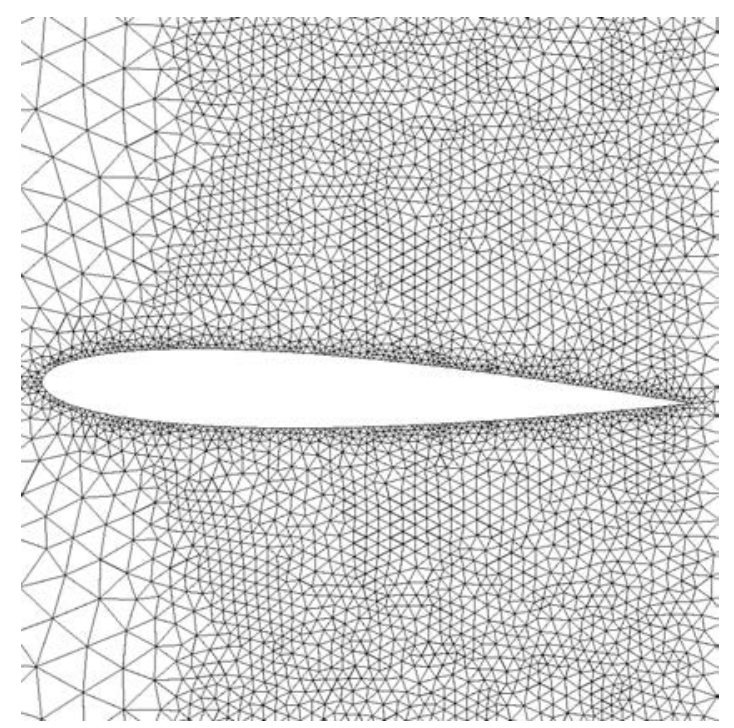

(b) Malha 2

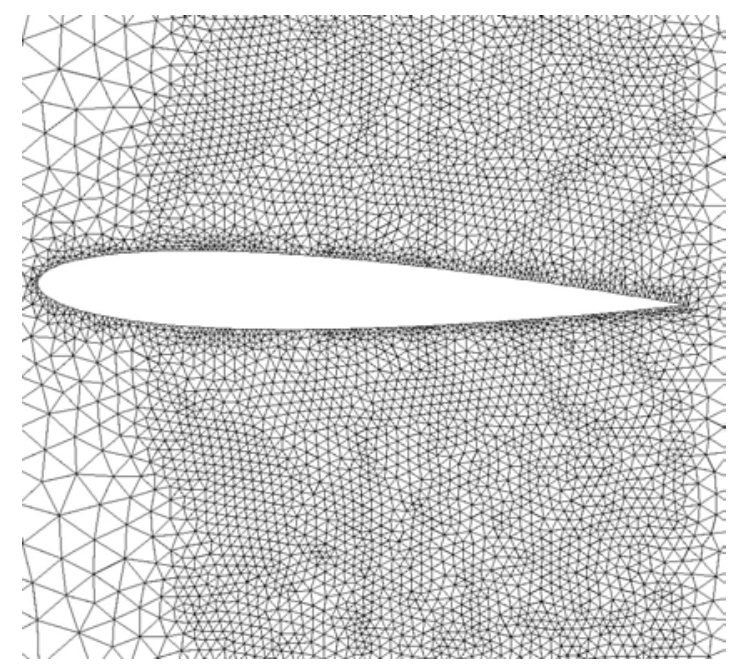

(c) Malha 3

Figura 5.36: Movimento em arfagem no aerofólio em três graus.

Foram testadas angulações maiores e analisadas suas células. As simulações numéricas em alguns casos utilizam angulações maiores para representar os escoamentos não estacionários. O método das molas semi-torcionais produziu elementos inválidos para os graus mostrados na Figura 5.37, de maneira diferente para cada malha. O bordo de fuga é a região que apresentou maiores problemas, pois se trata de uma região côncava, usualmente difícil de ser tratada.

Verificando-se os resultados, conclui-se que o refinamento da malha tem influência 


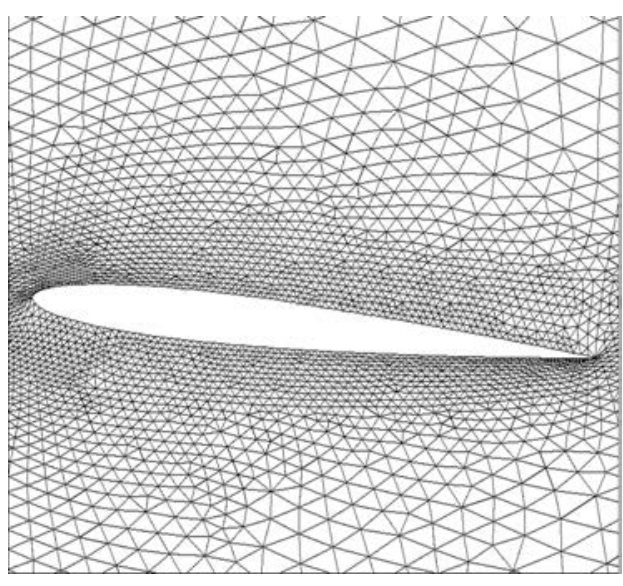

(a) Malha 1: Arfagem $6^{\circ}$

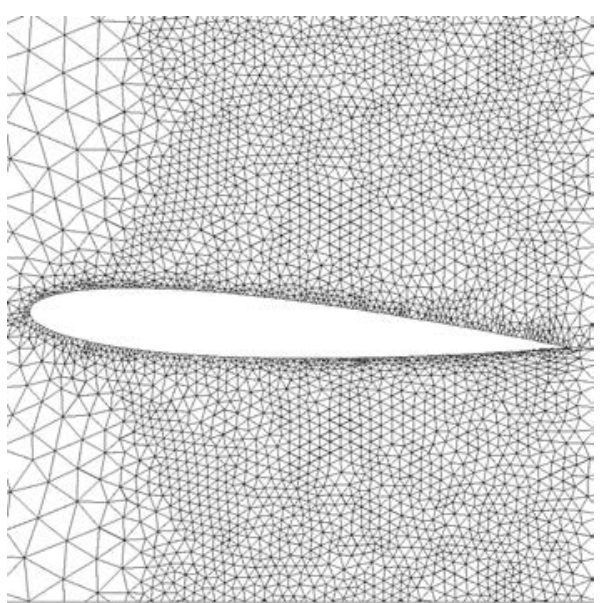

(c) Malha 2: Arfagem $5^{\circ}$

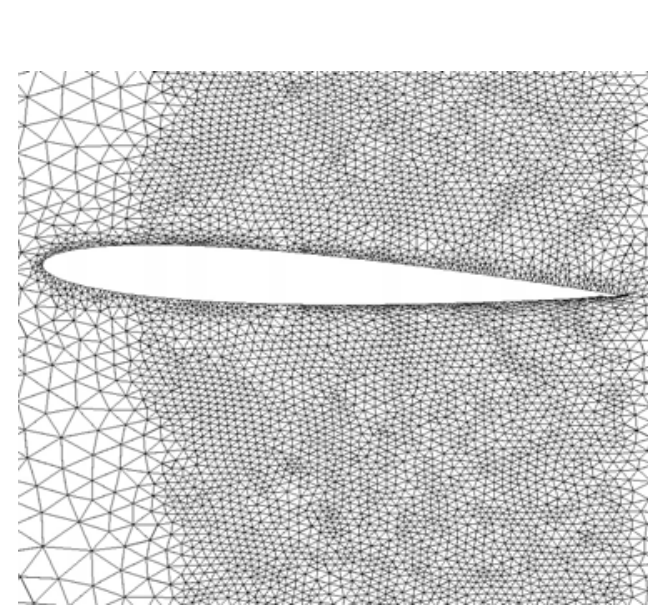

(e) Malha 3: Arfagem $5^{\circ}$

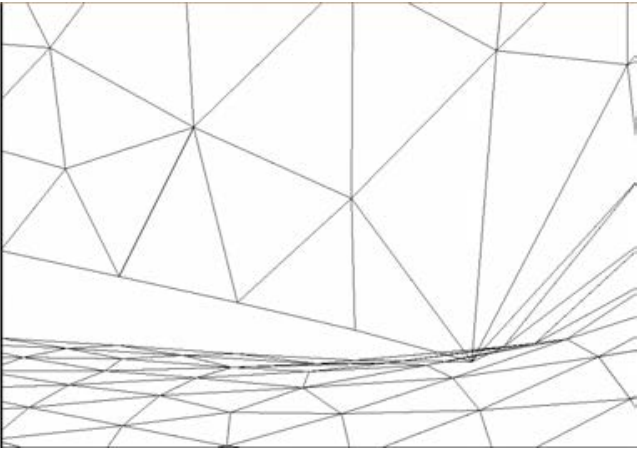

(b) Bordo de fuga

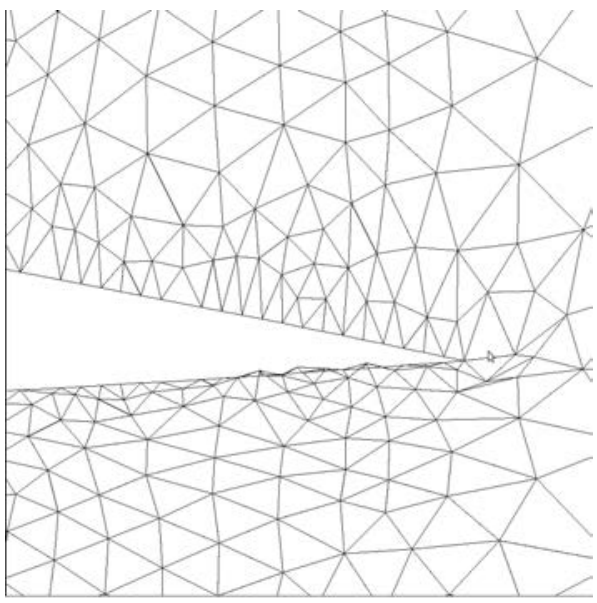

(d) Bordo de fuga

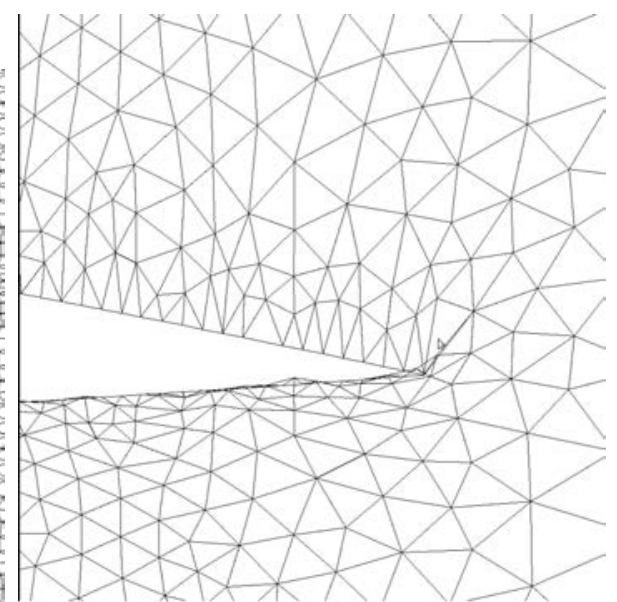

(f) Bordo de fuga

Figura 5.37: Movimento em arfagem no aerofólio com elementos inválidos.

na qualidade dos elementos resultantes da movimentação, mas não impediu que existissem elementos inválidos. Assim, além de controlar oscilações bruscas na movi- 
mentação, uma vez que o sistema de molas se comporta melhor quanto menor for a deformação do domínio da malha, deve-se também realizar um tratamento adicional na fronteira para certificar-se da manutenção de elementos válidos.

Uma possível solução para estes problemas foi proposto por Soares [Soares, 2007], que propôs uma técnica de correção da componente do bordo de fuga a partir do uso de molas conservativas na fronteira. As molas conservativas desempenham o papel de adicionar forças ao sistema de molas que contribuam para a "conservação" do aspecto original da fronteira. No entanto, o tratamento da fronteira pode criar uma descrição geométrica que difere da original, o que pode não ser aceitável em algumas aplicações. Assim, se a aplicação exige fidelidade na descrição geométrica, considera-se evitar este tratamento de fronteira e remodelar a geometria a cada passo da iteração.

\subsection{Considerações Finais}

Este capítulo abordou os esquemas não oscilatórios do tipo Essentially NonOscillatory (ENO), os esquemas Weighted Essentially Non-Oscillatory (WENO) e suas reconstruções para esquemas de segunda, terceira e quarta ordem de precisão. Os esquemas ENO e WENO foram desenvolvidos com a finalidade de capturar com eficiência descontinuidades presentes em problemas governados por equações diferenciais parciais hiperbólicas. Foram apresentados os trabalhos na literatura que utilizaram estes métodos em suas aplicações, mostrando a abrangência de aplicação do método.

Foram apresentadas as discretizações espaciais e temporais para o método em questão, assim como a maneira que é realizada a reconstrução dos polinômios interpoladores a partir das moléculas de cálculo. O processo de reconstrução dos esquemas ENO teve base na aproximação dos valores médios das variáveis primitivas para cada volume de controle da malha por polinômios de uma ordem inferior à ordem de precisão espacial desejada.

Foi realizada uma discussão detalhada sobre o acoplamento feito da estrutura de 
dados Mate Face ao simulador existente, apresentando a biblioteca desenvolvida que funciona como uma interface de comunicação entre os dois módulos, a estrutura de dados e o simulador. Nesta discussão, foram apresentadas todas as implicações deste acoplamento, uma vez que o acoplamento é feito a partir de duas linguagens de programação diferentes. Foram mostradas as alterações mais significativas no simulador existente para comportar a estrutura Mate Face, através de exemplos de consultas na malha.

Por fim, foram apresentadas aplicações para validar a estrutura de dados acoplada ao simulador através de experimentos realizados em casos distintos de aplicação. Além disso, foi realizado um estudo para investigar as malhas dinâmicas através do uso do método de molas semi-torcionais e suas implicações sobre movimentos de arfagem em aerofólios. 


\section{Capítulo \\ 6 \\ Método de Volumes Finitos Espectrais}

Este capítulo apresenta o método de volumes finitos espectrais, que é um método de alta ordem que foi desenvolvido para malhas não estruturadas para a obtenção de soluções estacionárias de escoamentos não viscosos e compressíveis, representado pelas equações de Euler. Este método é utilizado para se obter alta resolução espacial no domínio computacional. Neste método, os volumes de controle (CV) usados não são as células completas, mas volumes menores que são obtidos pelo particionamento de cada célula, também chamadas de volumes espectrais (SV), através de um modo pré-definido. Cada ordem de precisão define um particionamento diferente, formando diferentes células internas à célula original.

A formulação geral do método é apresentada, assim como os tipos de particionamentos realizados pelo método. É apresentada a formulação do limitador de fluxo, que possui a função de limitar algumas propriedades da reconstrução nos pontos de integração do fluxo para manter a estabilidade e convergência da simulação, se a solução no escoamento conter descontinuidades.

Como o particionamento feito pelo método gera elementos de diferentes topolo- 
gias, foi necessário modificar a estrutura de dados Mate Face de forma a suportar o armazenamento desses elementos. A extensão é mostrada com exemplos de utilização com base nos novos elementos gerados pelo método.

Por fim, são realizados experimentos que validam a modificação da estrutura de dados que auxilia o método de volumes finitos espectrais durante as simulações.

\subsection{Considerações Iniciais}

A metodologia básica do método de volumes finitos espectrais (SFV - do inglês Spectral Finite Volume) foi apresentado por Wang [Wang, 2002], junto com sua aplicação para leis de conservação hiperbólicas escalares de uma dimensão. A extensão do método SFV para equações escalares de duas dimensões e um estudo de diferentes estratégias limitantes para capturar descontinuidades na solução, foi apresentada mais tarde por Wang e Liu Wang and Liu, 2002. Os mesmos autores apresentaram a extensão para o método SFV para sistemas de leis de conservação unidimensionais, junto com um estudo de otimização das partições realizadas pelo método Wang and Liu, 2004.

A primeira aplicação para problemas de escoamentos não viscosos bidimensionais, governados por equações de Euler 2D, foi proposto por Wang et. al. Wang et al., 2004. Um problema muito importante com todos métodos de alta ordem, que é o tratamento de elementos curvos da fronteira, foi alvo de estudo para o método SFV 2D por Wang e Liu Wang and Liu, 2006, que utiliza um mapeamento geométrico de alta ordem das células espectrais próximas de tais fronteiras.

Breviglieri Breviglieri, 2010] aplicou o esquema SFV em um contexto de volumes finitos centrado na célula usando malhas não estruturadas. As equações de Euler representaram o escoamento estudado, e um esquema de discretização espacial de segunda, terceira e quarta ordem de resolução foram desenvolvidas. Para a integração no tempo foram utilizados esquemas implícitos e explícitos. Limitadores de fluxo foram utilizados para a aplicação de alta resolução. 
A extensão para sistemas tridimensionais de leis de conservação foi feita por Liu et. al. Liu et al., 2006, que aplicaram o método SFV para problemas eletromagnéticos computacionais 3D (CEM).

A primeira formulação do método SFV para equações de Navier-Stokes foi desenvolvida e apresentada por Sun et. at. Sun et al., 2006. Haga et. al. resolveram problemas de Navier-Stokes e de Euler 3D com o método SFV, usando um supercomputador.

Uma contribuição para o método SFV para problemas difusivos foi feito por Kannan et. al. Kannan and Wang, 2009, que investigaram diferentes formulações para a discretização dos termos difusivos junto ao método SFV. Uma comparação entre os métodos SFV e DG (método de Galerkin descontínuo) foi feita por Sun e Wang Sun and Wang, 2004 e também por Zhang e Shu Zhang and Shu, 2005.

O método SFV 3D é potencialmente caro computacionalmente se uma formulação padrão baseada em regras de quadratura gaussiana forem utilizadas. Em analogia com a formulação livre de quadratura no método DG, a formulação livre de quadratura do método SFV é mais eficiente que a formulação padrão em termos computacionais, conclusão esta presente no trabalho apresentado por Harris et. al. Harris et al., 2008.

Um esforço que foi orientado especificamente para a definição adequada de partições SFV de células simplexas, baseado no critério da constante de Lebesgue formulado por Wang e Liu Wang and Liu, 2002, foi feito por Chen Chen, 2005 Chen, 2006. Posteriormente, Van den Abeele et. al. den Abeele and Lacor, 2007 den Abeele et al., 2007 aplicou técnicas de análise de estabilidade para guarantir as propriedades de acurácia e estabilidade de esquemas correspondendo a partições SFV 1D, 2D e 3D de células simplexas. Um trabalho em particular, feito por Harris e Wang Harris and Wang, 2009, esta técnica de análise foi acoplada a um algoritmo de otimização, com o objetivo de identificar partições SFV ótimas.

Nesta etapa do trabalho foi utilizado o método dos volumes finitos espectrais 
para o caso bidimensional, baseando-se nos trabalhos correspondentes de Wang Wang et al., 2004 e no trabalho feito por Breviglieri Breviglieri, 2010. A formulação geral do método é apresentada na seção a seguir.

\subsection{Formulação Geral}

Assim como o método de volumes finitos, o método de volumes finitos espectrais usa médias sobre volumes de controle, como variáveis da solução. Entretanto, os volumes de controle que são usados com o método de volumes finitos espectrais não são as células completas, mas volumes menores que são obtidos por particionamento de cada célula, também chamadas de Volumes Espectrais, através de um modo pré-definido.

O número de volumes de controle, no qual uma célula é subdividida, depende da ordem de acurácia desejada, uma vez que um certo número de valores são minimamente necessários para construir um polinômio de tal grau. Para um esquema de ordem de acurácia de ordem $p+1$, uma reconstrução polinomial de grau $p$ é necessária. O número de volumes de controle $\left(N_{C V}\right)$ para segmentos de retas (caso 1D), triângulos (caso 2D) e tetraedros (caso 3D) nos quais os elementos são subdivididos é:

$$
N_{C V}=\frac{(p+d) !}{p ! d !}
$$

onde $d$ é a dimensionalidade e $p$ é o grau do polinômio escolhido. Para o caso de quadriláteros e hexaedros, o número de volumes de controle $N_{C V}$ é:

$$
N_{C V}=(p+1)^{d}
$$

As subdivisões para o caso unidimensional é feita em segmentos de reta, e podem ser realizadas conforme ilustrado na Figura 6.1. Na Figura 6.1(a) é feita a subdivisão em dois volumes de controle, referente ao esquema de ordem 2. Na Figura 6.1(b) é feita a subdivisão em três volumes de controle, referente ao esquema de ordem 3 , e a 
subdivisão mostrada na Figura 6.1(c) é ilustrado o caso do esquema de ordem 4. No caso das Figuras 6.1(b) e 6.1(c), o parâmetro $\alpha$ representa o grau de liberdade para a formação das partições, que será explicado mais adiante.

As subdivisões para células triangulares podem ser feitas de várias maneiras. Um exemplo é ilustrado na Figura 6.2 para células triangulares, para cada ordem de acurácia, chamada também de ordem espectral. Na Figura 6.2(a) temos a subdivisão da célula original em três volumes de controle, referente ao esquema de ordem 2. Na Figura 6.2(b) temos a subdivisão da célula original em seis volumes de controle, referente ao esquema de ordem 3. Por fim, a Figura 6.2 (c) mostra a subdivisão da célula original em 10 volumes de controle, referente ao esquema de ordem 4.

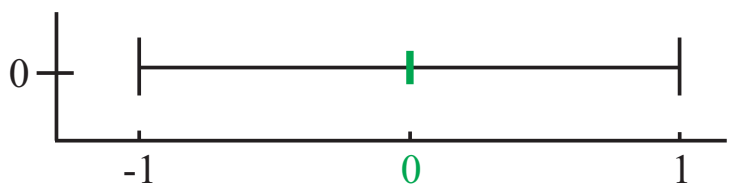

(a)

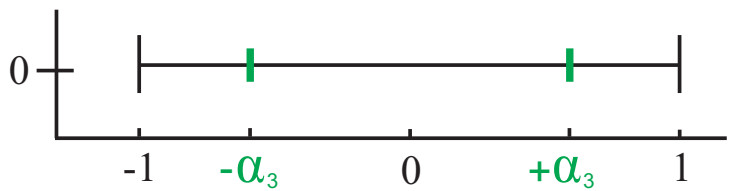

(b)

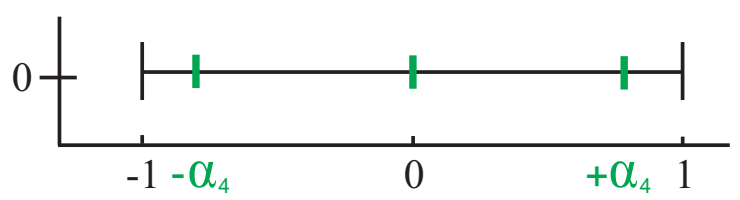

(c)

Figura 6.1: Exemplos de particionamento de células de volumes espectrais para o caso unidimensional.

Integrando a lei de conservação hiperbólica da Equação 3.33 para cada CV em cada célula SV e aplicando o teorema de Gauss, resulta

$$
\frac{d \mathbf{Q}_{i, j}}{d t}=\frac{1}{V_{i, j}} \int_{\partial S_{i, j}} \mathbf{P} \cdot \mathbf{n} d S
$$

onde $V_{i, j}$ é a área do volume de controle e a média das variáveis conservadas são 


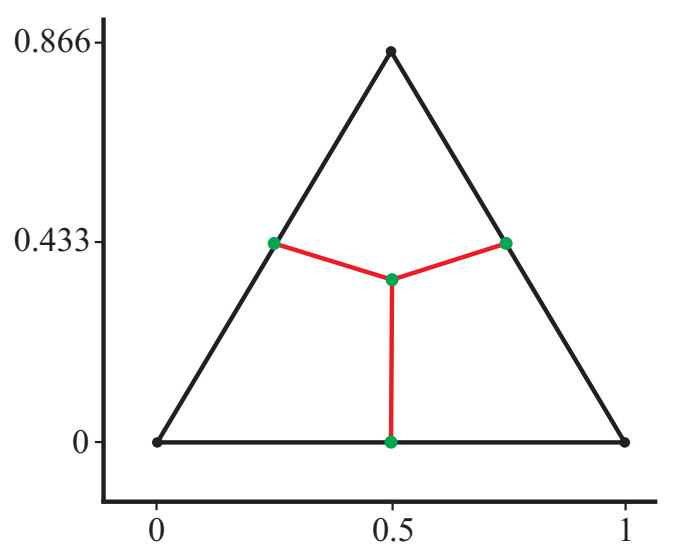

(a) Esquema de ordem 2

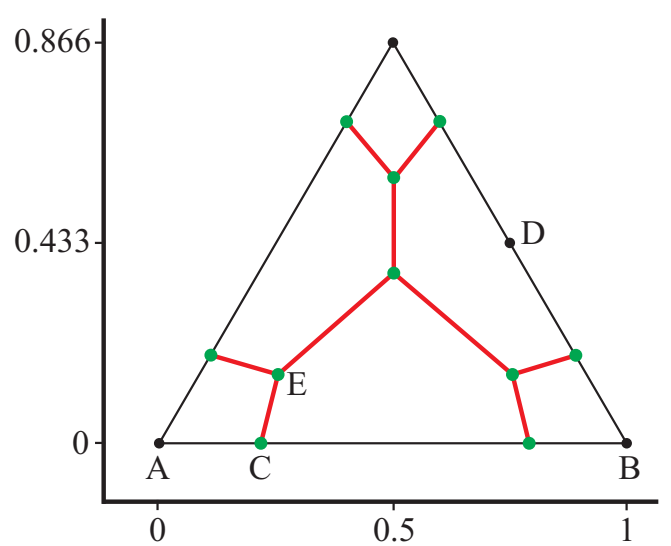

(b) Esquema de ordem 3

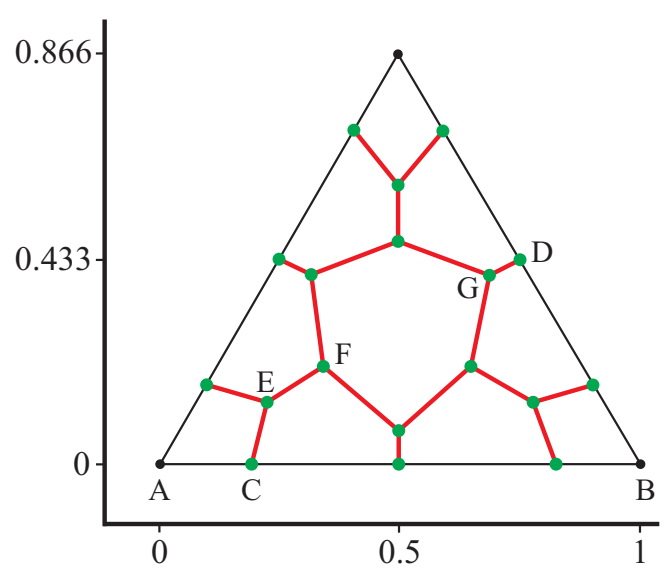

(c) Esquema de ordem 4

Figura 6.2: Exemplos de particionamento de células de volumes espectrais para o caso bidimensional.

definidas por

$$
\bar{Q}_{i, j}=\frac{1}{V_{i, j}} \int_{V_{i, j}} \mathbf{Q} d V
$$

A principal diferença deste método ao método de volumes finitos é que as variáveis conservadas, obtidas pelas médias dos volumes de controle de cada volume espectral, em cada célula $i$ permite facilmente construir um polinômio de grau $p$ que aproxima a solução naquela célula. O espaço de aproximação da solução do método SFV é então o espaço de partes de polinômios contínuos de grau $p$, que permite uma ordem de acurácia igual a $p+1$.

A solução polinomial em cada célula permite calcular as integrais de superfície nas arestas internas que formam os CVs com ordem de acurácia $(p+1)$, usando fórmulas 
de quadratura gaussianas adequadas. Nas arestas externas, que são posicionadas de modo a dividir as SVs, dois valores aproximados para as variáveis conservadas estão disponíveis pelas soluções polinomiais correspondentes às duas células vizinhas. A contribuição destas arestas à vizinhança dos CVs devem ser iguais em magnitude e opostas em sinal. Para garantir isto, são usados solvers de Riemann aproximados. Então, a expressão final da discretização espacial é

$$
\begin{aligned}
\frac{d \mathbf{Q}_{i, j}}{d t}= & -\frac{1}{V_{i, j}} \sum_{k=1}^{n f} \int_{\partial V_{i, j}} \mathbf{P} \cdot \mathbf{n} d S \\
& -\frac{1}{V_{i, j}} \sum_{k=1}^{n f} \int_{\partial V_{i, j}} \mathbf{f} \cdot \mathbf{n} d S=\mathbf{R}_{i, j}
\end{aligned}
$$

onde as arestas e as integrais das áreas devem ser calculadas usando quadraturas gaussianas que garantem a ordem de acurácia desejada. Dados os valores para as médias das variáveis conservadas, os resíduos $\mathbf{R}_{i, j}$ da Equação 6.5 podem ser calculados seguindo o mesmo procedimento que o realizado no método de volumes finitos. Note que para $p=0$, o método SFV se reduz para o método clássico de primeira ordem de volumes finitos.

\subsection{Particionamento}

A formação das partições podem ser realizadas de diferentes maneiras. As partições apresentadas aqui pertencem ao conjunto das possíveis partições disponíveis para o método SFV. Cada esquema de particionamento apresentado possui parâmetros que podem ser ajustados de modo a gerar diferentes geometrias para os vértices espectrais criados, mas mantendo a mesma topologia interna para cada volume espectral. Esses parâmetros ajustáveis são denotados por graus de liberdade, e estes estão definidos para um intervalo fixo para não alterar sua topologia.

No caso das partições para células unidimensionais, conforme ilustradas na Figura 
6.1. existem diferentes graus de liberdade para a formação de suas partições. No caso ilustrado na Figura 6.1(b), referente à partição de ordem 3, o particionamento possui um grau de liberdade definido por $\alpha_{3}$, que pode variar no intervalo $0<\alpha_{3}<1$. $\mathrm{O}$ caso mostrado na Figura 6.1(c) mostra uma partição para o esquema de quarta ordem. Novamente, existe um parâmetro $\alpha_{4}$ que define um grau de liberdade que pode variar novamente dentro do intervalo $0<\alpha_{4}<1$. Note que os intervalos são abertos para que não haja sobreposição de vértices de maneira a alterar a topologia dos volumes de controle.

As partições dos volumes espectrais em volumes de controle para esquemas SFV de segunda ordem de acurácia são definidas dentro das regras mostradas na Figura 6.2(a). Assim, os vértices são criados no ponto médio de cada aresta e no centroide da célula e não há nenhum grau de liberdade para essa topologia. Mas as partições de maior ordem podem ser definidas de maneira diferente.

$$
\begin{aligned}
& \alpha_{3}=\frac{|A C|}{|A B|}, 0<\alpha_{3}<\frac{1}{2} \\
& \beta_{3}=\frac{|A E|}{|A D|}, 0<\beta_{3}<\frac{2}{3}
\end{aligned}
$$

A partição de ordem 3 ilustrada na Figura 6.2(b) possui dois graus de liberdade, $\alpha_{3}$ e $\beta_{3}$, que são definidos dentro das proporções indicadas na Equação 6.6. Pode-se utilizar estes parâmetros dentro deste intervalo de modo a construir diferentes geometrias para este particionamento. O pontos $\{\mathrm{A}, \mathrm{B}, \mathrm{C}, \mathrm{D}, \mathrm{E}\}$ são mostrados na Figura 6.2(b) e são usados para definir as proporções dadas pelos graus de liberdade.

A partição de ordem 4 ilustrada na Figura 6.2(c) possui quatro graus de liberdade, definidos por $\alpha_{4}, \beta_{4}, \gamma_{4}$ e $\delta_{4}$, que são definidos dentro das proporções indicadas na Equação 6.7. Pode-se utilizar estes parâmetros dentro deste intervalo de modo a construir diferentes geometrias para este particionamento. O pontos $\{A, B, C, D, E, F, G\}$ são mostrados na Figura 6.2(c) e são usados para definir as proporções dadas pelos graus de liberdade. 


$$
\begin{aligned}
& \alpha_{4}=\frac{|A C|}{|A B|}, 0<\alpha_{4}<\frac{1}{2} \\
& \beta_{4}=\frac{|A E|}{|A D|}, 0<\beta_{4}<\frac{2}{3} \\
& \gamma_{4}=\frac{|G D|}{|A D|}, 0<\gamma_{4}<\frac{1}{3} \\
& \delta_{4}=\frac{|A F|}{|A D|}, \beta_{4}<\delta_{4}<\frac{2}{3}
\end{aligned}
$$

Um dos aspectos mais importantes para o método SFV, como em qualquer método CFD, é a reconstrução dos dados. Isto define um papel importante para determinar as propriedades de acurácia e estabilidade do esquema. As subseções a seguir definem o processo de reconstrução para os casos 1D e 2D.

\subsubsection{Reconstrução 1D}

Para definirmos a reconstrução polinomial baseada nas médias das variáveis das células, considere a lei de conservação unidimensional

$$
\frac{\partial}{\partial t} u(x, t)+\frac{\partial}{\partial x} f(u(x, t))=0
$$

com $u(x, 0)=u_{0}(x), \forall x \in[a, b]$ e as condições de contorno periódicas. Agora considere o intervalo padrão $[-1,1]$ como o volume espectral.

Os polinômios no conjunto base são polinômios de ordem $k-1$, os quais são dependentes somente na distribuição dos $k+1$ pontos da partição. Assim, para o caso $1 \mathrm{D}$, temos

$$
p_{i}(x)=\sum_{j=1}^{k} L_{j}(x) \bar{u}_{i, j}
$$

Na equação acima, L pode ser escrito como 


$$
h_{i, j} \sum_{r=j}^{k} \frac{1}{w^{\prime}\left(x_{i, r+0.5}\right)} \sum_{\substack{m=0 \\ m \neq 0}}^{k} \prod_{\substack{q=0 \\ q \neq r, m}}\left(x-x_{i, q+0.5}\right)
$$

$\operatorname{com} w(x)=\left(x-x_{i, 0.5}\right)\left(x-x_{i, 1.5}\right) \ldots\left(x-x_{i, k+0.5}\right)$.

Os polinômios resultantes se tornam menos oscilatórios se os pontos da malha no intervalo $[-1,1]$ são os pontos de Gauss-Lobatto, definidos por

$$
x_{i, j+0.5}=-\cos \left(\frac{j \pi}{k}\right), j=0, \ldots, k
$$

\subsubsection{Reconstrução 2D}

O stêncil de reconstrução para o método SFV é definido pela partição realizada nos volumes espectrais. Uma vez selecionada um esquema de particionamento, as bases polinomiais, ou funções de forma, definidas para aquela partição, são usadas para construir um polinômio de alta ordem para cada SV, para completar a reconstrução. Estas funções de forma, são calculadas como

$$
L(x, y)=e(x, y) R^{-1}
$$

onde $e$ representa o vetor de função base $\left[e_{1}, \ldots, e_{N}\right]$, que contém a base polinomial completa da dimensão do espaço de aproximação, e $R$ é a matriz de reconstrução, calculada por

$$
R=\left[\begin{array}{ccc}
\frac{1}{V_{i, 1}} \int_{C V_{i, 1}} e_{1}(x, y) d S & \ldots & \frac{1}{V_{i, 1}} \int_{C V_{i, 1}} e_{N}(x, y) d S \\
\vdots & \ldots & \vdots \\
\frac{1}{V_{i, N}} \int_{C V_{i, N}} e_{1}(x, y) d S & \ldots & \frac{1}{V_{i, N}} \int_{C V_{i, N}} e_{N}(x, y) d S
\end{array}\right]
$$

onde $C V_{i, j}$ é o j-ésimo volume de controle no volume espectral. Aqui, $N$ é usado para definir o número de volumes de controle nos volumes espectrais. Em geral, a forma e a partição de um volume espectral pode ser arbitrária enquanto a matriz de 
reconstrução seja não singular.

Para obter-se uma reconstrução universal para o método SFV, é necessário definir uma transformação do elemento físico para um elemento "padrão". Considere a transformação $\psi: S \rightarrow D$, que transforma um triângulo arbitrário $S$ para um triângulo $D$. Seja $(x, y)$ o espaço de coordenadas de $S$ e $(\xi, \eta)$ o espaço de coordenadas de $D$. Assumindo que $r_{0}=\left(x_{0}, y_{0}\right), r_{1}=\left(x_{1}, y_{1}\right)$ e $r_{2}=\left(x_{2}, y_{2}\right)$ definem o elemento triangular em $S$, cuja correspondência em $D$ é definida por $(0,0),(1,0)$ e $(0,1)$, respectivamente, a transformação pode ser escrita como:

$$
\psi: r=r_{0}+\left(r_{1}-r_{0}\right) \xi+\left(r_{2}-r_{0}\right) \eta, \quad \xi \geq 0, \quad \eta \geq 0, \quad e \xi+\eta \leq 1
$$

Uma vez que a transformação acima é linear, pode-se escrever:

$$
e(x, y)=e(\xi, \eta) T
$$

onde $T$ representa a matriz de transformação, contendo somente a posição nodal de $S$. Mais ainda, $d V=d x d y=2 V d \xi d \eta$. Substituindo nas Equações 6.15 e 6.12, tem-se

$$
\left[\begin{array}{ccc}
\int_{C V_{1}} e_{1}(\xi, \eta) d \xi d \eta & \ldots & \int_{C V_{1}} e_{N}(\xi, \eta) d \xi d \eta \\
\vdots & \ldots & \vdots \\
\int_{C V_{N}} e_{1}(\xi, \eta) d \xi d \eta & \ldots & \int_{C V_{N}} e_{N}(\xi, \eta) d \xi d \eta
\end{array}\right]^{-1}\left[\begin{array}{ccc}
\frac{V_{1}}{2 V} & 0 & 0 \\
0 & \ldots & 0 \\
0 & 0 & \frac{V_{N}}{2 V}
\end{array}\right]
$$

sendo que $L=\left[e_{1}(\xi, \eta), \ldots, e_{N}(\xi, \eta)\right]$.

Uma vez que as funções polinomiais base $e_{l}$ são escolhidas, as funções de forma $L$ são unicamente definidas pela partição do volume espectral. A maior vantagem do método SFV é que o processo de reconstrução não precisa ser refeito para cada elemento SV da malha. Uma vez que a partição dos SV é definida, a mesma partição pode ser aplicada para todos os elementos, pois a matriz de reconstrução é a mesma. Assim, as funções polinomiais base para as reconstruções linear, quadrática e cúbica 


\begin{tabular}{|c|c|}
\hline Ordem de Reconstrução & $\mathrm{e}$ \\
\hline linear & {$\left[\begin{array}{lll}1 & x & y\end{array}\right]$} \\
\hline quadrático & {$\left[\begin{array}{llllll}1 & x & y & x^{2} & x y & y^{2}\end{array}\right]$} \\
\hline cúbico & 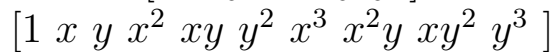 \\
\hline
\end{tabular}

Tabela 6.1: Funções polinomiais base para o método espectral.

são listadas na Tabela 6.1 .

A integração das funções base para a matriz de reconstrução é calculada com relações analíticas Liu and Vinokur, 1998, como mostrado a seguir. Note que a somatória é feita nos vértices da forma fundamental, neste caso um triângulo e portanto $n=3$.

$$
\begin{aligned}
\int x d S & =\frac{1}{n} \sum_{i}\left(x_{i}\right) \\
\int y d S & =\frac{1}{n} \sum_{i}\left(y_{i}\right) \\
\int x^{2} d S & =\frac{1}{n(n+1)}\left(\left(\sum_{i}\left(x_{i}\right)\right)^{2}+\sum_{i}\left(x_{i}^{2}\right)\right) \\
\int x y d S & =\frac{1}{n(n+1)}\left(\sum_{i}\left(x_{i}\right) \sum_{i}\left(y_{i}\right)+\sum_{i}\left(x_{i} y_{i}\right)\right) \\
\int y^{2} d S & =\frac{1}{n(n+1)}\left(\left(\sum_{i}\left(y_{i}\right)\right)^{2}+\sum_{i}\left(y_{i}^{2}\right)\right) \\
\int x^{3} d S & =\frac{1}{n(n+1)(n+2)}\left(\left(\sum_{i}\left(x_{i}\right)\right)^{3}+3\left(\sum_{i}\left(x_{i}\right) \sum_{i}\left(x_{i}^{2}\right)\right)+2\left(\sum_{i}\left(x_{i}^{3}\right)\right)\right) \\
\int x^{2} y d S & =\frac{1}{n(n+1)(n+2)}\left(\left(\sum_{i}\left(x_{i}\right)\right)^{2} \sum_{i}\left(y_{i}\right)+2\left(\sum_{i}\left(x_{i}\right) \sum_{i}\left(x_{i} y_{i}\right)\right)+\left(\sum_{i}\left(y_{i}\right) \sum_{i}\left(x_{i}^{2}\right)\right)+2\left(\sum_{i}\left(x_{i}^{2} y_{i}\right)\right)\right) \\
\int x y^{2} d S & =\frac{1}{n(n+1)(n+2)}\left(\sum_{i}\left(x_{i}\right)\left(\sum_{i}\left(y_{i}\right)\right)^{2}+\left(\sum_{i}\left(x_{i}\right) \sum_{i}\left(y_{i}^{2}\right)\right)+2\left(\sum_{i}\left(y_{i}\right) \sum_{i}\left(x_{i} y_{i}\right)\right)+2\left(\sum_{i}\left(x_{i} y_{i}^{2}\right)\right)\right) \\
\int y^{3} d S & =\frac{1}{n(n+1)(n+2)}\left(\left(\sum_{i}\left(y_{i}\right)\right)^{3}+3\left(\sum_{i}\left(y_{i}\right) \sum_{i}\left(y_{i}^{2}\right)\right)+2\left(\sum_{i}\left(y_{i}^{3}\right)\right)\right)
\end{aligned}
$$

Para a reconstrução linear do método SFV, é necessário saber as funções base e as funções de forma da partição. As integrais da matriz de reconstrução podem ser obtidas analiticamente para os elementos triangulares da malha. As funções de forma, como na Equação 6.12, são calculadas e armazenadas em memória para os pontos de quadratura do elemento padrão. Existe um ponto de quadratura no centro de cada aresta dos volumes de controle para a integração numérica, totalizando então 9 pontos de quadratura neste particionamento.

Para a reconstrução quadrática, foi utilizado um particionamento onde os parâmetros $\alpha_{3}$ e $\beta_{3}$, que são os graus de liberdade para esse particionamento, pos- 
suem os valores: $\alpha_{3}=91 / 1000$ e $\beta_{3}=18 / 100$, onde são usados na Equação 6.6 para definir os vértices a serem criados. Dois pontos de quadratura por aresta do volume de controle são necessários para a integração numérica.

Para a reconstrução cúbica, foi utilizado um particionamento onde os parâmetros $\alpha_{4}, \beta_{4}, \gamma_{4}$ e $\delta_{4}$, graus de liberdade para esse particionamento de acordo com a Equação 6.7. são ajustados para assumir os valores: $\alpha_{4}=78 / 1000, \beta_{4}=104 / 1000, \gamma_{4}=$ $52 / 1000$ e $\delta_{4}=351 / 1000$. Assim como a reconstrução quadrática, cada aresta dos volumes de controle possuem dois pontos de quadratura para a integração numérica do fluxo.

\subsection{Formulação do Limitador de Fluxo}

Para as equações de Euler, é necessário limitar algumas propriedades da reconstrução nos pontos de integração do fluxo para manter a estabilidade e convergência da simulação, se a solução no escoamento conter descontinuidades. A técnica de limitador de fluxo utilizada apresenta dois estágios. Primeiro, o solver precisa encontrar e marcar as células comprometidas que são, num estágio posterior, limitadas.

Para o processo de detecção e limitação, o limitador aplica uma expansão de séries de Taylor para a reconstrução para as derivadas nas médias das células. Assim, as células marcadas são limitadas da derivada de mais alta ordem para a de baixa ordem. Esta técnica de limitação é capaz de suprimir oscilações espúrias em descontinuidades da solução sem perda de acurácia.

Os sensores (ou marcadores) utilizados para malhas não estruturadas foram explorados por alguns autores na literatura Yang and Wang, 2009 Qiu and wang Shu, 2005. O limitador utilizado neste trabalho é chamado AccuracyPreserving TVD (AP-TVD). Um aspecto importante é que a célula marcada e as propriedades limitadas são inerentes ao elemento SV, e não aos CVs nos quais os cálculos de fluxo são realizados. 
O marcador é feito para primeiro checar os pontos de integração de fluxo em cada SV e marcar aqueles que não satisfazem o critério de monotonicidade. Para os elementos que devem ser limitados, um novo polinômio é calculado usando os momentos de área da célula. Esta formulação não necessita de nenhum dado a ser informado pelo usuário, ou seja, é um método automático e é chamado PFGM (Parameter Free Generalized Moment Limiter).

Para a reconstrução quadrática, por exemplo, o processo limitador é sumarizado nos seguintes passos.

1. Para um dado volume espectral $S V_{i}$, calcule os máximos e mínimos das médias nas células usando um stêncil local que inclui as células vizinhas diretamente à suas arestas.

$$
\begin{aligned}
& Q_{\min , i}=\min \left(Q_{i}, \min _{1 \leq r \leq n f} Q_{r}\right) \\
& Q_{\max , i}=\min \left(Q_{i}, \max _{1 \leq r \leq n f} Q_{r}\right)
\end{aligned}
$$

2. A i-ésima célula é considerada como uma célula a ser limitada se

$$
p_{i}\left(x_{r q}, y_{r q}\right)>1.001 Q_{\max , i} \text { ou } p_{i}\left(x_{r q}, y_{r q}\right)<0.999 Q_{\min , i}
$$

As constantes 1.001 e 0.999 não são dependentes do problema a ser tratado. Elas são usadas para corrigir um erro de aproximação de pontos flutuantes quando compara-se dois números deste tipo. Deste modo, esse passo realiza um teste para checar o critério de monotonicidade em cada célula.

3. Uma vez que os passos anteriores podem marcar mais SVs do que o necessário, é necessário verificar quais SVs podem ser desmarcadas em regiões consideradas como suaves no escoamento. Isso é feito por uma função TVD chamada minmod que é aplicada para verificar quando a segunda derivada de uma célula é limitada por uma estimativa da segunda derivada obtida usando as primeiras derivadas dos volumes espectrais na sua vizinhança. Este teste é feito da seguinte maneira: 
- Seja o vetor unitário na direção que conecta os centroides das i-ésimas e nbésimas células, denotado por $\vec{l}=l_{x} \hat{i}+l_{y} \hat{j}$, onde nb indica a aresta vizinha de um SV marcado, então a segunda derivada em tal direção é definida como

$$
Q_{U, i}=Q_{x x, i} l_{x}^{2}+2 Q_{x y, i} l_{x} l_{y}+Q_{y y, i} l_{y}^{2}
$$

- De maneira similar, as primeiras derivadas na mesma direção $\vec{l}$, para ambas células $i$ e $n b$, podem ser calculadas como

$$
\begin{gathered}
Q_{l, i}=Q_{x, i} l_{x}+Q_{y, i} l_{y} \\
Q_{l, n b}=Q_{x, n b} l_{x}+Q_{y, n b} l_{y}
\end{gathered}
$$

- Outra estimativa para a segunda derivada na direção $\vec{l}$ pode ser obtida como

$$
\tilde{Q}_{U, i}=\frac{Q_{l, n b}-Q_{l, i}}{\left|\overrightarrow{r_{i}}-\overrightarrow{r_{n} b}\right|}
$$

onde $\vec{r}$ é o vetor de coordenadas do centroide.

- Um limitador escalar para esta face é calculada de acordo com

$$
\phi_{i, n b}^{(2)}=\operatorname{minmod}\left(1, \frac{\tilde{Q_{U, i}}}{Q_{U, i}}\right)
$$

- O processo é repetido para as outras arestas do $S V_{i}$, e o limitador escalar para o SV é o mínimo dentre estes valores calculados para as faces:

$$
\phi_{i}^{(2)}=\min _{n b}\left(\phi_{i, n b}^{(2)}\right)
$$

- Se $\phi_{i}^{(2)}=1$, as derivadas segundas são limitadas, e o $S V_{i}$ pode ser desmarcado.

4. Uma vez realizado os passos anteriores, deve-se limitar os volumes espectrais que 
estiverem marcados. Neste caso, o limitador para a reconstrução da primeira derivada deve ser calculado. O procedimento segue a mesma abordagem que as segundas derivadas, e pode ser sumarizado como:

- Uma estimativa da primeira derivada na direção $\vec{l}$ é calculada como:

$$
\tilde{Q}_{l, i}=\frac{Q_{n b}-Q_{i}}{\left|\overrightarrow{r_{i}}-\overrightarrow{r_{n} b}\right|}
$$

- Tal estimativa é comparada com a primeira derivada da célula na direção $\vec{l}$, para obter-se o limitador escalar para a aresta como:

$$
\phi_{i, n b}^{(1)}=\operatorname{minmod}\left(1, \frac{\tilde{Q_{l, i}}}{Q_{l, i}}\right)
$$

- Como antes, o limitador escalar para a célula é o mínimo desses limitadores calculados para as arestas:

$$
\phi_{i}^{(1)}=\min _{n b}\left(\phi_{i, n b}^{(1)}\right)
$$

Finalmente, o polinômio limitado quadrático, o qual é usado para obter os valores das propriedades nos pontos de quadratura para uma célula SV marcada para limitação, é dado por:

$$
\begin{aligned}
p_{i}^{\text {limited }}\left(x_{r q}, y_{r q}\right)=Q_{i} & +\phi_{i}^{(1)}\left[\frac{1}{V_{i}}\left(Q_{x} M_{x}+Q_{y} M_{y}\right)_{i}\right] \\
& +\phi_{i}^{(2)}\left[\frac{1}{V_{i}}\left(\frac{1}{2} Q_{x x} M_{x^{2}}+Q_{x y} M_{x y}+\frac{1}{2} Q_{y y} M_{y^{2}}\right)_{i}\right]
\end{aligned}
$$

onde

$$
M_{x^{m} y^{n} \mid i}=\int_{S V}\left(x_{r q}-x_{i}\right)^{m}\left(y_{r q}-y_{i}\right)^{n} d V
$$

representa os momentos de área para as células. A reconstrução limitada é baseada nas variáveis primitivas $\{\rho, u, v, p\}^{T}$, ao invés das variáveis conservadas, de acordo com Bigarella [Bigarella, 2007]. Uma vez estas propriedades estão disponíveis para 
a reconstrução limitada, o vetor de variáveis conservadas é facilmente obtida para completar a integração numérica do fluxo.

Para a integração numérica do fluxo, considere a Equação 3.35, reescrita como

$$
\frac{\partial Q_{i}}{\partial t}=\int_{S_{i}}(\mathbf{P} \cdot \mathbf{n}) d S=\sum_{r=1}^{n f} \int_{S_{r}}(\mathbf{f} \cdot \mathbf{n}) d S
$$

Dado o fato de que $\mathbf{n}$ é constante para cada segmento de linha, a integração no lado direito da Equação 6.30 pode ser realizado numericamnente com uma fórmula de quadraturas gaussianas de k-ésima ordem

$$
\int_{S}(\mathbf{P} \cdot \mathbf{n}) d S=\sum_{r=1}^{n f} \sum_{q=1}^{n q} w_{r q} \mathbf{f}\left(\mathbf{Q}\left(x_{r q}, y_{r q}\right)\right) \cdot \mathbf{n}_{r} S_{r}+O\left(S_{r} h^{k}\right)
$$

onde $\left(x_{r q}, y_{r q}\right)$ e $w_{r q}$ são as coordenadas dos pontos de quadratura gaussianos e os pesos na r-ésima aresta da i-ésima célula, respectivamente. O número de pontos de quadraturas necessários na r-ésima aresta é dado por $n q=(k+1) / 2$, aproximado para um número inteiro.

Para esquemas de segunda ordem, um ponto de quadratura gaussiana é utilizada na integração. Dadas as coordenadas dos pontos na extremidade de uma aresta, $z_{1}$ e $z_{2}$, pode-se obter o ponto de quadratura como sendo o ponto médio da aresta $G_{1}=0.5\left(z_{1}+z_{2}\right)$. Para os esquemas de ordem três e quatro, dois pontos gaussianos são necessários em cada segmento de linha, e seus valores são

$$
\mathbf{G}_{\mathbf{1}}=\frac{\sqrt{3}+1}{2 \sqrt{3}} \mathbf{z}_{\mathbf{1}}+\left(1-\frac{\sqrt{3}+1}{2 \sqrt{3}}\right) \mathbf{z}_{\mathbf{2}} \quad e \quad \mathbf{G}_{\mathbf{2}}=\frac{\sqrt{3}+1}{2 \sqrt{3}} \mathbf{z}_{\mathbf{2}}+\left(1-\frac{\sqrt{3}+1}{2 \sqrt{3}}\right) \mathbf{z}_{\mathbf{1}},
$$

Assim, utilizando-se das operações acima descritas, pode-se calcular os valores para $\mathbf{Q}_{i}$ no instante $t$ para cada célula. Devido à descontinuidade dos valores reconstruídos para as variáveis conservadas nas fronteiras dos SVs, deve-se utilizar uma função numérica para o fluxo para aproximar os valores do fluxo nas fronteiras da célula. 


\subsection{Esquemas de Marcha no Tempo}

A discretização temporal das equações governantes do escoamento define o passo de tempo que é utilizado na simulação, estando relacionado com o custo computacional e com a qualidade desejada dos resultados. A escolha do esquema a ser utilizado para esta discretização é importante, devendo levar em consideração a precisão dos resultados, o tempo de cálculo e o consumo de memória.

\subsubsection{Integração Explícita}

Para obter-se uma solução estável para o escoamento a partir de uma condição inicial, é necessário um esquema de relaxação. O comportamento da convergência para o estado estável para os métodos de alta ordem, tal como o método SFV, é geralmente mais lento quando utilizadas abordagens de marcha no tempo explícitas, porém são simples de compreender e de implementar.

A abordagem tipicamente utilizada em CFD tem sido utilizar métodos RungeKutta de multi-estágios. Esquemas explícitos são simples de ser aplicados e consomem pouca memória em sua execução. O método aqui exposto é o esquema TVD RungeKutta para a integração explícita no tempo [Wolf and Azevedo, 2006]:

$$
\begin{gathered}
\mathbf{Q}^{(1)}=\mathbf{Q}^{n}+\Delta t \mathbf{R}^{n} \\
\mathbf{Q}^{(2)}=\alpha_{1} \mathbf{Q}^{n}+\alpha_{2}\left[\mathbf{Q}^{(1)}+\Delta t \mathbf{R}^{(1)}\right] \\
\mathbf{Q}^{(n+1)}=\alpha_{3} \mathbf{Q}^{n}+\alpha_{4}\left[\mathbf{Q}^{(2)}+\Delta t \mathbf{R}^{(2)}\right]
\end{gathered}
$$

onde os subscritos $n$ e $n+1$ denotam, respectivamente, os valores das propriedades no começo e no fim de cada passo no tempo $n, \mathbf{R}$ é o operador do resíduo, como definido nas Equações 3.37 e 6.31 . Aos coeficientes $\alpha$ são atribuidos: $\alpha_{1}=\frac{3}{4} ; \alpha_{2}=\frac{1}{4} ; \alpha_{3}=\frac{1}{3}$ e $\alpha_{4}=\frac{2}{3}$. 


\subsubsection{Integração Implícita}

Uma integração implícita geralmente melhora a convergência do método numérico em métodos de alta ordem, no caso o método SFV. O esquema LU-SGS se enquadra neste contexto, e é apresentado nesta subseção.

A Equação 3.37 pode ser reescrita da seguinte forma

$$
V_{i} \frac{d \mathbf{Q}_{i}}{d t}=-\mathbf{R}_{i}
$$

onde, $\mathbf{R}_{i}$ é o resíduo para a i-ésima célula e tende a zero conforme a simulação converge para uma solução de estado estacionário. Usando o método implícito de Euler para a integração temporal, a Equação 6.36 acima pode ser escrita na forma discreta como

$$
V_{i} \frac{\Delta \mathbf{Q}_{i}^{n}}{\Delta t}=-\mathbf{R}_{i}^{n+1}
$$

onde $\Delta t$ é o incremento no tempo e $\Delta \mathbf{Q}_{i}^{n}=\mathrm{Q}^{n}+1-\mathrm{Q}$. A equação anterior pode ser linearizada no tempo como

$$
V_{i} \frac{\Delta \mathbf{Q}_{i}^{n}}{\Delta t}=-\mathbf{R}_{i}^{n}-\frac{\partial \mathbf{R}_{i}^{n}}{\partial \mathbf{Q}} \Delta \mathbf{Q}_{i}^{n}
$$

O termo $\partial \mathbf{R} / \partial \mathbf{Q}$ representa a matriz Jacobiana. Escrevendo a equação para todos CVs, pode-se obter

$$
A \Delta \mathbf{Q}=-\mathbf{R}
$$

onde

$$
A=\frac{V}{\Delta t} \mathbf{I}+\frac{\partial \mathbf{R}^{n}}{\partial \mathbf{Q}}
$$

e I é a matriz identidade.

Para reduzir o número de entradas não positivas na matriz jacobiana, e por assim simplificando o processo de linearização, somente a representação de primeira ordem 
dos fluxos numéricos, $\vec{f}$, são linearizados. Portanto, as entradas da matriz jacobiana podem ser calculados e armazenados em uma visita às arestas da malha. O cenário ideal seria linearizar o operador implícito com a mesma ordem que o operador RHS, para melhor aproximar o precondicionador e melhorar a taxa de convergência. Entretanto, isto iria aumentar o espaço de armazenamento necessário. Então, a função de fluxo numérico simplificada, que é utilizada para formar o operador residual, é definida como

$$
\overrightarrow{f_{i}}\left(Q_{L}, Q_{R}, \mathbf{n}_{k}\right)=\frac{1}{2}\left[\mathbf{P}\left(Q_{L}, \mathbf{n}_{k}\right)+\mathbf{P}\left(Q_{R}, \mathbf{n}_{k}\right)-|\lambda|\left(Q_{R}-Q_{L}\right)\right]
$$

para a k-ésima aresta que compartilha a célula $i$ da esquerda $(L)$ e a célula $n b$ da direita $(R)$. Um modelo de dissipação escalar é usado para esse caso, onde

$$
|\lambda|=\left|u_{n}\right|+c
$$

Note que a dissipação na função de fluxo é aproximada pelo raio espectral da matriz jacobiana. A função de fluxo numérica simplificada é usada para obter as matrizes jacobianas. Então, a linearização das Equações 6.40 e 6.41 resulta

$$
\begin{gathered}
\frac{\partial \mathbf{R}_{i}}{\partial \mathbf{Q}_{i}}=\frac{1}{2}\left[J\left(Q_{L}\right)+|\lambda| \mathbf{I}\right] \\
\frac{\partial \mathbf{R}_{i}}{\partial \mathbf{Q}_{n} b}=\frac{1}{2}\left[J\left(Q_{R}\right)-|\lambda| \mathbf{I}\right]
\end{gathered}
$$

onde $J$ é o jacobiano dos vetores de fluxo invíscitos na direção normal da aresta.

A matriz jacobiana é armazenada nos componentes inferiores, superiores e diagonais, que são calculados como

$$
L=\frac{1}{2}\left[-J\left(Q_{R}, \mathbf{n}_{k}\right)-|\lambda| \mathbf{I}\right]
$$




$$
\begin{gathered}
U=\frac{1}{2}\left[-J\left(Q_{R}, \mathbf{n}_{k}\right)-|\lambda| \mathbf{I}\right] \\
D=\frac{V}{\Delta t} \mathbf{I}+\sum_{k=1}^{n f} \frac{1}{2}\left[J\left(Q_{R}, \mathbf{n}_{k}\right)-|\lambda| \mathbf{I}\right]
\end{gathered}
$$

Observe que $L, U$ e $D$ representam as matrizes inferior, superior e diagonal, respectivamente. A Equação 6.39 representa um sistema de equações algébricas simultaneamente lineares que precisam ser resolvidas a cada passo no tempo. O método de solução iterativa LU-SGS é aplicado e o sistema é solucionado em dois passos:

$$
\begin{gathered}
(D+L) \Delta \mathbf{Q}^{*}=\mathbf{R} \\
(D+U) \Delta \mathbf{Q}=D \Delta \mathbf{Q}^{*}
\end{gathered}
$$

O algoritmo de marcha no tempo pode ser usado independentemente do esquema de discretização espacial. Entretanto, note que o esquema SFV de quarta ordem, requer uma reconstrução polinomial cúbica e, portanto, cada elemento da malha é dividido em $10 \mathrm{CVs}$, gerando uma malha 10 vezes maior que a original, implicando em mais espaço e tempo gastos pelo esquema implícito.

Esta desvantagem deu origem ao esquema LU-SGS livre de matrizes. Ela possui a mesma formulação base exceto que a matriz jacobiana não é explicitamente calculada nem armazenada. Os produtos $J \Delta \mathbf{Q}^{*}$ e $J \Delta \mathbf{Q}$ da Equação 6.45 são substituídos por uma expansão de séries de Taylor dos fluxos Blazek, 2001. Assim, a partir da Equação 6.43, pode-se escrever

$$
(J \pm|\lambda| \mathbf{I}) \Delta \mathbf{Q} \approx \frac{1}{2}\left[\Delta \mathbf{f}\left(Q_{L}, Q_{R}, \mathbf{n}_{k}\right) \pm|\lambda| \Delta \mathbf{Q}\right]
$$

onde a atualização dos fluxos dado por

$$
\Delta \mathbf{f}^{n}=\mathbf{f}^{n+1}-\mathbf{f}^{n}
$$


Uma vez que nenhuma matriz jacobiana é formada, nenhuma condição de contorno implícita é necessária, o que simplifica muito o método. Para o componente da matriz diagonal $D$, como na Equação 6.44, como não é necessário calcular a matriz jacobiana, ele é substituído pelo raio espectral, como definido na Equação 6.42. A forma final do esquema pode ser escrita da seguinte forma

$$
\begin{gathered}
D \Delta \mathbf{Q}_{i}^{(1)}=-\mathbf{R}_{i}-\sum_{j \in L(i)} \frac{1}{2}\left[\Delta \mathbf{f}_{j}^{(1)}+|\lambda| \mathbf{I} \Delta \mathbf{Q}_{\mathbf{j}}{ }^{(1)}\right] \\
D \Delta \mathbf{Q}_{i}^{(n)}=D \Delta \mathbf{Q}_{\mathbf{i}}{ }^{(1)}-\sum_{j \in U(i)} \frac{1}{2}\left[\Delta \mathbf{f}_{j}^{(n)}-|\lambda| \mathbf{I} \Delta \mathbf{Q}_{\mathbf{j}}{ }^{(n)}\right]
\end{gathered}
$$

\subsection{Adequação da Mate Face ao Particionamento}

Neste seção será mostrada a alteração necessária na estrutura de dados Mate Face para representar o particionamento gerado pelo método de volumes finitos espectrais. Esta alteração foi feita estendendo-se a estrutura de dados de forma a comportar os novos tipos de elementos necessários ao método de volumes finitos espectrais.

Como já visto, o SFV divide a malha em volumes de controle. Estes volumes são divisões internas de cada volume espectral da malha. Como explicado nas seções anteriores, o número de divisões em cada célula depende da ordem escolhida do método, sendo utilizadas aqui as ordens dois, três e quatro.

Com essa divisão, os novos elementos formados na malha pelos volumes de controle podem ser quadrados, pentágonos e até hexágonos, sendo que a malha se torna híbrida, ou seja, composta por elementos diferentes.

O desafio aqui foi modificar a estrutura da Mate Face, pois ela não suporta todos os tipos de elementos necessários ao método espectral. Assim, foi feita uma extensão na estrutura de modo a conciliar estes novos elementos e possibilitar a realização de buscas a esses elementos.

A extensão proposta na estrutura pode ser visualizada na Figura 6.3. Na figura, 
os tipos de dados acrescentados estão organizados abaixo da linha tracejada. De um modo geral, foram acrescentadas duas classes para representar os dados necessários para a nova malha utilizada. Na estrutura estendida, cada célula da Mate Face (volume espectral) possui uma associação para um objeto célulaEspectral, que irá armazenar os volumes de controle (as células subdivididas). Todas as novas arestas criadas pela divisão foram representadas em um conjunto separado, chamadas de arestas espectrais.

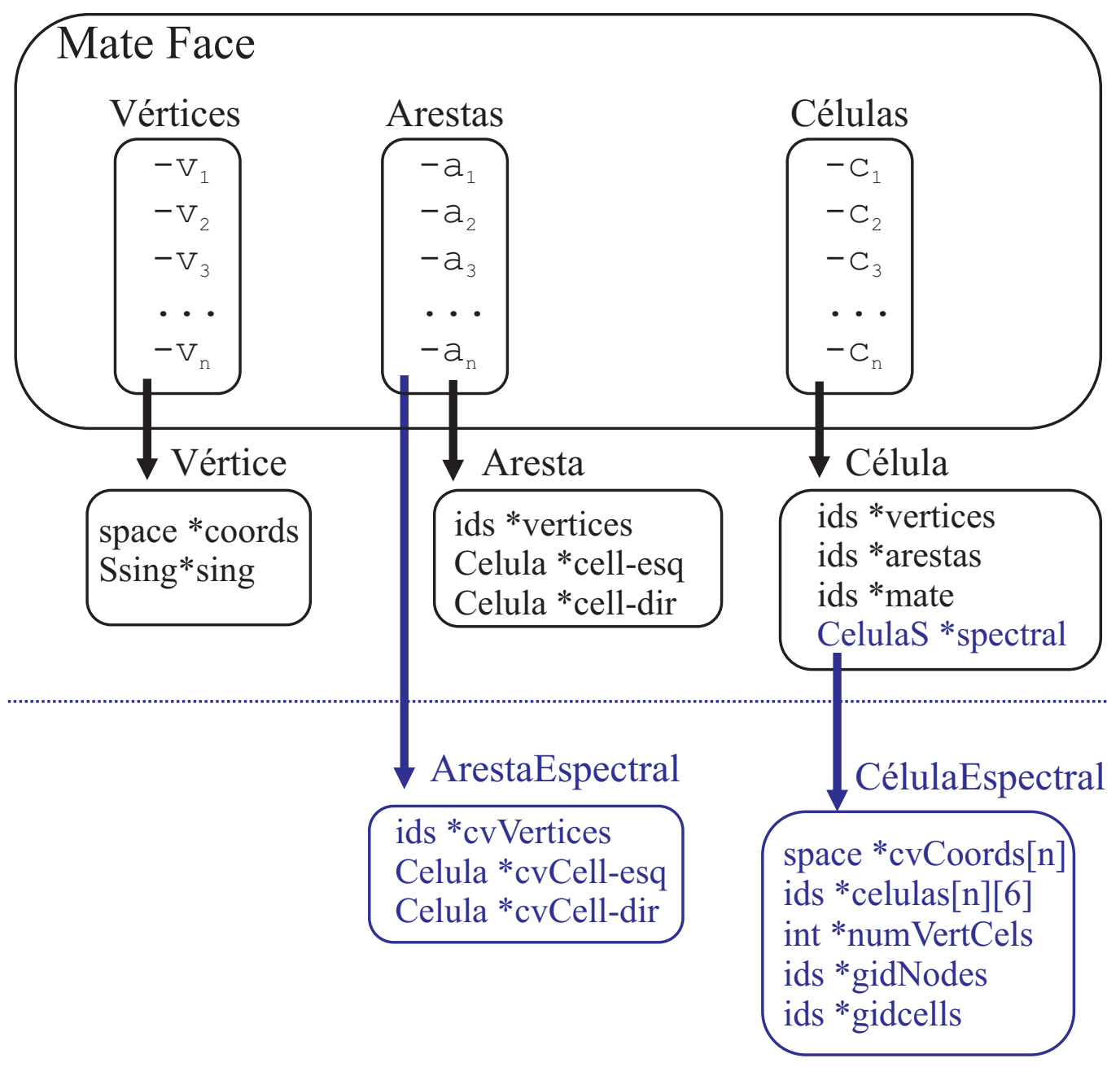

Figura 6.3: Classes da estrutura Mate Face estendida para o método SFV.

Pela Figura 6.3, cada célulaEspectral define a subdivisão das células internas ao volume espectral. Ela armazena suas coordenadas espaciais em cvCoords e a formação dos elementos na matriz células, onde irá indicar quais vértices fazem parte das células 
internas (chamadas de volumes de controle). O número de vértices que cada célula criada possui é armazenado no vetor numVertCels, uma vez que este número depende da ordem espectral utilizada para construir os elementos, pois são formados elementos de diferentes tipos. Além disso, foi necessário criar uma identificação global para cada vértice e cada célula criada para facilitar as buscas na estrutura e definir as propriedades da nova malha, como áreas, centroides, entre outros. Os vetores gidNodes e gidCells armazenam estas informações, respectivamente.

Ainda na Figura 6.3, foi necessário fazer o tratamento nas arestas da nova malha. Como as células criadas internamente possuem arestas ligadas pelos vértices internos ao volume espectral, estas devem ser mapeadas ao conjunto de arestas, mas nesse caso como arestas espectrais. Assim, temos dois conjuntos de arestas, as originais e as formadas pelas subdivisões. As arestas espectrais armazenam os vértices espectrais da extremidade da aresta e os identificadores para os volumes de controle esquerdo e direito da aresta.

As informações das arestas foram mantidas globais e não locais em cada célula pois existem arestas espectrais que estão localizadas no contorno da célula, como pode ser visualizada na Figura 6.4, que mostra um exemplo de uma malha com suas células subdivididas por um esquema de ordem dois.

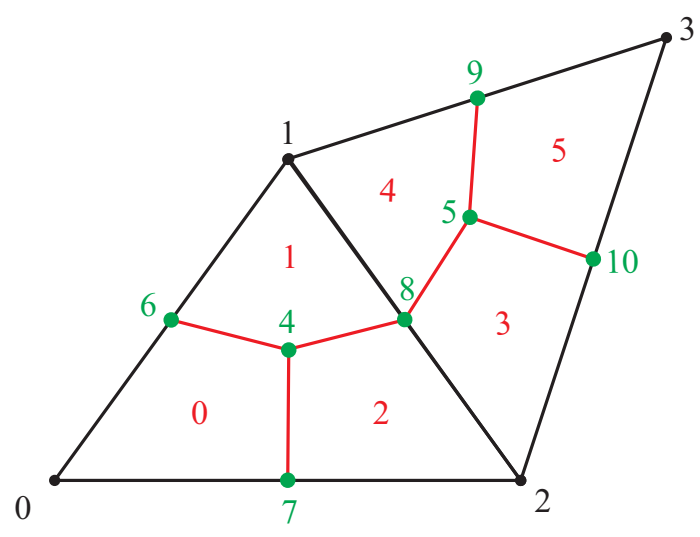

Figura 6.4: Exemplo de malha com subdivisões dos volumes espectrais.

As arestas no contorno das volumes espectrais são compartilhadas por células 
vizinhas, bem como suas arestas espectrais. Na Figura 6.4 tem-se duas células que foram subdivididas em seis células, formando novos elementos e novas arestas. No exemplo, vemos que a aresta 1-8 é adjacente aos volumes de controle 1 e 4 , esta informação deve ser armazenada em um objeto do tipo arestaEspectral e pertencer ao conjunto deste tipo de aresta na estrutura.

A montagem da lista das arestas espectrais pode ser feita em dois processos. Processam-se as arestas internas de cada célula, uma vez que estas não possuem referências a células vizinhas externas mas sim aos volumes de controle internos. Após este processamento, as próprias arestas organizadas na Mate Face são processadas, realizando-se as divisões nas arestas e registrando-se as vizinhanças necessárias de cada aresta espectral, utilizando a vizinhança da aresta já existente na Mate Face indicando o volume espectral vizinho para se procurar os volumes de controle vizinhos. Por exemplo, na Figura 6.4, o volume de controle 3 vizinho à direita da aresta 2-8 está contido no volume espectral referente à célula vizinha a direita da aresta $2-1$, já indexada na Mate Face. Isso facilita o gerenciamento e ordenação das arestas criadas.

O processo de criação dos números identificadores globais depende de cada ordem espectral escolhida. Utilizando o exemplo mostrado na Figura 6.4, tem-se que a sequência da numeração continua após todos os vértices e células originais sejam numerados na Mate Face.

Assim, a numeração dos vértices espectrais é feita da seguinte forma. Todos os vértices criados no interior da célula variam dentro da sequência: $\{$ NumVert, NumVert + NumCel\}, onde NumVert é o número de vértices na Mate Face, e NumCel é o número de células na Mate Face, uma vez que existe um único vértice criado no interior da célula na Mate Face. Os demais vértices estão localizados nas arestas da Mate Face, e sua numeração seguem a sequência: $\{$ NumVert + NumCel, NumVert $+\mathrm{NumCel}+$ NumArestas $\}$, onde NumArestas indica o número de arestas na Mate Face. A sequência de numeração segue este procedimento e como em $\mathrm{C}++$ os índices começam em zero, não há necessidade de somar um à essas variáveis que definem 
cada sequência. A mesma analogia é usada na numeração dos elementos formados por ordens espectrais 3 e 4, sendo que nestes o número de vértices internos à célula e nas arestas é maior.

O processo de numeração dos volumes de controle é realizado de acordo com a ordem espectral escolhida. Por exemplo, uma célula pode ser divida em 3, 6 ou 10 volumes de controle, dependendo da ordem espectral, como mostra a Figura 6.5.

Todos volumes de controle criados são mantidos e acessados a partir das células originais na Mate Face (os volumes espectrais). E além da numeração ser única para cada volume de controle criado, para poder identificar globalmente as propriedades como centroide e área, é necessário manter as associações entre os volumes espectrais e seus volumes de controle. Para isso, bastou manter um vetor de correspondência entre células, como pode ser vista na Figura 6.5. Pela figura, temos que a relação entre as células referencia a qual célula original (volume espectral) um volume de controle está contido. Isso é importante pois no método SFV esta informação é necessária para o cálculo do resíduo, mediante o método de reconstrução do elemento.

Como o particionamento da malha é diferente para cada ordem espectral escolhida, foi realizado um esquema de hashing para generalizar o acesso e o armazenamento das novas informações na extensão da Mate Face. Para montar este esquema, primeiramente foi feita uma identificação local em cada tipo de célula. Isso é possível pois todas as células subdivididas são de um mesmo tipo, dada sua ordem espectral. Assim, foi realizada uma rotulação de todos os vértices e células criados, de modo que facilitasse o acesso às informações de vizinhança e formação das células.

A rotulação dos vértices e células foi feita de modo que não houvesse repetição de rótulos num mesmo conjunto e que fosse intuitivo determinar qual o vértice ou a célula baseando-se apenas em seu rótulo. A Figura 6.6 mostra todas as rotulações definidas. Além disso, como o número de células e vértices criados em cada volume espectral é pequeno, justifica-se a abordagem de estruturação interna na célula de suas subdivisões, uma vez que o tamanho máximo dos vetores internos é definido como o 


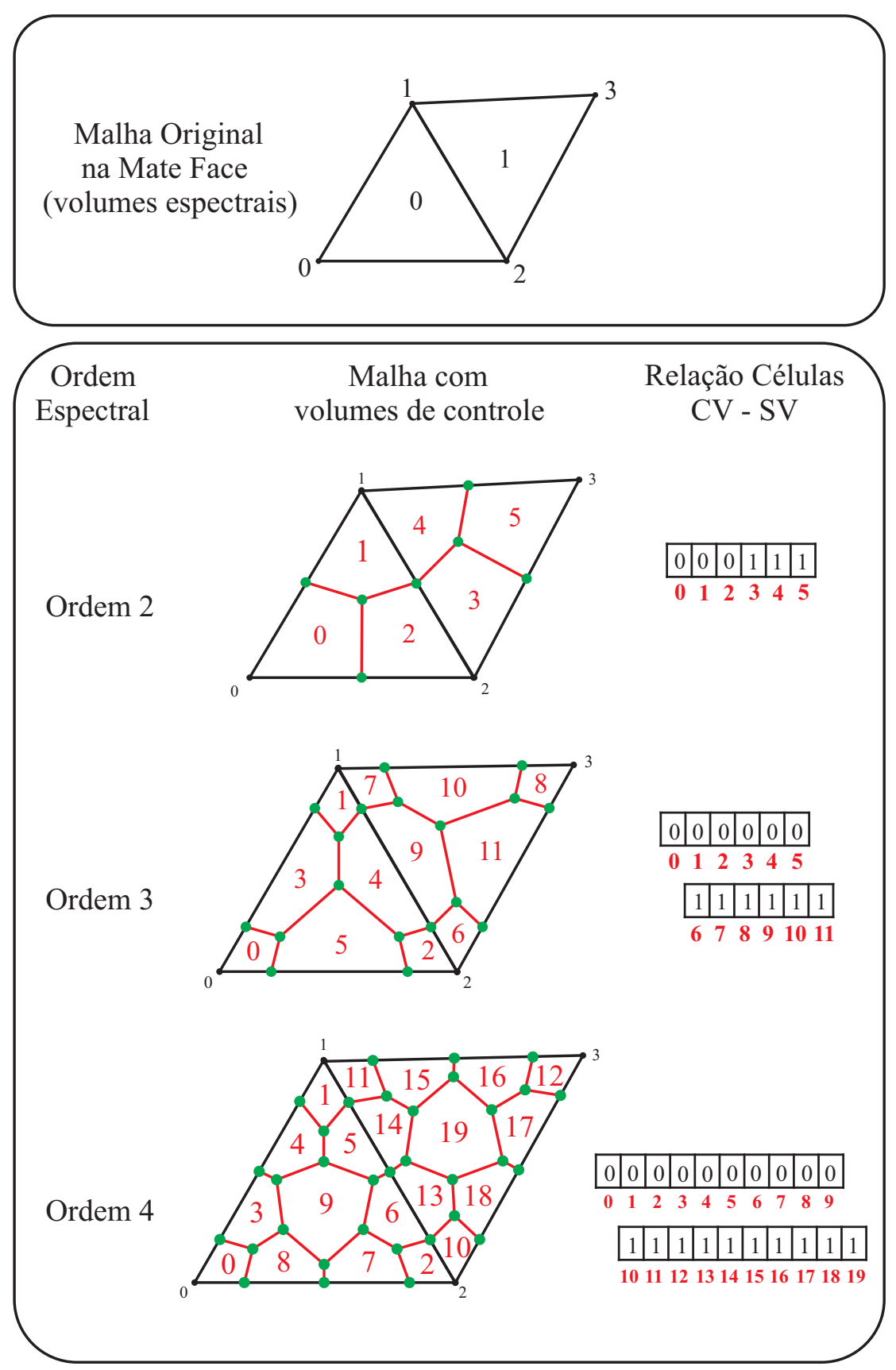

Figura 6.5: Associação entre volumes espectrais e volumes de controle para os particionamentos de segunda, terceira e quarta ordem de precisão.

máximo valor na tabela hash.

Deste modo, a Figura 6.6 mostra as rotulações feitas nos vértices e células resultantes da divisão da célula original (volume espectral), de acordo com a ordem espectral escolhida no método. A Figura 6.6(a) mostra a rotulação feita em um vo- 


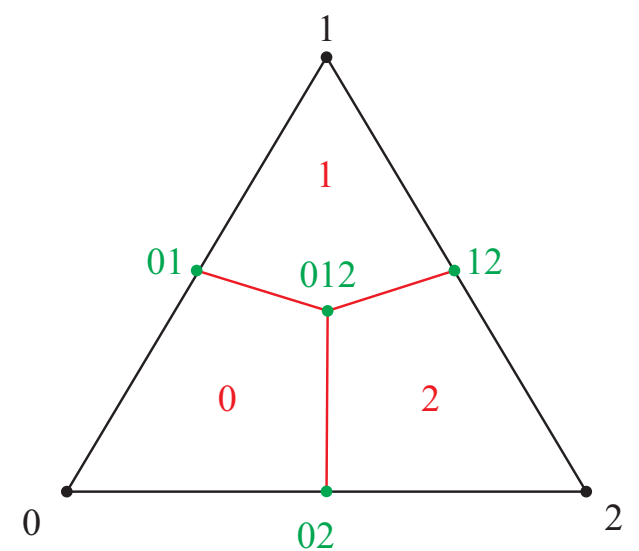

(a)

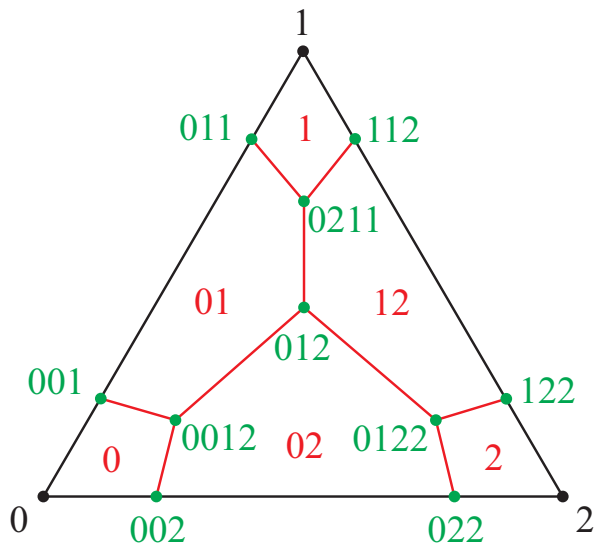

(b)

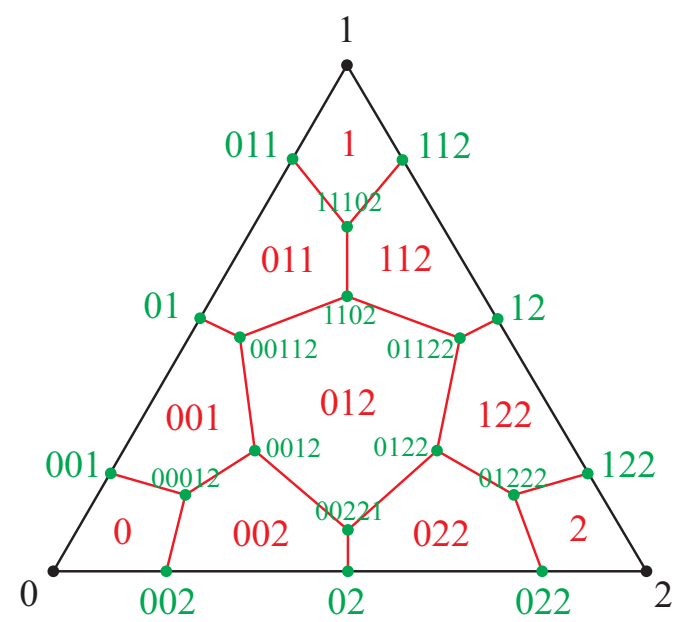

(c)

Figura 6.6: Rotulações realizadas nos volumes de controle para identificação interna.

lume espectral de ordem espectral 2, a Figura 6.6(b) mostra a rotulação com ordem espectral 3 e por fim a Figura 6.6(c) mostra a rotulação com ordem espectral 4.

Os rótulos dos vértices são independentes dos rótulos das células, pois são identificadores para objetos diferentes. Na Figura 6.6, os rótulos na cor verde indicam os chamados vértices espectrais, enquanto os rótulos vermelhos indicam os volumes de controle.

A geração dos rótulos tem relação com a proximidade do vértice original o qual o vértice espectral se encontra. Por exemplo, na Figura 6.6(a), o vértice "012" fica no centro da célula, equidistante dos vértices originais, enquanto que o vértice "01" fica na aresta entre os vértices 0 e 1, equidistante aos dois. Já na Figura 6.6(b) temos vértices 
internos que são diferentes aos anteriores, que foram configurados com quatro dígitos para sua identificação única. Um exemplo é o vértice "0012", ele recebeu este rótulo por estar no interior da célula, porém mais próximo do vértice 0 do que os demais. De maneira análoga são definidos os vértices "0122" e "0211". A Figura 6.6(c) mostra a divisão de ordem 4 espectral de um triângulo, onde a rotulação é mais complexa devido ao maior número de vértices e células criadas. Para a rotulação, usou-se até 5 dígitos para manter a analogia de proximidade aos vértices originais para rotulação dos vértices criados. Para todos os casos, a mesma analogia foi realizada para a rotulação das células criadas, indicadas na cor vermelha.

A tabela hash foi construída reunindo-se e ordenando-se todos os rótulos existentes, baseando-se no número de dígitos usados na rotulação. Ela pode ser vista na Tabela 6.2 .

\begin{tabular}{||l|l||}
\hline Rótulo & Índice \\
\hline I0 & 0 \\
\hline I1 & 1 \\
\hline I2 & 2 \\
\hline I01 & 3 \\
\hline I02 & 4 \\
\hline I12 & 5 \\
\hline I001 & 6 \\
\hline I002 & 7 \\
\hline I011 & 8 \\
\hline I012 & 9 \\
\hline I022 & 10 \\
\hline I112 & 11 \\
\hline I122 & 12 \\
\hline I0012 & 13 \\
\hline I0122 & 14 \\
\hline I0211 & 15 \\
\hline I1102 & 16 \\
\hline I00012 & 17 \\
\hline I00112 & 18 \\
\hline I00221 & 19 \\
\hline I01122 & 20 \\
\hline I01222 & 21 \\
\hline I11102 & 22 \\
\hline
\end{tabular}

Tabela 6.2: Relação dos rótulos e suas posições 
Utilizando a Tabela 6.2, fica definida qual posição nos vetores internos de cada volume espectral as informações espectrais serão armazenadas, de acordo com o rótulo. Foi acrescentado o caractere 'I' antes de cada rótulo para formar uma macro no código em $\mathrm{C}++$. Por exemplo, as informações do vértice "001", ou seja "I001", estão associadas à posição 6 dos vetores de coordenadas, e as células que possuem este vértice possuem o valor 6 na tabela de volumes de controle.

A tabela de rótulos possui 23 entradas, então os vetores de coordenadas, número de vértices em cada célula, e os identificadores globais terão 23 posições, ou seja, o valor de $n$ indicado na Figura 6.3 na classe CélulaEspectral. Isso torna a busca por um elemento na subestrutura por uma ordem constante, caso busque apenas pelo seu identificador global. Mas caso deseja-se apenas percorrer os vértices ou células, o acesso é direto nas informações na matriz células. Note que a divisão das células e estruturação de maneira local em cada célula original da Mate Face mantém a busca eficiente, uma vez que o tratamento é local em cada célula, tornando a busca com ordem constante.

Uma vez montada a tabela de rótulos, qualquer ordem espectral escolhida definirá a estrutura interna de organização dos vértices e células, variando-se apenas o número de vértices e células em cada caso, porém limitado a 23. Isso foi possível pois em qualquer caso de divisão das células este número não ultrapassa 23 vértices espectrais ou volumes de controle.

Com a tabela hash definida, pode-se definir a organização interna dos volumes de controle usando os rótulos internos, sendo que todos os volumes espectrais de uma mesma ordem de precisão terão a mesma divisão, variando-se apenas as coordenadas dos três vértices do triângulo original. A Figura 6.7 mostra a divisão dos volumes espectrais utilizando os rótulos criados na tabela hash.

A divisão dos volumes espectrais mostradas na Figura 6.7 foi feita utilizando os rótulos sem o caractere 'I' inicial, para não ficar confusa a explicação da figura e no texto. A figura mostra a organização interna dos volumes espectrais segundo as três 


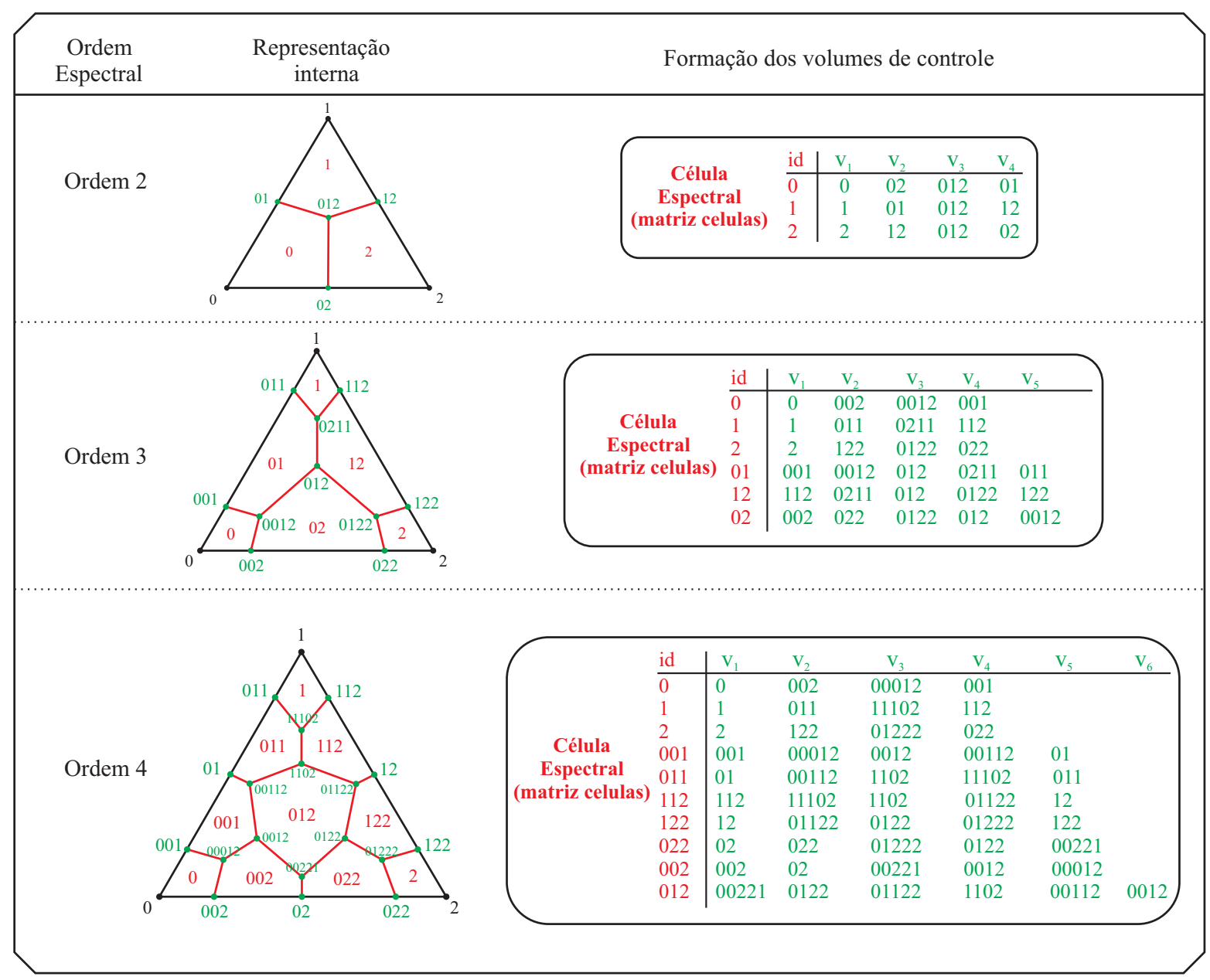

Figura 6.7: Organização interna dos volumes espectrais.

ordens espectrais definidas. Uma vez que os rótulos estão semanticamente associados à sua posição, a formação dos elementos internos foi facilitada na matriz celulas de cada volume espectral da malha, sendo que todas terão a mesma sequência de subdivisão. A solução aqui mostrada diminui a complexidade da divisão das células a um nível local em cada célula da malha original.

Pela Figura 6.7, é intuitivo notar as divisões celulares e quais os vértices que compõem cada volume espectral. Em cada célula, a divisão segue o mesmo padrão. Então, sabendo-se qual o rótulo de cada vértice, pode-se recuperar as informações de suas coordenadas e até seu identificador global. O mesmo vale para os volumes de controle, onde cada rótulo permite recuperar as informações associadas a cada 
célula. Ainda na Figura 6.7, nota-se que nem todas colunas na matriz celulas são preenchidas, isso se dá pois o número de nós em cada célula muda. Além disso, o vetor num VertCels da classe CélulaEspectral indica o número correto de nós em cada volume de controle, de acordo com o seu rótulo, assim como os demais atributos.

As arestas espectrais são formadas a partir das arestas já existentes na estrutura Mate Face. A criação das arestas espectrais é feita a partir da divisão dessas arestas e ligadas pelos novos vértices criados nelas. A Figura 6.8 mostra um exemplo de montagem dessas arestas.

Pela Figura 6.8, temos a malha original indexada na Mate Face antes da divisão dos elementos, a malha dividida usando ordem espectral dois como exemplo, e suas legendas. A figura também mostra as arestas espectrais criadas a partir da criação dos vértices criados, e os correlaciona com as arestas originais antes da divisão. O processo de criação das arestas espectrais pode ocorrer junto com a criação dos vértices espectrais nas arestas de cada célula. Basta percorrer as arestas na Mate Face e realizar as operações de criação dos pontos e registrar suas arestas. Um aspecto importante dessa implementação é manter contíguos em memória cada aresta criada em relação à aresta anterior, pois se as arestas estiverem ordenadas anteriormente, será mantida a ordenação após a criação das arestas. Essa ordenação de arestas comumente é utilizada para organizar quais arestas pertencem à fronteira da malha, ou seja, as arestas no bordo.

Após criada a nova estrutura, deve-se adequar as consultas feitas na malha à nova configuração das células, de modo a acessar a estrutura interna de cada célula acessada. Deste modo, para facilitar algumas pesquisas, foi criado um vetor de correspondência entre vértices espectrais e volumes espectrais, onde para cada vértice espectral sabe-se qual volume espectral na Mate Face ele pertence. A maioria das consultas na malha são intuitivas utilizando-se as estruturas criadas, exceto pela consulta do tipo estrela em um vértice, que é explicada a seguir. 

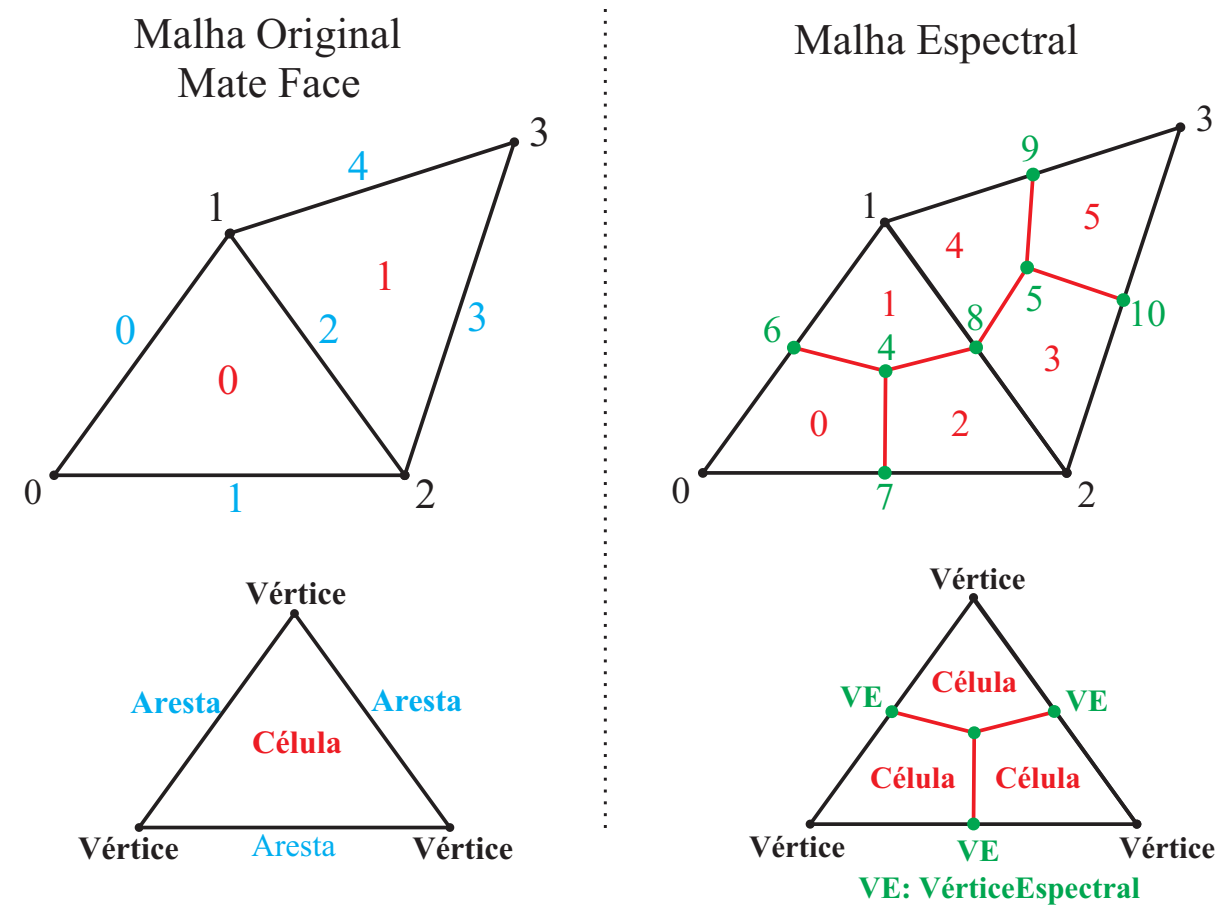

\begin{tabular}{|c|c|c|c|c|}
\hline \multirow{3}{*}{$\begin{array}{c}\text { Aresta } \\
\text { MF }\end{array}$} & \multicolumn{4}{|c|}{ Aresta Espectral } \\
\hline & \multicolumn{2}{|c|}{ cvVertices } & \multirow[b]{2}{*}{ cvCell-esq } & \multirow[b]{2}{*}{ cvCell-dir } \\
\hline & & & & \\
\hline \multirow{2}{*}{ Aresta 0} & 1 & 6 & 1 & $\begin{array}{l}-1 \\
\end{array}$ \\
\hline & 6 & 0 & 0 & -1 \\
\hline \multirow{2}{*}{ Aresta 1} & 0 & 7 & 0 & -1 \\
\hline & 7 & 2 & 2 & -1 \\
\hline \multirow{2}{*}{ Aresta 2} & 2 & 8 & 2 & 3 \\
\hline & 8 & 1 & 1 & 4 \\
\hline \multirow{2}{*}{ Aresta 3} & 2 & 10 & 3 & -1 \\
\hline & 10 & 3 & 5 & -1 \\
\hline \multirow{2}{*}{ Aresta 4} & 3 & 9 & 5 & -1 \\
\hline & 9 & & 4 & -1 \\
\hline
\end{tabular}

Figura 6.8: Montagem das arestas espectrais na MF estendida a partir da malha original.

A consulta na estrela de um vértice recupera as células ao redor de um vértice de pesquisa. Este tipo de consulta pode ser visualizado na Figura 6.9, que mostra um 
exemplo deste tipo de consulta em uma malha sem particionamento e em uma malha com o particionamento proposto pelo método de volumes finitos espectrais.

\section{Consulta na estrela do vértice}

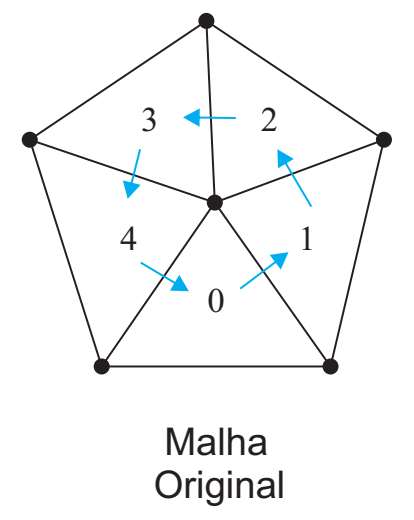

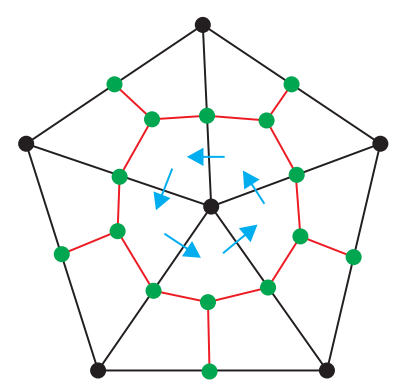

Malha

Particionada

$2^{\mathrm{a}}$ ordem

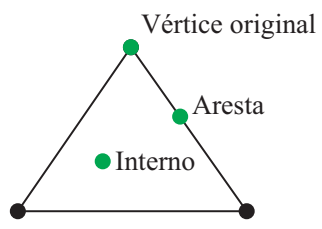

Posição do ponto de pesquisa

Figura 6.9: Esquema de looping em células espectrais.

A consulta às células na estrela de um vértice na Mate Face é realizada por um iterador que utiliza a relação de vizinhança armazenada em cada célula. Já a mesma consulta realizada em uma malha particionada deve ser tratada de modo diferente. Primeiramente, é necessário saber a localização do vértice de pesquisa na célula onde inicia-se a pesquisa, recuperada pelo vetor de associação entre vértices espectrais e volumes espectrais. Esta informação pode ser recuperada de duas maneiras. Caso a implementação utilize-se da sequência de numeração dos vértices aqui propostos, sabe-se qual a localização do vértice diretamente pelo seu número identificador. Caso escolha-se um esquema de numeração diferente, pode-se utilizar um método existente na estrutura Mate Face que realiza este cálculo e retorna o tipo do vértice conforme sua localização na célula passada como parâmetro.

De acordo com a Figura 6.9, um vértice pode localizar-se em três diferentes posições: pode ser interno ao volume espectral, pertencer a uma aresta ou coincidir com algum vértice original da malha antes do particionamento. Para cada caso, a 
pesquisa é realizada de modo diferente, conforme explicado a seguir.

1. Vértice interno: É o caso mais simples, onde basta percorrer os volumes de controle na estrutura interna do volume espectral, verificando-se qual deles possui o vértice de pesquisa como um de seus vértices, adicionando-os ao resultado.

2. Vértice original: Utiliza-se o iterador existente na Mate Face, onde para cada volume espectral recuperado é investigada sua estrutura interna, de modo a recuperar todos volumes de controle que compartilham o vértice de pesquisa.

3. Vértice na aresta: Identifica-se qual aresta original na Mate Face (a partir da célula conhecida) o vértice pertence, e recupera-se as células vizinhas esquerda e direita, cvCell-esq e cvCell-dir, respectivamente. Em seguida investiga-se a estrutura interna de cada volume espectral recuperado, percorrendo-se os volumes de controle e adicionando ao resultado aqueles que compartilham o vértice de pesquisa.

Note que os algoritmos para os procedimentos de pesquisa listados acima possuem complexidade constante, de modo que a pesquisa na estrutura interna de qualquer volume espectral é feita em ordem constante. O mesmo procedimento de pesquisa explicado acima é aplicado para qualquer ordem de precisão. No caso da pesquisa dos volumes de controle vizinhos a um volume de controle de pesquisa, utiliza-se diretamente a informação das arestas espectrais da vizinhança esquerda e direita de cada aresta.

\subsection{Aplicações}

Nesta seção são apresentados os resultados de experimentos realizados nas implementações. O intuito é comparar os resultados dos simuladores e validar a implementação do simulador que utiliza a Mate Face para o particionamento da malha. Os resultados são comparados com a ferramenta desenvolvida por Breviglieri 
Breviglieri, 2010.

\subsubsection{Escoamento Sobre o Perfil RAE 2822}

Neste caso de teste, considera-se um escoamento transônico em um aerofólio RAE 2822 com um ângulo de ataque de $2.31^{\circ}$ e o valor de Mach $M_{\infty}=0.729$. A Figura 6.10 mostra a representação esquemática do escoamento nesse caso. A malha utilizada possui 16.383 nós e 32.399 volumes, dos quais 340 volumes estão na superfície do aerofólio. A Figura 6.11 mostra a malha sobre o aerofólio utilizada nos testes.

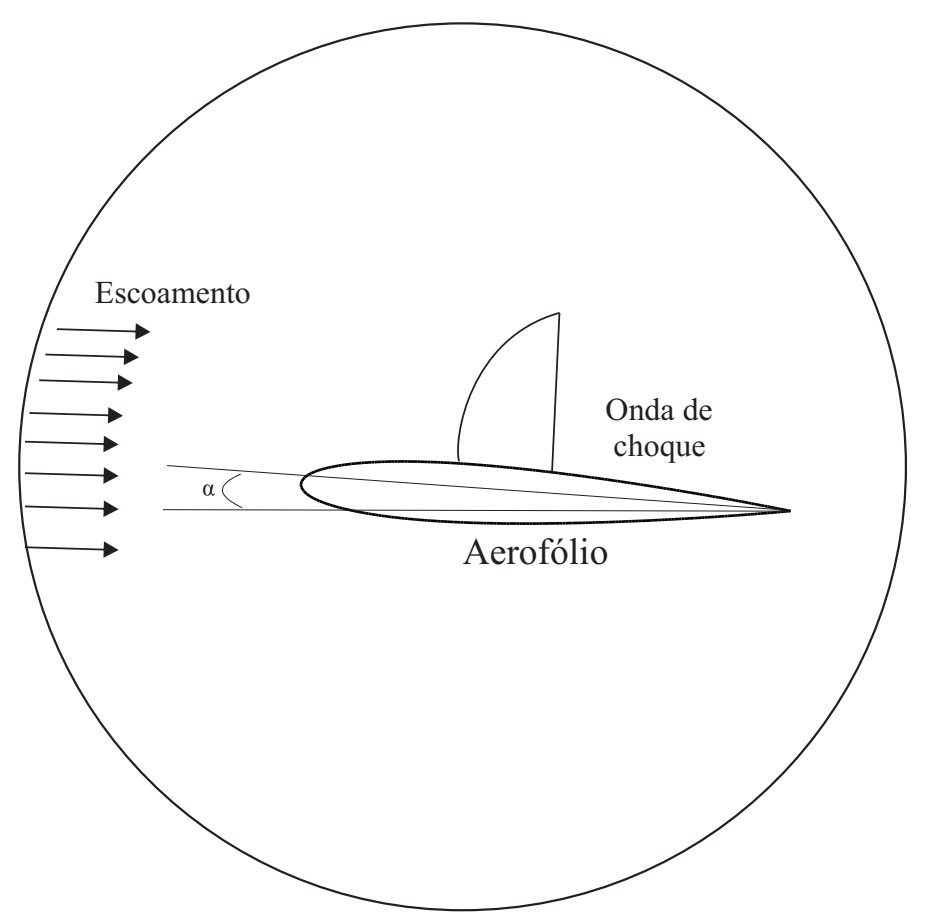

Figura 6.10: Representação do esquema do escoamento sobre o aerofólio RAE 2822.

A Figura 6.12 mostra duas visualizações da malha após o particionamento pelo método espectral de segunda ordem. Em (a) é mostrada a região do bordo de ataque no perfil, e em (b) é mostrada a região de bordo de fuga no perfil. Note que foram criados elementos de diferentes topologias aos originais dentro das células originais. Após o particionamento, a nova malha gerada é mais refinada, possuindo três vezes o número de volumes para o esquema de segunda ordem de precisão. Em particular, este particionamento gerou uma nova malha com 97564 vértices e 97197 volumes. 


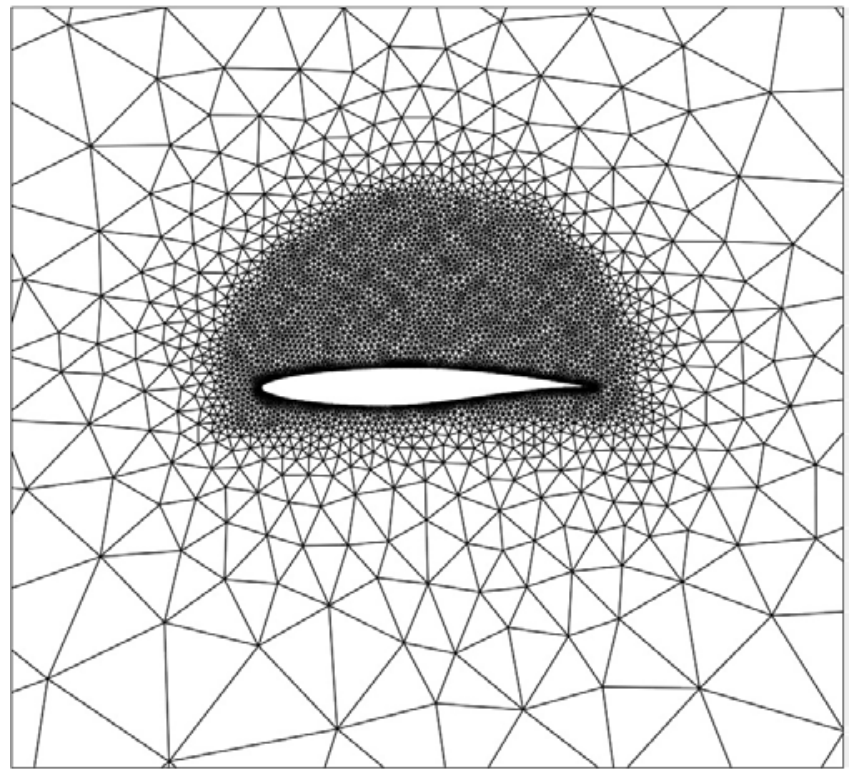

Figura 6.11: Malha sobre o aerofólio RAE 2822.

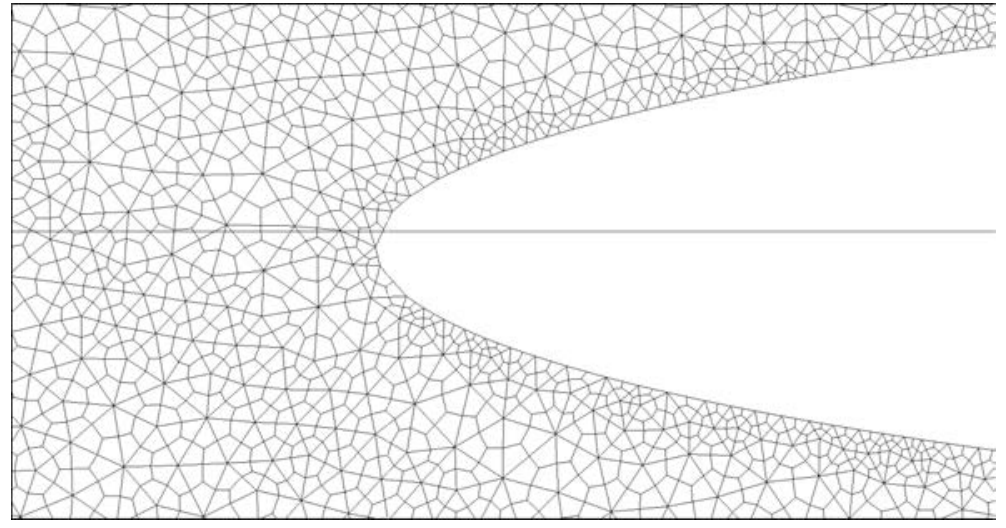

(a) Bordo de ataque

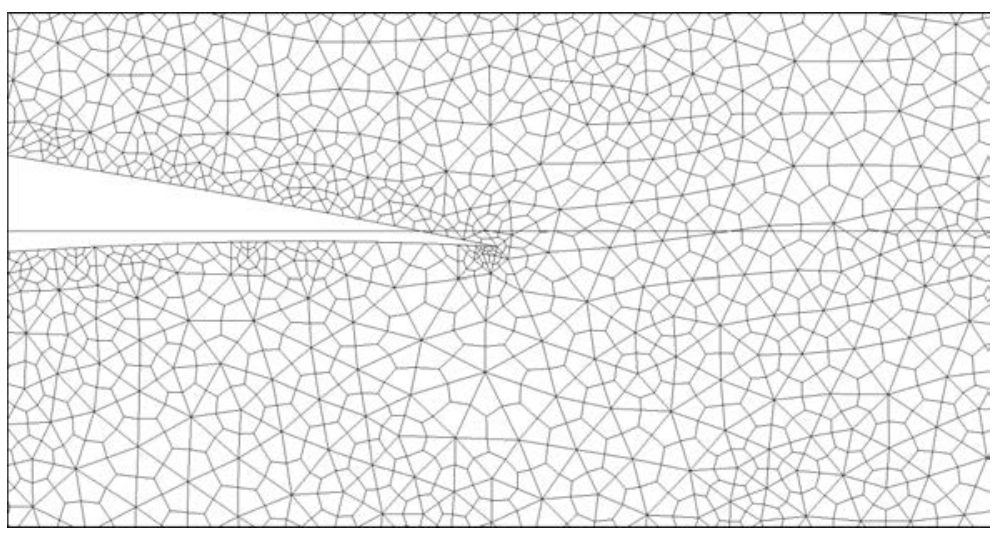

(b) Bordo de fuga

Figura 6.12: Malha com os volumes espectrais de segunda ordem após o particionamento. Detalhe na região de bordo de ataque (a) e bordo de fuga (b). 
Foram realizados experimentos nos dois simuladores testados, e a Figura 6.13 mostra os resultados obtidos da distribuição de coeficiente de pressão (Cp) na corda do aerofólio. Os resultados também são comparados com os dados experimentais divulgados por Cook Cook et al., 1979]. Pela figura, nota-se que as soluções se aproximaram da solução experimental. Porém, é importante ressaltar que os choques transônicos produzidos pelos dados experimentais não poderiam ser reproduzidos nos algoritmos aqui simulados, uma vez que são utilizadas as equações de Euler.

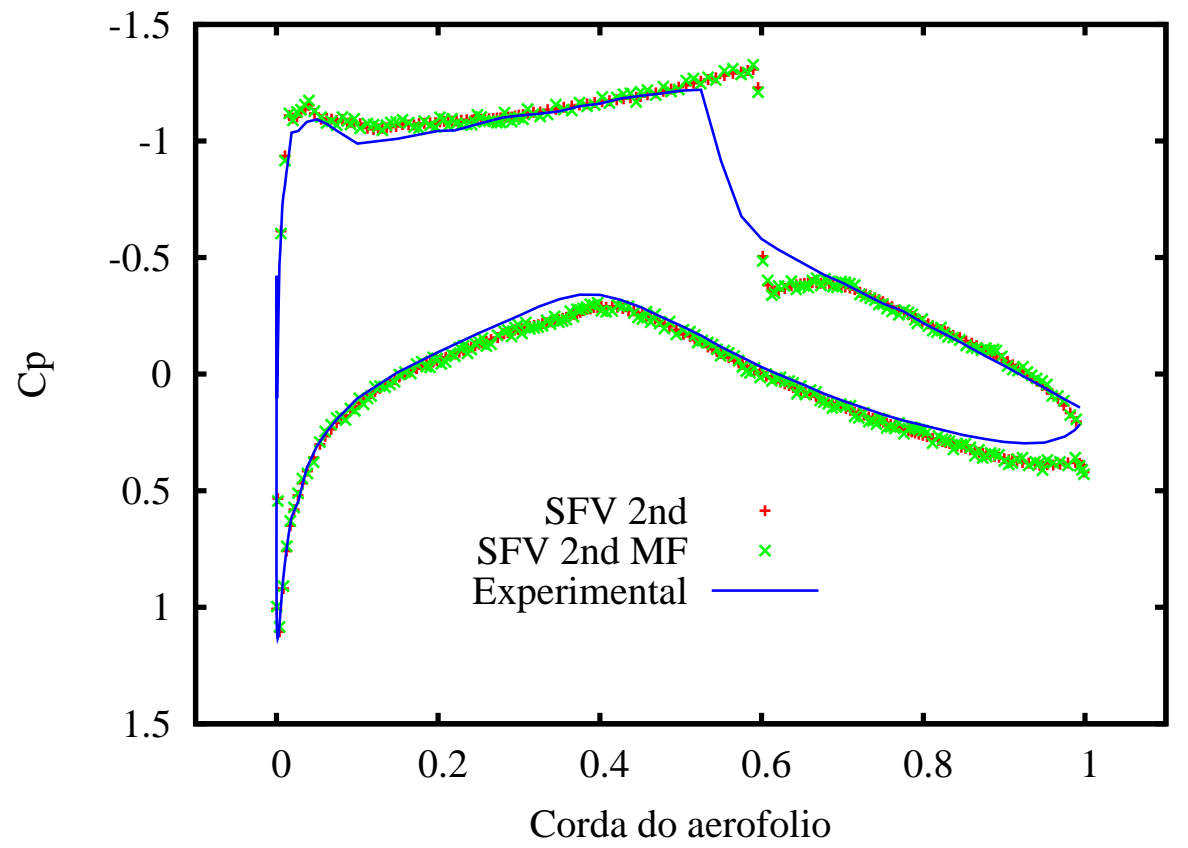

Figura 6.13: Distribuição de coeficiente de pressão ao longo da corda do aerofólio RAE 2822 para SFV de segunda ordem.

A Figura 6.14 mostra o histórico do resíduo para as primeiras 5000 iterações efetuadas, onde é visto que a variação do resíduo se torna baixa a partir deste número de iteração.

Também foi executado o mesmo experimento para o esquema de terceira ordem de precisão. A Figura 6.15 mostra duas visualizações da malha após o particionamento pelo método espectral de segunda ordem. Em (a) é mostrada a região do bordo de ataque no perfil, e em (b) é mostrada a região de bordo de fuga no perfil. Note que foram criados elementos de diferentes topologias aos originais dentro das células 


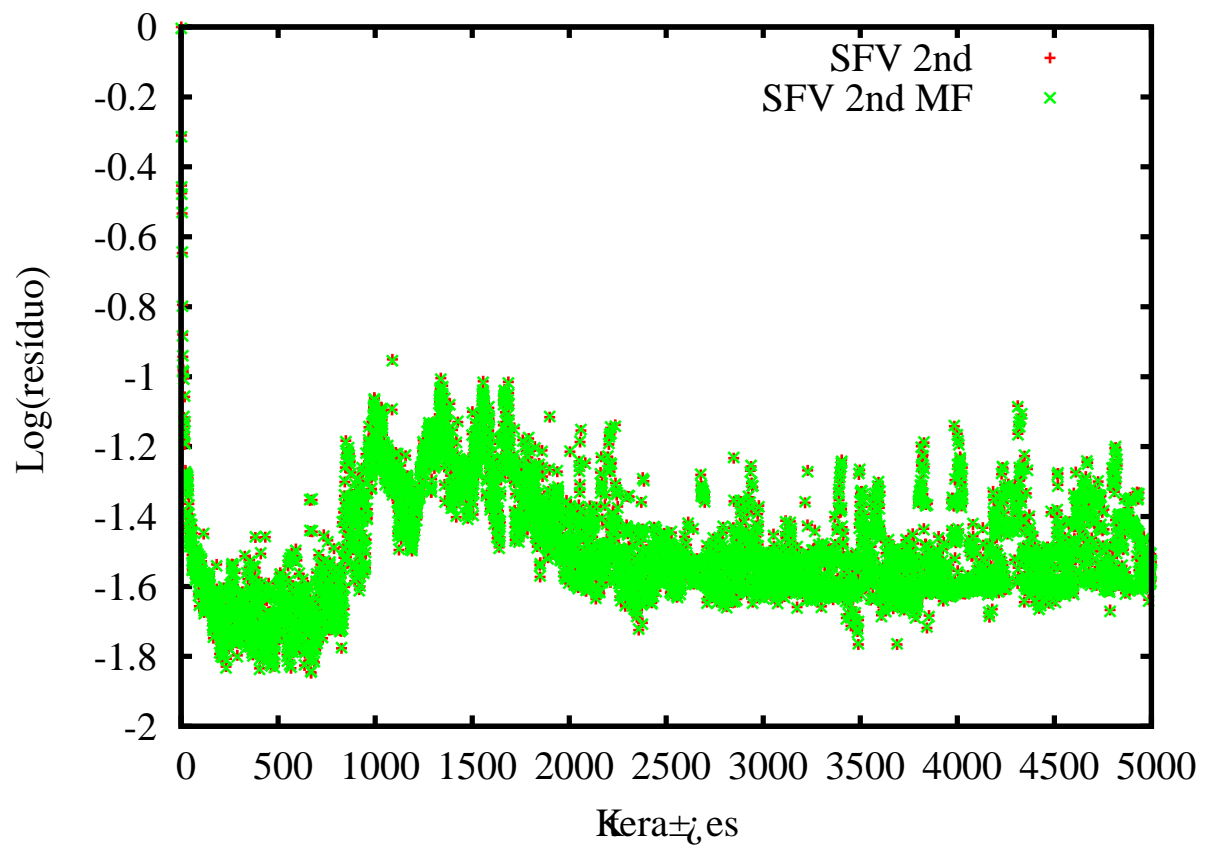

Figura 6.14: Histórico do resíduo para o aerofólio RAE 2822 com $M_{\infty}=0.729$ e $\alpha=2.31^{\circ}$ para SFV de segunda ordem.

originais. Após o particionamento, a nova malha gerada é mais refinada, possuindo seis vezes o número de volumes para o esquema de terceira ordem de precisão. Em particular, este particionamento gerou uma nova malha com 243543 vértices e 194394 volumes.

Novamente, foram realizados experimentos nos dois simuladores testados, e a Figura 6.16 mostra os resultados obtidos da distribuição de coeficiente de pressão (Cp) na corda do aerofólio. Os resultados também são comparados com os dados experimentais divulgados por Cook Cook et al., 1979. Pela figura, nota-se que as soluções se aproximaram da solução experimental. Ressalta-se que os fenômenos de choques transônicos produzidos pelos dados experimentais não foram reproduzidos nos algoritmos aqui simulados, uma vez que são utilizadas as equações de Euler.

A Figura 6.17 mostra o histórico do resíduo para as primeiras 5000 iterações efetuadas, onde é visto que a variação do resíduo se torna baixa a partir deste número de iteração. 


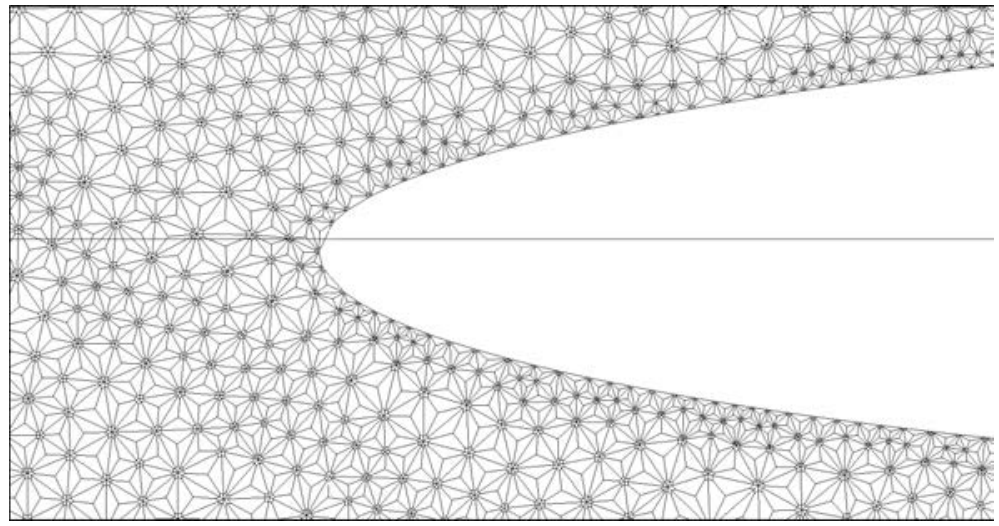

(a) Bordo de ataque

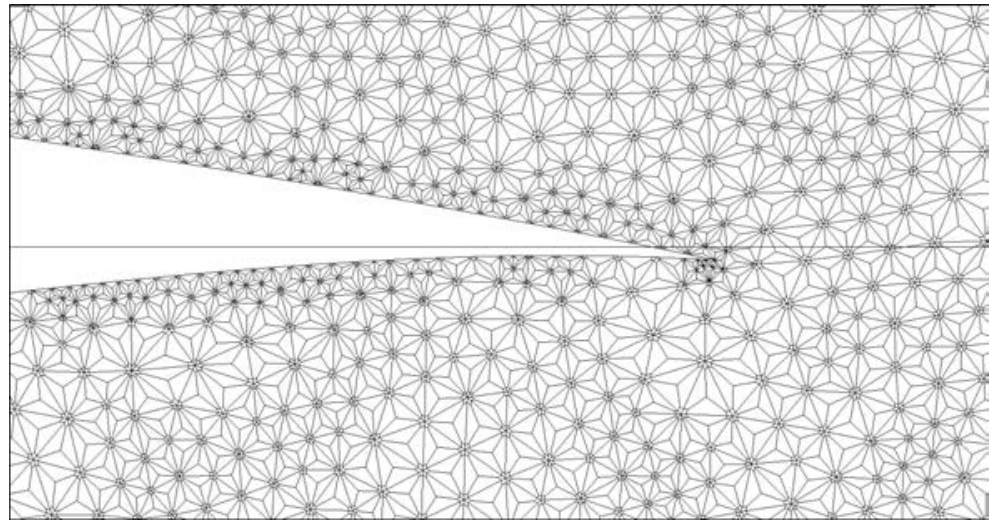

(b) Bordo de fuga

Figura 6.15: Malha com os volumes espectrais de terceira ordem após o particionamento. Detalhe na região de bordo de ataque (a) e bordo de fuga (b).

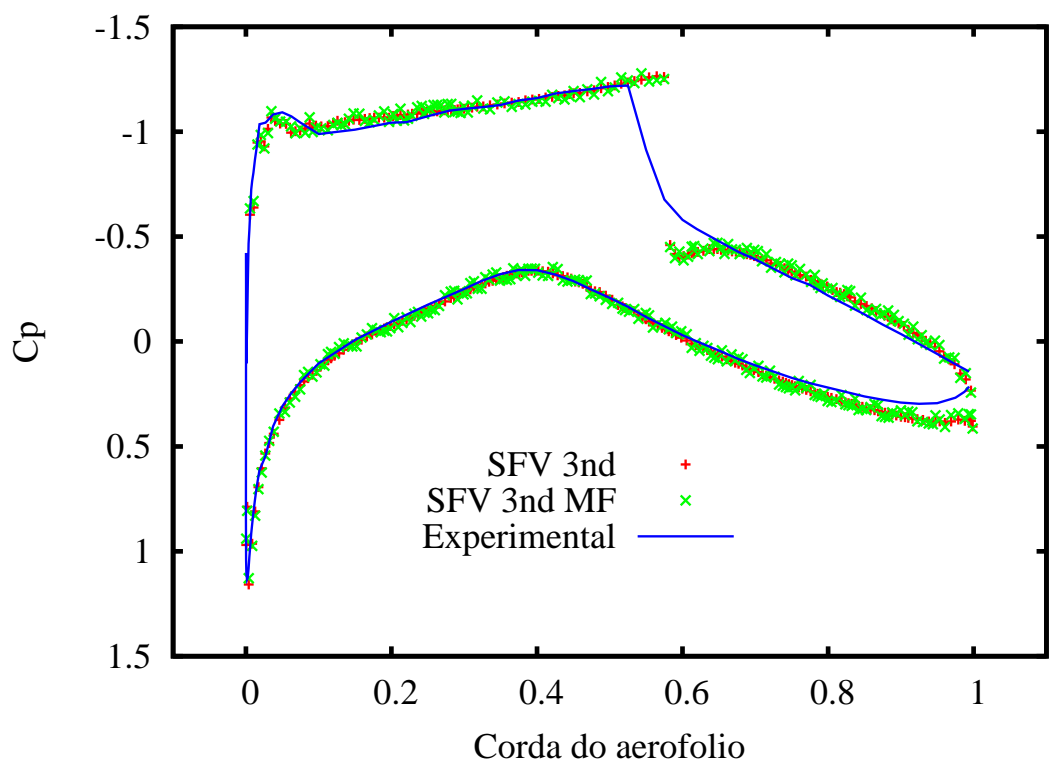

Figura 6.16: Distribuição de coeficiente de pressão ao longo da corda do aerofólio RAE 2822 para SFV de terceira ordem. 


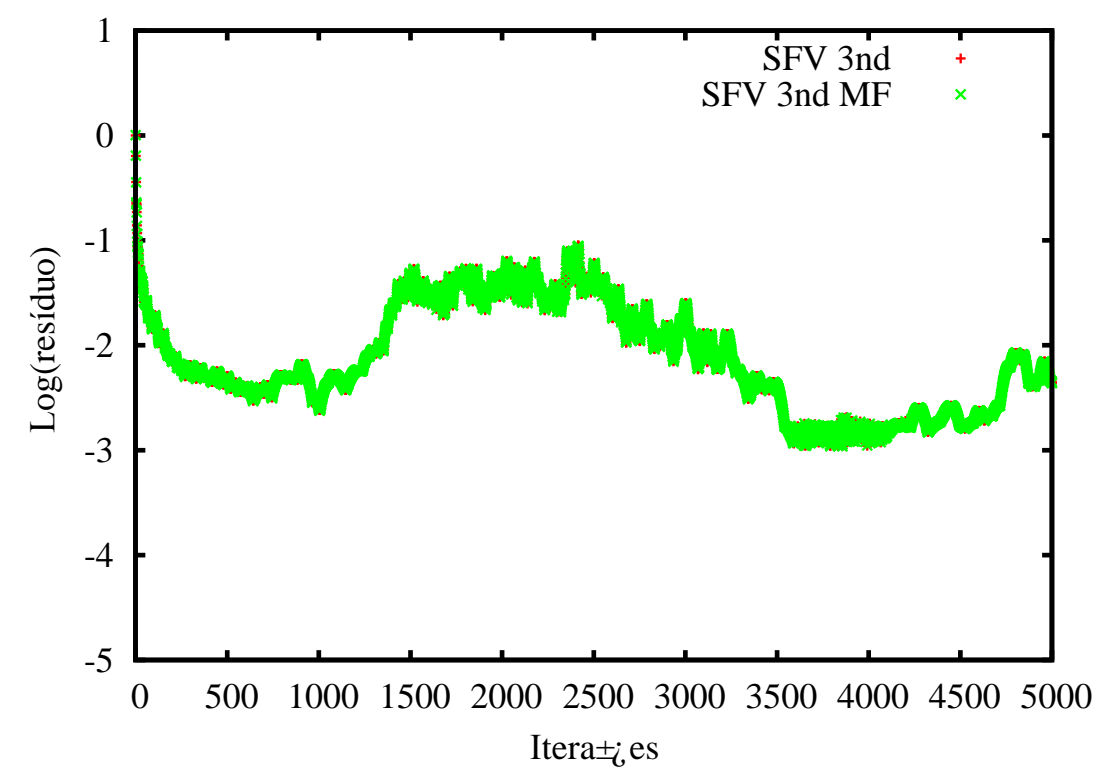

Figura 6.17: Histórico do resíduo para o aerofólio RAE 2822 com $M_{\infty}=0.729$ e $\alpha=2.31^{\circ}$ para SFV de terceira ordem. 


\subsubsection{Escoamento Sobre uma Rampa}

Neste experimento, uma onda de choque plana com número de Mach $M_{1}$ encontra uma rampa de ângulo fixo $\theta$ e é refletida pela superfície da rampa. Para este caso, o número de Mach utilizado é $M_{1}=2.5$ e é usado um ângulo $\theta=15^{\circ}$. O ângulo de choque $\beta$ é dado como $\beta=36.94$. O início da rampa é localizado nas coordenadas $x=0$ e $y=0$. A condição de entrada (inflow) é localizada em $x=-0.5$, e a condição de saída (outflow) é localizada em $x=1.0$. A condição não reflexiva (farfield) é localizada em $y=1.0$.

A malha utilizada nos testes possui 2360 vértices e 4524 volumes. O primeiro teste foi realizado com o esquema espectral de ordem 2. O particionamento da malha por esta ordem pode ser visualizada na Figura 6.18, juntamente com uma aproximação visual (zoom) na região indicada, de modo a mostrar a divisão realizada nos elementos internos de cada volume espectral. A malha particionada possui 13767 vértices e 13572 volumes.
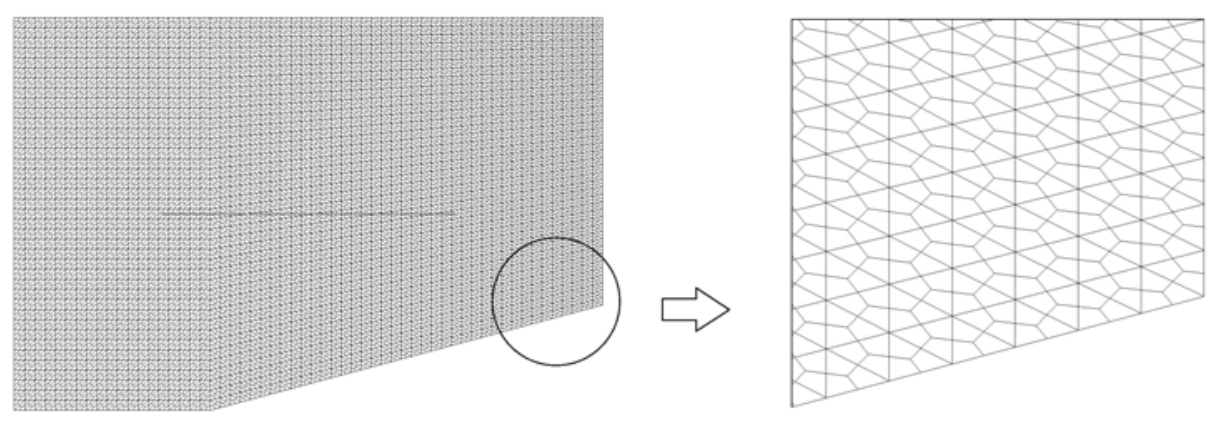

Figura 6.18: Malha gerada pelo método de volumes finitos espectral de segunda ordem.

O segundo e o terceiro teste foram realizados utilizando os esquemas espectrais de ordem 3 e 4, respectivamente. Os particionamentos da malha para estas ordens podem ser visualizados nas Figura 6.19 e 6.20, respectivamente. Ambas as figuras possuem aproximações visuais (zoom) nas regiões indicadas, de modo a mostrar a 
divisão realizada nos elementos internos de cada volume espectral de cada esquema. A malha particionada para a ordem de precisão 3 possui 34222 vértices e 27144 volumes, enquanto que a malha particionada para a ordem de precisão 4 possui 63725 vértices e 45240 volumes.
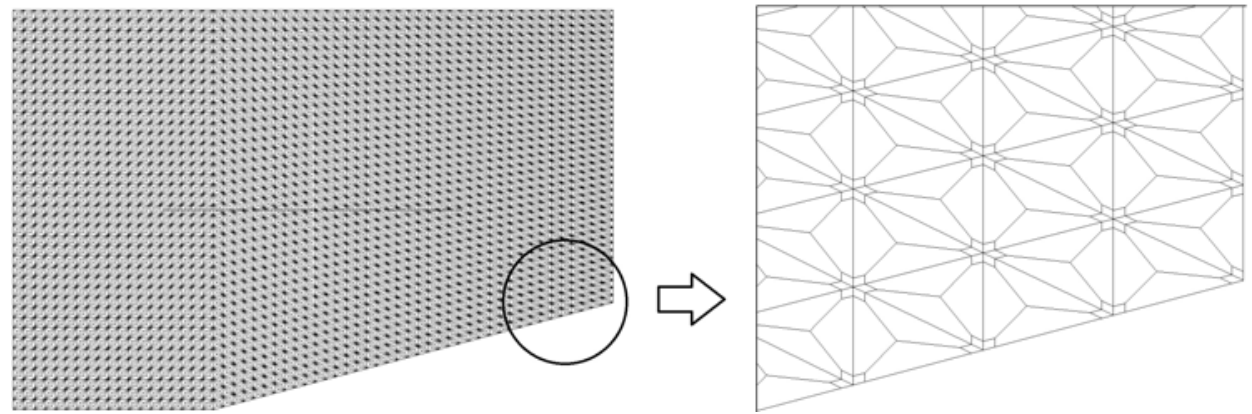

Figura 6.19: Malha gerada pelo método de volumes finitos espectral de terceira ordem.
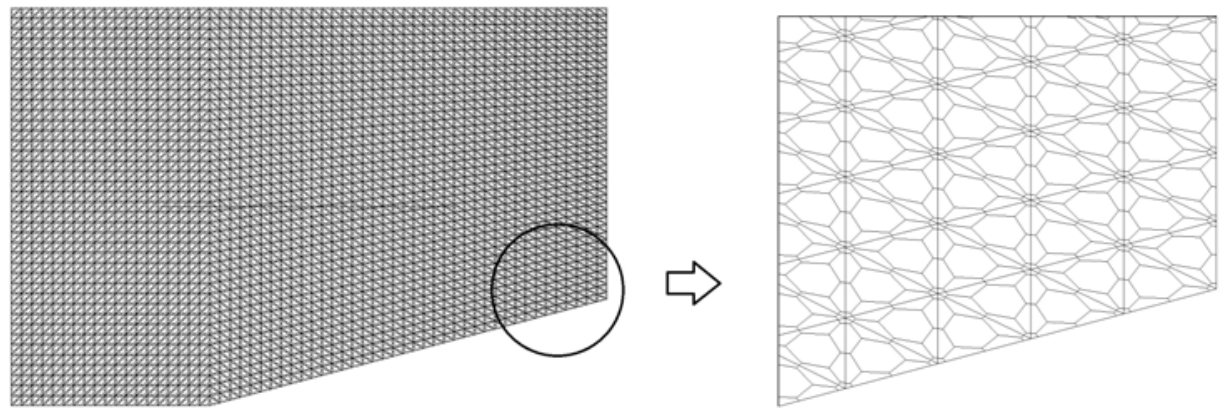

Figura 6.20: Malha gerada pelo método de volumes finitos espectral de quarta ordem.

A Figura 6.21 mostra o histórico de resíduo nas primeiras 5000 iterações realizadas em ambas implementações, para todos as ordens de precisão utilizadas nos testes. O esquema de quarta ordem de precisão foi o que mostrou maior convergência do método.

Os gráficos mostrados na Figura 6.22 mostram a distribuição de coeficiente de pressão (Cp) sobre a superfície da rampa comparados com os valores da solução analítica Anderson, 1990, para ambas implementações realizadas. Na Figura 6.22(a) 


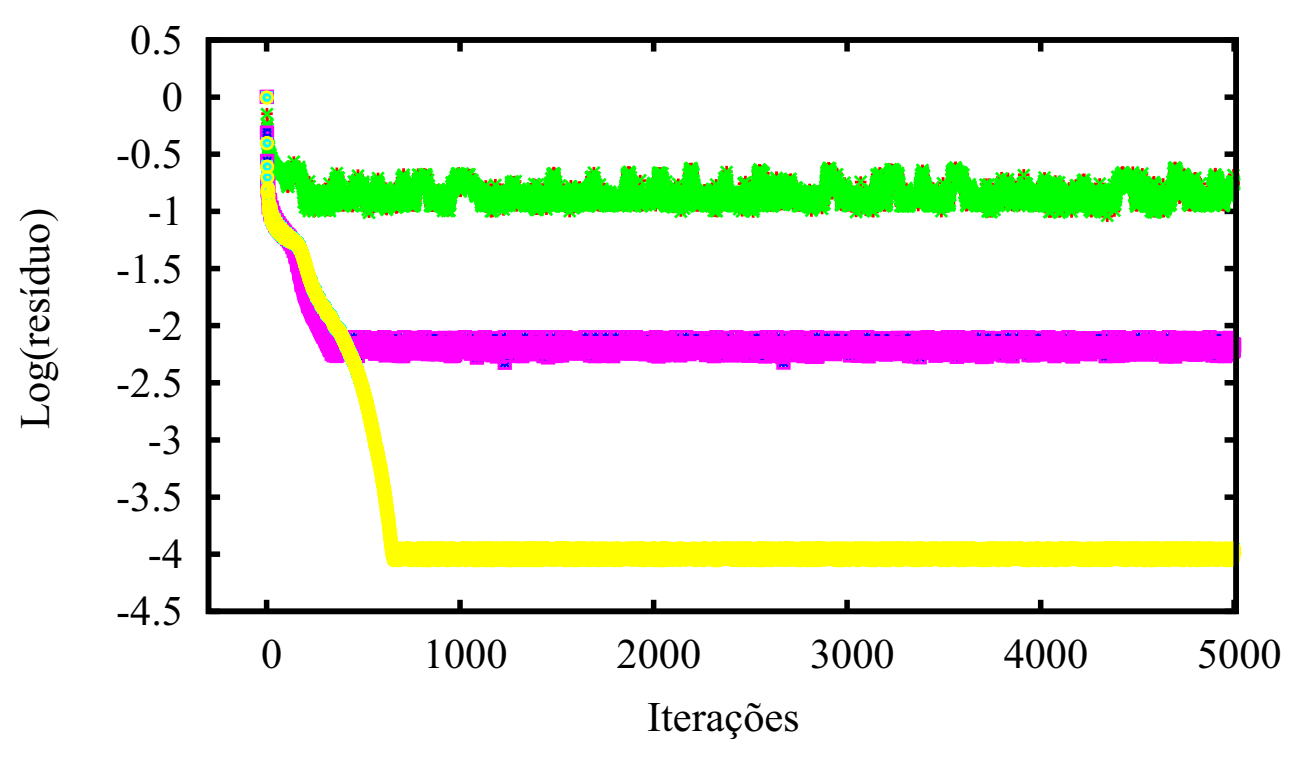

\begin{tabular}{|rrrr|}
\hline SFV 2nd & + & SFV 3nd MF & $\square$ \\
SFV 2nd MF & $\times$ & SFV 4nd & $\square$ \\
SFV 3nd & $*$ & SFV 4nd MF & \\
\hline
\end{tabular}

Figura 6.21: Histórico dos resíduos para todos os esquemas simulados.

é mostrada a distribuição de coeficiente de pressão $(\mathrm{Cp})$ para o esquema de segunda ordem, enquanto nas Figuras 6.22(b) e 6.22(c) são mostradas as distribuições de coeficientes de pressão $(\mathrm{Cp})$ resultantes para os esquemas de terceira e quarta ordem, respectivamente. Observa-se que o esquema de quarta ordem de precisão foi o que produziu melhores resultados comparando-se com a solução analítica, evidentemente pelo fato do esquema gerar um maior número de pontos e dessa forma, capturar maiores detalhes da simulação numérica. 


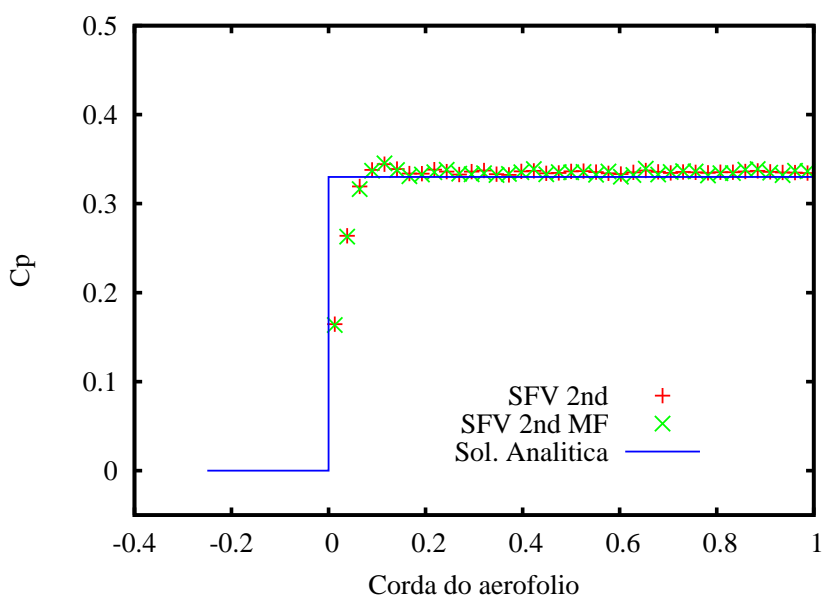

(a)

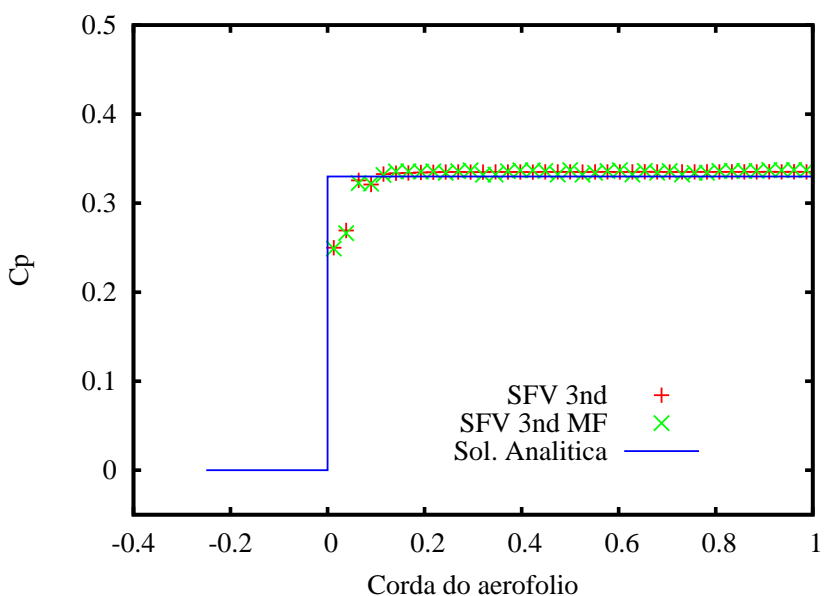

(b)

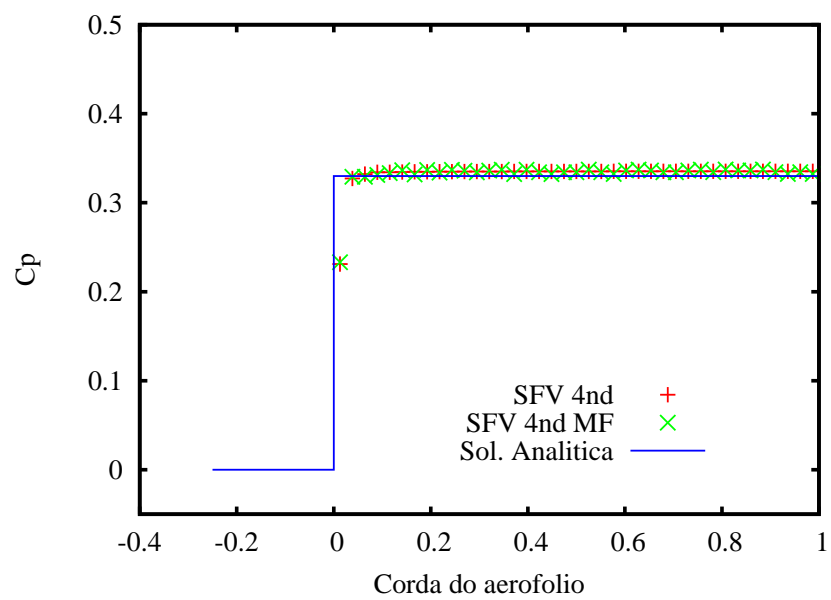

(c)

Figura 6.22: Gráficos de distribuição de coeficiente de pressão para as ordens de precisão simuladas, (a) segunda ordem de precisão, (b) terceira ordem de precisão e (c) quarta ordem de precisão. 


\subsection{Considerações Finais}

Este capítulo apresentou o método de volumes finitos espectrais, um método de alta ordem desenvolvido para malhas não estruturadas para a obtenção de soluções estacionárias de escoamentos não viscosos e compressíveis, representado pelas equações de Euler. Este método foi utilizado para se obter alta resolução espacial no domínio computacional, a partir de partições das células da malha original (volumes espectrais) em células menores (volumes de controle).

Existem várias ordens de precisão para o método, onde cada ordem divide a célula espectral em um número diferente de elementos, e utilizando parâmetros pré-definidos para essa formação. A formulação geral para o método de volumes finitos espectrais foi apresentada, assim como detalhado o particionamento efetuado na malha de entrada, e foram apresentados os limitadores de fluxo. Como visto, os limitadores de fluxo limitam algumas propriedades da reconstrução nos pontos de integração do fluxo para manter a estabilidade e convergência da simulação, caso a solução no escoamento conter descontinuidades. Os esquemas de marcha no tempo foram apresentados como possíveis métodos para efetuar o avanço da solução temporal.

Como a Mate Face não suportava elementos diferentes de triângulos e quadriláteros a priori, foi desenvolvida uma extensão da estrutura de modo a possibilitar a representação de elementos de variadas topologias, o que inclui de triângulos até hexágonos. De um modo geral, foram acrescentadas classes para representar os dados necessários para a nova malha utilizada. Na estrutura estendida, cada célula da Mate Face possui uma associação para uma célula espectral, que irá armazenar os volumes de controle (as células subdivididas), e todas as novas arestas criadas pela divisão foram representadas em um conjunto separado de arestas espectrais. Deste modo, o particionamento é feito localmente em cada volume espectral, minimizando o custo computacional de acesso aos elementos específicos em uma dada célula.

Foram realizados experimentos para validar os métodos mostrados neste capítulo 
bem como a extensão da estrutura Mate Face para indexar a malha modificada pelo método de volumes finitos espectrais. Desta forma, verificou-se que a nova estrutura comporta adequadamente a nova geometria formada pelos particionamentos do esquema espectral. 


\section{Capítulo 7 \\ Conclusão}

Este trabalho focou o estudo e a aplicação de estruturas de dados para auxiliar o desenvolvimento de métodos numéricos construídos para simular escoamentos de fluidos sob diferentes abordagens. Para tal, foram estudados diferentes métodos para resolver problemas específicos nas simulações dos escoamentos, que por sua vez fazem o uso de malhas não estruturadas formadas para representar vários domínios de aplicações.

Inicialmente, este trabalho apresentou os conceitos básicos para o desenvolvimento dos métodos numéricos apresentados, o que incluiu detalhar conceitos sobre mecânica de fluidos computacional, métodos de alta ordem e modelos aerodinâmicos. A partir destes conceitos, foi apresentado o modelo matemático do escoamento, onde foram expostas as equações governantes do escoamento de fluidos. O método dos volumes finitos, utilizado em todas as implementações, foi apresentado juntamente com as discretizações para os métodos abordados dentro de cada capítulo específico.

Além desses conceitos, uma vez que um dos pilares no desenvolvimento desta tese baseia-se na estrutura de dados que rege as operações e armazenamento de malhas não estruturadas, foram apresentadas as estruturas de dados topológicas existentes na literatura para o gerenciamento de malhas não estruturadas, assim como o detalhamento da estrutura de dados utilizada durante todo o trabalho, a Mate Face. 
A primeira frente deste trabalho foi adequar uma ferramenta de simulação que resolve as equações de Euler bidimensionais através da técnica de volumes finitos utilizando malhas não estruturadas para a representação do domínio. Esta ferramenta dispõe de vários métodos para a solução das equações governantes para casos de escoamentos de fluidos estacionários, dentre eles os esquemas ENO e WENO, que foram desenvolvidos com o objetivo de capturar com acurácia as descontinuidades presentes nas simulações envolvendo altos números de Mach.

Foram apresentados os esquemas não oscilatórios do tipo Essentially NonOscillatory (ENO), os esquemas Weighted Essentially Non-Oscillatory (WENO) e suas reconstruções para esquemas de segunda, terceira e quarta ordem de precisão. A discretização espacial, baseada no contexto do método de volumes finitos foi apresentada para o método. A discretização temporal foi realizada utilizando-se o método de Runge-Kutta TVD de três estágios. Para o cálculo do fluxo numérico foi utilizado o método de Roe e o indicador de oscilação utilizado nos experimentos foi o proposto por Jiang e Shu.

Um dos objetivos deste trabalho foi realizar o acoplamento da estrutura de dados Mate Face ao código de simulação, mostrando exemplos de utilização da estrutura e consultas utilizadas no simulador. O acoplamento da estrutura de dados Mate Face ao simulador foi realizada através da criação de uma biblioteca desenvolvida que atua como uma interface de comunicação entre os dois módulos, a estrutura de dados e o simulador, que foram implementadas em diferentes linguagens de programação. Deste modo, todas as funcionalidades existentes na Mate Face tornaram-se acessíveis ao simulador na forma de procedimentos.

Um estudo investigativo no contexto de malhas dinâmicas foi realizado envolvendo o método das molas para movimentação de malhas produzindo movimentações que são comuns em simulações de escoamentos não estacionários, como por exemplo movimentos de arfagem no perfil de aerofólios. O estudo analisou a aplicação do método baseado em molas, em específico utilizando-se molas semi-torcionais. Verificou-se que 
algumas angulações produziram elementos inválidos, o que inviabilizaria a utilização em simulações de escoamentos não estacionários, sem um tratamento adicional na execução da malha dinâmica, como por exemplo algoritmos de remalhamento na inicialização das simulações, dependendo da geometria do domínio abordado.

Uma outra contribuição deste trabalho foi estender a estrutura Mate Face para representar elementos que não eram suportados, possibilitando sua utilização para simulações de escoamentos baseados no método de volumes finitos espectrais. O método dos volumes espectrais é um método utilizado para se obter alta resolução espacial do domínio computacional, que também atribui valores das propriedades aos centroides dos volumes de controle, porém, os volumes de controle são particionados em volumes menores de variadas topologias, de acordo com os esquemas de ordem de precisão definidos. Portanto, foi desenvolvida uma extensão da Mate Face para representar a nova malha para a aplicação do método, representando cada particionamento localmente em cada volume espectral. Na estrutura estendida, cada célula da Mate Face possui uma associação para uma estrutura interna chamada célula espectral, que armazena os volumes de controle (as células que foram subdivididas). Todas as novas arestas criadas, chamadas de arestas espectrais, foram representadas em um conjunto separado.

Para todas as etapas deste trabalho, realizaram-se experimentos que validaram a utilização da estrutura de dados Mate Face junto a métodos numéricos. Desta forma, pode-se concluir que a estrutura de dados Mate Face pode auxiliar as ferramentas de simulações de escoamentos de fluidos no gerenciamento e acesso à malha computacional.

Uma proposta para trabalhos futuros é o desenvolvimento do método de volume finito espectral tridimensional, uma vez que a Mate Face suporta elementos tridimensionais. Uma outra proposta é desenvolver o método espectral baseado em vértices, conhecido como Vertex-Center, utilizando a estrutura de dados Mate Face. 


\section{Referências Bibliográficas}

[Abgrall, 1994] Abgrall, R. (1994). On essentially non-oscillatory schemes on unstructured meshes: Analysis and implementation. Journal of Computational Physics, 114, No.1:45-58.

[Adams and Shariff, 1996] Adams, N. and Shariff, K. (1996). A high-resolution hybrid compact-eno scheme for shock-turbulence interaction problems. Journal of Computational Physics, 127(1):27 - 51.

[Ames et al., 1996] Ames, A. L., Nadeau, D. R., and Moreland, J. L. (1996). VRML 2.0 Sourcebook. Wiley.

[Anderson, 1995] Anderson, J. (1995). Computational fluid dynamics: the basics with applications. McGraw-Hill series in mechanical engineering, 1 edition.

[Anderson, 1982] Anderson, J. D. (1982). Modern Compressible Flow. McGrall-Hill, Singapore.

[Anderson, 1990] Anderson, J. D. J. (1990). Modern compressible flow with historical perspectives. McGraw - Hill International Editions.

[Anderson, 1991] Anderson, J. D. J. (1991). Fundamentals of aerodynamics. McGraw - Hill International Editions.

[Anderson, 1963] Anderson, W. (1963). A comparison of finite volume flux vector splittings for the euler equations. American Institute of Aeronautics and Astronautics - AIAA.

[Ashley, 1980] Ashley, H. (1980). Role of shocks in the sub-transonic flutter phenomenon. Journal of Aircraft, 17, n.3:187-197.

[Azevedo et al., 2010] Azevedo, J. A. L. F., Figueira da Silva, L. A.-s. F., and Strauss, D. (2010). Order of accuracy study of unstructured grid finite volume upwind schemes. Journal of the Brazilian Society of Mechanical Sciences and Engineering, $32: 78-93$.

[Batina, 1990] Batina, J. T. (1990). Unsteady Euler airfoil solutions using unstructured dynamic meshes. AIAA Journal, 28(8):1381-1388. 
[Batina, 1993] Batina, J. T. (1993). Implicit upwind solution algorithms for treedimensional unstructured meshes. AIAA Journal, 31:801-805.

[Baumgart, 1975] Baumgart, B. G. (1975). A polyhedron representation for computer vision. In AFIPS National Computer Conference, volume 44, pages 589-596.

[Beam and Warming, 1976] Beam, R. M. and Warming, R. F. (1976). An implicit finite-difference algorithm for hyperbolic systems in conservation law form. Journal of Computational Physics, 22:87-109.

[Bigarella, 2007] Bigarella, E. (2007). Advanced Turbulence Modelling for Complex Aerospace Applications. PhD thesis, Ph. D. Thesis, Instituto Tecnológico de Aeronáutica, São José dos Campos, SP, Brazil, 2007.[Links].

[Bisplinghoff et al., 1996] Bisplinghoff, R. L., Ashley, H., and Halfman, R. L. (1996). Aeroelasticity. Dover, New York.

[Blazek, 2001] Blazek, J. (2001). Computational fluid dynamics: Principles and applications. pages -.

[Blom, 2000] Blom, F. J. (2000). Considerations on the spring analogy. International Journal for Numerical Methods in Fluids, 32(6).

[Boissonnat et al., 2000] Boissonnat, J. D., Devillers, O., Teillaud, M., and Yvinec, M. (2000). Triangulations in cgal. In 16th Annu. ACM Sympos. Comput. Geom. ACM.

[Boris and Book, 1973] Boris, J. P. and Book, D. L. (1973). Flux corrected transport: I. shasta, a fluid transport algorithm that works. Journal of Computational Physics, 11, No. 1:38-69.

[Bossen, 1996] Bossen, F. J. (1996). Anisotropic mesh generation with particles. Technical Report CMU-CS-96-134.

[Bottasso et al., 1998] Bottasso, C. L., Klaas, O., and Shephard, M. S. (1998). Data structures and mesh modification tools for unstructured multigrid adaptive techniques. Engineering with Computers, 14:235-247.

[Breviglieri, 2010] Breviglieri, C. J. (2010). High-Order Unstructured Spectral Finite Volume Method for Aerodynamic Applications. PhD thesis, ITA, Brasil.

[Briley and McDonald, 1975] Briley, W. and McDonald, H. (1975). Solution of the three-dimensional compressible Navier-Stokes equation by an implicit technique. Proceedings of the Fourth International Conference on Numerical Methods in Fluid Dynamics. New York.

[Burg, 2004] Burg, C. O. E. (2004). A robust unstructured grid movement strategy using three-dimensional torcional springs. AAIA Fluid Dynamics Conference and Exhibit, 
[Casper and Atkins, 1993] Casper, J. and Atkins, H. L. (1993). A finite-volume high-order eno scheme for two-dimensional hyperbolic systems. J. Comput. Phys., 106(1):62-76.

[Chawner, 2003] Chawner, J. R. (2003). Mesh generation and automated simulation: Part ii. issues in applied mesh generation. 7th US National Congress on Computational Mechanics.

[Chen, 2005] Chen, Q.-Y. (2005). Partitions of a simplex leading to accurate spectral (finite) volume reconstruction. SIAM J. Sci. Comput., 27(4):1458-1470.

[Chen, 2006] Chen, Q.-Y. (2006). Partitions for spectral (finite) volume reconstruction in the tetrahedron. J. Sci. Comput., 29(3):299-319.

[Chyu et al., 1981] Chyu, W., Davis, S. S., and Chang, K. S. (1981). Calculation of unsteady transonic flow over an airfoil. AIAA Journal, 19:684-690.

[Cook et al., 1979] Cook, P. H., McDonald, M. A., and Firmin, M. C. P. (1979). Aerofoil rae 2822 - pressure distributions and boundary layer and wake measurements. Technical report, Experimental DataBase for Computer Program Assessment - Aguard Report AR 138.

[Courant et al., 1952] Courant, R., Issacson, E., and Rees, M. (1952). On the solution of nonlinear hyperbolic differential equations by finite differences. Commun. Pure Appl. Math., 5:243-255.

[Cunha, 2009] Cunha, I. L. L. (2009). Estrutura de dados Mate Face e aplicações em geração e movimento de malhas. PhD thesis, Dissertação de Mestrado, Universidade de São Paulo.

[Dadone and Moretti, 1988] Dadone, A. and Moretti, G. (1988). Fast euler solver for transonic airfoils part i: theory. AIAA Journal, 23:409-416.

[Degand and Farhat, 2002] Degand, C. and Farhat, C. (2002). A Three-Dimensional Torsional Spring Analogy Method for Unstructured Dynamic Meshes. Computers and Structures, 80:305-316.

[den Abeele et al., 2007] den Abeele, K. V., Broeckhoven, T., and Lacor, C. (2007). Dispersion and dissipation properties of the $1 \mathrm{~d}$ spectral volume method and application to a p-multigrid algorithm. Journal of Computational Physics, 224(2):616 636.

[den Abeele and Lacor, 2007] den Abeele, K. V. and Lacor, C. (2007). An accuracy and stability study of the $2 \mathrm{~d}$ spectral volume method. Journal of Computational Physics, 226(1):1007 - 1026.

[Dobkin and Laszlo, 1989] Dobkin, D. P. and Laszlo, M. J. (1989). Primitives for the manipulation of three-dimensional subdivisions. Algorithmica, 4:3-32. 
[Doi and Alonso, 2002] Doi, H. and Alonso, J. J. (2002). Fluid/structure coupled aeroelastic computations for transonic flows in turbomachinery. In ASME Turbo Expo 2002.

[Dolezal and Wong, 1995] Dolezal, A. and Wong, S. (1995). Relativistic hydrodynamics and essentially non-oscillatory shock capturing schemes. Journal of Computational Physics, 120(2):266 - 277.

[Dowell, 1996] Dowell, E. H. (1996). Eigenmode analysis in unsteady aerodynamics: reduced-order models. AIAA Journal, 34, n.8:1578-1588.

[Drikakis and Tsangaris, 1992] Drikakis, D. and Tsangaris, S. (1992). Local solution acceleration method for the Euler and Navier-Stokes equations. AIAA Journal, $30(2): 340-348$.

[Dubuc, 1997] Dubuc, L. (1997). Solution of the Euler unsteady equations using deforming grids. Aero Report 9704.

[ERLEBACHER et al., 1997] ERLEBACHER, G., HUSSAINI, M. Y., and SHU, C.W. (1997). Interaction of a shock with a longitudinal vortex. Journal of Fluid Mechanics, 337:129-153.

[Farhat et al., 1998] Farhat, C., Degand, C., Koobus, B., and Lesoinne, M. (1998). Torsional Springs for Two-Dimensional Dynamic Unstructured Fluid Meshes. Computer Methods in Applied Mechanics and Engineering, 163:231-245.

[Ferziger and Peric, 1997] Ferziger, J. H. and Peric, M. (1997). Computational methods for fluid dynamics. Springer-Verlag.

[Fletcher, 1984] Fletcher, C. A. J. (1984). Computatiqnal Techniques for Fluid Dynamics 8. Fundamental and General Techniques. Springer-Verlag.

[Fletcher, 1992a] Fletcher, C. A. J. (1992a). Computational techniques for fluid dynamics: fundamental and general techniques. Springer-Verlag.

[Fletcher, 1992b] Fletcher, C. A. J. (1992b). Computational techniques for fluid dynamics: specific techniques for different flow categories. Springer-Verlag.

[Floriani and Hui, 2003] Floriani, L. D. and Hui, A. (2003). A scalable data structure for three dimensional non-manifold objects. ACM, Symposium on Geometry Processing, 4:72-82.

[Fortuna, 2000] Fortuna, A. O. (2000). Técnicas Computacionais para Dinâmica dos Fluidos. Edusp.

[Fox et al., 2004] Fox, R. W., Mcdonald, A. T., and Pritchard, P. J. (2004). Introdução à Mecânica dos Fluidos. 6. ed, Ltc Editora.

[Friedrich, 1998] Friedrich, O. (1998). Weighted essentially non-oscillatory schemes for the interpolation of mean values on unstructured grids. Journal of Computational Physics, 144, N. 1:194-212. 
[Gersten, 2009] Gersten, K. (2009). Hermann schlichting and the boundary-layer theory. volume 102 of Notes on Numerical Fluid Mechanics and Multidisciplinary Design, pages 3-17. Springer Berlin / Heidelberg.

[Godunov, 1959] Godunov, S. K. (1959). A difference scheme for numerical computation of discontinuous solution of hydrodynamic equations. Math Sbornik, 47:271306.

[Gooch, 1997] Gooch, C. F. O. (1997). High order eno schemes for unstructured meshes based on least-squares reconstruction. Technical Report P631-1296, Argonne National Laboratory, Mathematics and Computer Science Division.

[Goodman and O'Rourke, 1997] Goodman, J. E. and O'Rourke, J., editors (1997). Handbook of discrete and computational geometry. CRC Press, Inc., Boca Raton, FL, USA.

[Gopi et al., 2000] Gopi, M., Krishnan, S., and Silva, C. T. (2000). Surface reconstruction based on lower dimensional localized delaunay triangulation.

[Guibas and Stolfi, 1985] Guibas, L. and Stolfi, J. (1985). Primitives for the manipulation of general subdivisions and the computation of Voronoi diagrams. $A C M$ Trans. On Graphics, 4(2):74-123.

[Guruswamy, 1990] Guruswamy, G. (1990). Unsteady aerodynamics and aeroelastic calculations for wings the euler equations. AIAA Journal, 28:461-469.

[Hannappel et al., 1995] Hannappel, R., Hauser, T., and Friedrich, R. (1995). A comparison of eno and tvd schemes for the computation of shock-turbulence interaction. Journal of Computational Physics, 121:176-184.

[Harris et al., 2008] Harris, R., Wang, Z., and Liu, Y. (2008). Efficient quadraturefree high-order spectral volume method on unstructured grids: Theory and $2 \mathrm{~d}$ implementation. Journal of Computational Physics, 227(3):1620 - 1642.

[Harris and Wang, 2009] Harris, R. and Wang, Z. J. (2009). Partition design and optimization for high-order spectral volume schemes. 47th AIAA Aerospace Sciences Meeting.

[Harten, 1983] Harten, A. (1983). High resolution schemes for hyperbolic conservation laws. Journal of Computational Physics, 49:357-393.

[Harten and Chakravarthy, 1991] Harten, A. and Chakravarthy, S. R. (1991). MultiDimensional ENO Schemes for General Geometries. Tech. Rep. 91-76, ICASE.

[Harten et al., 1987] Harten, A., Osher, S., Engquist, B., and Chakravarthy, S. R. (1987). Uniformly high-order accurate essentially non-oscillatory schemes iii. Journal of Computational Physics, 71, No.2:231-303.

[Helenbrook, 2003] Helenbrook, B. T. (2003). Mesh deformation using the biharmonic operator. International Journal for Numerical Methods in Engineering, 56(7):10071021. 
[Hirsch, 1989] Hirsch, C. (1989). Numerical Computation of Internal and External Flows, volume 1. A Wiley-Interscience Publication.

[Hirsch, 1990] Hirsch, C. (1990). Numerical Computation of Internal and External Flows, Vol.2. Willey, Salisbury.

[Hirsch, 2007] Hirsch, C. (2007). Numerical Computation of Internal and External Flows: Fundamentals of Computational Fluid Dynamics. Number v. 1 in Butterworth Heinemann. Elsevier/Butterworth-Heinemann.

[Hoffman and Chiang, 2000] Hoffman, K. A. and Chiang, S. T. (2000). Computational Fluid Dynamics. 4 ed. USA, Engineering Education System.

[Hoffren, 1996] Hoffren, J. (1996). Special issues in unsteady Navier-Stokes simulations with deforming bodies. In 20th Congress of the International Council of the Aeronautical Sciences, ICAS-96-1.1.4, Sorrento.

[Hu and Shu, 1999] Hu, C. and Shu, C.-W. (1999). Weighted essentially nonoscillatory schemes on triangular meshes. Journal of Computational Physics, 150(1):97 - 127 .

[Huang and Menq, 2002] Huang, J. and Menq, C. (2002). Combinatorial manifold mesh reconstruction and optimization from unorganized points with arbitrary topology. Computer-Aided Design, 34(2):149 - 165.

[Hwang and Wu, 1993] Hwang, C. J. and Wu, S. J. (1993). Adaptive finite volume upwind approach on mixed quadrilateral triangular meshes. AIAA Journal, 30:6167.

[Jamenson, 1997] Jamenson, A. (1997). Essential elements of computational algoritmos for aerodynamic analysis and design. NASA Langley Research Center, Hampton, $V A$.

[Jameson and Mavriplis, 1986] Jameson, A. and Mavriplis, D. (1986). Finite volume Solution of the Two-Dimensional Euler Equations on a Regular Triangular Mesh. AIAA Journal, 24(4):611-618.

[Jameson et al., 1981] Jameson, A., Schmidt, W., and Turkel, E. (1981). Numerical Solution of the Euler Equations by Finite volume Methods using Runge-Kutta Time-stepping Schemes. In AIAA 14th Fluid and Plasma Dynamics Conference, AIAA Paper No. 81-9259.

[Jiang and Shu, 1996] Jiang, G.-S. and Shu, C.-W. (1996). Efficient implementation of weighted eno schemes. Journal of Computational Physics, 126(1):202 - 228.

[Kannan and Wang, 2009] Kannan, R. and Wang, Z. J. (2009). A study of viscous flux formulations for a p-multigrid spectral volume navier stokes solver. J. Sci. Comput., 41(2):165-199.

[Käser and Iske, 2005] Käser, M. and Iske, A. (2005). Ader schemes on adaptive triangular meshes for scalar conservation laws. J. Comput. Phys., 205(2):486-508. 
[Kettner, 1999] Kettner, L. (1999). Using generic programming for designing a data structure for polyhedral surfaces. Computational Geometry - Theory and Applications, 13:65-90.

[Kruger et al., 2002] Kruger, W. R., Heinrich, R., and Spieck, M. (2002). Fluidstructure coupling using cfd and multibody simulation methods. ICAS 2002 Congress.

[Kwok et al., 1995] Kwok, W., Haghighi, K., and Kang, E. (1995). An efficient data structure for the advancing-front triangular mesh generation technique. Communications in Num. Meth. Engineering, 11:465-473.

[Lage et al., 2005] Lage, M., Lewiner, T., Lopes, H., and Velho, L. (2005). Chf: A scalable topological data structure for tetrahedral meshes. In Computer Graphics and Image Processing, 2005. SIBGRAPI 2005. 18th Brazilian Symposium on, pages $349-356$.

[Lamb, 1879] Lamb, H. (1879). A treatise on the mathematical theory of the motion of fluids. The University press.

[Lax and Wendroff, 1960] Lax, P. and Wendroff, B. (1960). Systems of conservation laws. Communications on Pure and Applied Mathematics, 13:217.

[Lee-Rausch and Batina, 1996] Lee-Rausch, E. and Batina, J. (1996). Wing flutter computations using an aerodynamic model based on the Navier-Stokes equations. Journal of Aircraft, 33(6):1139-1147.

[Liou, 1995] Liou, M. S. (1995). A continuing search for a near-perfect numerical flux scheme. part i: Ausm+. Technical report, NASA, NASA Lewis Research Center, Cleveland. TM 106524.

[Liou, 1996] Liou, M. S. (1996). A sequel to ausm: Ausm+. Journal of Computational Physics, 129, No. 2:364-382.

[Liu et al., 1994] Liu, X. D., Osher, S., and Chan, T. (1994). Weighted essentially non-oscillatory schemes. Journal of Computational Physics, 115, No.1:200-212.

[Liu and Vinokur, 1998] Liu, Y. and Vinokur, M. (1998). Exact integrations of polynomials and symmetric quadrature formulas over arbitrary polyhedral grids. Journal of Computational Physics, 140(1):122 - 147.

[Liu et al., 2006] Liu, Y., Vinokur, M., and Wang, Z. J. (2006). Spectral (finite) volume method for conservation laws on unstructured grids v: Extension to threedimensional systems. J. Comput. Phys., 212(2):454-472.

[Lizier, 2006] Lizier, M. (2006). Geração de Malhas a partir de imagens com textura. PhD thesis, Qualificação de Doutorado, Universidade de São Paulo.

[Lohner, 2001] Lohner, R. (2001). Applied CFD Techniques - An Introduction based on Finite Element Methods. John Wiley \& Sons. (Chapt. 1, pp.1-7). 
[Lopes and Tavares, 1997] Lopes, H. and Tavares, G. (1997). Structural operators for modeling 3-manifolds. ACM, Solid modeling and applications, pages 10-18.

[Maliska, 1995] Maliska, C. A. (1995). Transferência de Calor e Mecânica dos Fluidos Computacional. LTC Editora - Rio de Janeiro.

[Mantyla, 1988] Mantyla, M. (1988). Introduction to Solid Modeling. W. H. Freeman \& Co., New York, NY, USA.

[Mantyla, 1989] Mantyla, M. (1989). An Introduction to Solid Modeling. Computer Science Press.

[Marques, 1997] Marques, F. D. (1997). Multi-Layer Functional Approximation of Non-Linear Unsteady Aerodynamic Response. PhD thesis, University of Glasgow, Glasgow, UK.

[Neal, 1991] Neal, T. F. (1991). Upwind scheme for solving the euler equations on unstructured tetrahedral meshes. AIAA Journal, 30(1):70-77.

[Nielson, 2000] Nielson, G. (2000). Volume modeling. In et al., M. C., editor, Volume Graphics, pages 29-48. Springer.

[Nixon, 1989] Nixon, A. (1989). Unsteady transonic aerodynamics. American Institute of Aeronautics and Astronautics, Progress in Astronautics and Aeronautics, v. 120.

[Nonato et al., 2008] Nonato, L. G., Lizier, M. A. S., Batista, J., de Oliveira, M. C. F., and Castelo, A. (2008). Topological triangle characterization with application to object detection from images. Image Vision Comput., 26(8):1081-1093.

[Obayashi et al., 1991] Obayashi, S., Guruswamy, G., and Goorjian, P. (1991). Streamwise upwind algorithm for computing unsteady transonic flows about oscillating wings. AIAA Journal, 29:1668-1677.

[Oliveira, 1993] Oliveira, L. C. (1993). Uma metodologia de análise aeroelástica com variáveis de estado utilizando técnicas de aerodinâmica computacional. Master's thesis, Instituto Tecnológico de Aeronáutica, São José dos Campos, SP, Brazil.

[Osher, 1983] Osher, S. (1983). Upwind schemes and boundary conditions with applications to euler equations in general geometries. Journal of Computational Physics, 50:447-481.

[Osher and Sethian, 1988] Osher, S. and Sethian, J. A. (1988). Fronts propagating with curvature-dependent speed: algorithms based on hamilton-jacobi formulations. J. Comput. Phys, 79(1):1-49.

[Patankar, 1980] Patankar, S. (1980). Numerical Heat Transfer and Fluid Flows. Hemisphere Publishing Co.

[Prananta and Hounjet, 1996] Prananta, B. B. and Hounjet, M. H. L. (1996). Aeroelastic simulation with advanced cfd methods in 2-d and 3-d transonic flow. The Rouyal Aeronautical Society - Unsteady Aerodynamics - Two day Conference, pages 7.1-7.16. 
[Pulliam, 1986] Pulliam, T. H. (1986). Artificial dissipation models for the euler equations. AIAA Journal, 24, N.12(Oxford University):1931-1940.

[Pulliam, 1988] Pulliam, T. H. (1988). Implicit methods in cfd. Conference on Numerical Methods for Fluid Dynamics, 50(Oxford University).

[Qiu and wang Shu, 2005] Qiu, J. and wang Shu, C. (2005). A Comparison of Troubled-Cell Indicators for Runge-Kutta Discontinuous Galerkin Methods Using Weighted Essentially Nonoscillatory Limiters. Siam Journal on Scientific Computing, 27:995-1013.

[Roe, 1981] Roe, P. L. (1981). Approximate riemman solver, parameter vectors. Journal of Computational Physics, 43:357-372.

[Rossignac et al., 2001] Rossignac, J., Safonova, A., and Szymczak, A. (2001). 3D compression made simple: Edgebreaker on a corner table. In Shape Modeling International.

[Scalabrin, 2002] Scalabrin, L. C. (2002). Numerical simulation of three-dimensional flows over aerospace configurations. Master's thesis, Instituto Tecnológico de Aeronáutica, São José dos Campos, SP, Brazil.

[Schroeder et al., 1998] Schroeder, W., Martin, K. M., and Lorensen, W. E. (1998). The visualization toolkit (2nd ed.): an object-oriented approach to 3D graphics. Prentice-Hall, Inc., Upper Saddle River, NJ, USA.

[Schuster et al., 1990] Schuster, D., Vadyak, J., and Atta, E. (1990). Static aeroelastic analysis of fighter aircraft using a three-dimensional Navier-Stokes algorithm. Journal of Aircraft, 27(9):820-825.

[Shaw, 1992] Shaw, C. T. (1992). Using Computational Fluid Dynamic. 1. ed. USA, Prentice Hall.

[Shephard, 1997] Shephard, M. W. B. M. (1997). A general topology-based mesh data structure. Int. J. for Numerical Methods in Engineering, 40:1573-1596.

[Shu et al., 2002] Shu, C. W., Hu, C., and Shi, J. (2002). A technique of treating negative weights in weno schemes. Journal of Computational Physics, 175:108-127.

[Shu and Jiang, 1996] Shu, C. W. and Jiang, G. (1996). Efficient implementation of weighted eno schemes. Journal of Computational Physics, 126:202-228.

[Shu and Osher, 1988] Shu, C. W. and Osher, S. (1988). Efficient implementation of essentially non-oscillatory shock-capturing schemes. Journal of Computational Physics, 77, N.2:439-471.

[Shu and Zeng, 1997] Shu, C.-W. and Zeng, Y. (1997). High-order essentially nonoscillatory scheme for viscoelasticity with fading memory. Q. Appl. Math., $\mathrm{LV}(3): 459-484$. 
[Silva, 2004] Silva, R. G. A. (2004). A Study on Correction Methods for Aeroelastic Analysis in Transonic Flow. PhD thesis, Instituto Tecnológico de Aeronáutica, São José dos Campos.

[Simoes and Azevedo, 1999a] Simoes, C. F. C. and Azevedo, J. L. F. (1999a). The influence of numerical parameters on unsteady airfoil inviscid flow simulations using unstructured dynamic meshes. Brazilian Progress in Aeroespace Enginnering.

[Simoes and Azevedo, 1999b] Simoes, C. F. C. and Azevedo, J. L. F. (1999b). Unsteady airfoil inviscid flow simulations using unstructured dynamic meshes. Anais do 15th Congresso Brasileiro de Engenharia Mecânica - COBEM 99.

[Smith et al., 2000] Smith, M., Hodges, D., and Cesnik, C. (2000). Evaluation of computational algorithms suitable for fluid-structure interactions. Journal of Aircraft, $37(2): 282-294$.

[Soares, 2007] Soares, I. P. (2007). Movimento de malhas e remalhamento de malhas superficiais. PhD thesis, Biblioteca Digital de Teses e Dissertaçõeswww.teses.usp.br, ICMC-USP-São Carlos, Brasil.

[Sudharsan et al., 2004] Sudharsan, N., Ajaykumar, R., Murali, K., and Kumar, K. (2004). A comparative study of dynamic mesh updating methods used in the simulation of fluid-structure interaction problems with a non-linear free surface. Proceedings of the I MECH E Part C Journal of Mechanical Engineering Science, 218(3):283-300.

[Sun and Wang, 2004] Sun, Y. and Wang, Z. (2004). Evaluation of discontinuous galerkin and spectral volume methods for scalar and system conservation laws on unstructured grids. International Journal for Numerical Methods in Fluids, 45(8):819-838.

[Sun et al., 2006] Sun, Y., Wang, Z. J., and Liu, Y. (2006). Spectral (finite) volume method for conservation laws on unstructured grids vi: Extension to viscous flow. J. Comput. Phys., 215(1):41-58.

[Tannehill et al., 1997] Tannehill, J. C., Anderson, D. A., and Pletcher, R. H. (1997). Computational Fluid Mechanics and Heat Transfer. 2. ed. Washington, Taylor and Francis.

[Theodorsen, 1934] Theodorsen, T. (1934). General theory of aerodynamic instability and the mechanism of flutter. NACA Report 496.

[van Leer, 1974] van Leer, B. (1974). Towards the ultimate conservative difference scheme. ii. monotonicity and conservation combined in a second order scheme. Journal of Computational Physics, 14, No. 4:361-370.

[van Leer, 1977] van Leer, B. (1977). Towards the ultimate conservative difference scheme. iv. a new approach to numericla convection. Journal of Computational Physics, 23. No.3:276-299. 
[van Leer, 1979] van Leer, B. (1979). Towards the ultimate conservative difference scheme. v. a second order sequel to godunov's method. Journal of Computational Physics, 32. No.1:101-136.

[Van Leer, 1982] Van Leer, B. (1982). Flux-vector splitting for the euler equations. Lecture Notes in Physics, 170:507-512.

[Venkatakrishnan and Jameson, 1988] Venkatakrishnan, V. and Jameson, A. (1988). Computation of unsteady transonic flows by the solution of Euler equation. AIAA Journal, pages 974-981.

[Versteeg and Malalasekera, 2007] Versteeg, H. K. and Malalasekera, W. (2007). Introduction to Computational Fluid Dynamics- The Finite Volume Method. 2 ed. England, Person Prentice Hall.

[von Terzi et al., 2001] von Terzi, D. A., Linnick, M., Seidel, J., and Fasel, H. (2001). Immersed boundary techniques for high-order finite-difference methods. In AIAA Fluid Dynamics Conference and Exhibit, AIAA Paper No. 01-2818, Anaheim, CA.

[Wang, 2002] Wang, Z. J. (2002). Spectral (finite) volume method for conservation laws on unstructured grids: basic formulation. J. Comput. Phys., 178(1):210-251.

[Wang and Liu, 2002] Wang, Z. J. and Liu, Y. (2002). Spectral (finite) volume method for conservation laws on unstructured grids: Ii. extension to twodimensional scalar equation. J. Comput. Phys., 179(2):665-697.

[Wang and Liu, 2004] Wang, Z. J. and Liu, Y. (2004). Spectral (finite) volume method for conservation laws on unstructured grids iii: One dimensional systems and partition optimization. J. Sci. Comput., 20(1):137-157.

[Wang and Liu, 2006] Wang, Z. J. and Liu, Y. (2006). Extension of the spectral volume method to high-order boundary representation. J. Comput. Phys., 211(1):154178.

[Wang et al., 2004] Wang, Z. J., Zhang, L., and Liu, Y. (2004). Spectral (finite) volume method for conservation laws on unstructured grids iv: extension to twodimensional systems. J. Comput. Phys., 194(2):716-741.

[Wolf and Azevedo, 2006] Wolf, W. and Azevedo, J. (2006). High-order unstructured essentially nonoscillatory and weighted essentially nonoscillatory schemes for aerodynamic flows. AIAA Journal, 44. No. 10:2295-2310.

[Wolf, 2006] Wolf, W. R. (2006). Simulação de Escoamentos Aerodinâmicos Compressíveis Utilizando Esquemas Não Oscilatórios de Alta Ordem de Precisão em Malhas Não Estruturadas. PhD thesis, Instituto Tecnológico de Aeronáutica, São José dos Campos-SP.

[Yang and Wang, 2009] Yang, M. and Wang, Z. (2009). A Parameter-Free Generalized Moment Limiter for High-Order Methods on Unstructured Grids. Advances in Applied Mathematics and Mechanics. 
[Zeng and Ethier, 2001] Zeng, D. and Ethier, C. R. (2001). A semitorcional spring analogy model for updating unstructured meshes. Proceedings of 9th Annual Conference of the CFD Society of Canada.

[Zhang and Shu, 2005] Zhang, M. and Shu, C.-W. (2005). An analysis of and a comparison between the discontinuous galerkin and the spectral finite volume methods. Computers 8 Fluids, 34:581 - 592. Residual Distribution Schemes, Discontinuous Galerkin Schemes and Adaptation.

[Zienkiewicz and Taylor, 2000] Zienkiewicz, O. and Taylor, R. (2000). The Finite Element Method Volume 1. Butterworth-Heinemann, 5th edition. 